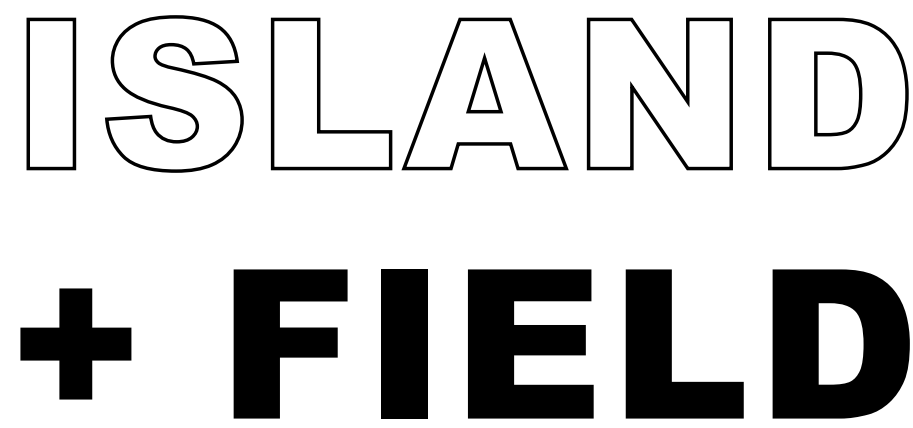





\section{ISLAND AND FIELD}

Addressing urban discontinuities with pedestrian architecture

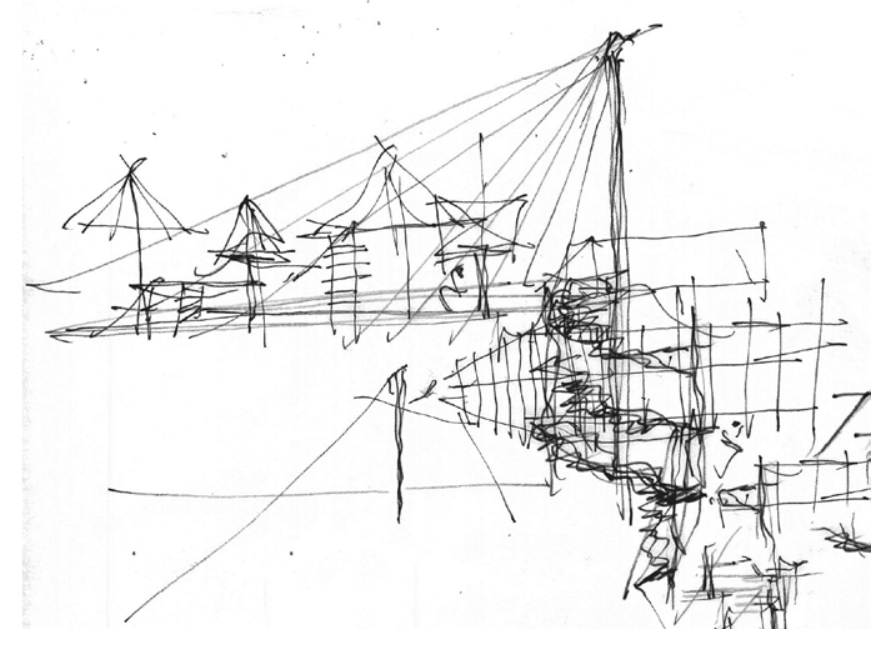

No man is an island entire of itself; every man is a piece of the continent, a part of the main;

\section{Cameron Wilson}

A 120 point Thesis submitted in partial fulfilment of the requirements for the Master of Architecture [Professional]

Victoria University of Wellington

School of Architecture

2019 


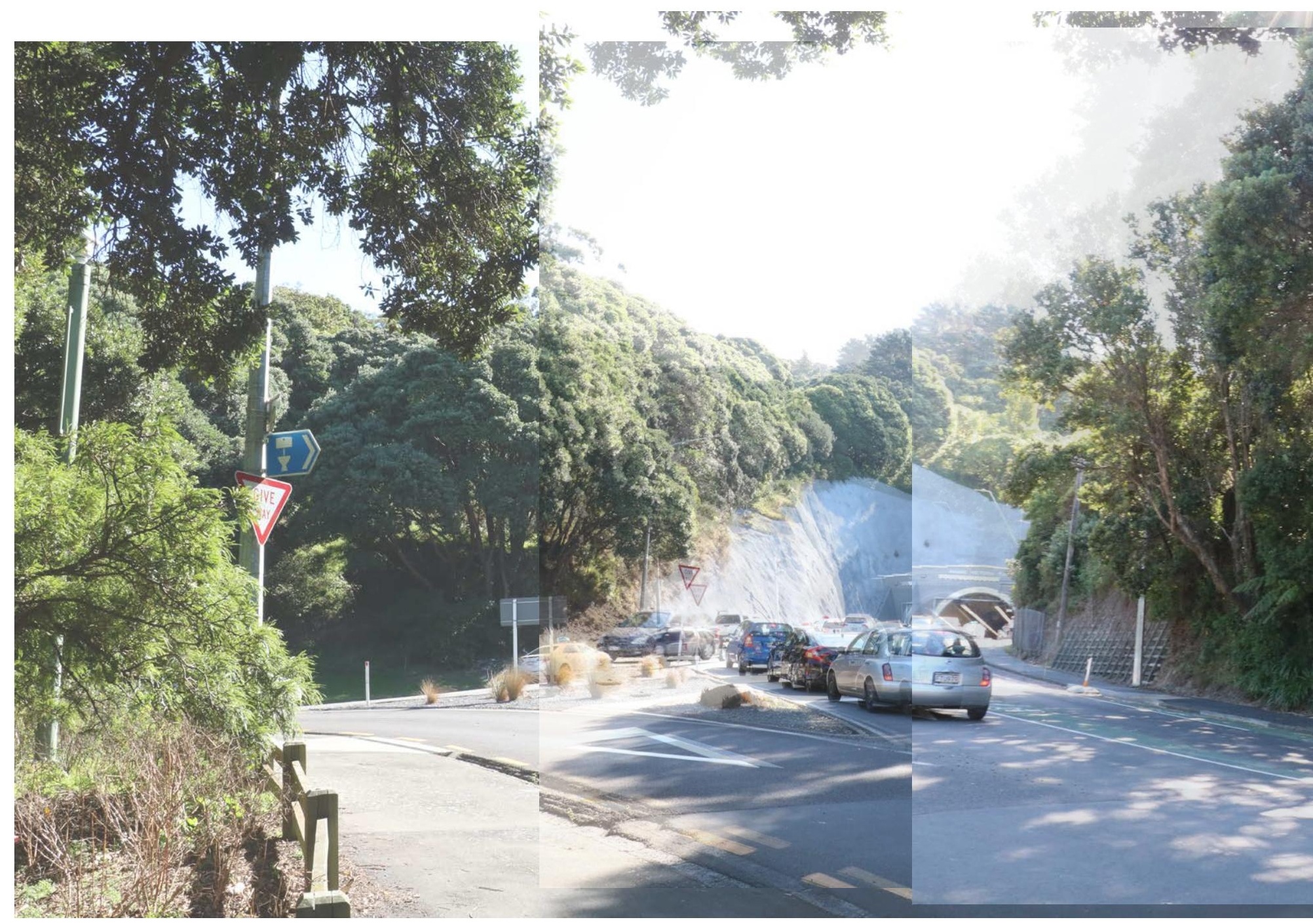

Fig 0.01 (Previous Spread) Loose sketch and excerpt from 'No Man is an Island'.

Fig 0.02 (Above) Intersection of Taurima Street and State Highway 1, Hataitai. 


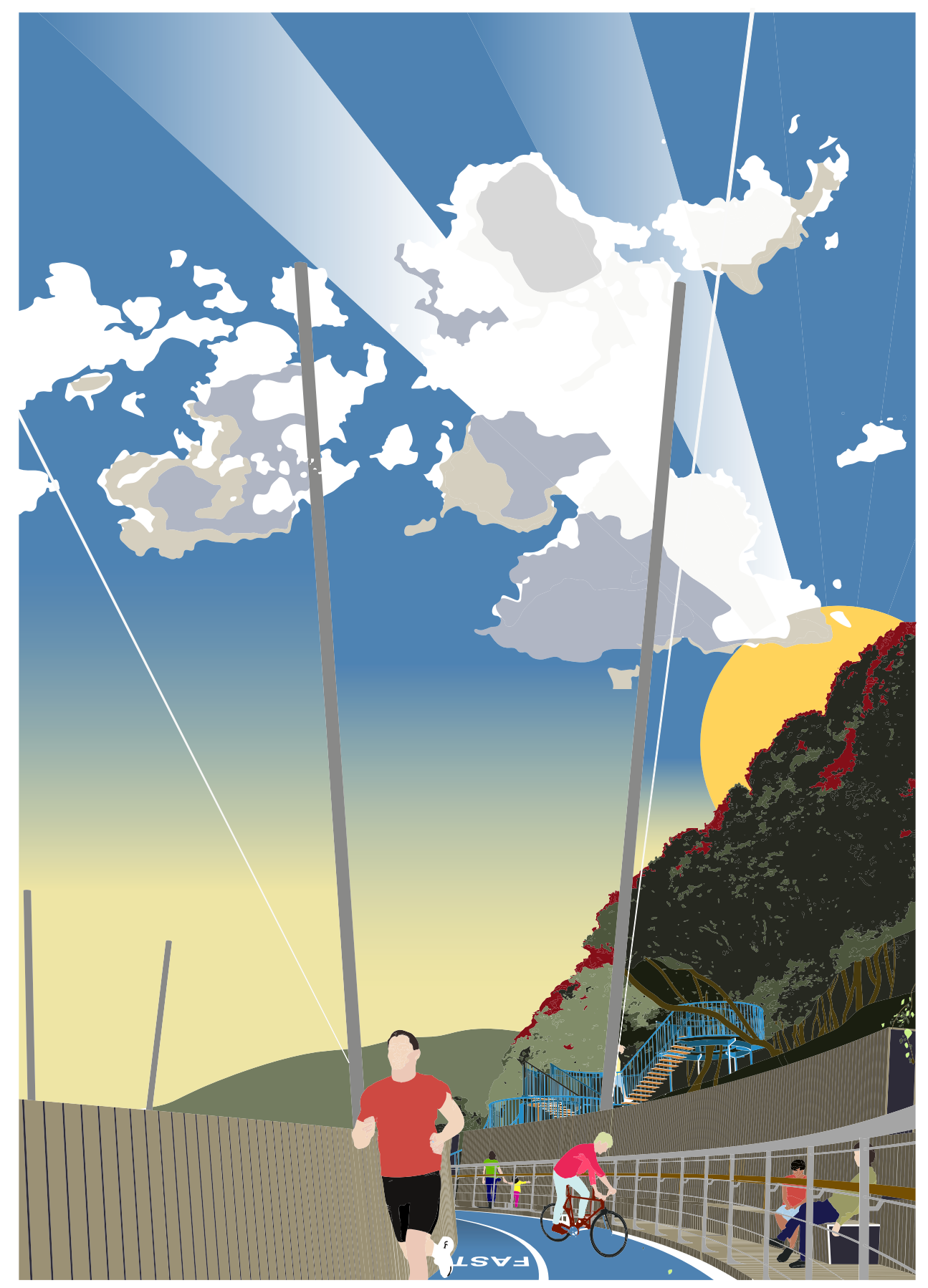

Fig $\mathbf{0 . 0 3}$ Bridge deck of the final scheme. 


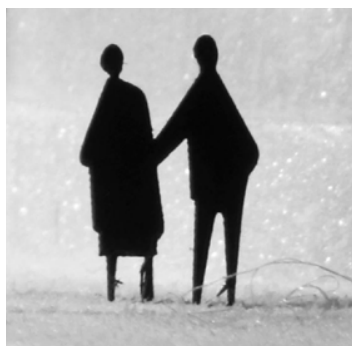

\section{ACKNOWLEDGEMENTS}

To Mum and Dad. Thank you for your endless, unconditional love and support over these past years. This pursuit began long before I started at university and you always encouraged me to go for it.

To Sam Kebbell. Your support and guidance over the past 15 months, beginning with the Kāpiti Watchtower project, and leading into this thesis, have been hugely challenging and equally rewarding. Thank you.

To my friends. Those of you in studio and those of you outside. Thank you for making these five years the experience it has been, and for providing the laughs and enjoyment in the lifestyle that is this degree. 
canasanarann

(1)

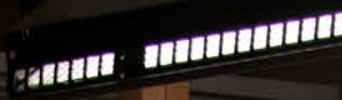

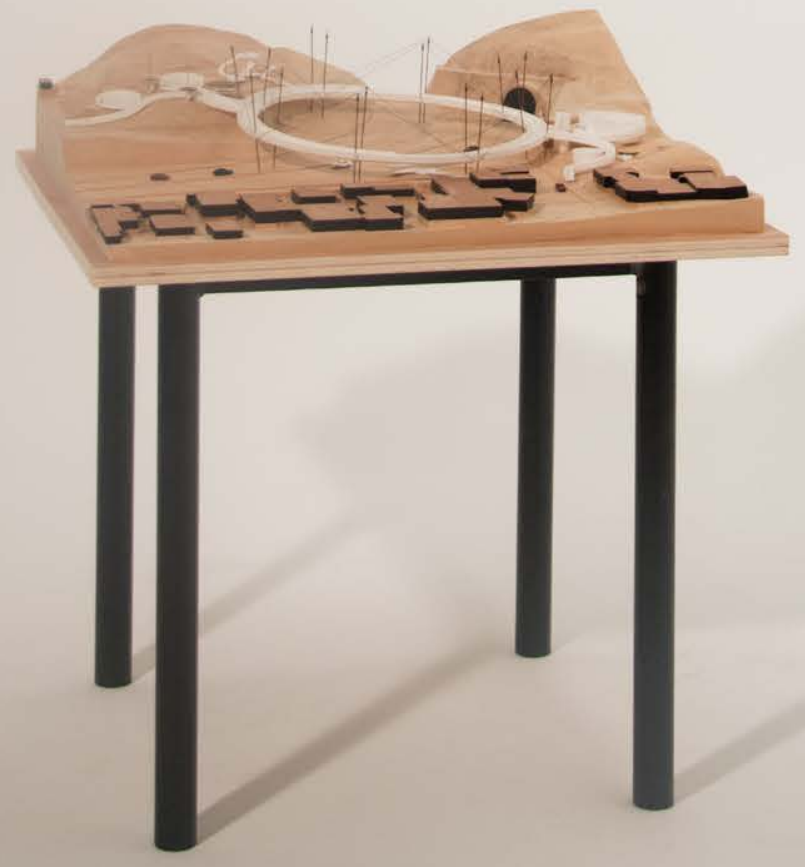




\section{ABSTRACT}

We build transport infrastructure to move about the city efficiently. However, in New Zealand, it is often one-dimensional and disconnected from the urban fabric. This is the case in Hataitai, where State Highway 1 imposes a boundary between the nearby village and the Town Belt that could be bridged when new work on the Mt Victoria Tunnel takes place.

What could be the nature of a pedestrian bridge that connects these disparate urban territories?

I explored this question with two distinct methods. The first used 'fast and loose' hand drawing and physical modelling to explore a ubiquitous mesh structure, replacing the ground plane of the site. This Field accommodated a variety of programmed elements and crossings. The second experiment replaced the mesh with an autonomous loop between the park, village and tunnel. This Island required more precise digital modelling tools and a more measured design process.

The two methods offer vastly different approaches to urban design. The ubiquitous mesh replaces the existing ground by extending it. The Loop structure is an autonomous figure over the existing and messy ground of the urban junction below.

The research demonstrates the tensions between these two approaches to urban intervention and how they can offer alluring moments in the everyday life of the city.

Fig 0.04 Model overview of the final scheme. 


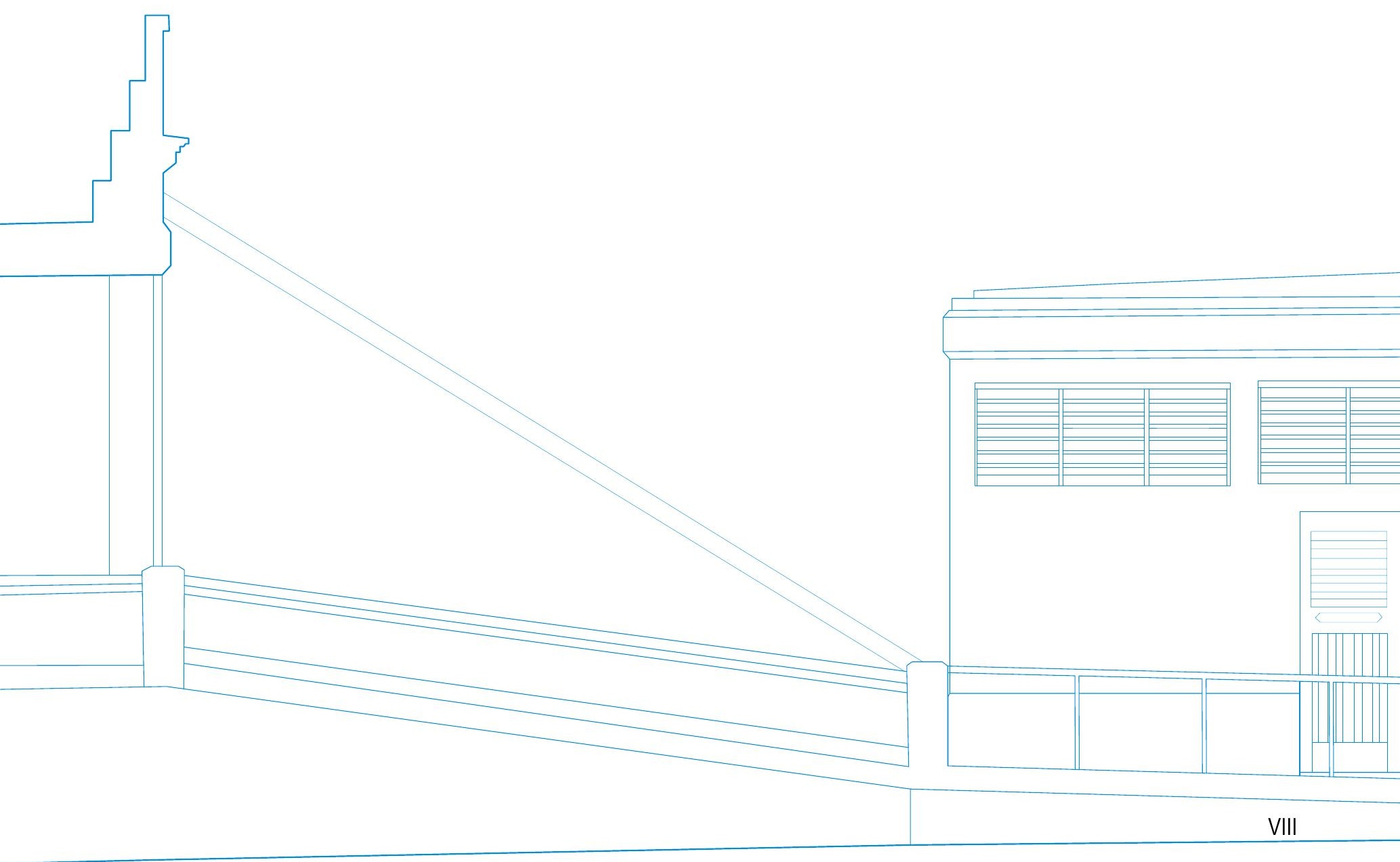




\section{TABLE OF CONTENTS}

ACKNOWLEDGEMENTS

ABSTRACT

1 - INTRODUCTION

1

INTRODUCTION

AIMS

METHODOLOGY

SCOPE OF RESEARCH

1

4

4

5

2 - (DIS)CONTINUOUS CITY

HATAITAI

PROPOSALS

CASE STUDY: WELLINGTON INNER CITY

THEORETICAL CONTEXT

3 - CASE STUDIES

WATERVIEW CONNECTION

LIGHTPATH

36

LUCHTSINGEL

4 - FIELD

BOUNDARIES

PLEASURE

NEW BABYLON

VISUAL ESSAY

74

EDGE

96

5 - ISLAND

109

ARCHIPELAGO

110

WANDERLUST

112

LOOP

116

FRIVOLOUS INFRASTRUCTURE

FABRICATION

6 - ISLAND AND FIELD

165

TRIVIAL PURSUIT

168

SUMMARY

192

CRITICAL REFLECTION

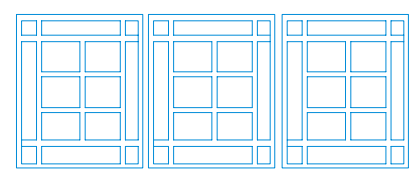

Fig 0.05 (Left) Mt Victoria tunnel portal \& fan house no. 4. 


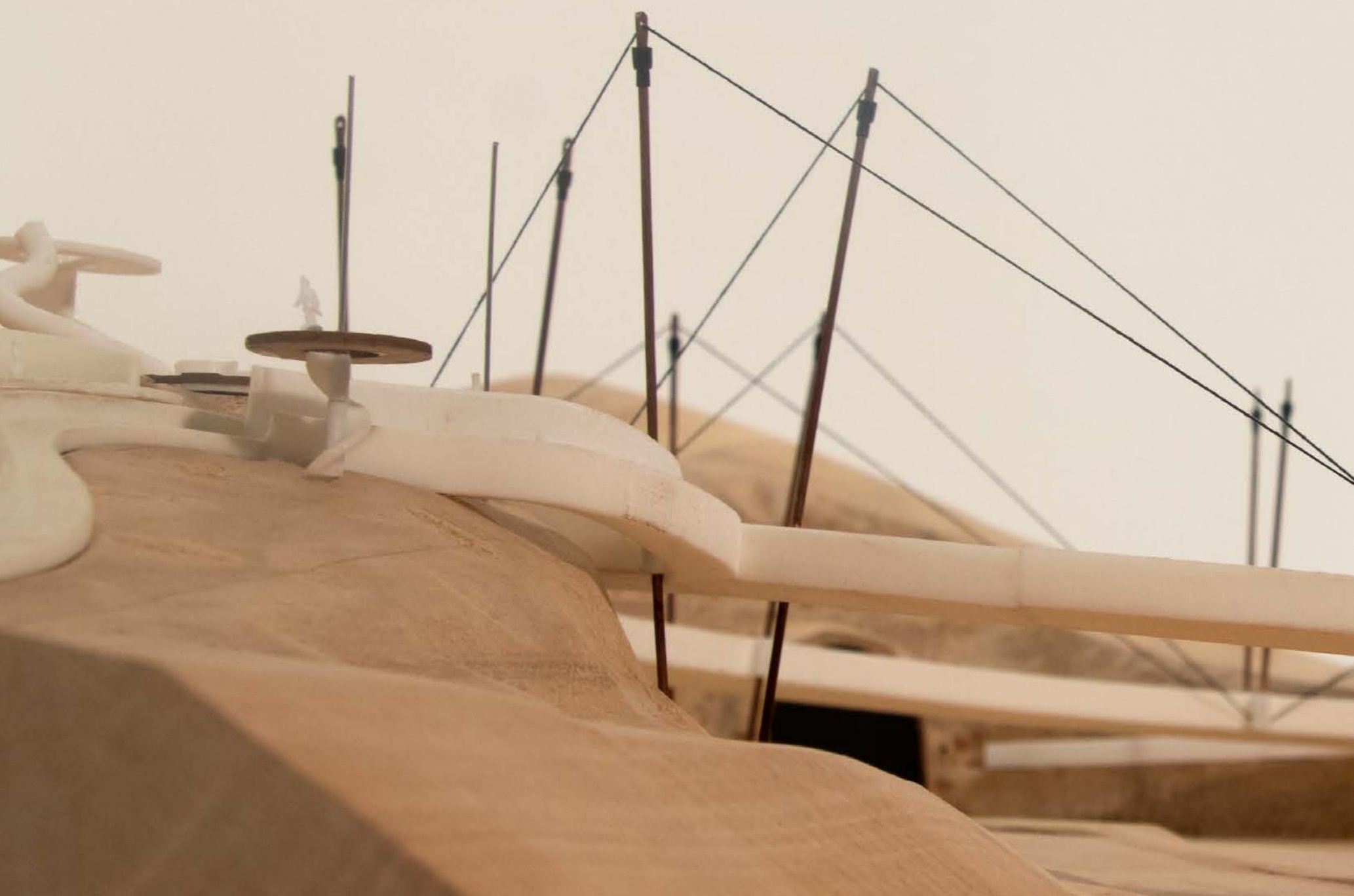

WHAT COULD BE THE NATURE OF A PEDESTRIAN BRIDGE CONNECTING DISPARATE URBAN TERRITORIES IN HATAITAI? 


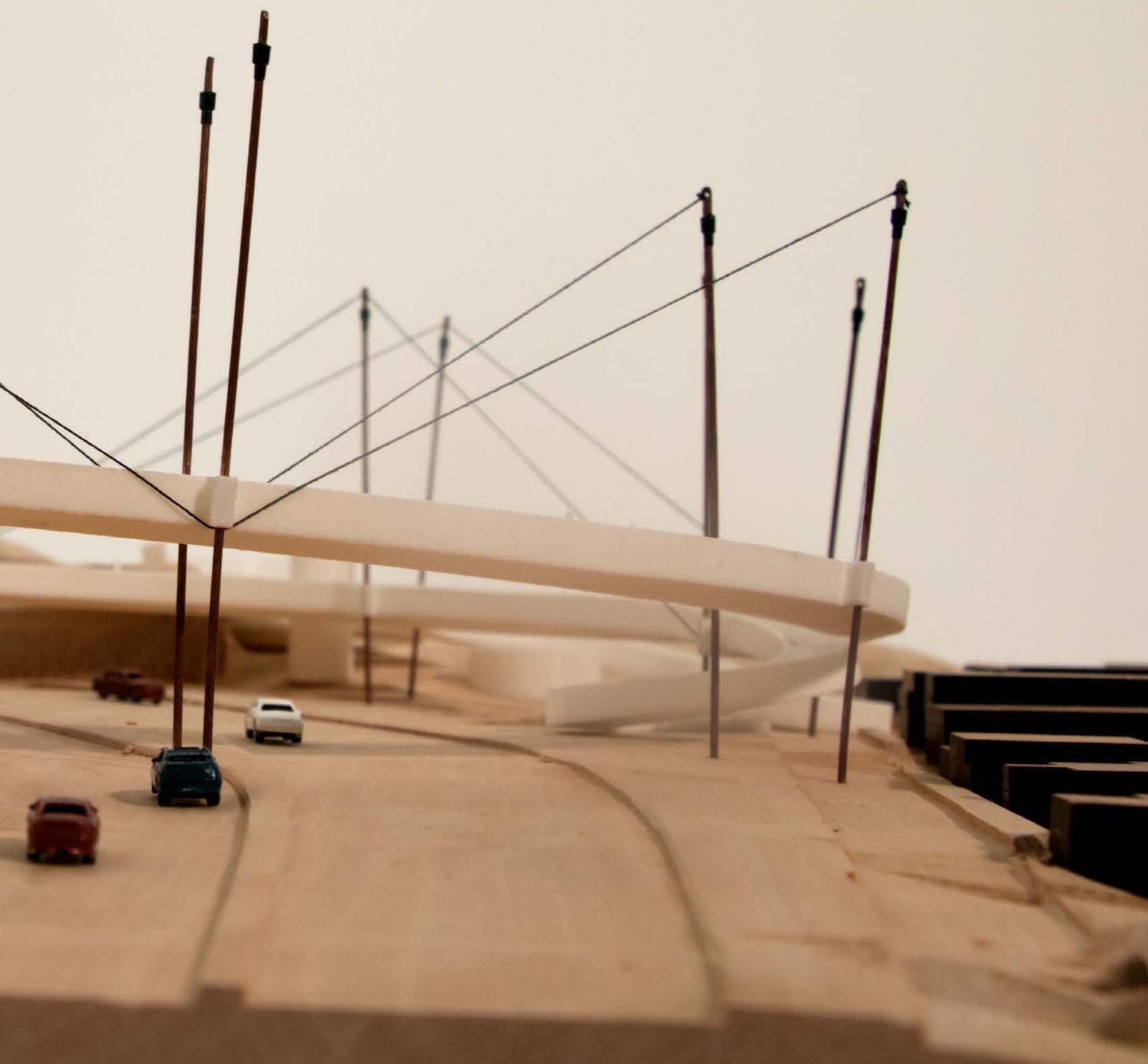


$$
0
$$

\section{0

$$
0
$$ \\ 1.0}

(2)

(2) 


\section{Introduction}

Cities are built for people. However many cities today are heavily car-centric with infrastructure that reflects this. The requirement for efficient traffic infrastructure to keep cities moving often comes at the expense of the pedestrian experience - roads create physical boundaries and can dehumanise the urban fabric. Robert Ellis painted the effects of car-centric urbanism in Auckland during the 1960's, in which plots of city land are distinguished by motorways, creating boundaries between the suburbs and the sea (Fig 1.01). Today, New Zealand has one of the highest rates of car ownership in the world and successive governments have continued to invest heavily in road projects and less in active and public transport methods (Conder 2009). Ellis' paintings still seem an accurate representation of New Zealand cities, half a century on.

The form of a city's infrastructural networks undoubtedly plays a role in the quality of its urban realm. New Zealand cities have very basic pedestrian and cycling infrastructure and poor connectivity between networks (Shaw and Russell 2016). Unsurpris- ingly, the New Zealand Household Travel Survey (2010-2013) found that only $1 \%$ of all trips are made by bicycle. Walking contributes to $16 \%$, whilst the motor vehicle dominates with $79 \%$ of all journeys (Shaw and Russell 2016). In the Netherlands, the modal share of cycling is around $27 \%$. The country of 17 million inhabitants owns 23 million bicycles (Bicycle Dutch 2018). Dutch cycling infrastructure is simply phenomenal, and city streets are full of life. The cultures and attitudes towards cycling in New Zealand are miles behind.

This is largely due to the lack of dedicated infrastructure.

The city fabric is often considered as a continuous field, populated with distinct objects, buildings, road networks, and so on. Stan Allen describes the city as a 'field of forces, and the aggregation of small, self-similar parts to create local difference while maintaining overall coherence' (Allen 1999). The infrastructural networks of the modern city are a distinct field condition. Like in Ellis' painting, there is a clear unity within the road system. It is a unifying, connected system. The urban blocks 
and recreational spaces represent a vastly different field condition. Like an archipelago of islands, perpetually isolated from one another. Although the fluid traffic networks aim to connect the city, they can have the opposite effect for the human experience - the peripheries of busy roads are often desolate and unappreciated places. This can be exacerbated by a lack of people cycling and walking throughout the city.
There is a tension between people and traffic. Where the city is made more accessible to vehicles, it can be made more isolated and disconnected to people. Traffic infrastructure is a utilitarian, fundamental requirement, but its omnipresence can degrade and isolate parts of the everyday urban fabric. Architects can play a critical role in enriching pedestrian culture and humanising the urban fabric of car-centric cities. But how?

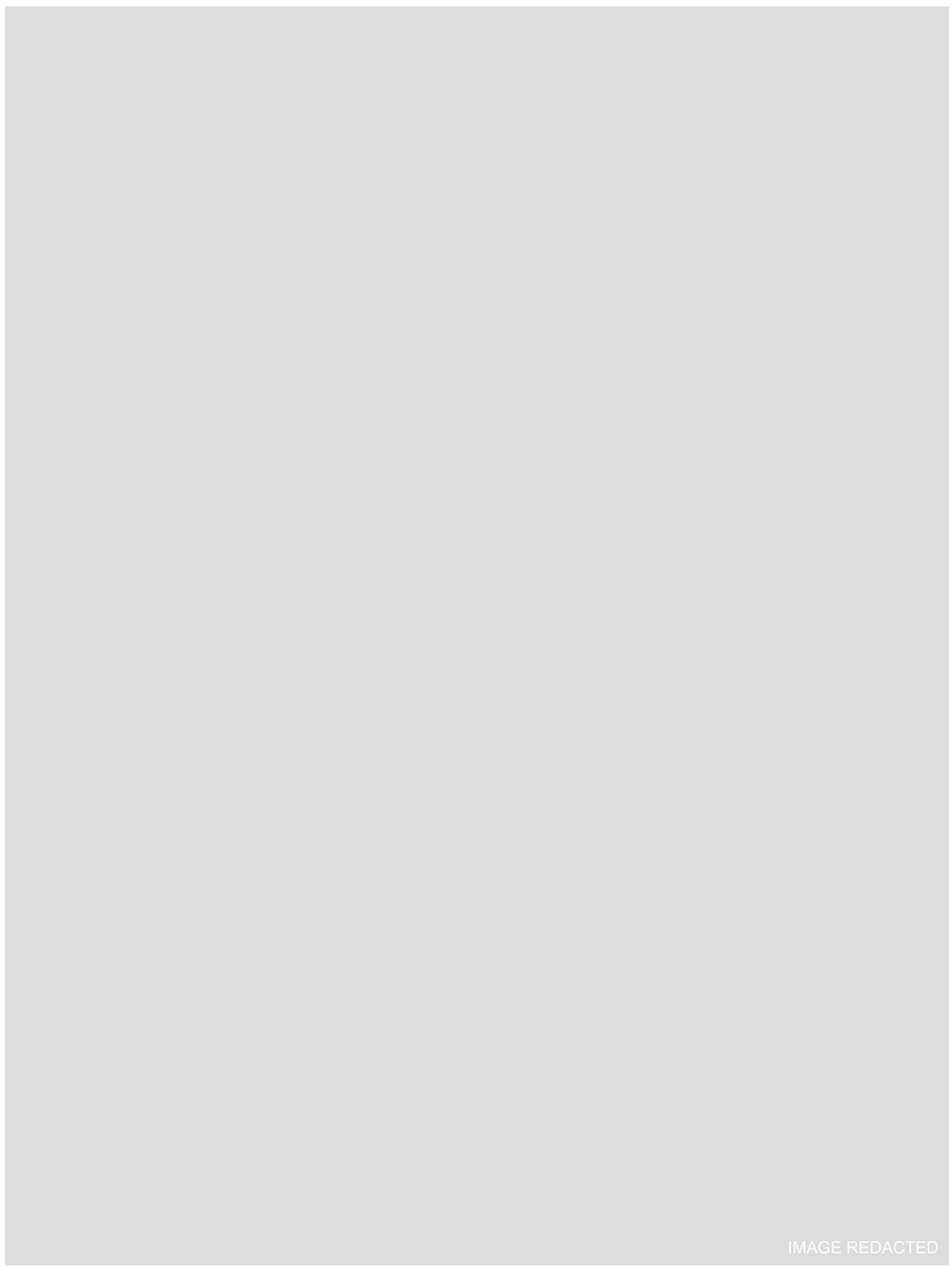

Fig 1.01 Motorway/city, Robert Ellis. 


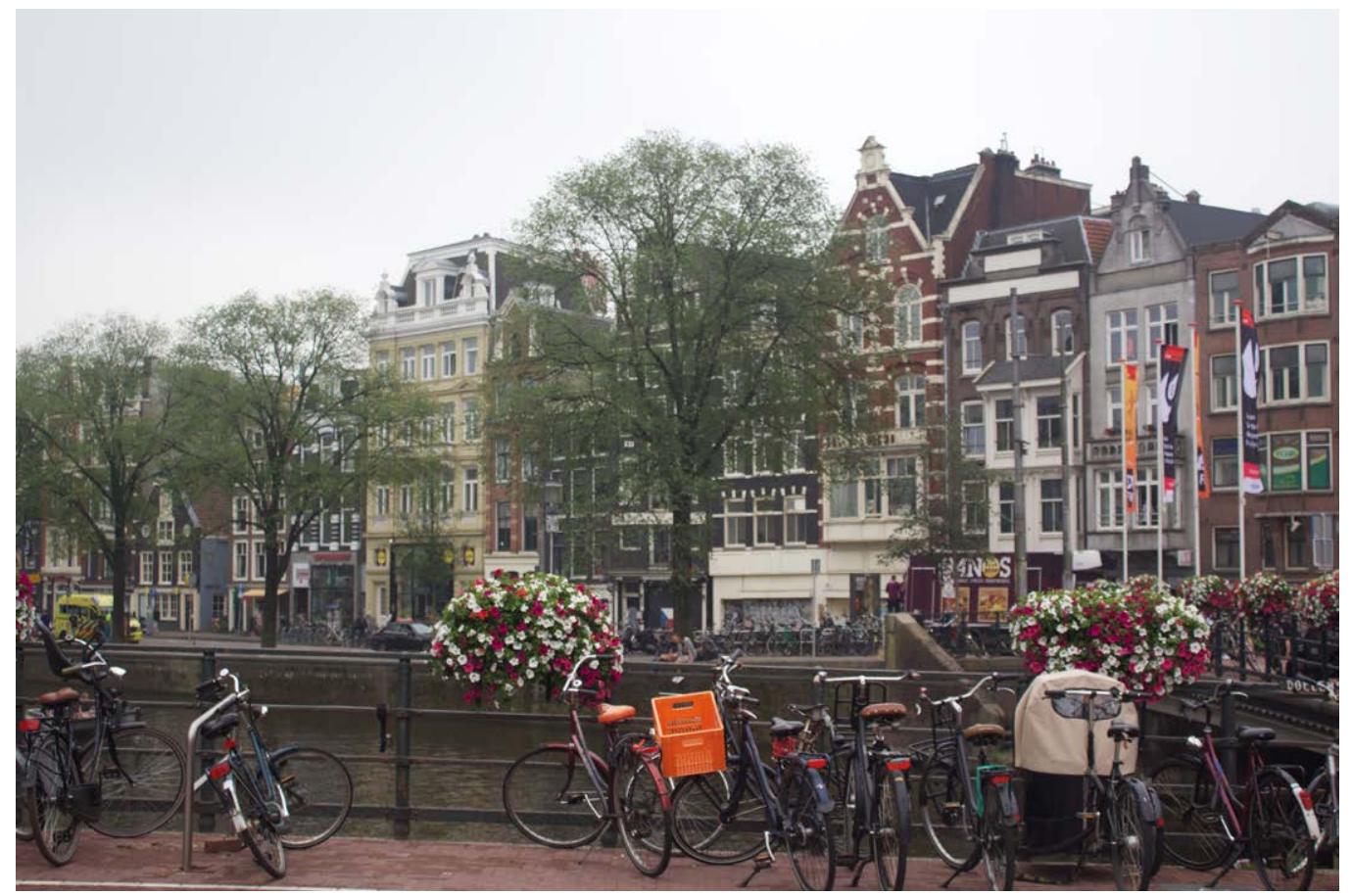

Fig 1.02 In the Netherlands, many streets are cycle-priority and the vehicle is a guest Fietsstraat.

Fig 1.03 Cycle infrastructure in New Zealand is often controversial and tokenistic, like the Island Bay Cycleway pictured here. 


\section{AIMS}

In response to the highlighted tensions between vehicle traffic and pedestrian/cyclists in New Zealand cities, this thesis aims to:

1) Address the tensions between people and traffic in the context of a proposed major traffic infrastructure in Hataitai, Wellington (a car-centric city).

2) Explore what formal languages might strengthen infrastructural connections (for pedestrians and cyclists) and humanise the surrounding urban fabric.

\section{METHODOLOGY}

This thesis explores theses aims and objectives through:

\section{1) Context}

This chapter introduces the physical and theoretical contexts of the research. I begin by introducing the suburb of Hataitai and the proposed NZTA road infrastructures affecting the suburb. I also discuss previous Wellington traffic projects, whose social, political, and formal tensions would likely be applicable to Hataitai. I then introduce the theories and projects that my own designs draw from.

\section{2) Case Studies}

This short chapter simply discusses a few New Zealand and international Case Studies. These projects include a large traffic infrastructure project, and two pedestrian/cycling infrastructure projects. I chose these for their multimodal approaches, profound urban effects, and innovative design strategies. I aim to utilise similar qualities in my own ensuing designs.

\section{3) Field}

The first of two distinct experiments, this experiment aimed to overcome the boundaries created by the road, increase and intensify the social and recreational possibilities of the suburb, and develop a playful formal language. I began with fast and loose hand sketches and physical modelling. This developed into an expansive mesh, placed across the site to connect the park and village over the highway. Playful nodes and figures inhabited the mesh, which became an armature for programmed spaces and crossings. The mesh complimented the form of the trees in the Town Belt and became a way to extend or replace the existing ground, and blur the boundaries between the existing but disparate urban territories - the park, the highway and the suburban village. I built physical models to expand of the scope of the loose sketches. I photographed these and drew them graphically to add a sense of inhabitation and atmosphere. Digital modelling in Rhinoceros (Rhino) developed in parallel with the physical studies to expand the scope of the sketches, models and drawings. However, it was very difficult to 'find the edge' of the mesh. The allure of these studies came from their apparent infinity in the physical drawings, which were mostly in perspective. They had no plan or section. Aligning these drawings 
to a plan and section required digitisation; however, this persistently

resulted in an unfavourable rationalisation of the mesh. This ultimately led to the end of the experiment. Situationist theories concerning the dissolution of boundaries and continuity of space provided much stimulation throughout this experiment. These theories and a case study of New Babylon are also presented in this chapter.

\section{4) Island}

This chapter presents the second of the two experiments and a vastly different approach to urban intervention. I removed the mesh completely and adopted a loop structure that was one of the later experiments in the mesh. The Loop had more pragmatic benefits as a piece of infrastructure, linking the park, village and tunnel in one simple move. It had also received positive feedback in discussion with my peers, and later at my August review. The playful nodes of the mesh could also be applied to The Loop. These developed at the periphery. I continued 'fast and loose' processes to develop these playful and informal spaces. However, a more 'precise and measured' approach was required to develop The Loop. I used digital modelling techniques to develop this structure (Rhino with Grasshopper). These programs allowed for iterative testing of The Loop's placement, undulation, diameter, height above ground, deck sections and so on. The legible, definitive boundary of The Loop was easier to digitise than the infinite mesh. I continued a dialogue between the 'fast and loose' processes to develop the playful periphery spaces and the 'precise and measured' processes for The Loop. This dialogue provided the basis for a series of iterations, which ultimately resulted in the final scheme. This experiment differs to the previous one in that it accepts the boundaries created by the roads. In response, it presents both an autonomous figure (The Loop) to create a dialogue with the road, and subtle moments of continuity into the surrounding field (pathways and urban play areas). Theories and case studies around autonomy are presented in this chapter.

\section{SCOPE OF RESEARCH}

The scope of this research is limited to a selected site in suburb of Hataitai. The site encircles the portal end of the Mt Victoria Tunnel and its traffic lanes, the shoulder of the Town Belt, and a small section of Hataitai Village. The research I present assumes a series of proposed traffic infrastructure upgrades for my chosen site and is limited to what data and information is available to the public. This includes indicative plans and drawings only. My research does not propose a solution to citywide traffic infrastructure, but speculates beyond the scope of my site to a diagrammatic and suggestive level of detail. I acknowledge that any number of detailed traffic infrastructure solutions might be possible beyond the scope of the site as well as within my chosen site.

Fig 1.04 (Following spread) The existing Mt Victoria Tunnel portal. The narrow $1.5 \mathrm{~m}$ pedestrian path is the only direct link for pedestrians and cyclists between the city and eastern suburbs (in both directions). 

2.0 0 


\section{(Dis)Continuous City}

Hataitai is an inner city suburb of Wellington. The suburb is disconnected from the nearby Town Belt by State Highway 1, which emerges at the Mt Victoria Tunnel. A proposed duplication of the tunnel and its traffic lanes will favour the vehicular realm over the pedestrian and likely result in a more fragmented urban landscape.

What are the typical solutions to traffic infrastructure provision in Wellington? What could an alternative approach offer?

This chapter introduces the physical context with an overview of Hataitai and the traffic infrastructure proposed there. I discuss previous inner city traffic projects in Wellington to highlight the political, social and formal tensions, which would likely shape the NZTA proposal in Hataitai. I then discuss the theoretical frameworks, which stimulate my ensuing designs. These include avant-garde projects, the value of play, and debates around autonomy.

The projects presented in this chapter display that typical solutions to infrastructure design usually neglect the human and pedestrian experience of the city. The theories introduced exhibit the importance of the human quality of the urban fabric and of the enjoyability of everyday life. I intend to use these theories to develop an atypical solution to an infrastructural project in Hataitai. 


\section{HATAITAI}

Town Belts created the 'lungs' of overcrowded British cities in the 19th century. The novel concept was used by the New Zealand Company in 1839 during Wellington's early settlement to provide recreational parkland for the city's inhabitants (Wellington City Council, 2019). At this time, the Town Belt provided a buffer between the suburbs of Wellington, and the undeveloped, rural pastures beyond. Today, the city's suburbs extend much further beyond the first line of hills and a major road infrastructure severs parts of the city from this recreational zone.

Hataitai developed as a small rural village during Wellington's early settlement, physically disconnected from the city by Mt Victoria and the Town Belt. The 'country sections' that developed on the eastern slopes of the hill followed the contours of the landscape and Hataitai's urban form grew organically (Kebbell and Ombler 2018). This is a stark contrast to the emphatically orthogonal urban grid of suburban Mt Victoria and the city centre on the western slopes of the hill (Fig 2.02). Hataitai's density is relatively low at 33 people per hectare (pph), compared to Mt Victoria, 43 pph (Id Profile, 2018).

Direct connection to the city centre didn't occur until 1907 when a tram tunnel was constructed. This was a catalyst for development in the eastern suburbs (Humphris 2010). The Mt Victoria traffic tunnel followed in 1931 - allowing direct access to vehicles for the first time (McCrone 2016). An extension of this road eventually connected the city to the Airport. Today, this is a part of State Highway 1.

The development of the road connecting the city to the airport imposed a sudden disconnection between Hataitai's town centre and the recreational green belt. This land had not anticipated a major piece of infrastructure. The expansion of this infrastructure was also not well forecast. The need for a second Mt Victoria tunnel to cope with increasing traffic demands became apparent as early as the 1960's - barely 30 years after the completion of the tunnel (Fig 2.01). A pilot tunnel, completed in 1974 lies directly to the north of the existing tunnel (McCrone 2016). However, 50 years after the need was established, the second tunnel and its roads are yet to be realised.

The haphazard, incremental growth of Hataitai is evident today in its urban form and infrastructure. Allen states that 'form matters, but not so much the forms of things but the forms between things' (Allen 1999). Consider this with regard to Fig 2.02. Although both suburbs are composed of the same objects (small buildings and roads), their conditions are unique. The orthogonal planning and gridlike blocks of Mt Victoria makes connections for both vehicles and pedestrians simple and direct. However, the long, irregular, islandlike blocks of Hataitai are much more suited to the vehicle than the pedestrian, for whom the suburb is discontinuous and fragmented.

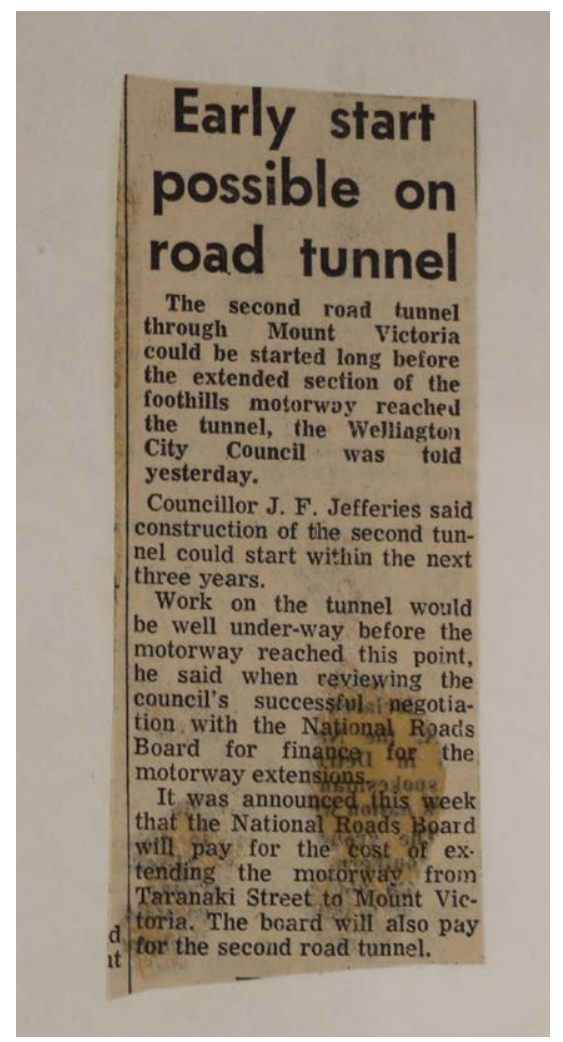

Fig 2.01 Newspaper clipping from the Dominion Post, April 2nd 1968. 
Fig 2.02 Figure ground of Mt Victoria (left) and Hataitai (right) showing the differences in their urban forms and densities. The Mt Victoria town belt separates the two suburbs.

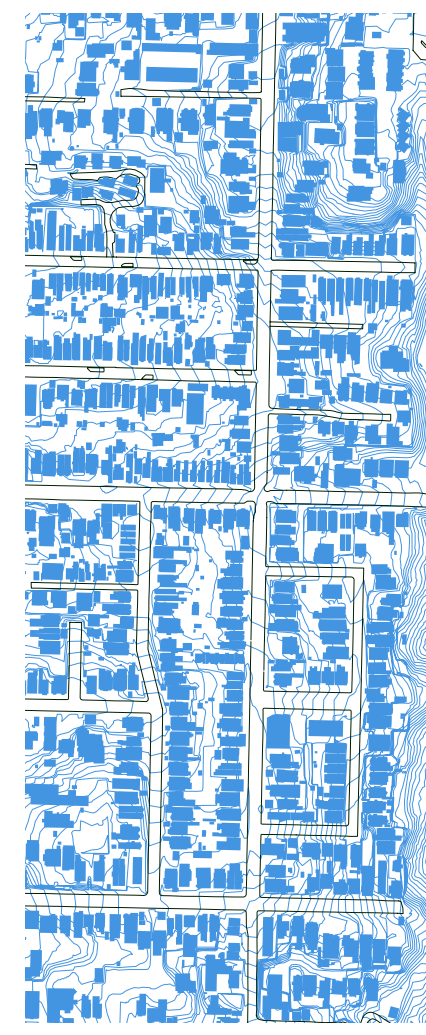

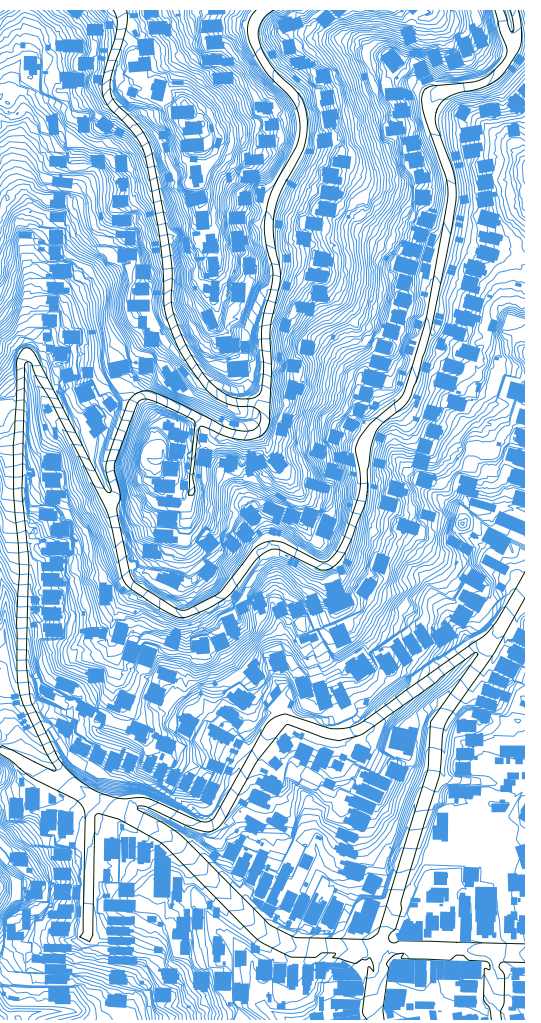

Fig 2.03 Image

from 1894 of Hataitai Village, taken from the Town Belt.

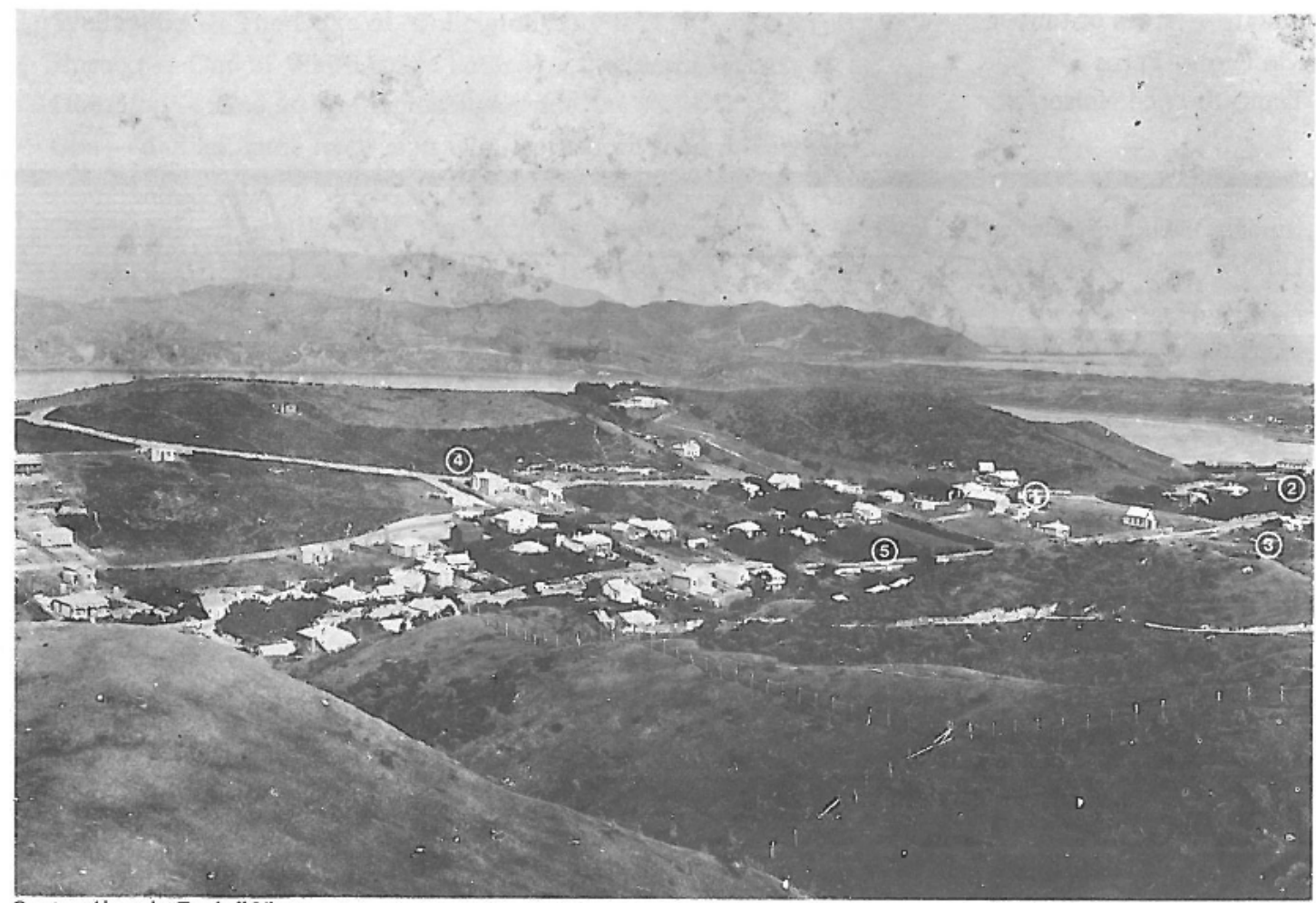




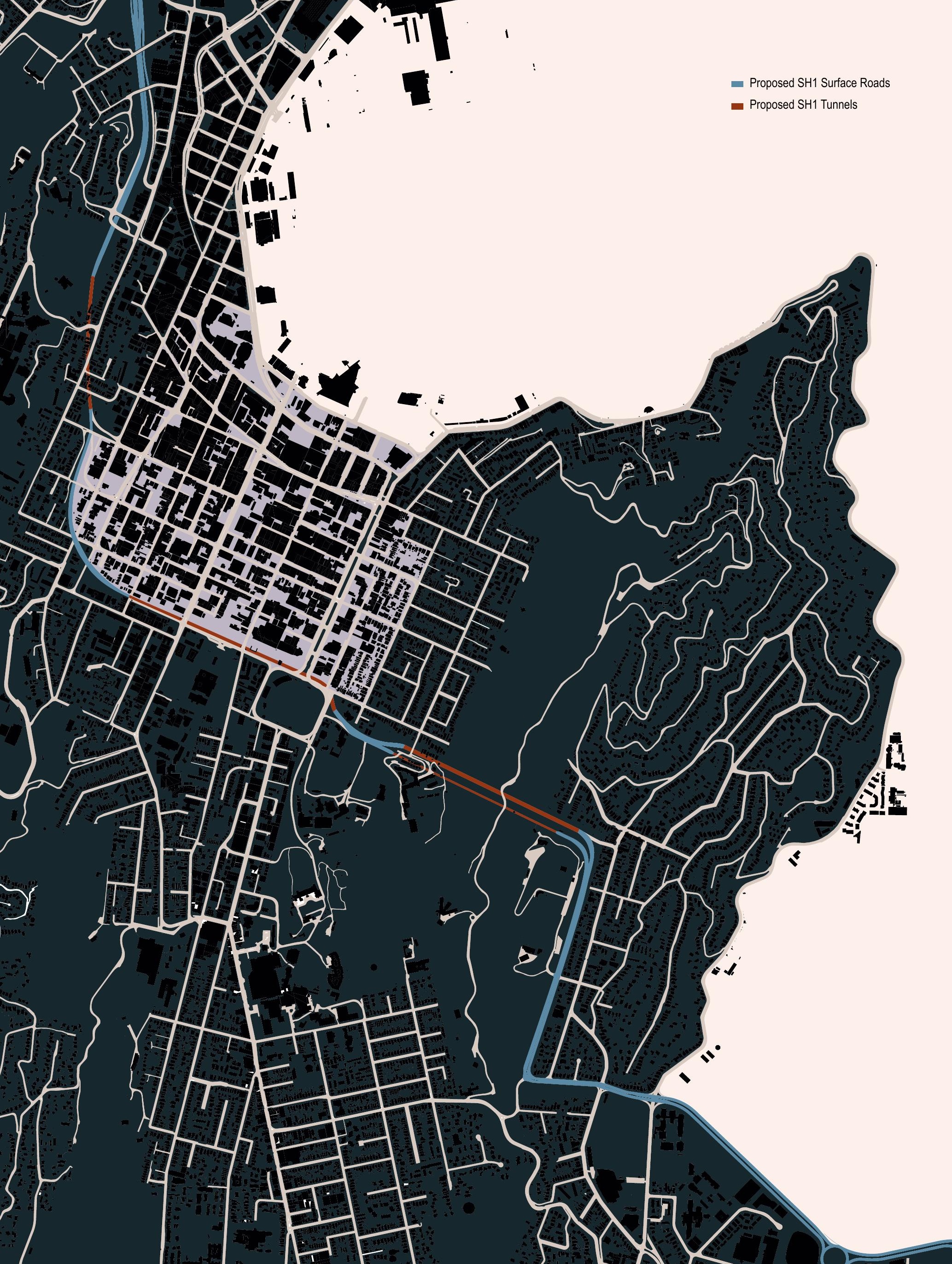




\section{PROPOSALS}

Despite delays, the proposals for the tunnel duplication have developed over the last decade. Public engagement and dialogue has increased since the establishment of Let's Get Wellington Moving (LGWM) - a joint initiative between the New Zealand Transport Agency (NZTA) and Wellington City Council (WCC). The aim of the initiative is to improve traffic infrastructure between Ngauranga Gorge and the Airport (Let's Get Wellington Moving, 2017). The most ambitious discussions for this focus area include a tunnel through the inner city to link up with a duplicated Mt Victoria Tunnel (Fig 2.04). Major surface road realignments would also occur. For Hataitai, this would mean:

-Another tunnel directly to the north of the existing one, facilitating two lanes of eastbound traffic and a wider cycling/pedestrian path.

-Taurima Street, linking the tunnel to the village becomes one-way.

-The existing tunnel facilitates two lanes of city-bound traffic.

-Ruahine Street (State Highway 1 between the tunnel portal and Kilbirnie) becomes a four-lane highway and encroaches into the town belt, resulting in a loss of up to $3 \%$ of town belt space.

-The existing pedestrian bridge linking Taurima Street to the park is replaced with a similar bridge and a cycleway is wedged between the highway and village, leading towards Kilbirnie (New Zealand Transport Agency, 2013). These are illustrated in Fig 2.05 and Fig 2.06.

The provision of traffic infrastructure comes at no small cost, especially where tunnels are involved. The most ambitious proposals for Wellington could cost as much as \$1.9B-\$2.3B (Let's Get Wellington Moving, 2017). Allen discusses the importance of the design of urban infrastructure as 'not simply performing minimum engineering strategies, but as capable of triggering complex and unpredictable urban effects in excess of its designed capacity' (Allen, Baird et al. 2010). The NZTA-proposed pedestrian bridge and cycle path are essential infrastructures, but are token gestures in comparison to the scale and magnitude of the roads.

Wellington has a diverse geography, beautiful landscapes and a relatively favourable climate for much of the year. The central suburbs are accessible without vehicles, but the city's infrastructure does not currently reflect this. Cycling and walking is a greener and healthier way to get around the city and is suitable for small, scenic cities like Wellington.

The existing proposals will do little to encourage a greater modal share of these active methods of mobility. The design of this infrastructure could be much more ambitious and multi-layered, transcending the vehicle-dominated NZTA approach, and aiming to better connect the pockets of city fabric inhabited by people.
Fig 2.04 Possible extent of State Highway 1 upgrades in Wellington. 

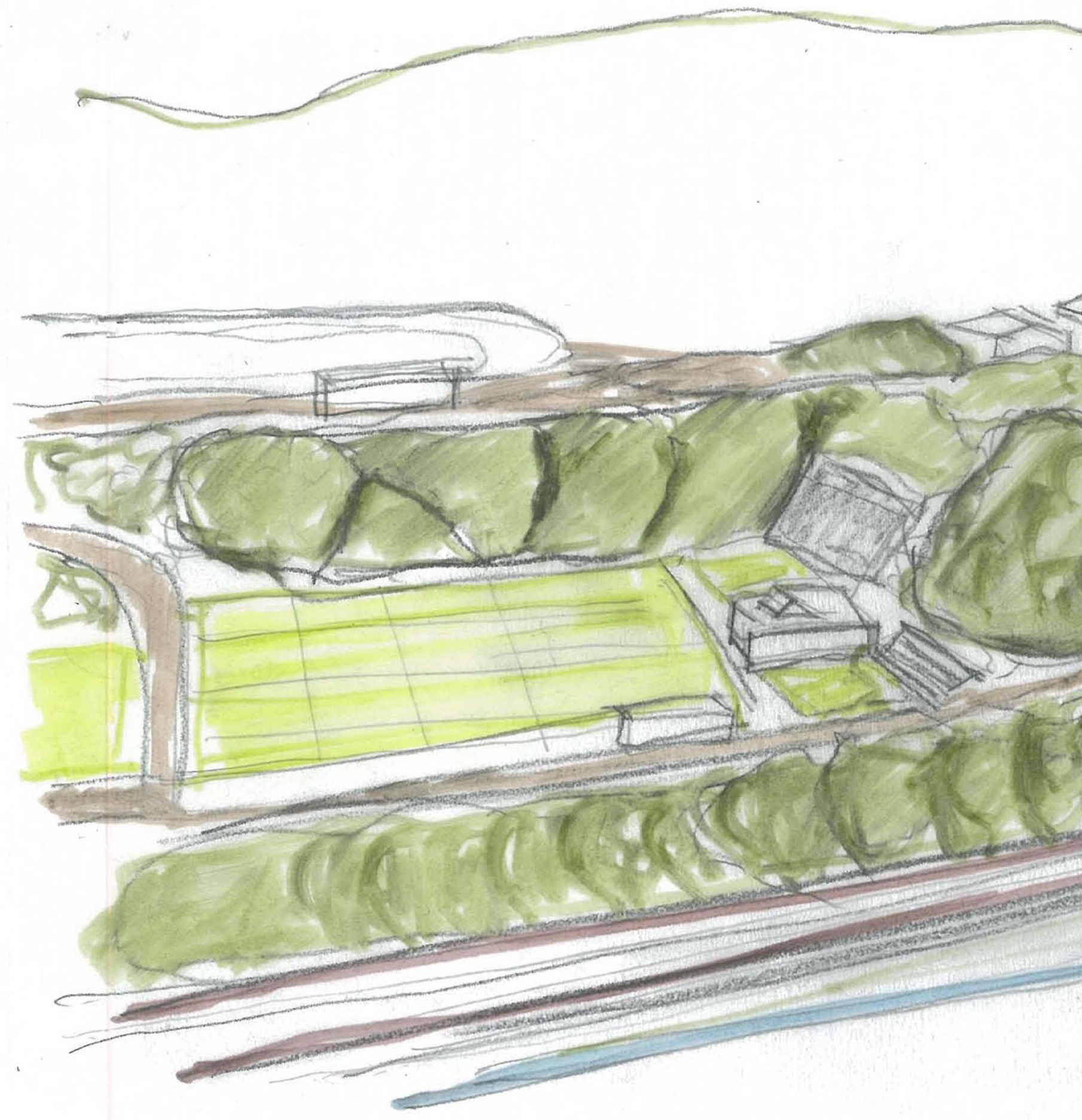

Fig 2.05 Aerial sketch of the existing NZTA proposals in Hataitai. 



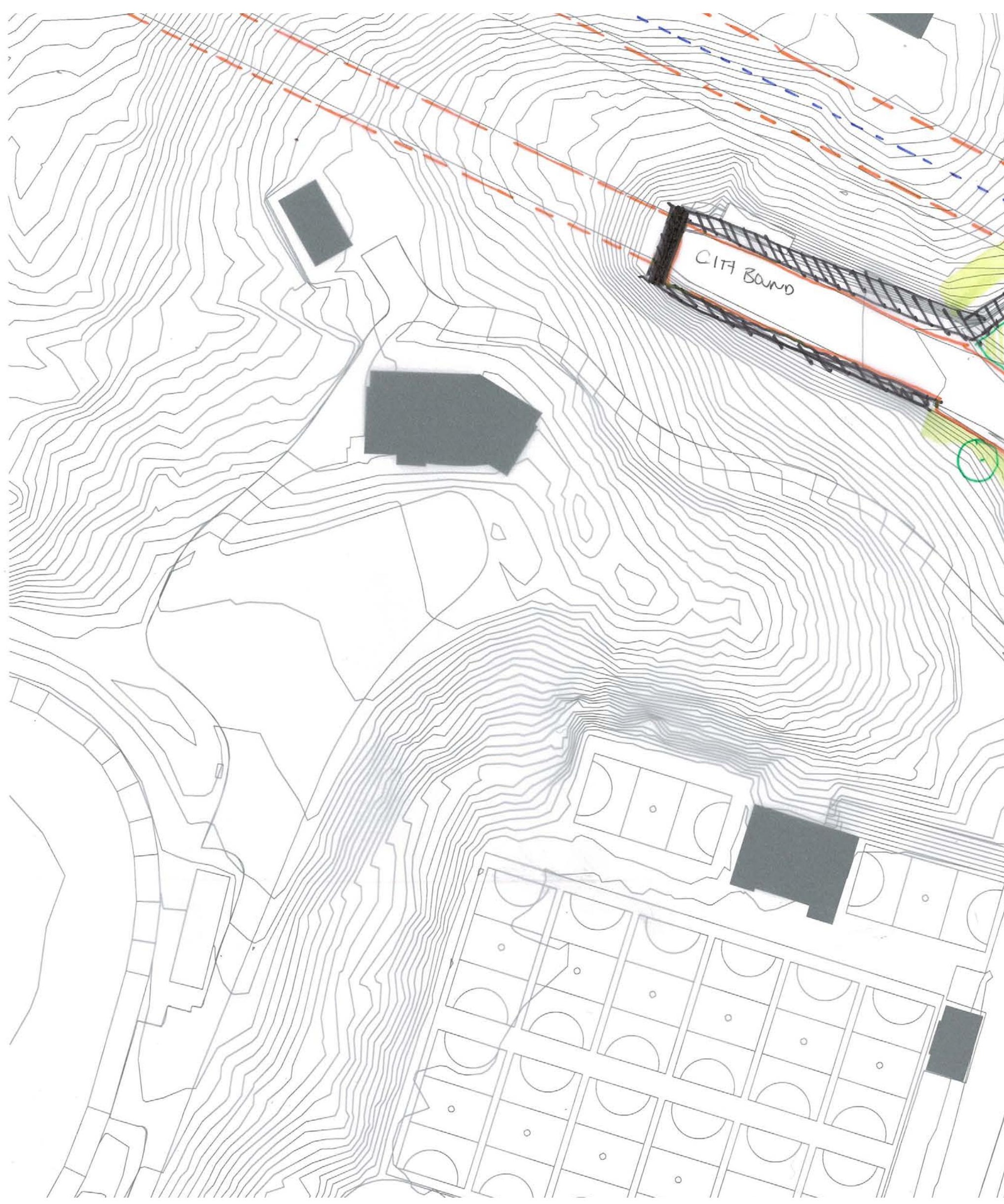

Fig 2.06 Sketch plan of the existing NZTA proposals in Hataitai, 1:1000. 


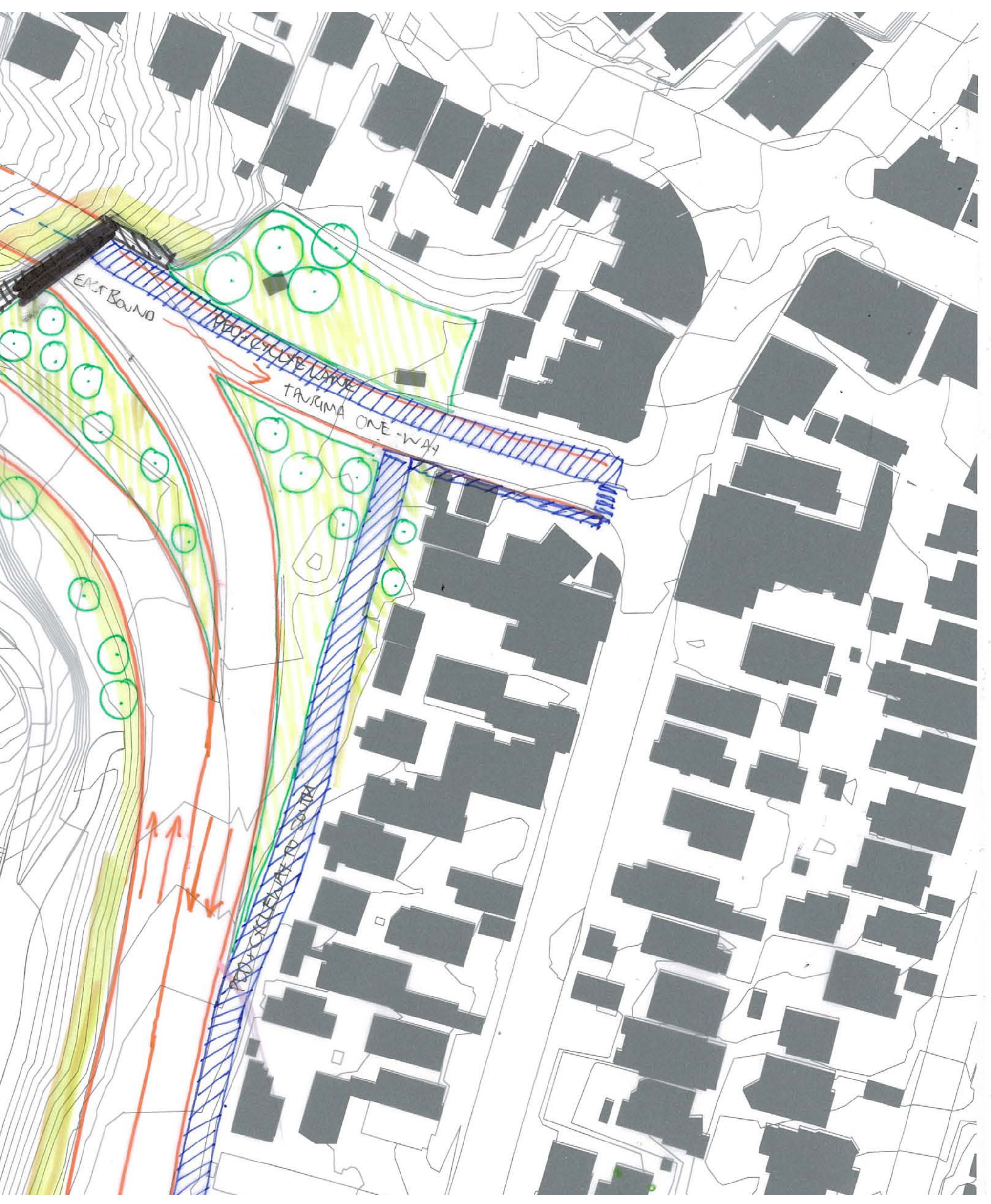




\section{CASE STUDY - WELLINGTON INNER CITY}

The purpose of this case study is to provide further background to Wellington's urban motorway system between the Terrace and Mt Victoria Tunnels. This portion of the motorway is 'inner-city'. The studies presented include completed works as well as abandoned proposals. They aim to highlight both the controversies and benefits that have derived from the ongoing upgrade of Wellington's arterial traffic routes.

INNER-CITY (TE ARO) BYPASS

The completion of the Wellington Urban Motorway between Ngauranga Gorge and Terrace Tunnel in 1978 saw slow progress for the remainder of the city's motorway extension. This was a result of funding issues and ongoing debate about what form the motorway should take through the inner city. Since the 1990's there have been further plans between NZTA and the WCC on how to best provide these arterial roads, without compromising the quality of the urban realm (New Zealand Transport Agency, 2013).

The key effect of these proposals was to divert traffic coming off the motorway, from the inner city. This resulted in the closure of the Ghuznee Street off-ramp and traffic instead being directed a block south to link up with Vivian Street, which subsequently became a one-way road and an extension of State Highway 1. Buckle Street would simultaneously provide one-way traffic in the opposite direction, requiring the acquisi- tion and partial demolition of the Tonks Ave precinct on upper Cuba Street, a rich cultural and bohemian centre of Wellington. The loss of a number of heritage buildings and prospect of an urban motorway through this area was cause for significant public debate. However, the appeal to Environment Court was dismissed in 1999 and work was completed between 2004 and 2007 (O’Neil 2015).

The loss of the heritage and cultural amenity in Tonks Ave was the result of the Transport Authority's decision to provide this portion of motorway at grade (at ground level) instead of a with tunneled road. As The Evening Post reported in October 2001,

'The sad fact about urban motorways is that they have to go through somebody's backyard' (O’Neil 2015). 
Fig 2.07 Incremental upgrades of inner city traffic. Stage 3 was dismissed.

Fig 2.08 Construction of Stage 2 of the ICB, c. 2006. 


\section{ARRAS TUNNEL}

The last proposed stage of the inner city bypass was the establishment of a dual carriageway between the Mt Victoria and Terrace Tunnels (Stage 3). This was dismissed amidst increased concerns over the environmental and urban effects. The project constructed instead is a vast improvement on the original proposal. Work began in 2012 for a 300m 'cut and cover' trench that would move part of
Buckle Street's northbound traffic underground. The construction of an open space over the top of the trench would facilitate the Pukeahu National War Memorial Park - a public space that extends the scope of the National War Museum (New Zealand Transport Agency 2018). The park and tunnel were completed in time for centenary ANZAC Day events on April 25, 2015. Thousands attend-

Fig 2.09 Sketch proposal of Stage 3 of the inner city bypass, a 'tunnel link'. This was a frightening prospect for the urban realm. 
ed a dawn celebration in the park and on the surrounding roads, including inside the tunnel.

The park provides a continuous public and pedestrian realm between a previously disconnected portion of Te Aro and Mt Cook. The expansive public space invigorates the heritage value of the nearby Mt Cook Police Barracks, the old Museum, and the ceno- taph. Other than the historical and cultural values offered by the new space, the physical separation of traffic and pedestrians/cyclists made possible with a 'cut and cover' trench demonstrates how ambitious traffic infrastructure projects can also address the human scale and pedestrian needs of the city. 


\section{BASIN BRIDGE}

The Basin Reserve has long presented a challenge for Wellington's traffic planners. The historic cricket ground severs any possibility of a direct traffic link between the Mt Victoria and Terrace Tunnels. Effectively a huge roundabout, it is a major cause of congestion in Wellington, where north-south and east-west traffic flows converge.

A bridge or flyover was first proposed in 2001 to address these issues and reduce weaving of traffic (New Zealand Transport Agency 2013). Serious proposals did not occur until 2012 and were met with strong opposition. Much of this opposition was concerned with the loss of heritage character of the Basin Reserve and the impropriety of a motorway flyover in such a location. Resource Consent for the project was initially declined in July 2014, and the High Court delivered the final blow in August 2015 upon 
rejecting the appeal lodged by NZTA (Forbes 2015). The rejection of the Basin Bridge put a halt to any immediate duplication of the Mt Victoria Tunnel. However, this does not mean that the project will not occur at all - it is widely acknowledged that the traffic issues around the Basin must be addressed in some form in the future. Where some opponents to the $\mathrm{Ba}$ sin Bridge are vehemently opposed to any new roads (and instead call for greener solutions such as light rail), others called for a 'less ugly' solution to a flyover, including tunneling or trenching (Forbes 2015).

These solutions could significantly improve the pedestrian experience, like at the nearby Memorial park, but would conceivably incur a much greater cost than the proposed $\$ 90 \mathrm{M}$ flyover. 


\section{THEORETICAL CONTEXT}

The preceding projects demonstrate the social, political, historical and formal tensions intertwined with traffic infrastructure provision in Wellington. These tensions are not dissimilar to those that would exist in most other cities in New Zealand or abroad. A common conception is that urban traffic infrastructure is a necessary, utilitarian function. This infrastructure is not always beautiful, but the function of the city relies on it. 'The sad fact about urban motorways is that they have to go through somebody's backyard' (O'Neil 2015). This is a reflection of the typical NZTA approach and usually results in minimal social and environmental mitigation, which might include basic sound walls and pedestrian overpasses - the kind of functionally minimal and visually banal structures that attract vandalism and motorists don't offer a second glance to. Traffic infrastructure is often hugely disruptive to the surrounding urban fabric, so adequate social and environmental mitigation is necessary. More ambitious projects, like Pukeahu National War Memorial Park offer new urban spaces, sculptural engineering and meaningful environmental additions. This multi-modal approach to infrastructure can offer a lot to the city and arguably negate the adverse effects of a road. I will present some examples as case studies in the following chapter.
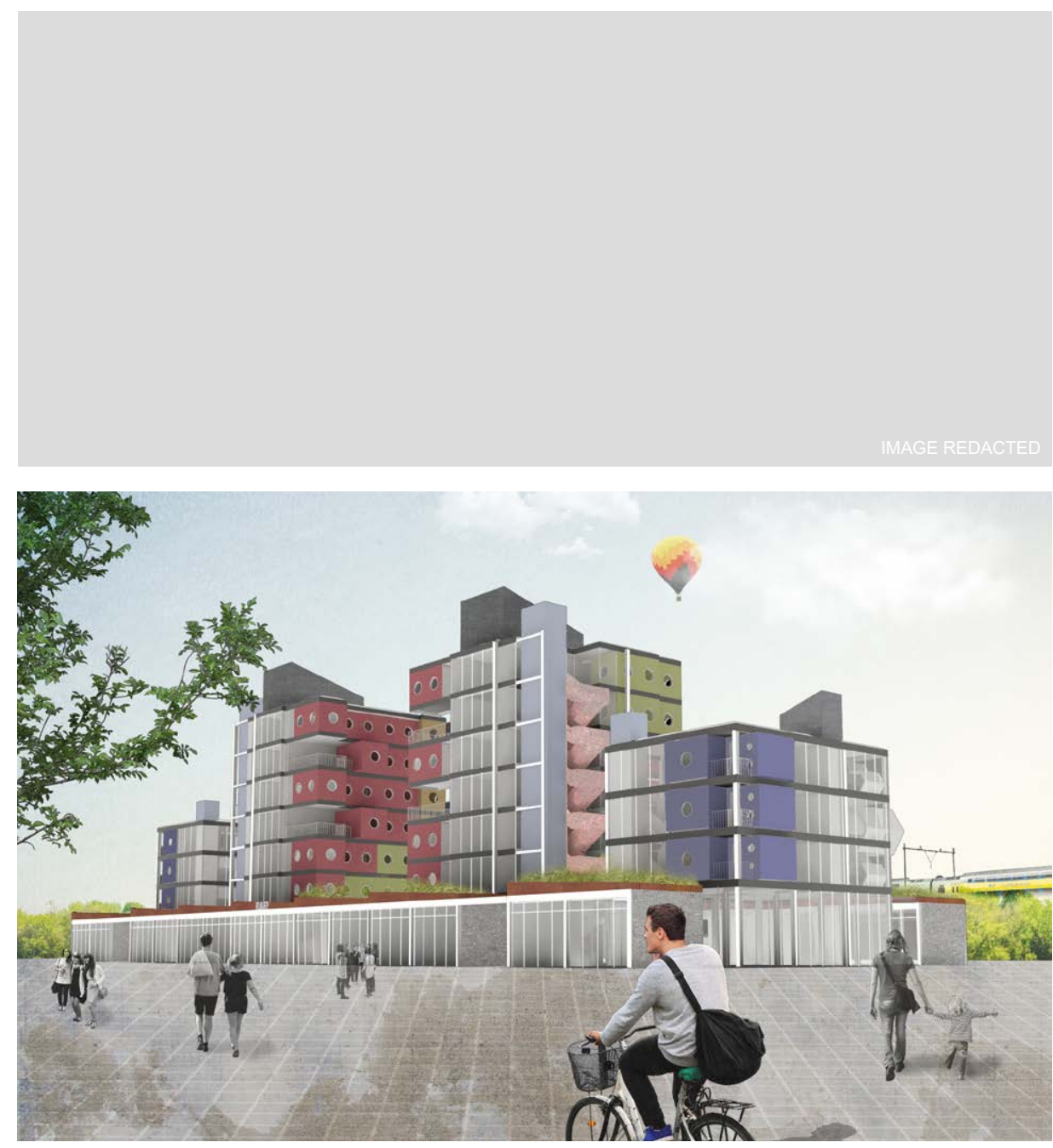

Fig 2.12 Archigram's Plug-in City, 1964.

Fig 2.13 Onderweg - In Transit. Amsterdam project, 2017. 


\section{THE ROMANCE OF AVANT-GARDE INFRASTRUCTURE DESIGN}

The aesthetics of the 'open-form' and superstructures of Archigram, Yona Friedman, Cedric Price, Kenzo Tange (Tokyo Bay Plan), and the Metabolists et al. have always beguiled me. They are provocative, powerful images. The radical scale and expansive nature of these projects made me question how this kind of design language might allow for new urban spaces above the highway in Hataitai. The roads are undoubtedly an essential infrastructure, but they are hardly democratic - NZTA plans to spend 100 's of millions on roads and tunnels, acquiring land and property to do so. How can we bridge across the dehumanised space lost to the highway, and also occupy it as a valuable urban place?

In 2017, I did an exchange to the Technical University of Eindhoven. My studio project's brief was to design a hotel, in Amsterdam. I wanted to design a 'flexible' building where the user might have control over their environment. This was rationalised into a scenario where the building might be able to adapt over a longer time-frame in response to more profound implications than the desires of the individual: housing crisis, Olympic village, emergency housing etc. Each of the accommodation areas were autonomous pods, which could conceivably be shifted by cranes in the cores of the towers. I did not succeed in the rationalised solution either. My pragmatic
Dutch teachers insisted that once it was built it would never change, like the Nakagin capsule tower. I removed the cranes and ended up with a cluster of pods, lamentably trapped in a perpetually fixed form (Fig 2.13). The whole concept derived from a reasonably superficial understanding of Plugin-City and other Archigram-esque projects, which perpetuated the ideas of 'pleasure' and control.

It is through this thesis that I have come to understand more about their political agendas. How they aim to 'change the relationship between the individual and society' with new ways of living, new ownership models, and living environments for which the radical urban forms were instruments (Lemonier 2014). I think that this avant-garde approach to infrastructure design could be a provocative and innovative way to create and occupy space (I.e. above a highway) and concurrently make a bold statement to contest the instrumentality and onedimensionality of the road below.

How might this work in Hataitai? Where would the boundary be? Through the lens of the Situationist City, New Babylon, and with a ubiquitous mesh structure, I attempt to answer these questions in Chapter 4 - Field. 
I am fascinated by the role of play in architecture. I believe this is where my interest in the popart images of Archigram and other avant-gardes developed; the colourful pods, balloons, and the nomadic structures. I have always incorporated a playful streak in my design. Similar elements are also inherent to projects by Price, Constant and Tschumi, which I will discuss in Chapter 4.

The value of play in culture has been theorised by many notable philosophers and academics. Johan Huizinga is perhaps the most vociferous proponent of play culture in history. His theory Homo Ludens (1938) suggested that play is not only the basis of human nature, but also of human culture and civilisation. War, religion, politics, sports and art all contain elements of play. 'Play must serve something which is not play' (Huizinga 1956). Huizinga was not the first to discuss this. Friedrich Schiller was amongst the first western writers to discuss play as the essence of human nature, at the end of the 18th century. Play was a way to 'tame the savageness of life' (Schiller, 1920). The Dadaists of the early 20th century used an explosion of 'therapeutic, liberating irrationality of play' in the arts as a way to overcome the traumatic events of WW1 (Lefaivre 2007). Henri Lefebvre asserted the 'right' to the city as a place of pleasure and enjoyment. 'A good city, like a good civilisation, was one that integrated play into its human and social fabric' (Lefebvre 1996).

The Situationist procedures of psychogeography and dérive, which encouraged strange and unfamiliar explorations of quotidian urban areas, are also washed with wildly playful conceptions. They inspire a kind of wandering, which could be invigorated with strange and unfamiliar architectural forms. I will develop these whimsical moments in the enclaves of everyday Hataitai through 'fast and loose' sketching and modelling techniques in later chapters. A common thread among these theories is the idea that a meaningful life should not consist of instrumental activities, production and consumption. Play and humour are also fundamental to a meaningful life.

But where, in the modern city, are these moments provided? The motorway running through Hataitai is an essential piece of capitalist infrastructure, but it is an engineering pursuit that dehumanises the surrounding environment. What could be the possibility of a playful architecture as a vital piece of urban infrastructure in Hataitai could it learn from the avant-gardes discussed previously? What could an infrastructure for nonsensical activities look like? The pursuit of a playful architecture/infrastructure begins early in design experiments and continues as a major thread throughout my design process. 
Fig 2.14 Marcel Duchamp's 1913 Bicycle Wheel, one of the first Dadaist Artworks.

Fig 2.15 Guy Debord's Psychogeographic Guide to Paris.

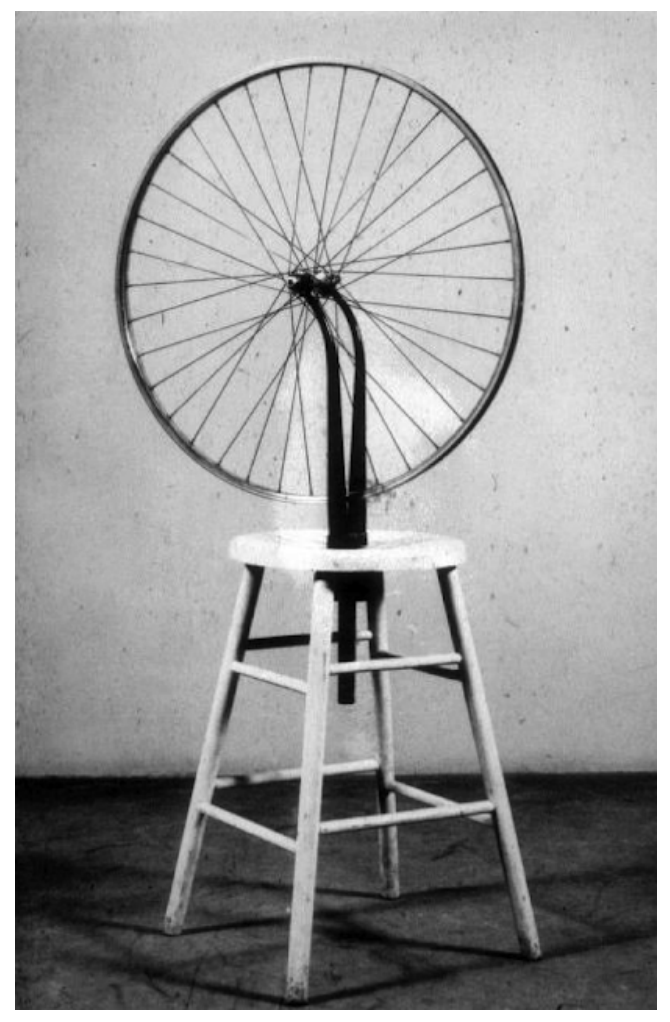




\section{AUTONOMY AND AN ISOLATION FROM EVERYDAY LIFE}

There is a tension in my mind between a desire to create large provocative projects, and an often overpowering sense to produce more rational and pragmatic solutions. This is perhaps why my Amsterdam project didn't result in the way I had initially wanted it to. I have always considered projects like Plug-in-City and Fun Palace to be utopian provocations rather than proposals for projects to be built. The evidence comes from the fact that most of these groups never built their projects. The 'openform' and superstructures are very difficult to plan and program. I eventually decided that my scheme would need an edge. But how do you determine the edge of a feasibly infinite environment - especially in a real life urban situation like Hataitai? I wrestle with this question throughout Chapter 4. Consequently, in Chapter 5, I explore the antithesis of the borderless environment.

In the 1970's, Manfredo Tafuri understood a critique of capitalism as coming from the categories and forms that actually participate in its production. He was the first intellectual to declare this (Aureli, 2011). In other words, real social and political change would come about from tangible solutions, not romantic and utopian ideas. Similarly, in The Possibility of an Absolute Architecture, Pier Vittorio

Fig 2.16 Dogma's Stop-City demonstrates clearly demarcated boundaries. 
Aureli testifies the importance of a 'sharpened formal consciousness in architecture', which he sees as essential to engage politically, culturally, and socially in the city (Aureli, 2011).

In Chapter 5, and in light of these interpretations, I shift the paradigm from a literal mesh to an isolated object with an absolute and definitive boundary. The strangeness of the discrete moment, isolated from the quotidian city evokes similarities to the frivolous wanderings of the Situationists' dérive. O.M. Ungers and Rem Koolhaas' 1977 manifesto for the designed decay of Berlin also championed the richness of discrete, site-specific islands in the city, in the most radical sense. A separation from reality was a quality I developed in my sketches in Chapter 4. But it was not unique to the difficult formal language of the mesh.

What could be the nature of unique and whimsical moments in the enclaves of Hataitai? What architectural languages could support these moments? I address these questions in Chapter 5, aided by discussions on autonomy, and a child-like fascination with wandering.

Fig 2.17 Where the Wild Things Are, an escape from real life. 
3.0

$$
0
$$




\section{Case Studies}

Traffic infrastructure is widely considered an essential, utilitarian function. However, the provision of roads, motorways and highways can adversely affect the urban areas that they pass through. Traffic infrastructure is expensive to construct, and therefore social and environmental impact mitigation often comes at a minimum standard.

This is not true in every case. The barriers presented by infrastructure can also present opportunities for innovative, urban intervention.

This chapter exhibits a few examples of traffic-related infrastructure projects that aim to invigorate their surroundings by strengthening pedestrian connections and providing new spaces. These projects range from a large-scale road project with multiple associated urban spaces, to a simple cycle path utilising a former motorway off ramp. I present each case study with a short description, and my own interpretation on how they revitalise an otherwise disconnected pedestrian fabric.

The qualities and opportunities presented in these case studies demonstrate the powerful urban potentials of a strong pedestrian culture. 


\section{WATERVIEW CONNECTION, AUCKLAND}

The Waterview Connection in Auckland is one of the country's largest and most ambitious infrastructure projects. The framework completes Auckland's western ring route and offers alternative routes between the CBD and Airport, as well as a means of bypassing the city centre (New Zealand Transport Agency, 2018).

The project includes twin $2.4 \mathrm{~km}$ tunnels between Point Chevalier and Mt Roskill. The tunnel is the longest and deepest in the country and provides three lanes of traffic in each direction. The tunnels were bored by a specifically engineered machine nicknamed 'Alice', and reach a depth of up to $45 \mathrm{~m}$ below the city surface (Zwolle, 2014). This is below sea level. Although expensive, (the cost of tunneling alone cost $\$ 1.4 \mathrm{~B}$ ) the deep bored construction allows the city to remain largely intact on the surface. The residential homes and suburban streets of Mt Albert and Avondale lie directly above the path of the tunnel (Fig 3.01).

The project is celebrated not only for the increased efficiency of Auckland's roads, but also for the urban design that occurred alongside the road and tunnel con-

struction. Architecturally designed ventilation stacks adorn the tunnel portals at either end, and an elegant pedestrian bridge connects the disparate sides of the highway above six lanes of traffic (Fig 3.02). A handful of recreational urban spaces including boardwalks and bike paths, skate parks, a playground, sports fields and storm water wetlands were included as a part of the infrastructure project to contribute new public spaces the neighbouring suburbs (New Zealand Transport Agency, 2018).

Fig 3.01 (Opposite) Ventilation stack.

Fig 3.02 (Next spread) Pedestrian bridge, pathways, storm water wetlands, sports fields. 




\section{LIGHTPATH, AUCKLAND}

Much like the Waterview Connection, Auckland's pink Lightpath forms the completion of an inner city route, but for pedestrians and cyclists. The route utilises a former motorway off ramp between Grafton Gully and Victoria Street, connecting previously isolated cycleways in the city centre and west of the city centre.

The infrastructure's history as an off ramp and location adjacent to a major motorway provides a dynamic and energetic setting for its non-vehicular transit. The path is a $600 \mathrm{~m}$ strand, threaded amongst a confluence of fast moving roads. Its iconic pink surface and interactive, light up spine are playfully distinct, and generate a fun and popular urban space out of an ordinary everyday infrastructure (ArchDaily, 2016).

Fig 3.03 (Opposite) Interactive LED lights and a brightly painted surface make the path a popular route for pedestrians \& cyclists.

Fig 3.04 (Following spread) Lightpath weaving between motorways and ramps, as seen from above. 




\section{LUCHTSINGEL, ROTTERDAM}

Luchtsingel (air canal), connects three historically neglected districts in Rotterdam and repurposes vacant buildings and rooftops into vibrant public spaces.

The 400m, 3-pronged pedestrian bridge was accomplished almost entirely through crowdfunding, initiated by its architects who wished to see public life returned to the forgotten areas. This was achieved by selling the wooden planks of the bridge to the public, whose names would be inscribed on their respective planks. A cancelled office development plan, leaving multiple vacant buildings provided the catalyst for the intervention, with the architects transforming the lot into an entrepreneurial laboratory, information centre and rooftop farm (ArchDaily, 2015).

The bright yellow bridge connects this creative hub to the former Hofplein Train Station roof- across a 7-lane road and major railway track. The station's roof has also become a vibrant public space. A park and playground occupy the ground at the terminus of the remaining prong and completes the connection between Rotterdam Centrum (central) and Rotterdam Noord (north) (Luchtsingel, 2016).

The project exemplifies how neglected urban territories, especially those affected by traffic (and rail) infrastructure can be transformed into lively public and pedestrian spaces. Not only does the bridge facilitate formerly inaccessible crossings for pedestrians with contemporary design, the heritage and industrial undertones of the urban fabric are renewed by the adaptive reuse of existing infrastructure.
Fig 3.05 (Opposite) The bridge links a series of public buildings and rooftops.

Fig 3.06 (Following spread) Luchtsingel as seen from above. 


4.0

$$
0
$$




\section{Field}

A highway is a product of capitalist instrumentality. It is built for an essential purpose: to connect places. However, it can also isolate urban territories and dehumanise the surrounding fabric. This is the case in Hataitai, where State Highway 1 compromises pedestrian networks between the Village and Town Belt.

By considering the city fabric as a continuous field, how might the landscape of the Town Belt be stretched across the highway as an extension of this field, to mitigate its dividing qualities?

I explored this with an experiment that aimed to replace the existing, disconnected ground plane in Hataitai, with a continuous scaffold. I used 'fast and loose' hand drawings and physical models to develop a ubiquitous mesh structure and placed this across the landscape to join the disparate urban territories on either side of the highway. I then placed programmed pavilions and crossing spaces within the mesh. I studied the Situationist city New Babylon, which supports the dissolution of boundaries in everyday life, with an expansive physical environment and an open social condition. In this chapter, I aim to apply these principals to a real urban scenario in Hataitai.

The ensuing drawings and studies offer alluring approaches to urbanism and intervention. However, determining 'the edge' of the mesh environment persistently provided a challenge. I found that while this approach is romantic and provocative, it is very difficult to apply to real urban situation as it requires a dogmatic shift of existing everyday models, and its plan is not fixed. 


\section{BOUNDARIES}

State Highway 1 severs Hataitai from the recreational Town Belt, enforcing the dominance of the vehicular realm in the city. The impropriety of this dehumanised environment is exacerbated by the modest suburban typology of the adjacent village. A simple pedestrian bridge unspectacularly links either side of the highway - emerging from the trees in the Town Belt, it ramps into a grassed no-mans-land that is not quite part of the village (Fig 4.01). The park, although visible from the village, does not much feel part of the suburb. A handful of facilities there cater mostly to sports teams and so aside from Saturday morning sports, it is largely devoid of activity.

There is little crossover of activities between the park and the suburb. The physical boundary imposed by State Highway 1 also creates distinct boundaries in everyday life activities. The park and village are geographically close, but perceptibly distant. Even within the suburb, homes are detached from each other in every

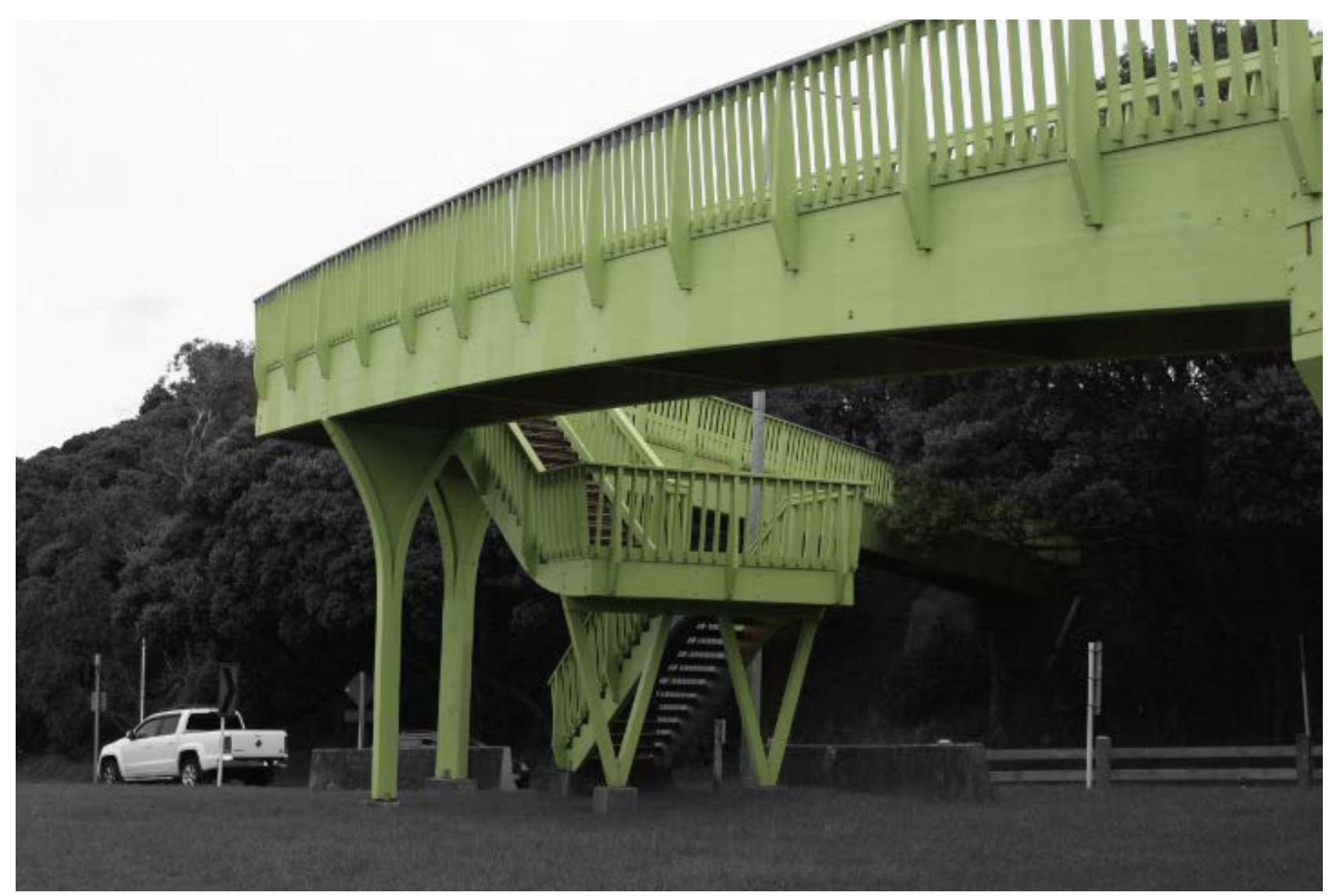

Fig 4.01 Existing, banal pedestrian bridge. 
sense.

The highway is a capitalist construction. Henri Lefebvre might categorise it as an object of production or consumption. In his Critique de la vie quotidienne (Critique of everyday life, 1947) he argued that is was the humble, ordinary and leftover parts of the city that could contribute to the most poetic experiences of social life. He asserted the 'right to the city' as a place of pleasure, independent of the imperatives of economy (Lefaivre 2007). Although far from the Parisian blue-collar neighbourhoods he was referring to, we could consider the leftover territories at the periphery of the highway as an 'everyday' space. The proximity between suburb and park present opportunities for an enriched and more inclusive urban environment. This would require a solution to bridge the physical boundaries between the isolated territories, as well as the cultural boundaries in Hataitai.

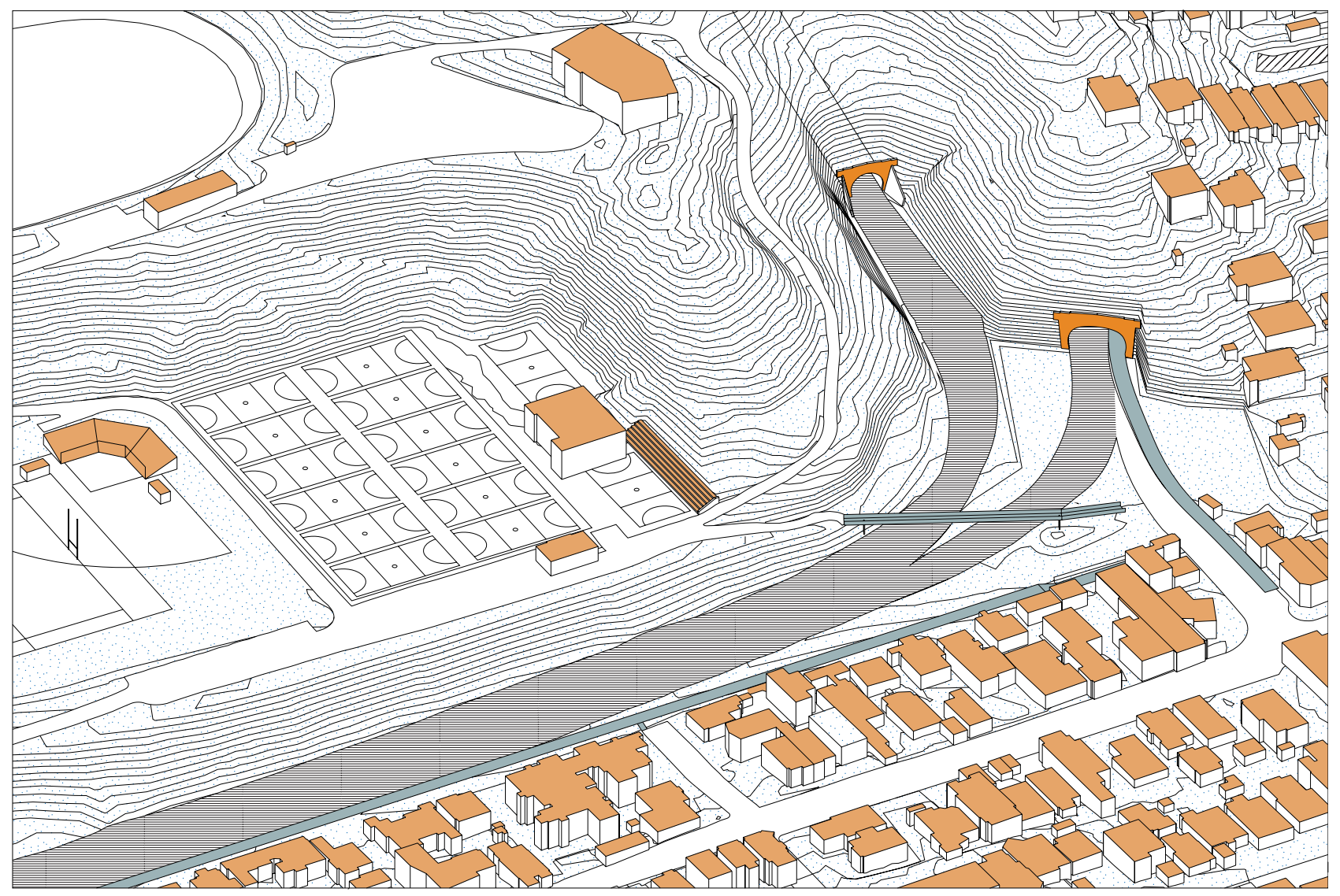

Fig 4.02 Emergence of tunnels in Hataitai and the resulting fragmented urban landscapes. 


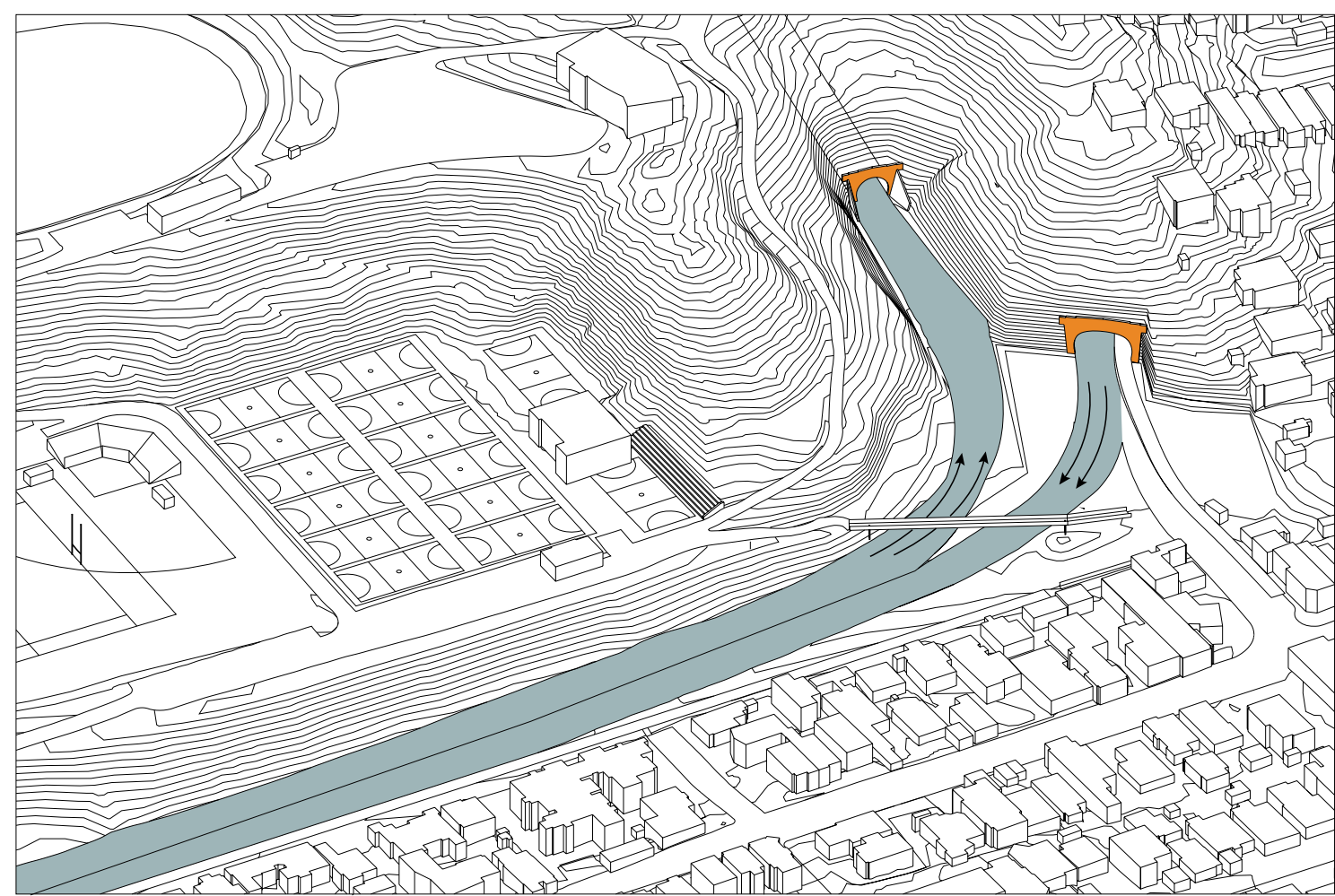

Fig 4.03 State Highway 1 traffic lanes.

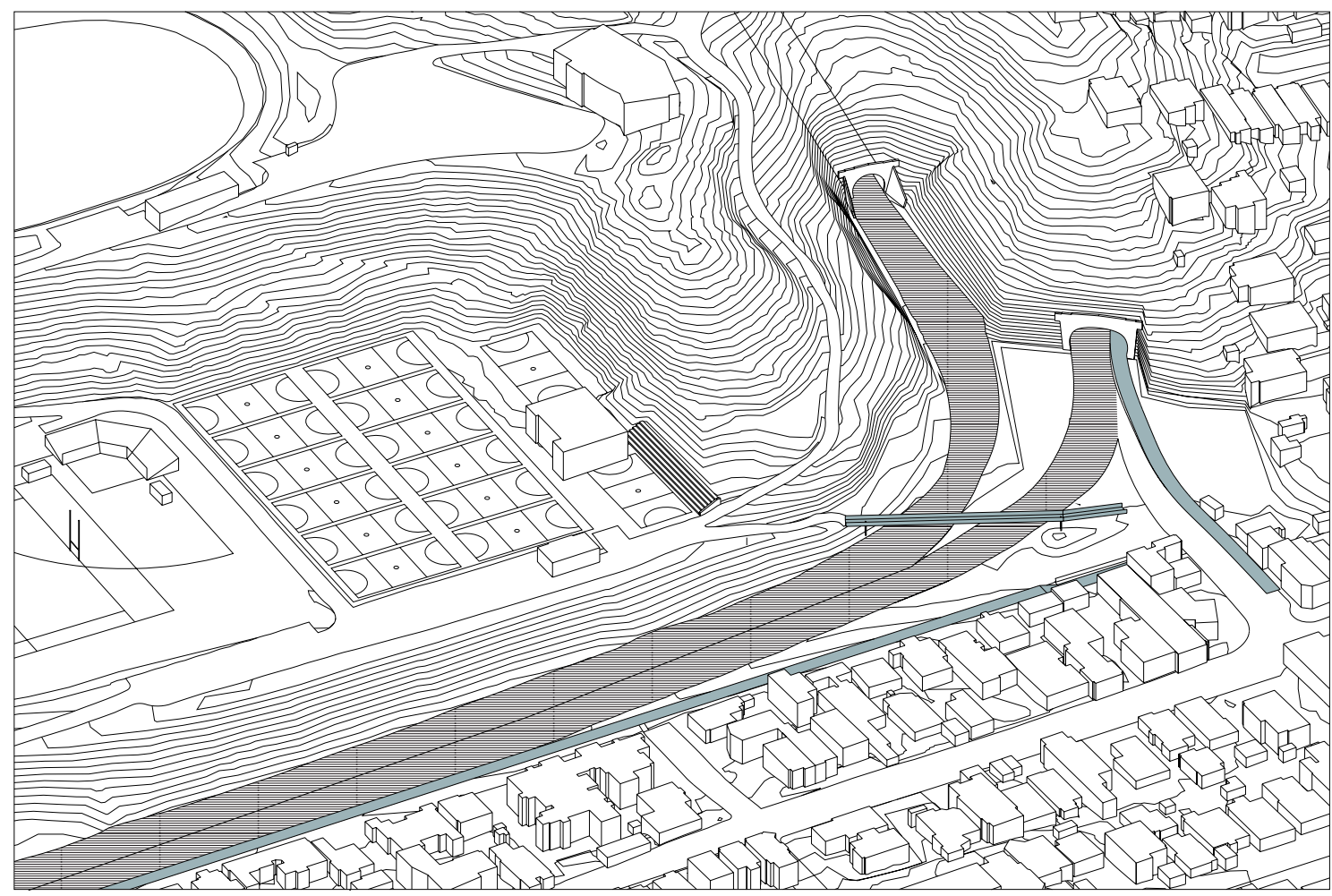

Fig 4.04 The pedestrian/cycle paths are thin threads in comparison to the torrents of fast moving traffic. 


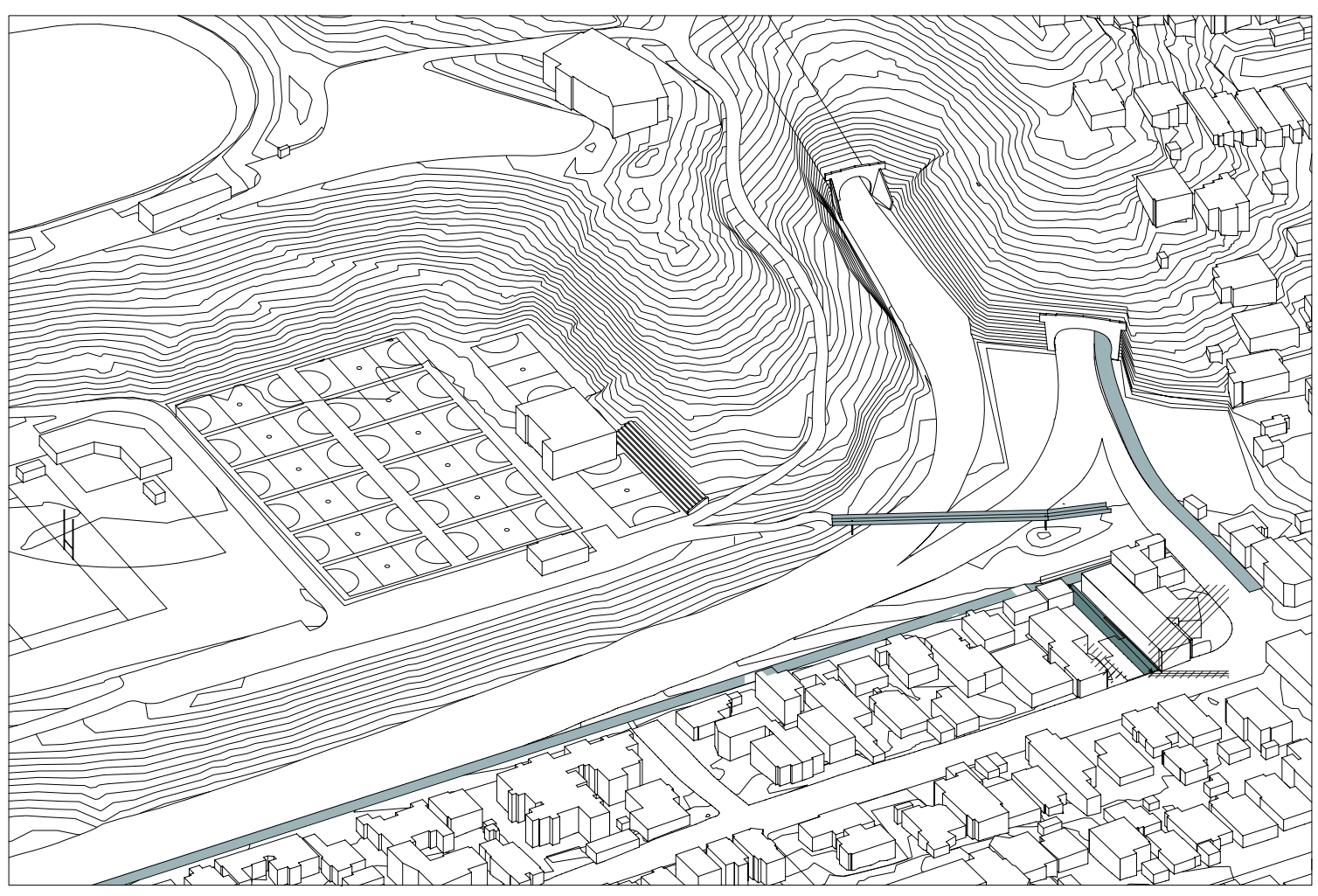

Fig 4.05 An infill connection between Moxham Ave and the shared path could make the pedestrian paths more accessible.

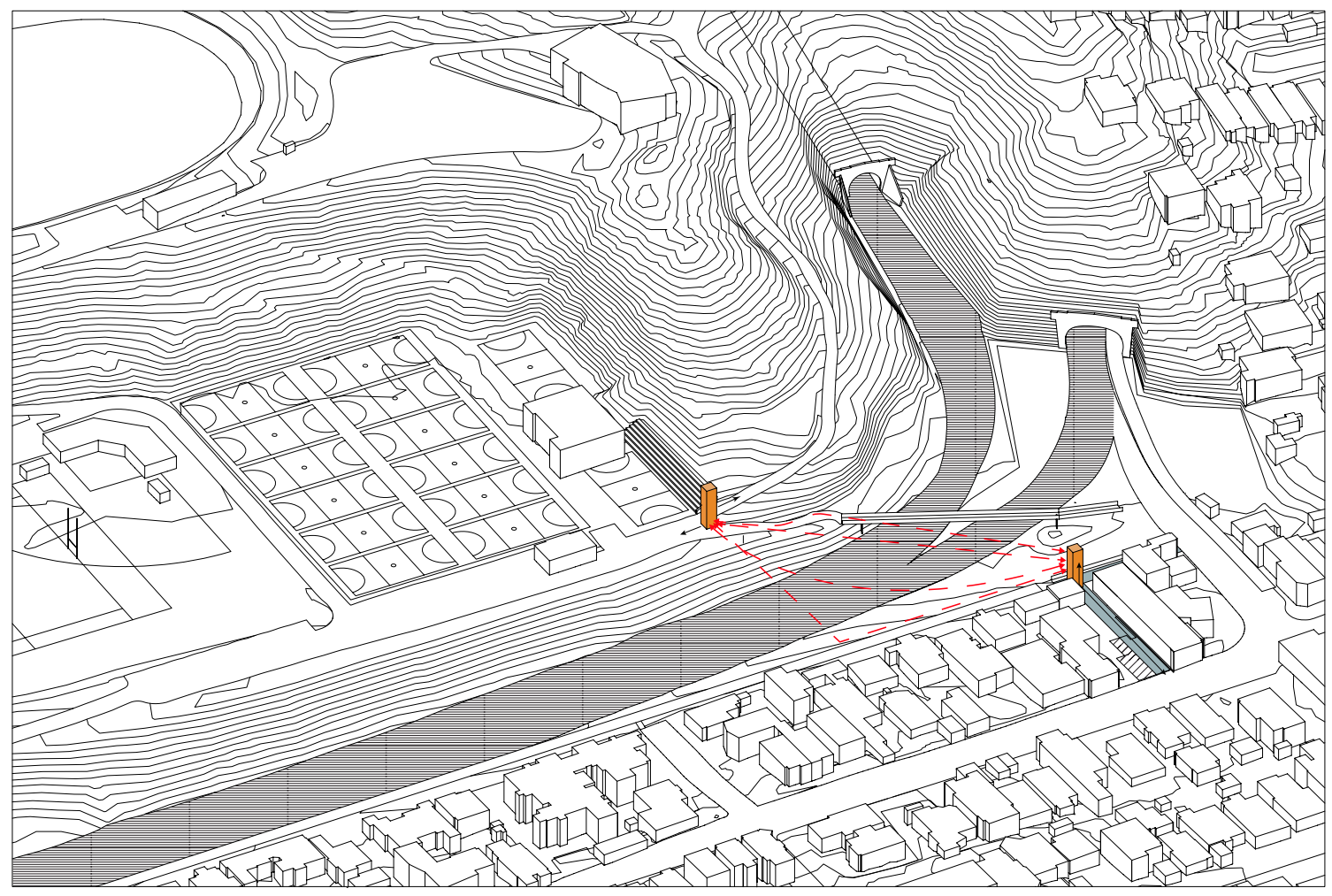

Fig 4.06 Possible anchor points and lines to bridge across.

49 


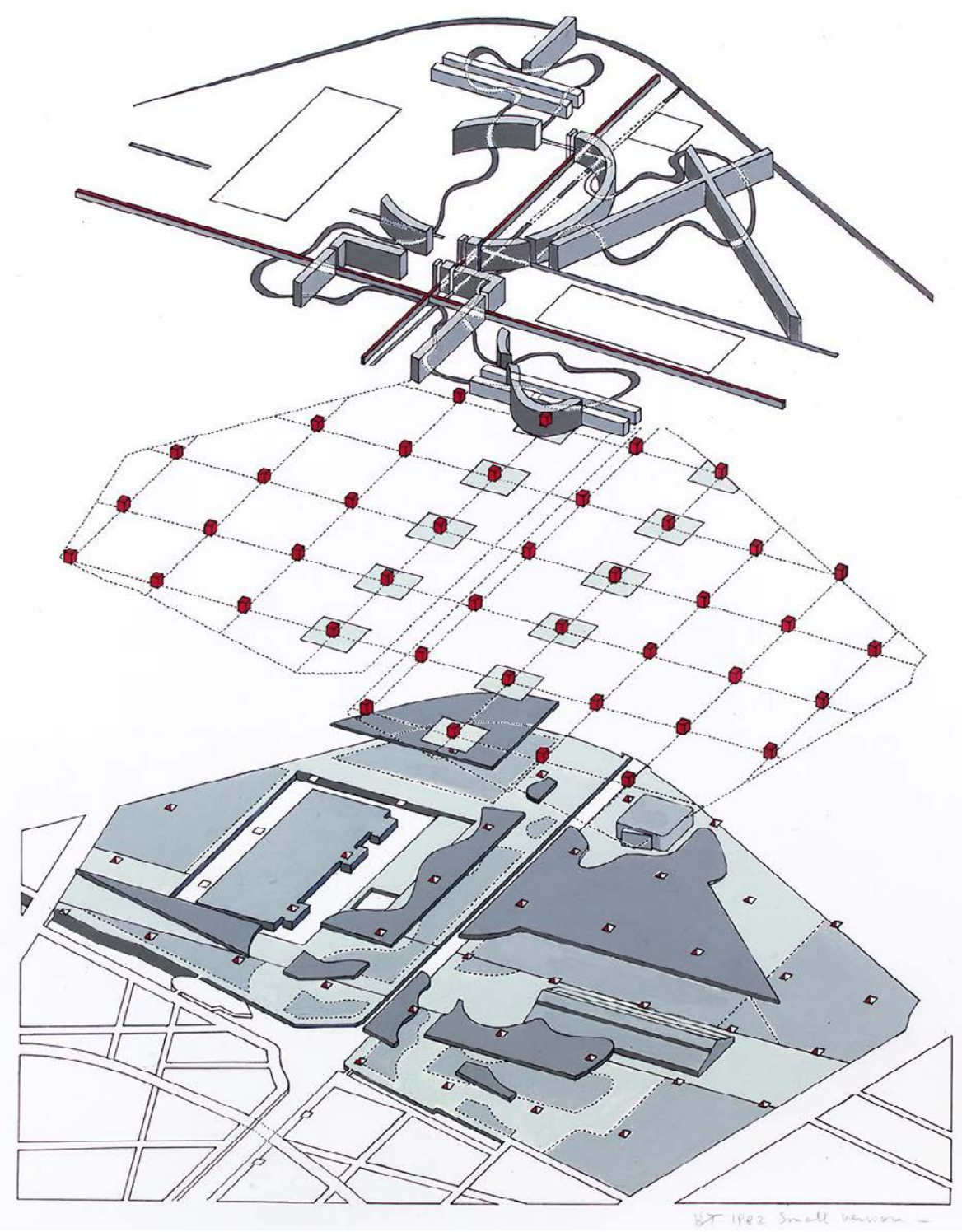

Fig 4.07 Parc de la Villette as Points, Lines \& Surfaces.

Bernard Tschumi classifies three distinct elements that construct his Parc de la Villette: Points, Lines, and Surfaces. My ensuing sketches borrow some of these principals. Anchor points at either end of the bridges suggest how they might facilitate vertical circulation or programed spaces, similar to the follies Tschumi refers to as points. Lines facilitate movement, this occurs on the bridge decks. Some sketches suggest that these could be sculptural or curved to facilitate fast-moving bikes. Separate lines of movement for different users could be a playful but pragmatic approach. The surfaces in my schemes offer moments of pause, interaction and play. These drawings suggest the possibility of a pedestrian infrastructure as a piece of architecture that creates space instead of simply bridging it. They are playful and intentionally superfluous. Tschumi's follies are deliberately un-programmed spaces which 'provide escape from the regulations which police routine behaviour' (Taylor, 2003). Mark 


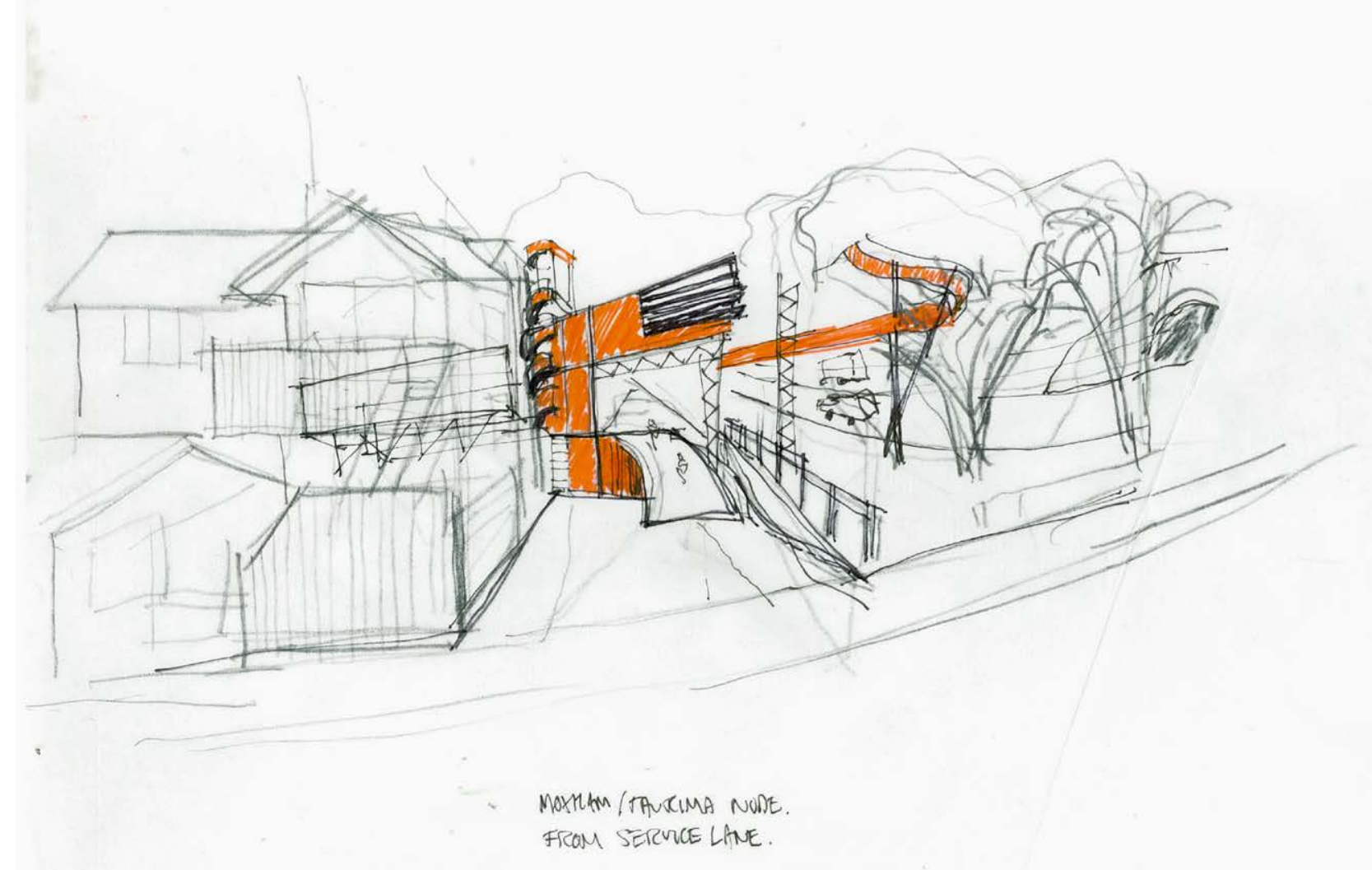

Fig 4.08 One of Tschumi's follies reimagined as a pavilion in Hataitai, May 2018.

Taylor suggests that the inherent uselessness of these structures is a strength, in a society governed by profit (2003). Their pleasure derives immediately from their pointlessness, as Tschumi points out in his manifesto Fireworks, 'Good architecture must be conceived, erected and burned in vein' (Tschumi, 1974).

Tschumi's apparent nonchalance about the use value of his follies is a fitting example of Huizinga's Homo Ludens in architecture. 


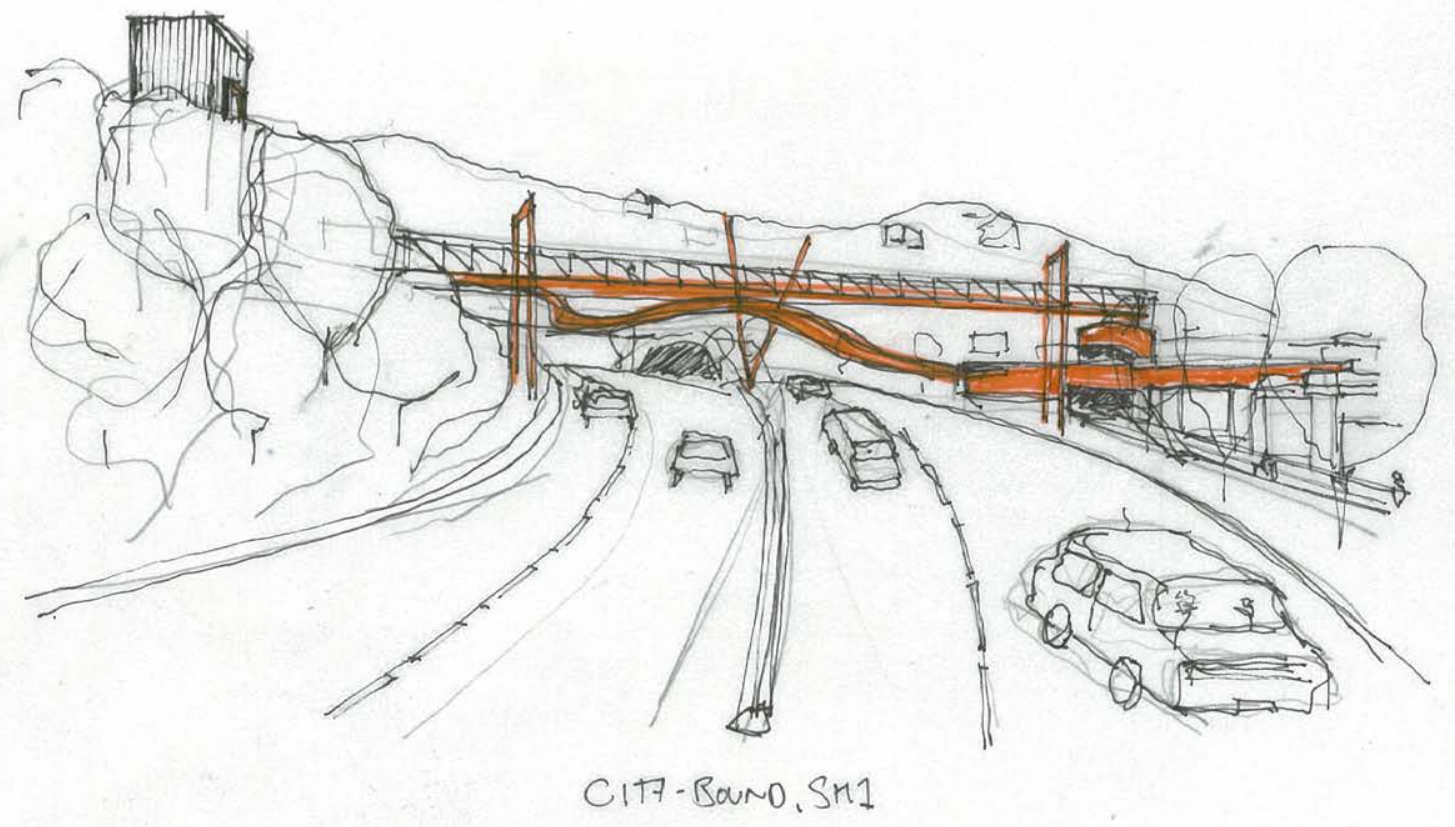

Fig 4.09 Superfluous pathways and pavilions in the vein of Parc de la Villette. 


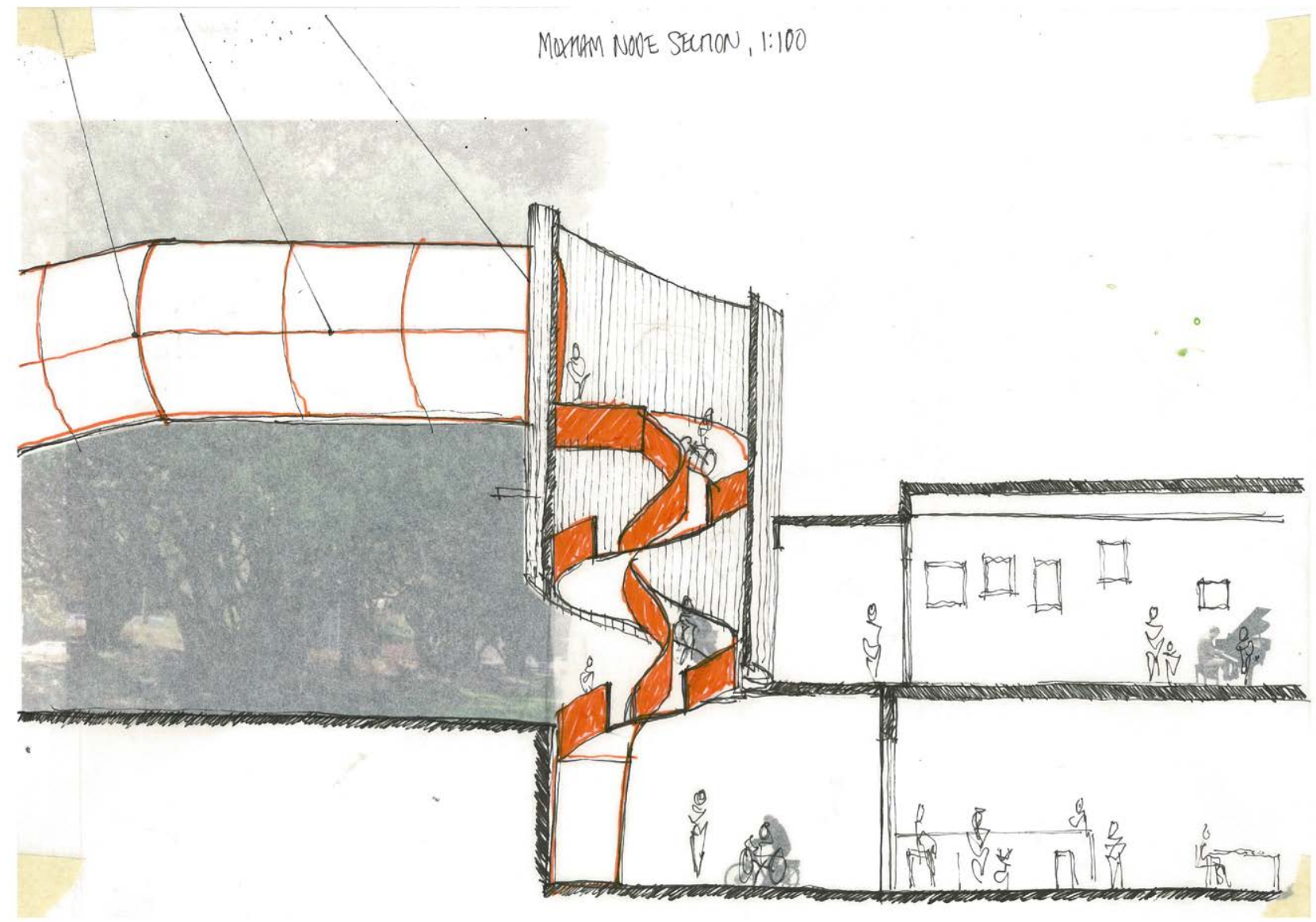

Fig 4.10 A vertical node linking a bridge deck to the path below and a programmed space in the village. 


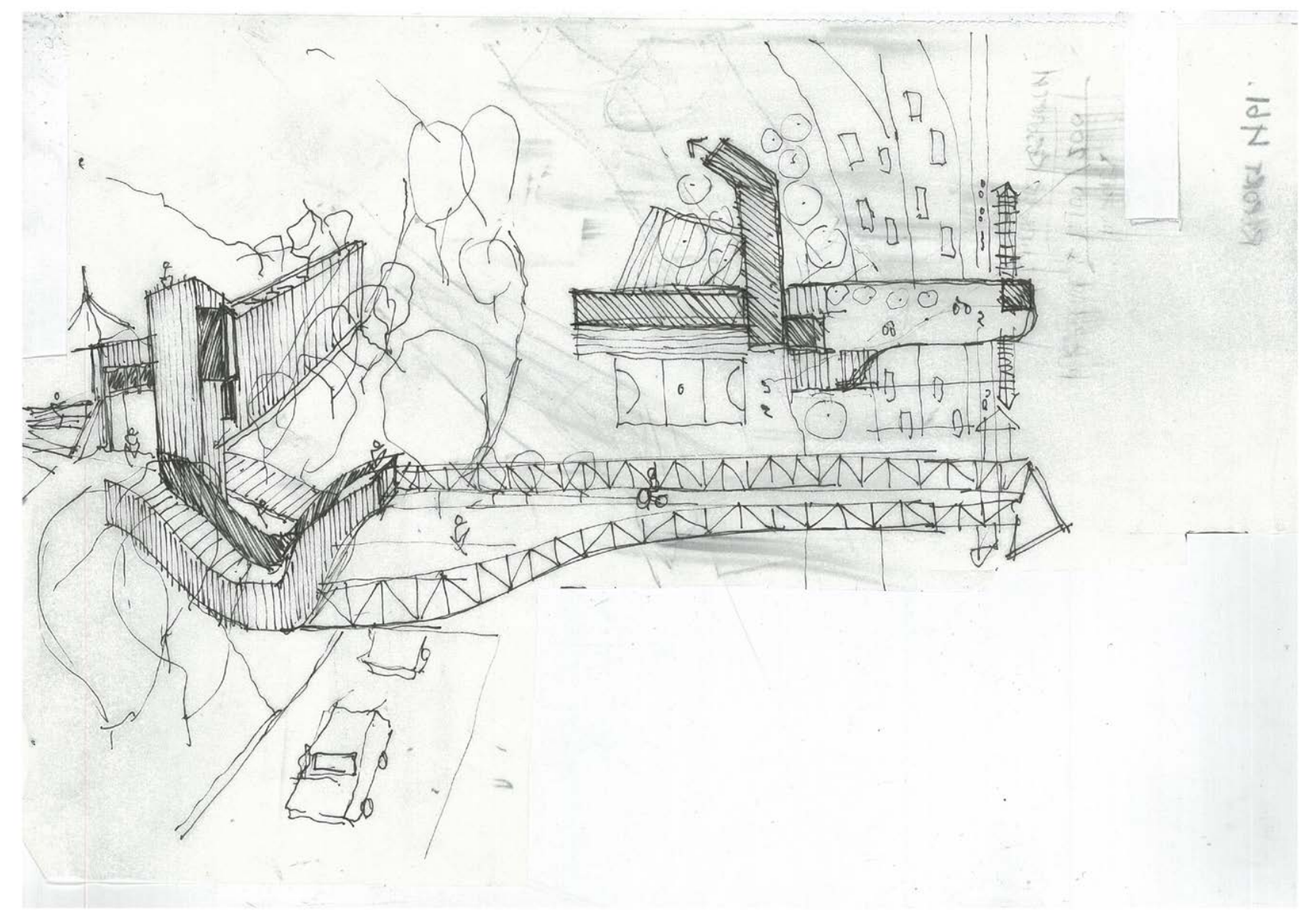

Fig 4.11 A playful and sculptural ap-

proach with pavilions integrated into the bridge, April 2018. 


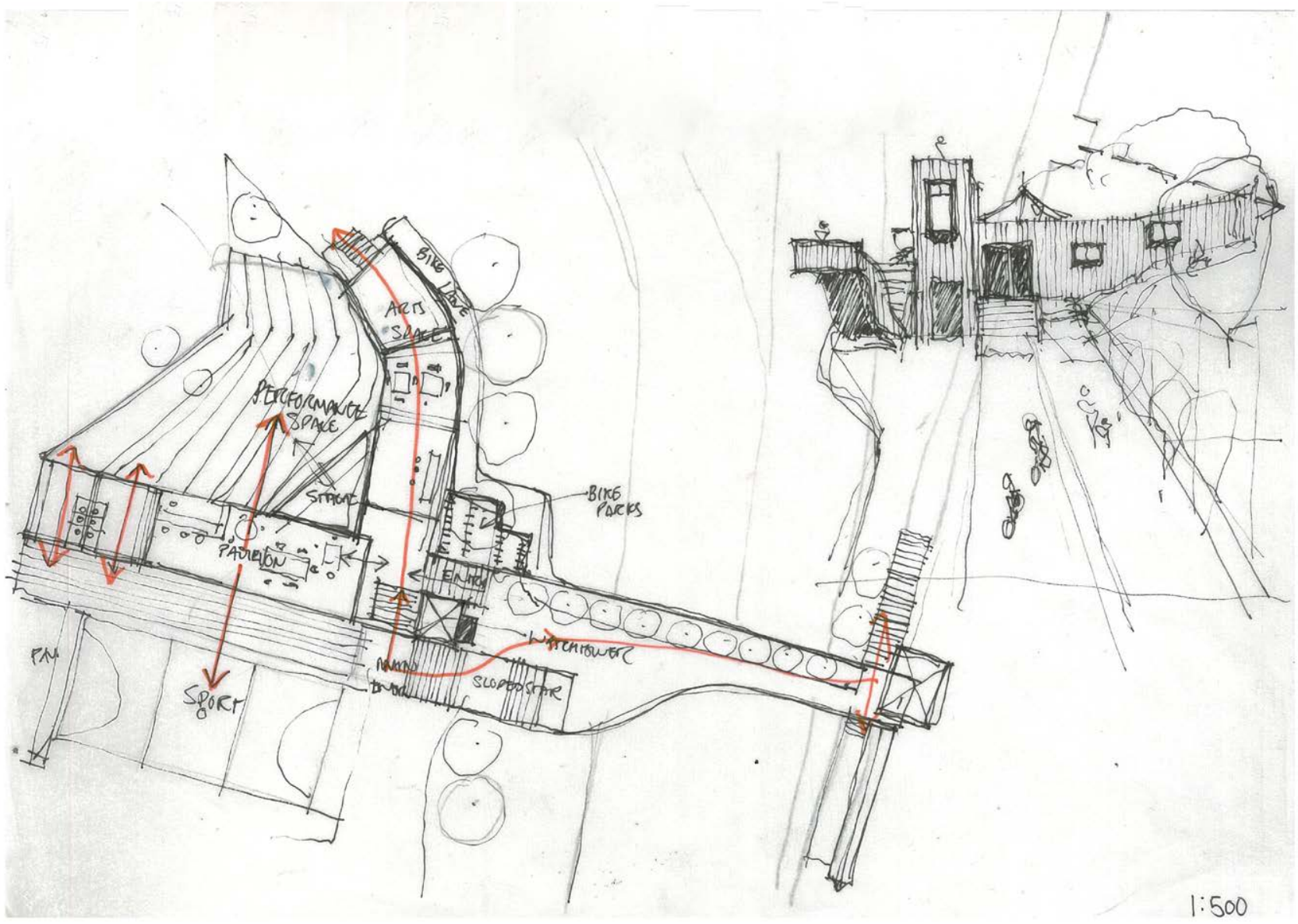

Fig 4.12 Plan sketch from the opposite drawing. 


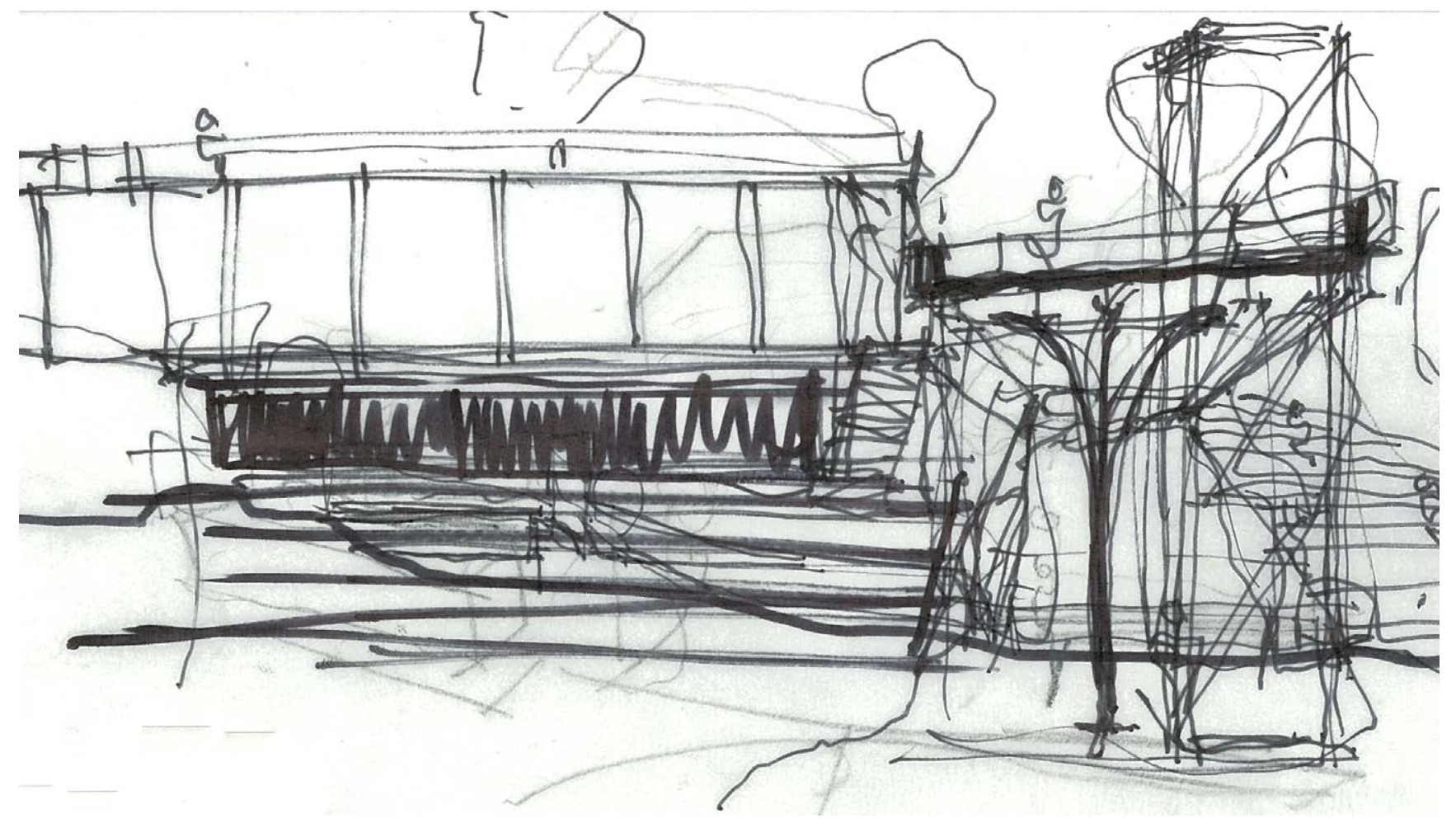

Fig 4.13 Netball pavilion loose sketch,

April 2018. 


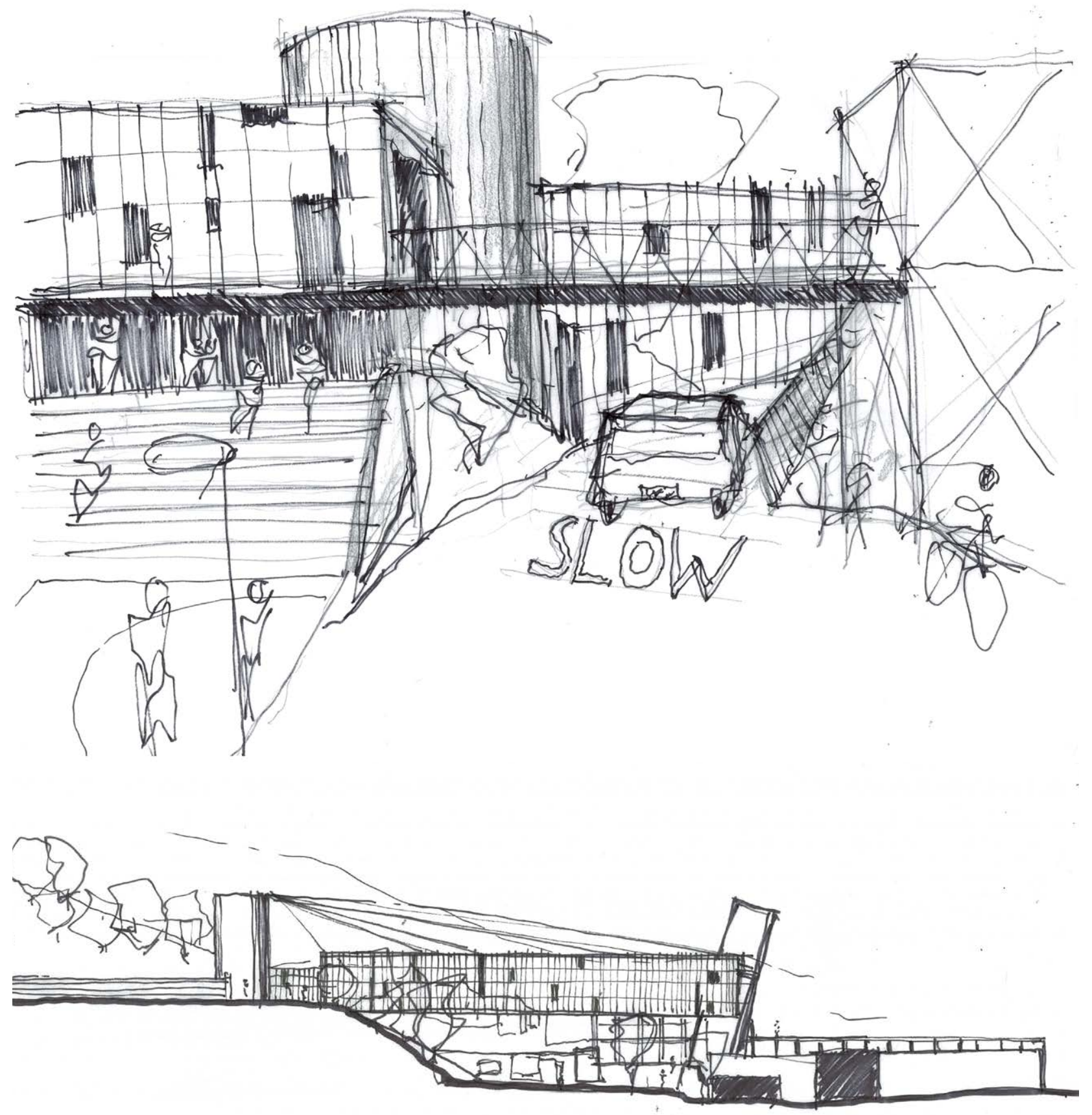

Fig 4.14 Pavilion and bridge deck sketches, May 2018. 


\section{PLEASURE}

Space is political because it is produced by the social structures that occupy it; it is equally economic because the possession and 'exploitation' of space determine the morphology of the city,

(Henri Lefebvre).

In order to make up for land lost by the highway, my approach was to construct a framework that would simultaneously create a continuous pedestrian realm, and provide recreational and social space for the city. My drawings at this time were heavily concerned with program and the resulting typology was that of an inhabited bridge. A way to extend the pedestrian realm above the highway, and occupy the space created. Not a simple line, but a three-dimensional surface with many points of interest. The 'feasible utopian', Yona Friedman, had proposed a similar environment in his Ville Spatiale (Fig 4.15). This was a mobile and improvised city in which people would plan their own spaces, given a minimal spaceframe structure (Friedman 2016). In an interview conducted in 2016, Friedman asserted,

This style is not about aesthetics. It is purely practical and pragmatic, (Friedman 2016).

Cedric Price was another to champion this kind of architecture, which he saw as 'mediating between the complexity of a society in crisis, 
and the necessity of producing the urban built environment' (Lemonier 2014). His Fun Palace (Fig 4.16) of 1961-64 is more the expression of a social, political and economic program than the representation of a form to be built' (Lemonier 2014). These projects are washed with a notion of 'pleasure'. But more than mere amusement, they were intended as vehicles for change, 'an instrument capable of setting in motion and transforming the relationship between the individual and society by designing new ways of living' (Lemonier 2014).

These projects re-imagined the traditional city, formally and politically. They did not adhere to physical or social borders. Yet neither were built.

I decided to narrow the scope of my site to the immediate surroundings of the junction around the tunnel portal. But I was still unsure as to where to draw the line - what ways of living can I and should I influence? I developed a heavily programmed bridge, stretching the 'ground' for pedestrians and creating new space. However, the scale and bulk of this scheme seemed inappropriate in the confines of my site, adjacent to the village.

The following sketches illustrate this impropriety and scale issue. 


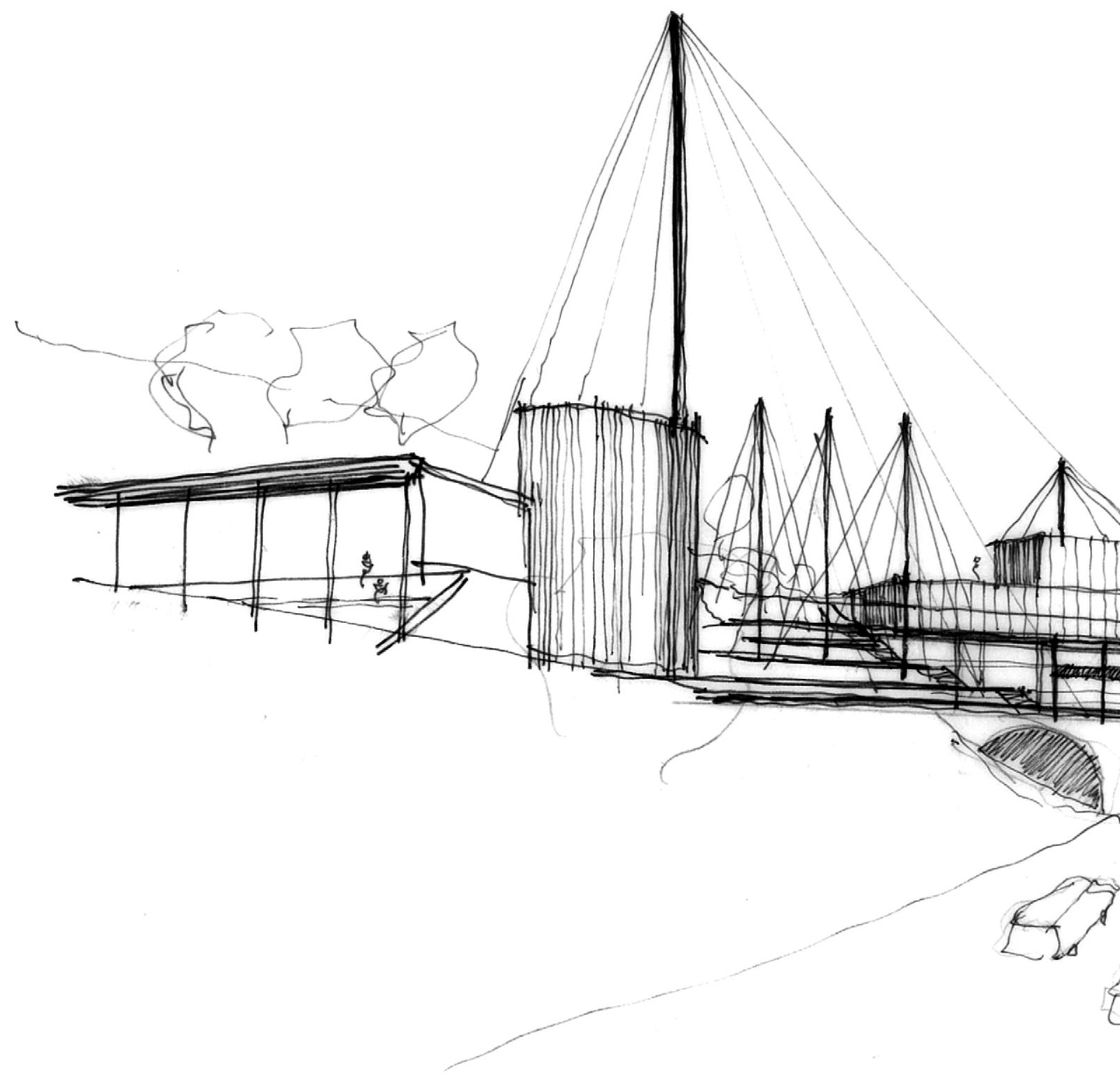

Fig 4.17 Sketch for an inhabited bridge as seen from State Highway 1. 


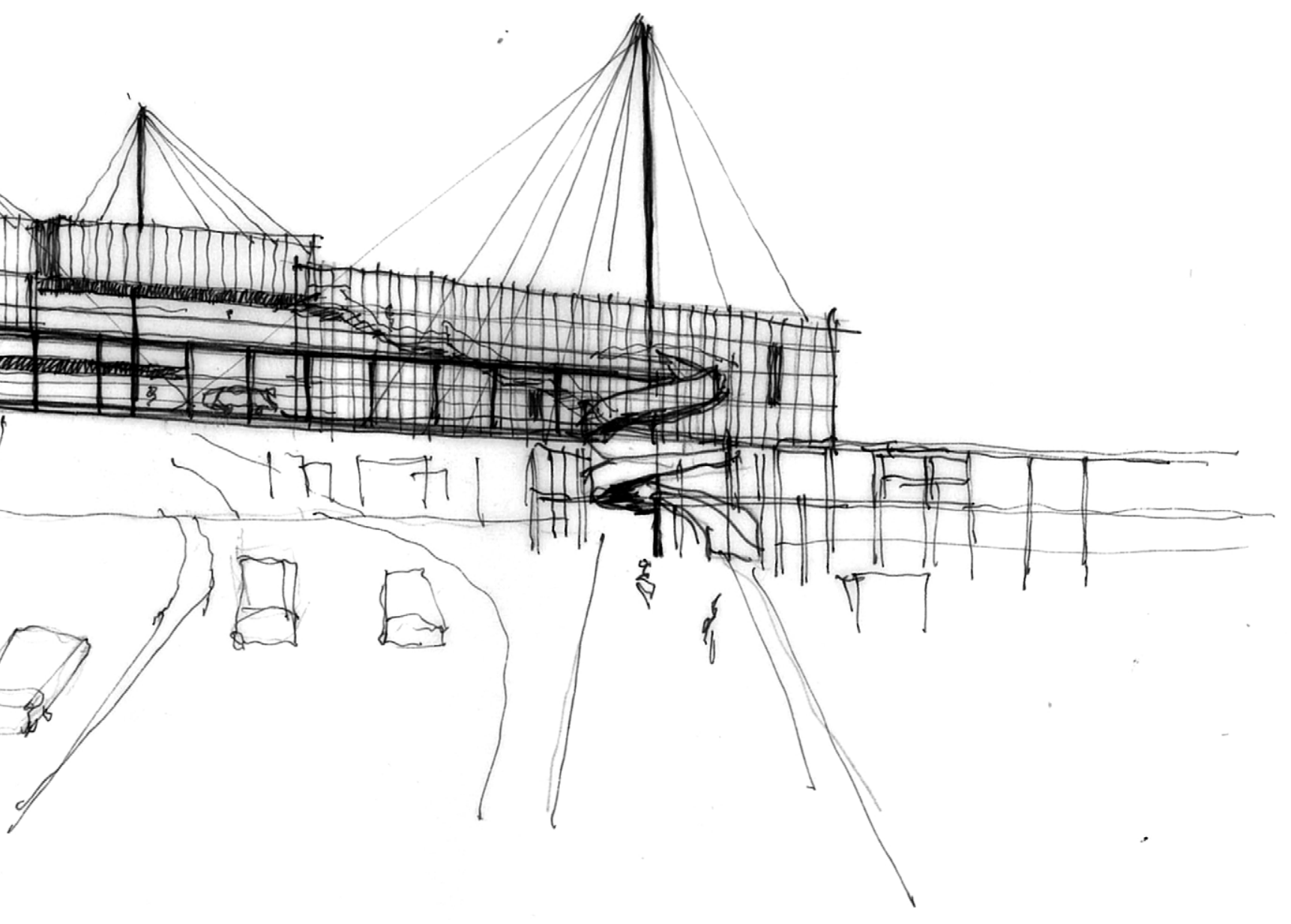




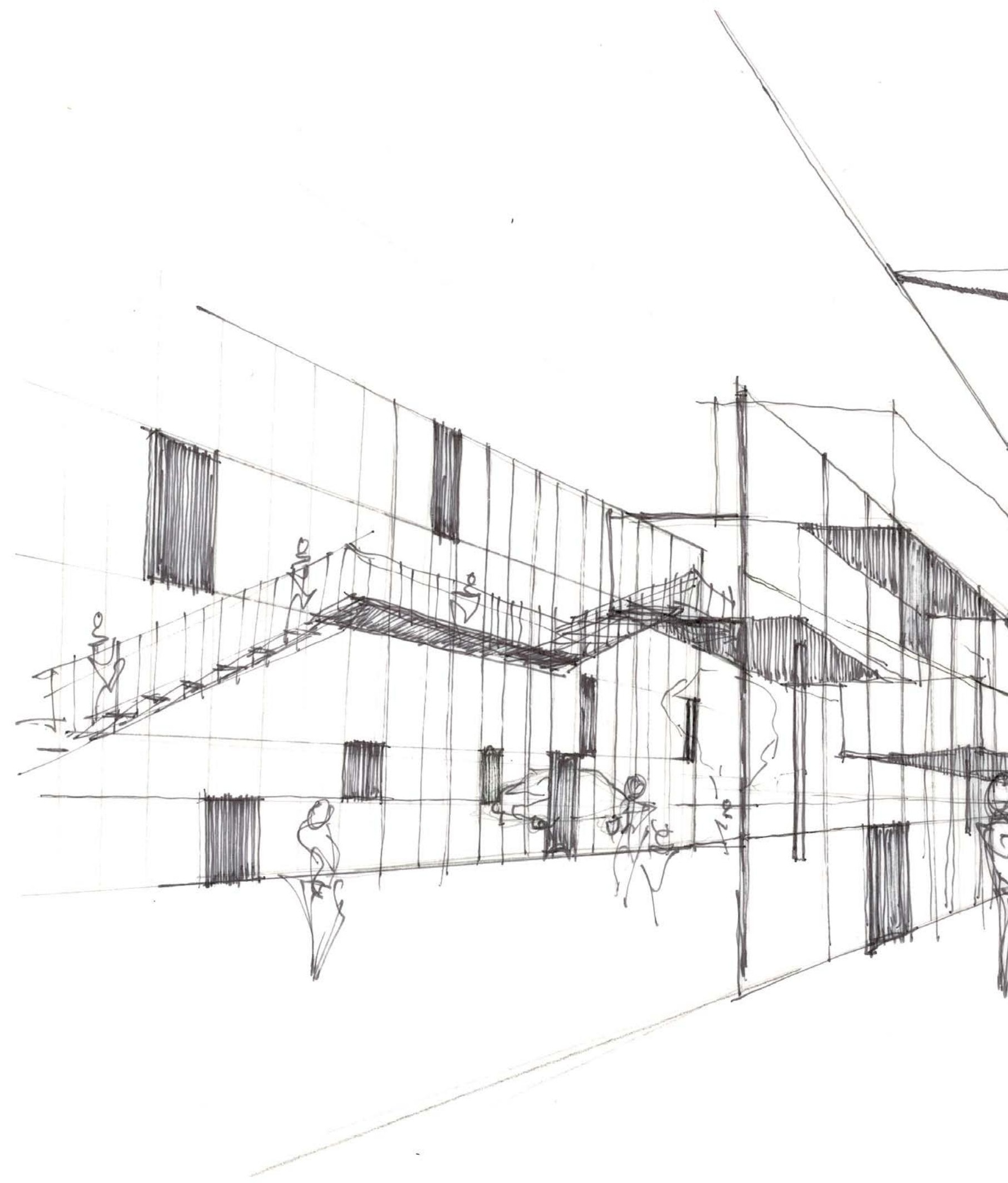

Fig 4.18 Bridge deck perspective with inhabited spaces. 


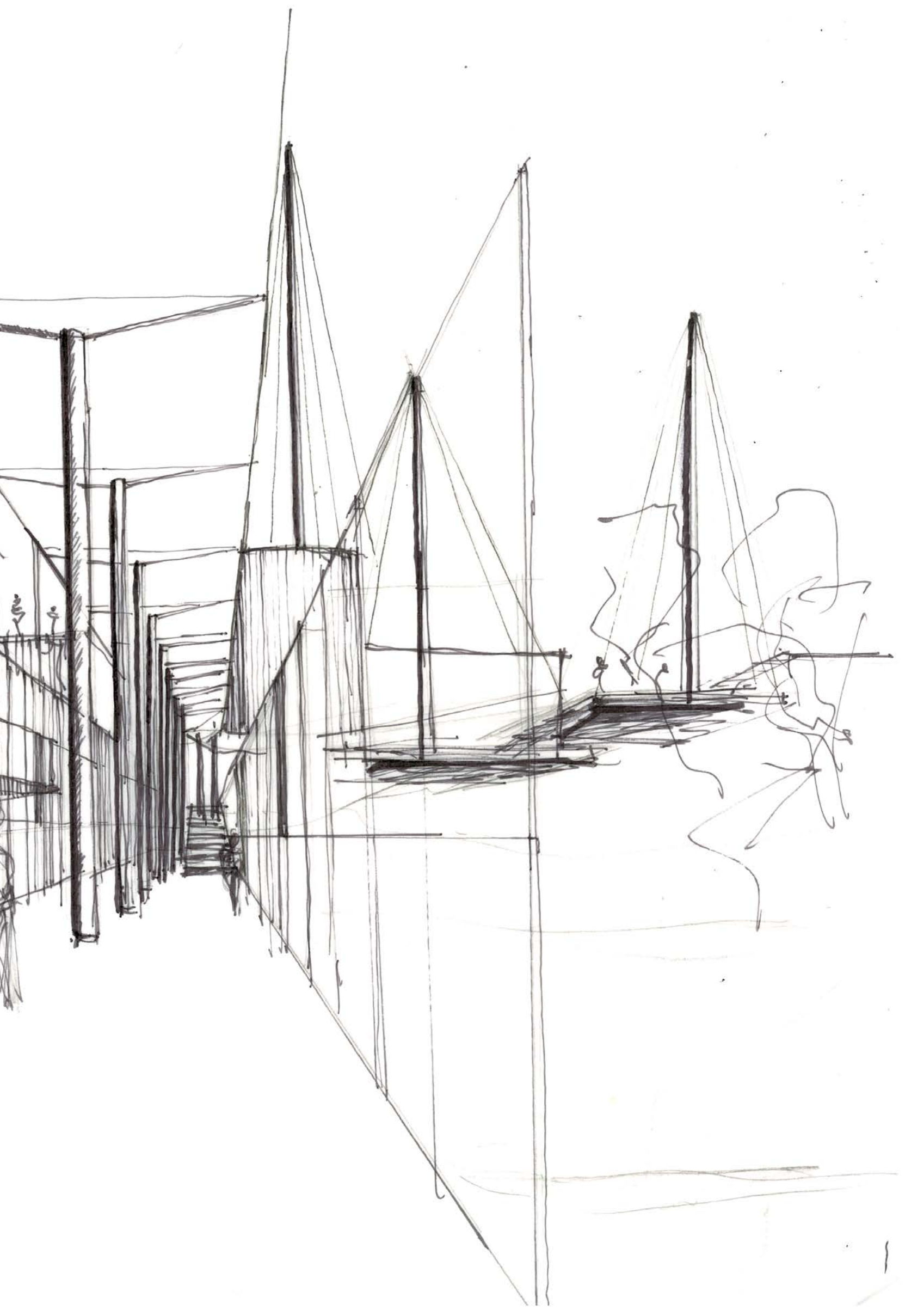




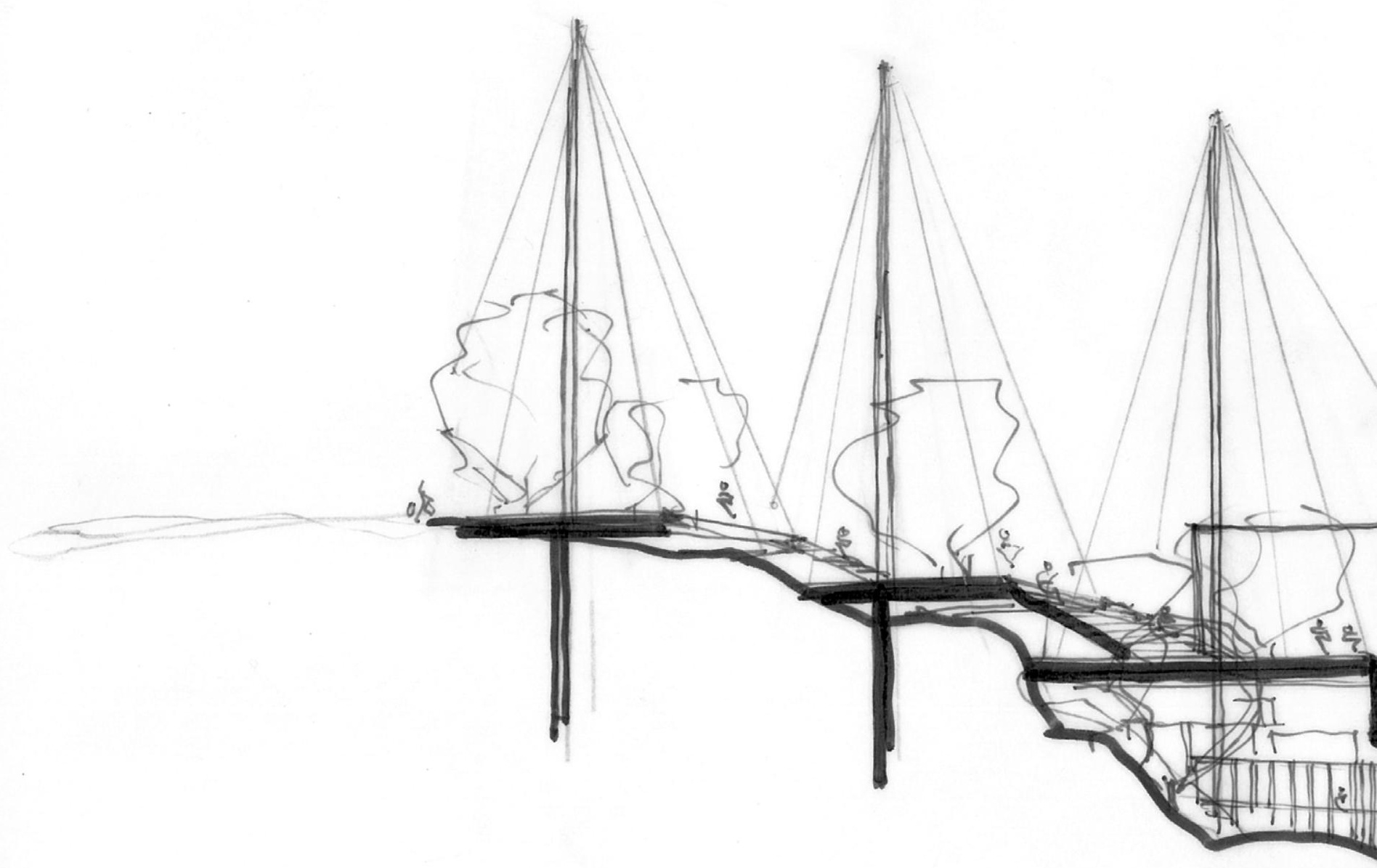

Fig 4.19 Perspective section from the shoulder of the town belt looking towards the village. A vehicular crossing was briefly considered as a direct link between park and village to remove traffic from the main park entry, June 2018. 
The notion of 'pleasure' remained, however. In the sketches and models that ensued, I became more interested in trivial activities than the infrastructural problem itself. I sketched the natural spaces in the park, the Pohutukawa Trees that hug the side of the hill. I drew platforms to sit amongst the trees like lilipads, playful structures to climb on, inhabit, wander in, and do nothing in particular.

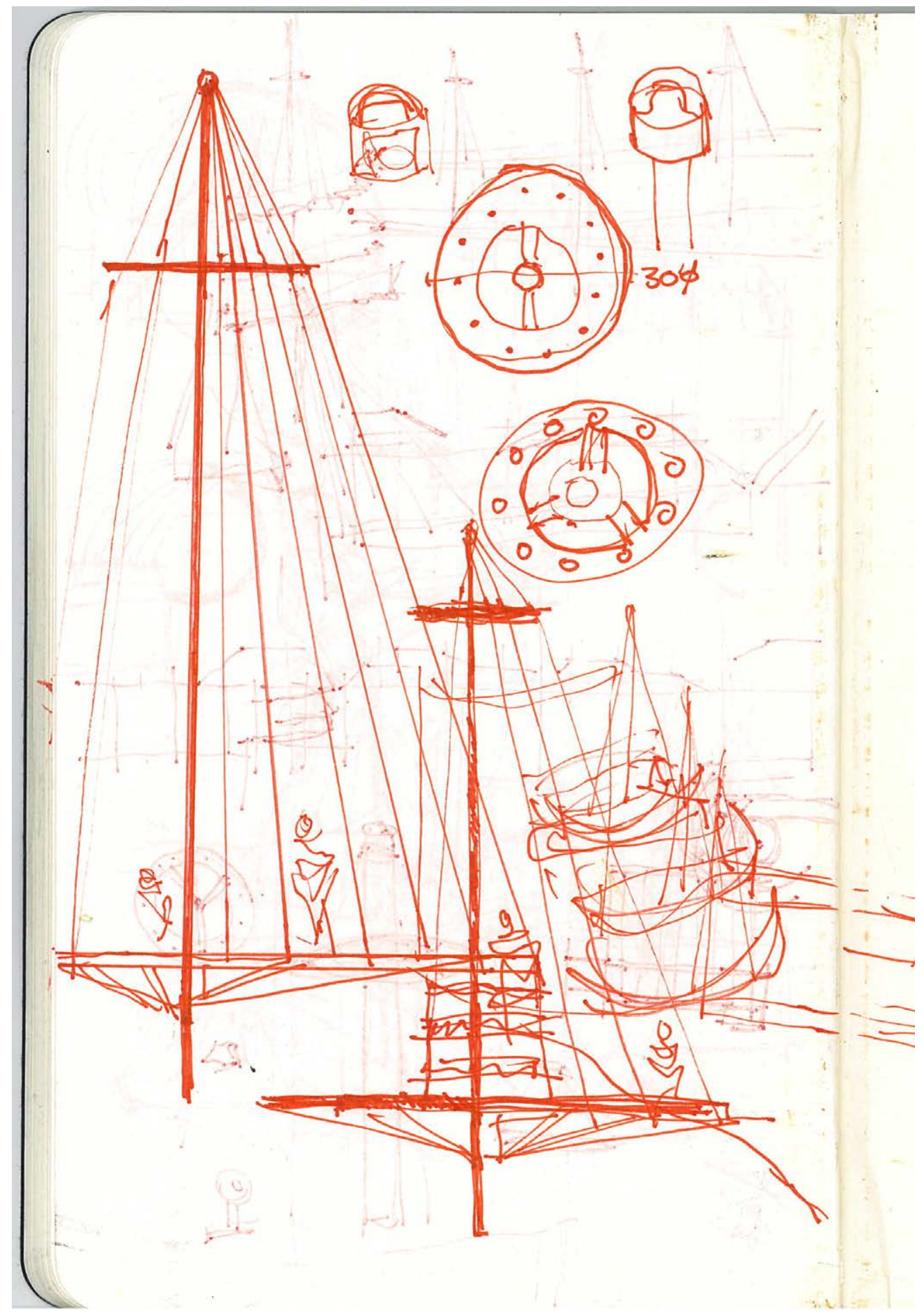




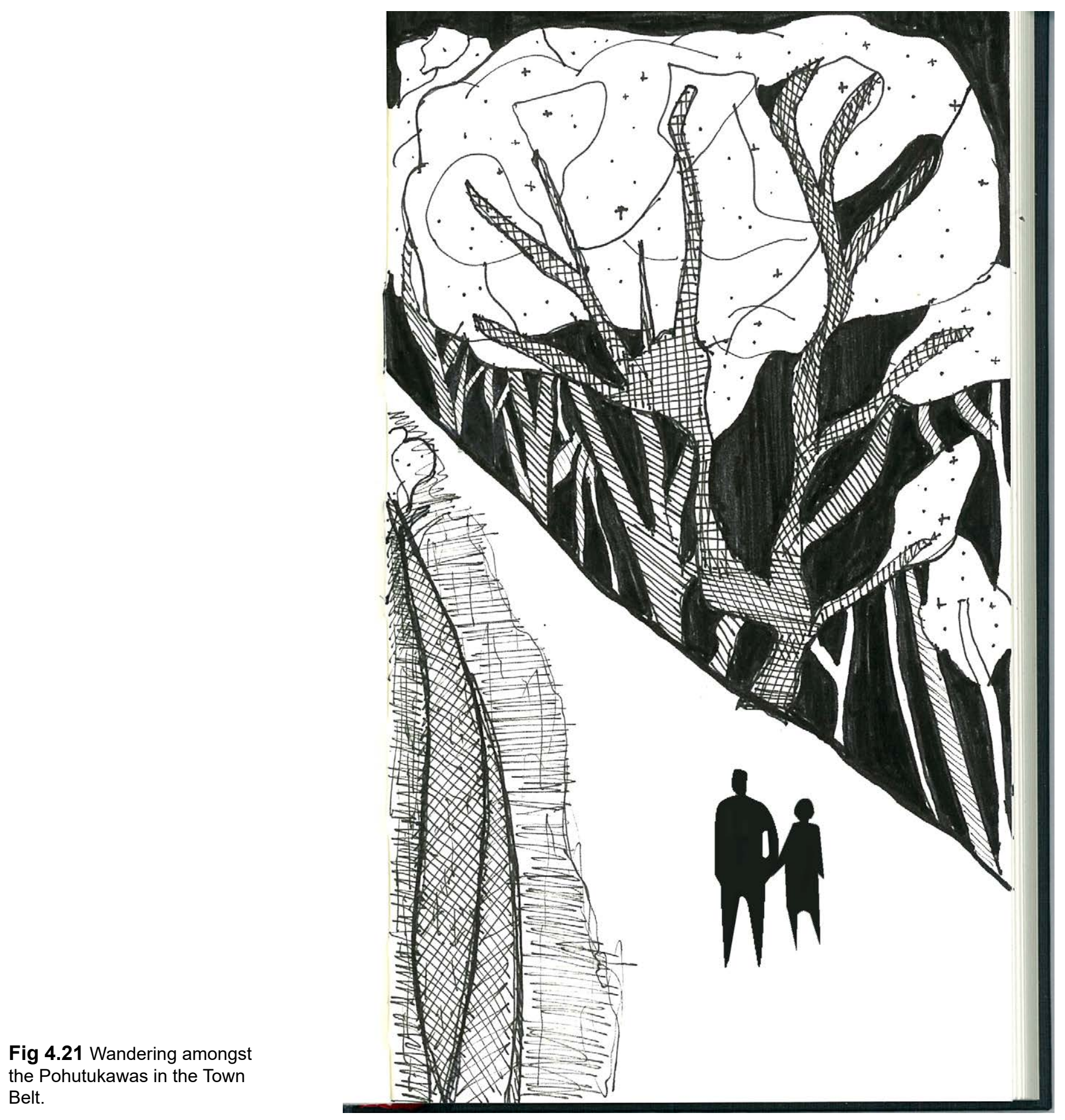



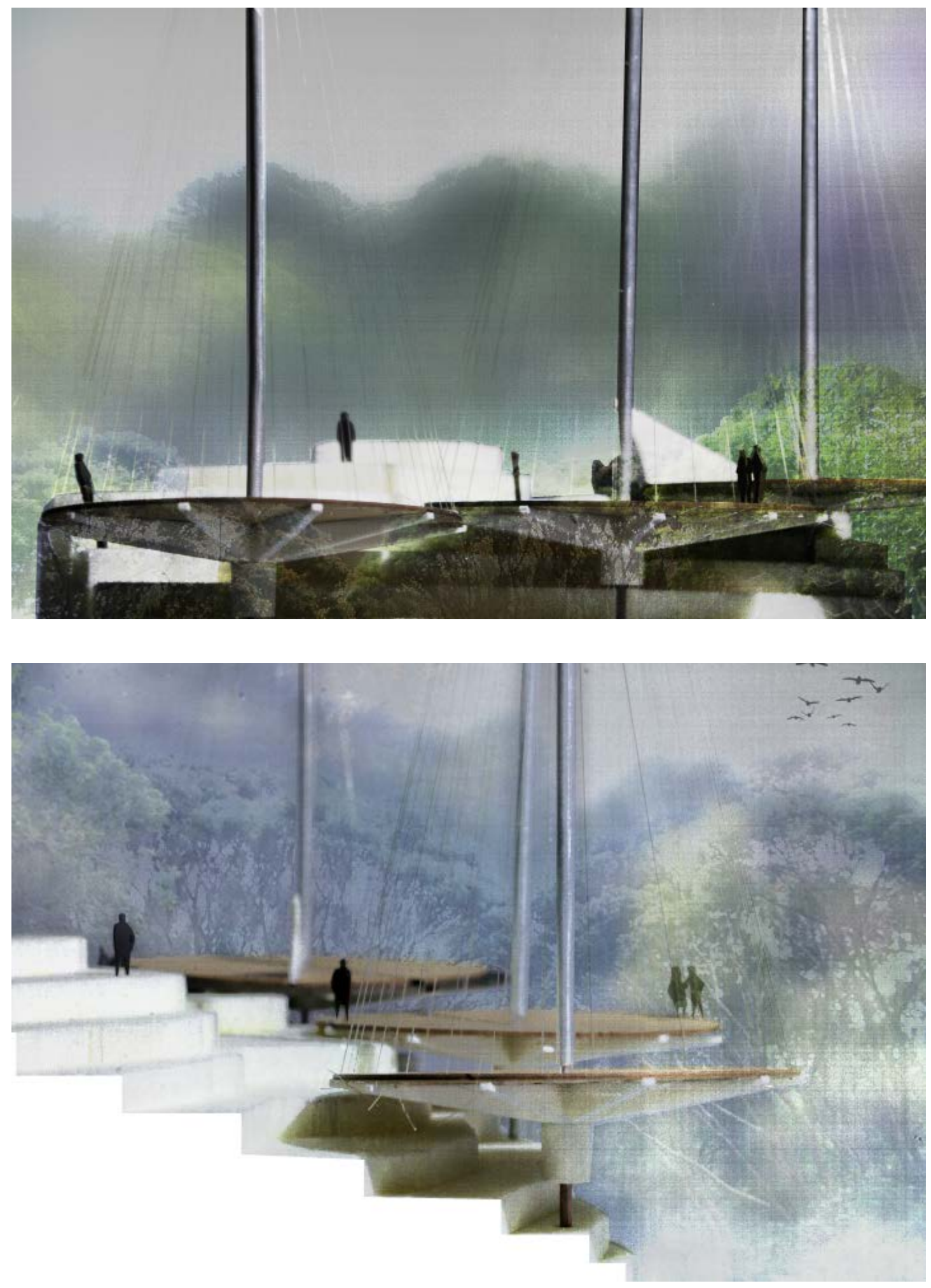

Fig 4.22 Lilipad platforms to inhabit the treetops. Models built from laser cut card, 3D printed structures, steel dowels, nylon string, June 2018. 


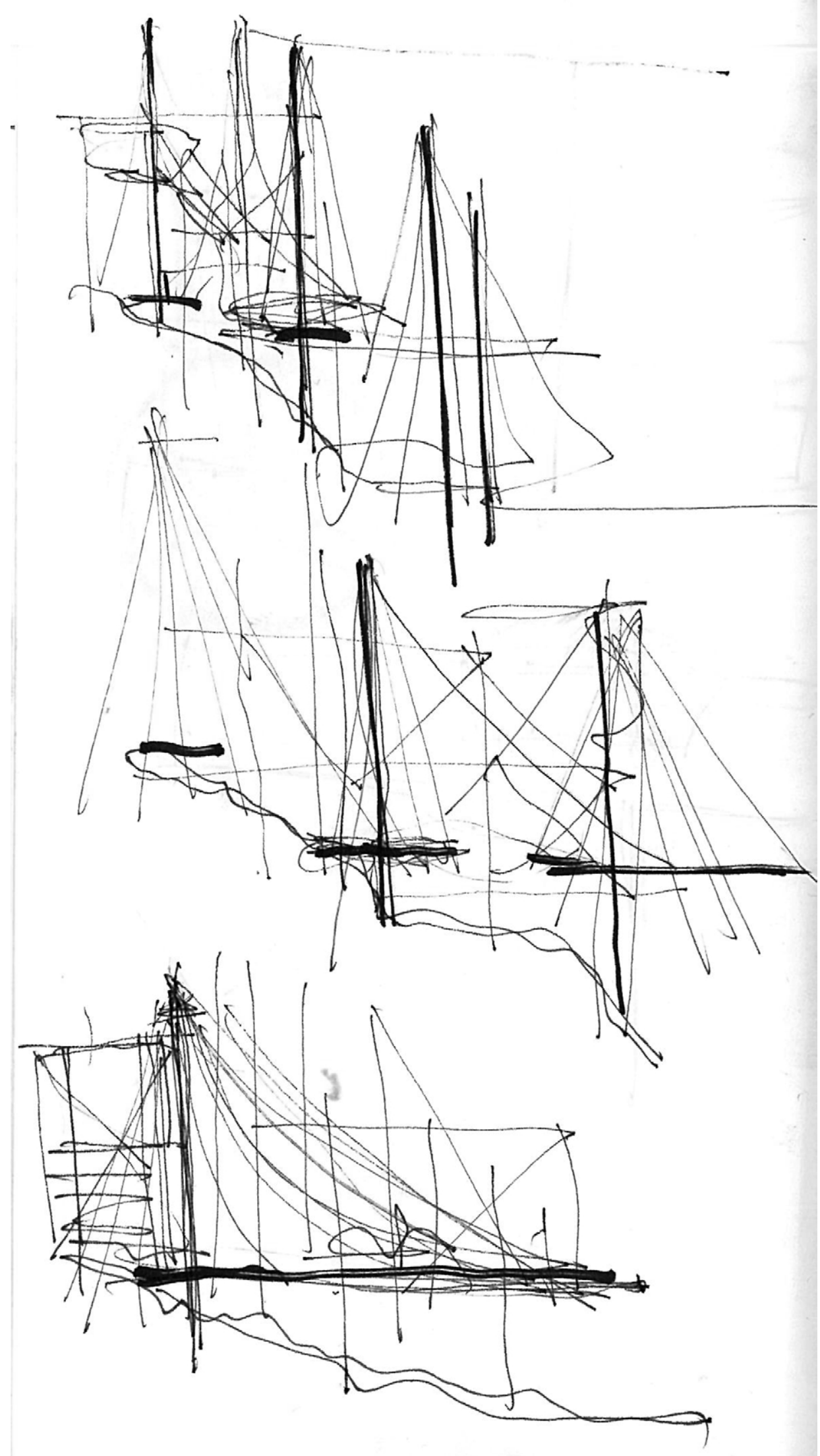

Fig 4.23 Moving from isolated structures to a linked system. 


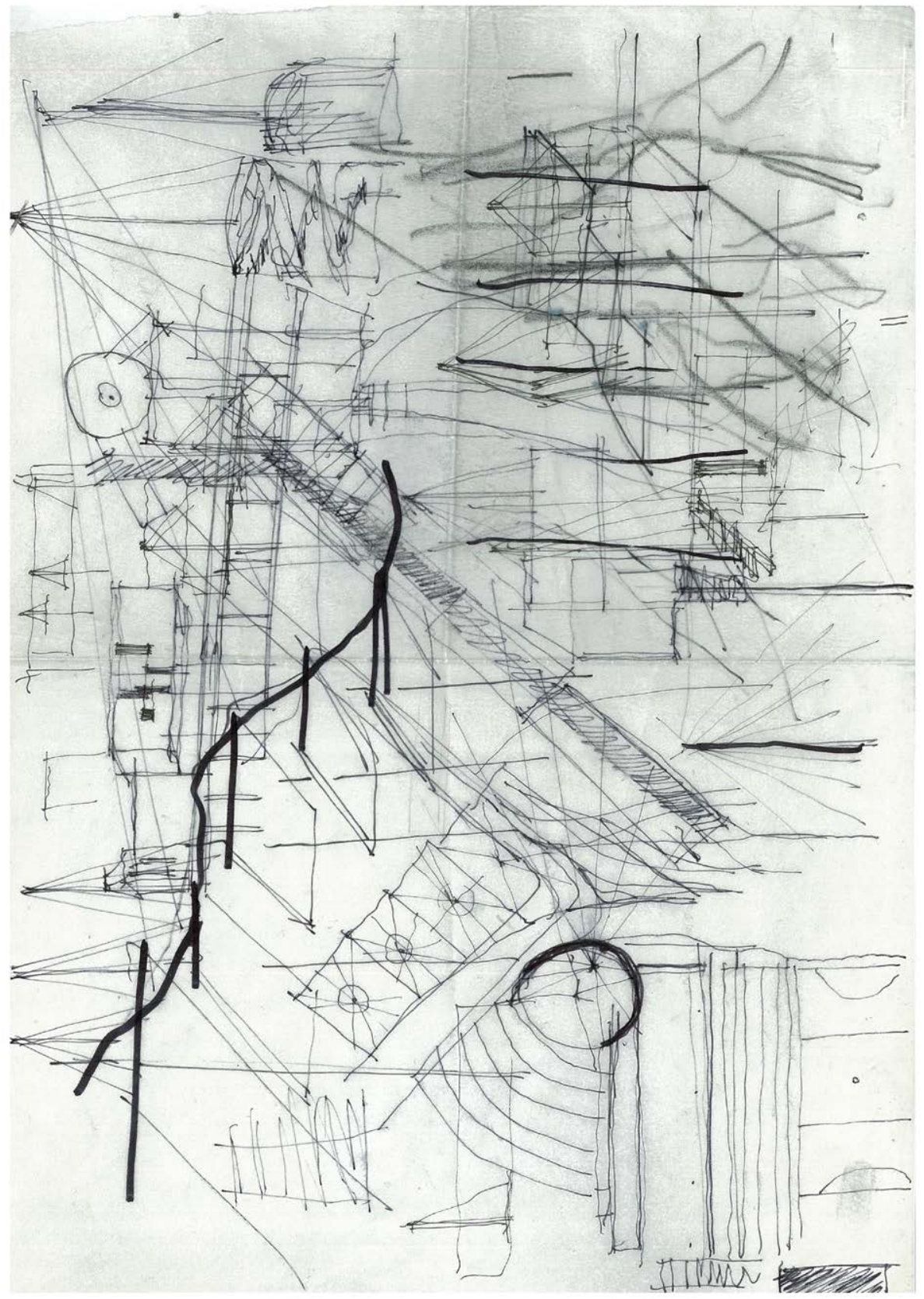

Fig 4.24 (Above) I drew inspiration from Constant Nieuwenhuys' loose sketching technique.

Fig 4.25 (Opposite) Constant's New Babylon, a sketch from 1963. 
Rem Koolhaas in conversation with Constant Nieuwenhuys for Haagse Post, August 6, 1966.

Haagse Post (Koolhaas) - And then the tima (sic) has come for New Babylon... When that moment has arrived, will it cover the entire surface of the earth?

Constant - Yes, it will indeed. A network of sectors will span the globe. I have abandoned the idea of the city as a kind of node, this round shape marked on the map like a red blot. I am thinking about a very open structure, entirely coherent, so that you can travel through it, and with all the fragments of the landscape integrated within it.

Haagse Post - Like a football in a net.

Constant - Yes, like a net draped over the globe. And in the meshes of this net life will unfold. 


\section{NEW BABYLON}

Friedman et al. were not alone in their exasperation with consumer society and the rational city. The Situationist International (SI) refuted modern capitalism, the consumer culture it created and the isolated organisation of everyday life that reduced the lives of its citizens to trivial repetitions of obligatory activities and consumption (Sadler 1999).

I learned of the Situationists through images of Constant's New Babylon - a Situationist city. Formally, this city was detached from the ground, free from traffic and production. An expansive mesh constructed of a continuous scaffold, not a fixed node or a simple line. Socially, founded upon the practices of
Psychogeography ${ }^{1}$, Dérive $e^{2}$ and Unitary Urbanism ${ }^{3}$, creating a Détournement ${ }^{t}$ of the capitalist city (Richard, n.d.).

I was beguiled by the borderless qualities of New Babylon. I saw its framework as a means to overcome the borders of the site, and the disconnections created by the supposedly connecting roads. But I also understood it beyond its formal values, for which I had taken Friedman too literally. The humanisation of the undiscriminating human milieu resonated with me.

The romance of the continuous scaffold enticed me as I had already drawn this kind of environment in earlier sketches. The anti-autocratic

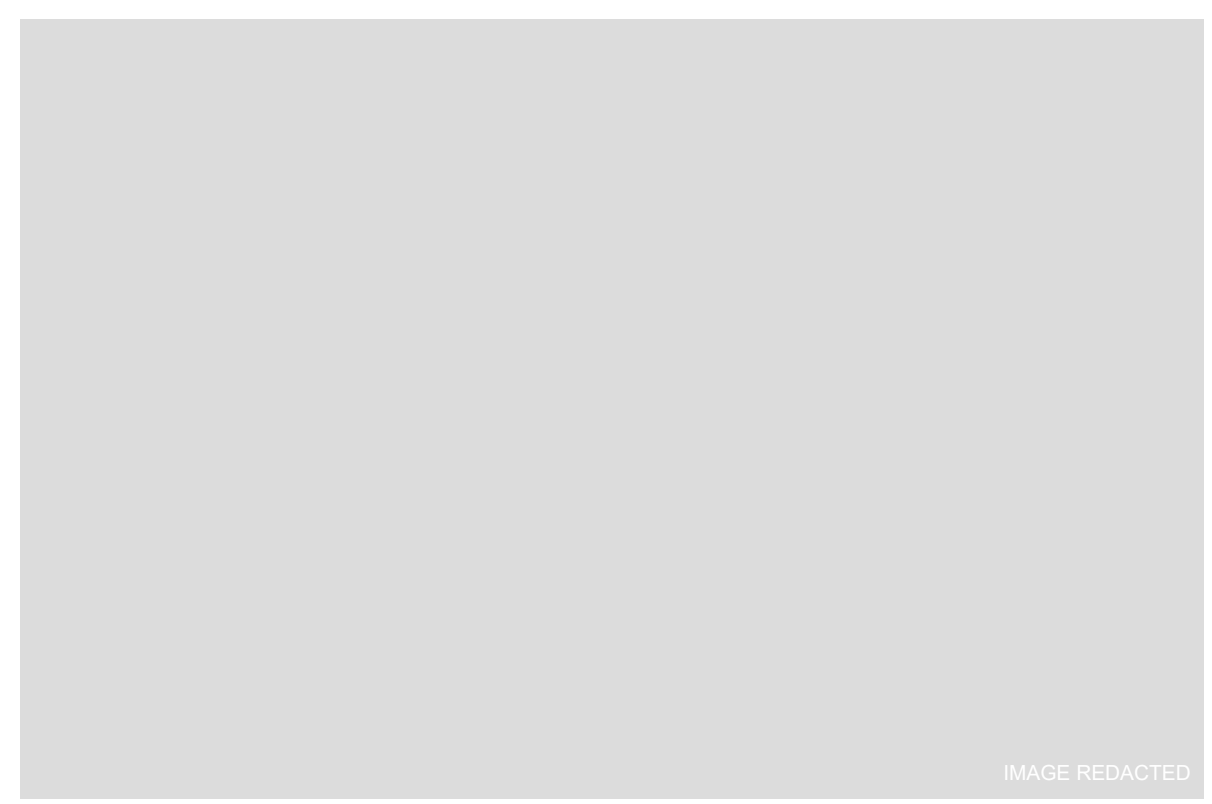

Fig 4.26 Sketch from Constant's New Babylon, c.1960's.

1 'The study of the precise laws and specific effects of the geographical environment, consciously organized or not, on the emotions and behaviour of individuals' (Debord 1955). I.e. perceived distance, rather than actual distance.

2 A technique of drifting, or unplanned journey through varied ambiances (Sadler 1999). 
views of the SI seemed appropriate within the context of my own project. The highway and the consequent degradation of its surrounding fabric is a constructed reality of consumerism. An extreme and bold intervention seemed like the appropriate response. A rebellion of sorts.

Constant rejected that it was utopian project.

If the project we have just traced out on bold strokes risks being taken for a fantastic dream, we insist on the fact that it is feasible from the technical point of view, that it is desirable from the human point of view, that it will become indispensable from the social point of view. The increasing dissatisfaction which dominates the whole of humanity will arrive at the point where all will be forced to execute projects whose means we possess; and which we will contribute to the realization of a richer and more filled life.

(Nieuwenhuys 1959, Wigley 1998).

I continued my 'fast and loose' sketching and modelling processes. I developed a ubiquitous mesh and placed it on the site to link the disconnected territories - the highway, the park, and the village.

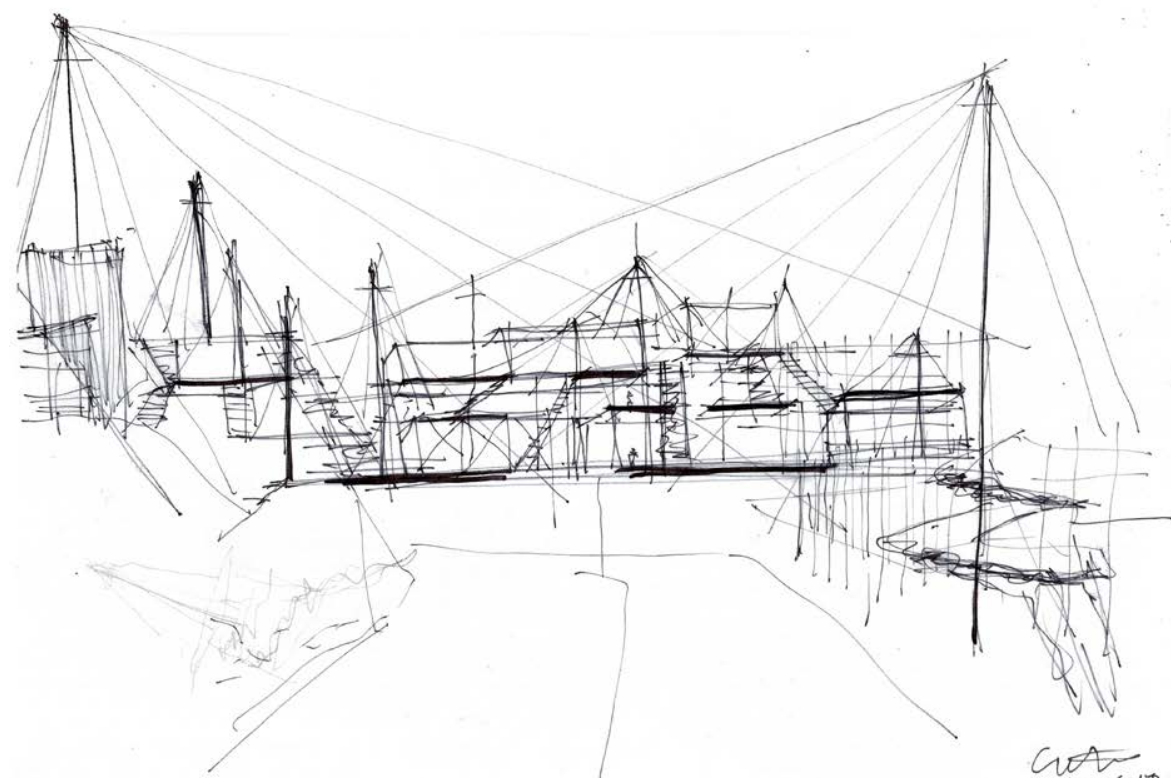

Fig 4.27 A New Babylon inspired bridge, using 'fast and loose' sketching techniques, June 2018.

3 An environment that 'acknowledges no boundaries; it aims to form a human milieu in which separations such as work/leisure or public/private will finally be dissolved.'(Debord 1959).

$4 \mathrm{~A}$ politics of re-appropriation, a devaluation process of the initial artifact by altering its context (Richard, n.d.). 


\section{VISUAL ESSAY}

The following pages display the designs and schemes that developed in parallel with the theories described in the preceding sections. I aimed to dissolve the boundaries imposed by the roads, and create lines of connection rather than division. My 'fast and loose' sketching and modelling methods developed over this period.

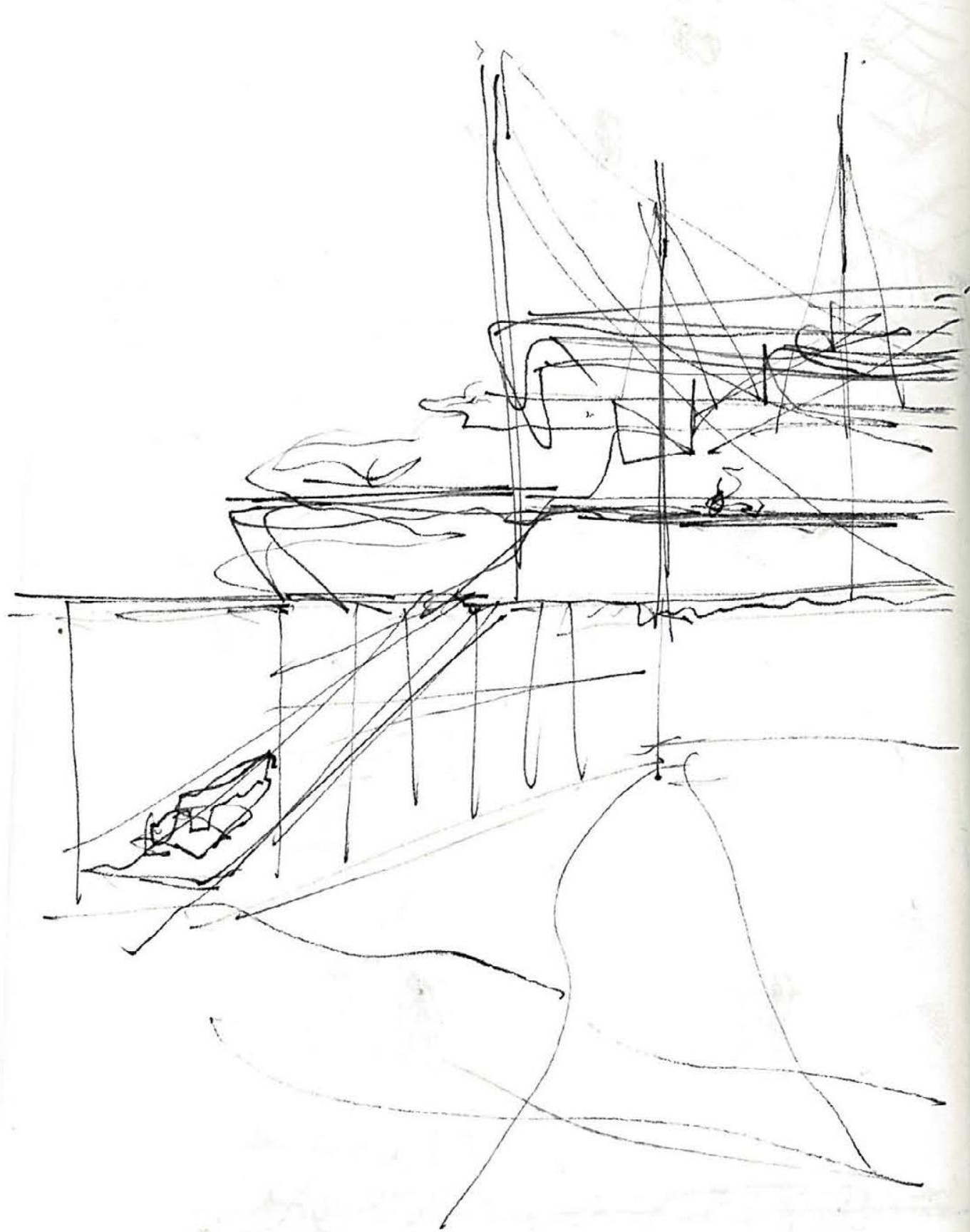

Fig 4.28 Delicate bridge. 



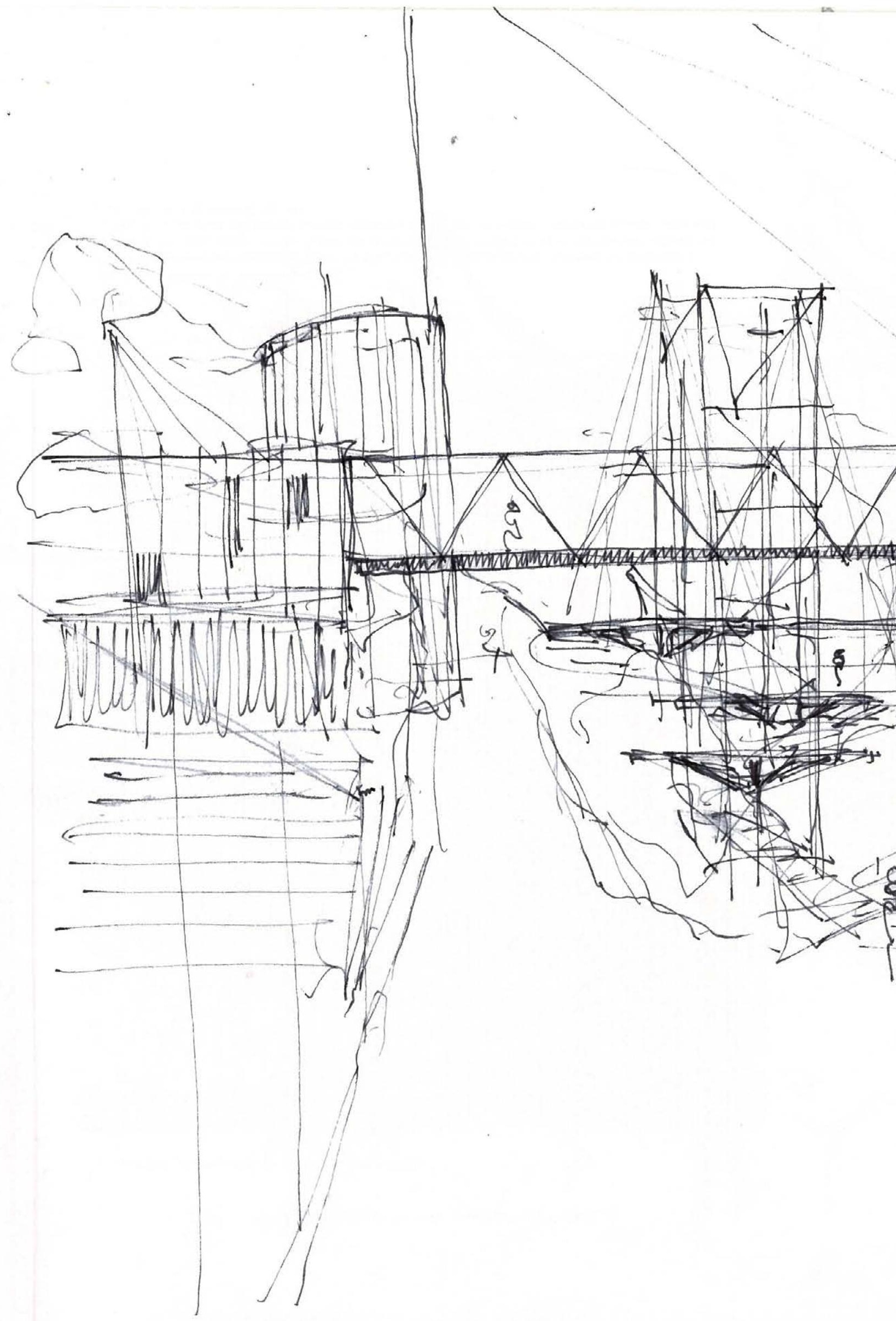

Fig 4.29 Expansive structure with many paths, July 2018. 


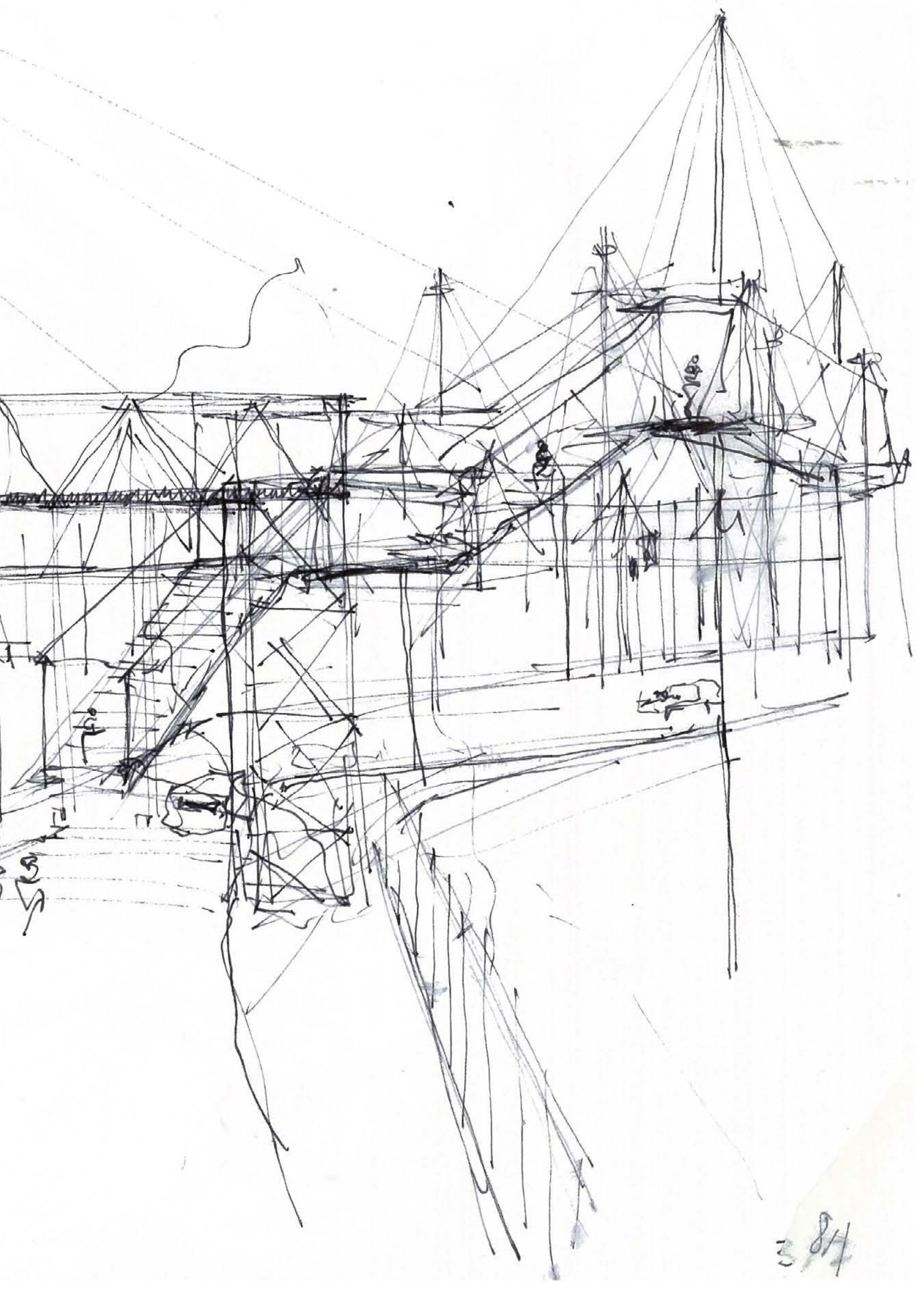




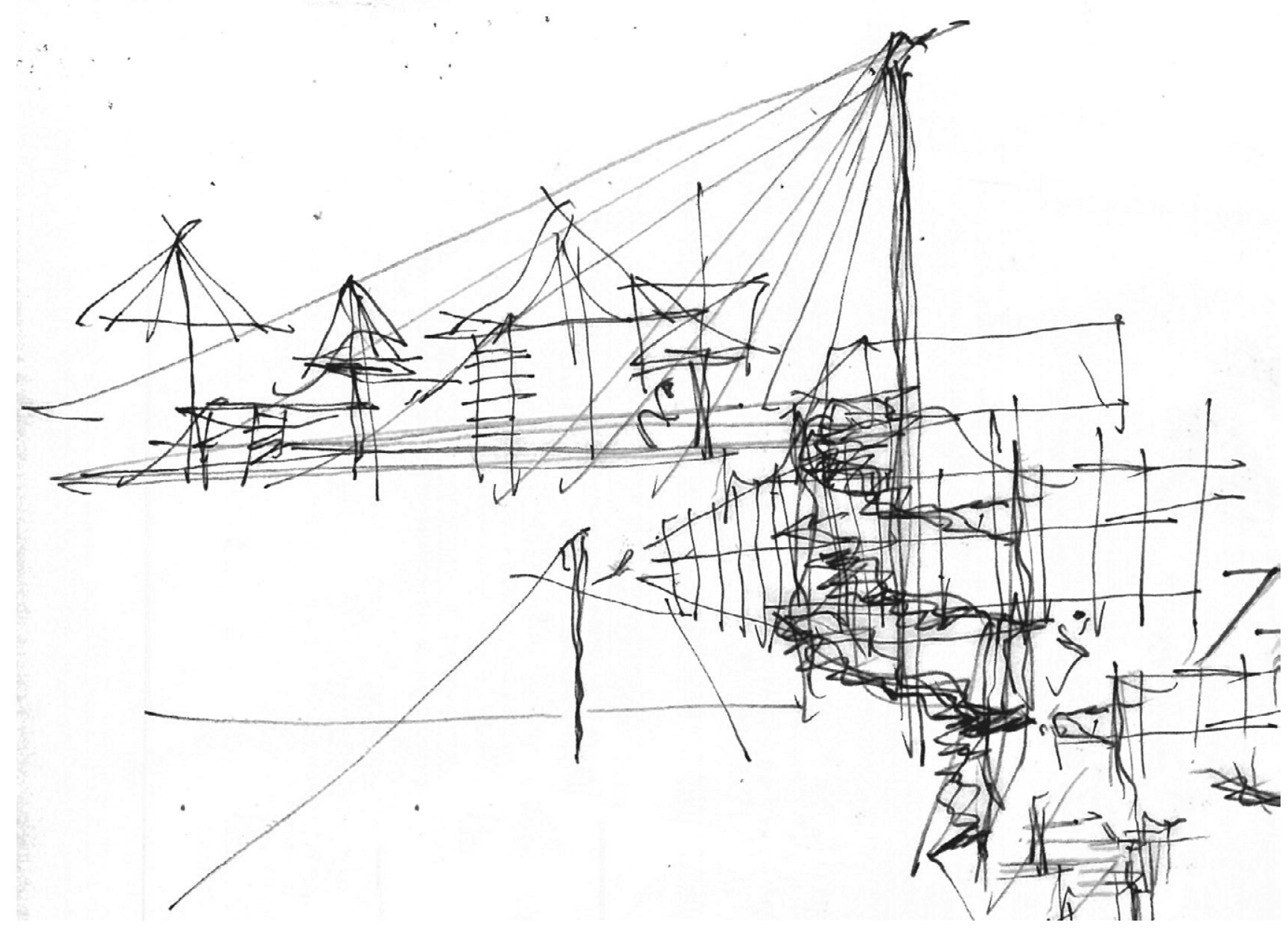

Fig 4.30 Dissipating the energy of a traditional cable-stayed or suspension structure. 


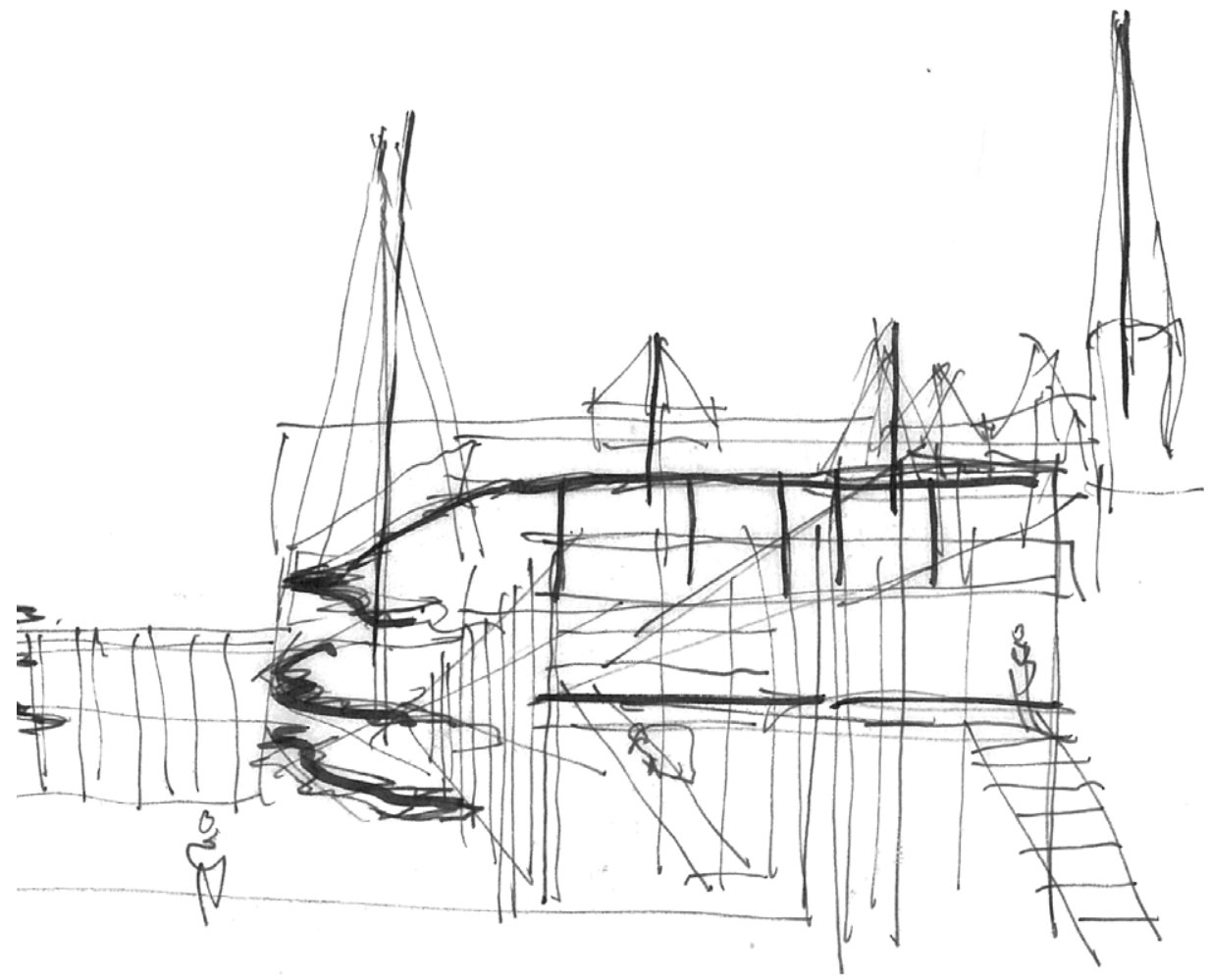

Fig 4.31 Loose sketch.

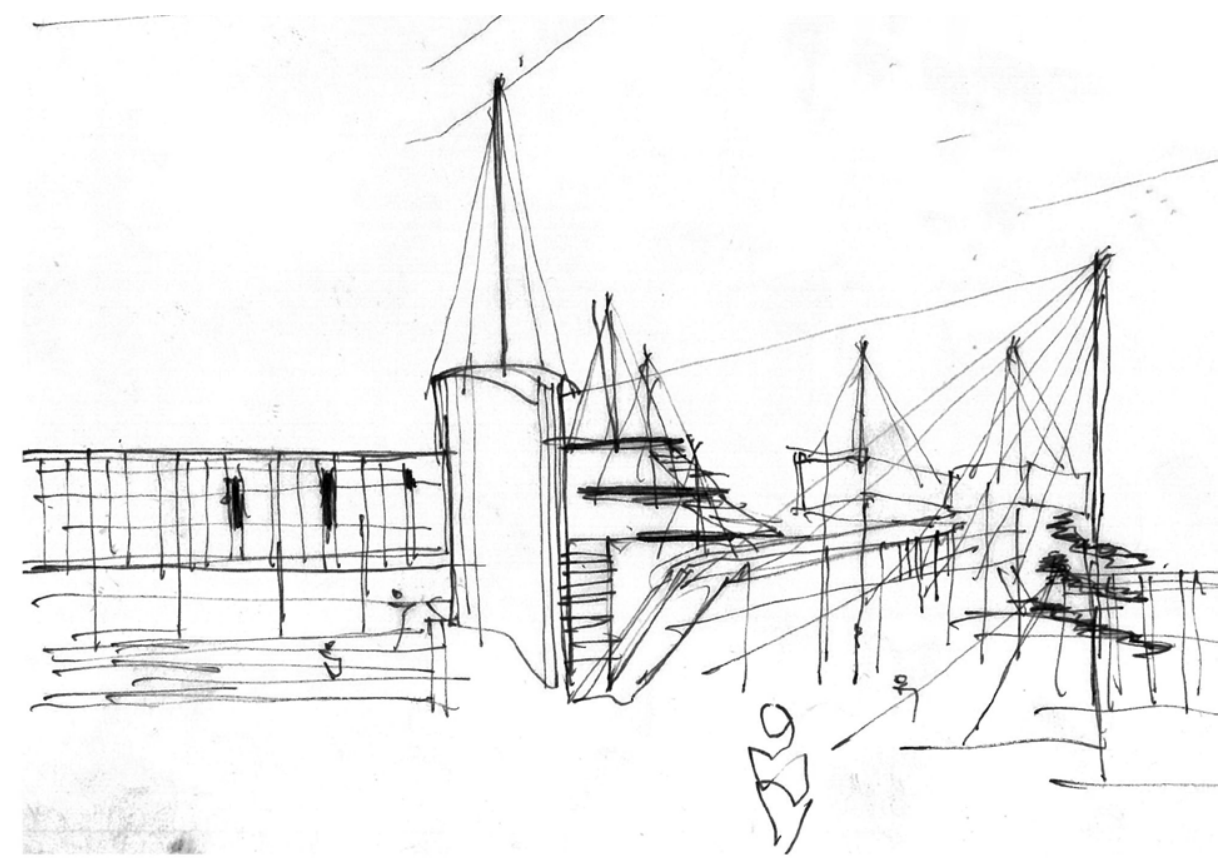

Fig 4.32 Loose sketch. 
I tried to digitise the mesh environment that was beginning to take hold. It quickly became rigid and fixed. I suspended elements within the mesh, but it didn't look as natural as in the sketches. The inherent wonkiness of the drawings was lost. I returned to physical models and drawings for a while.
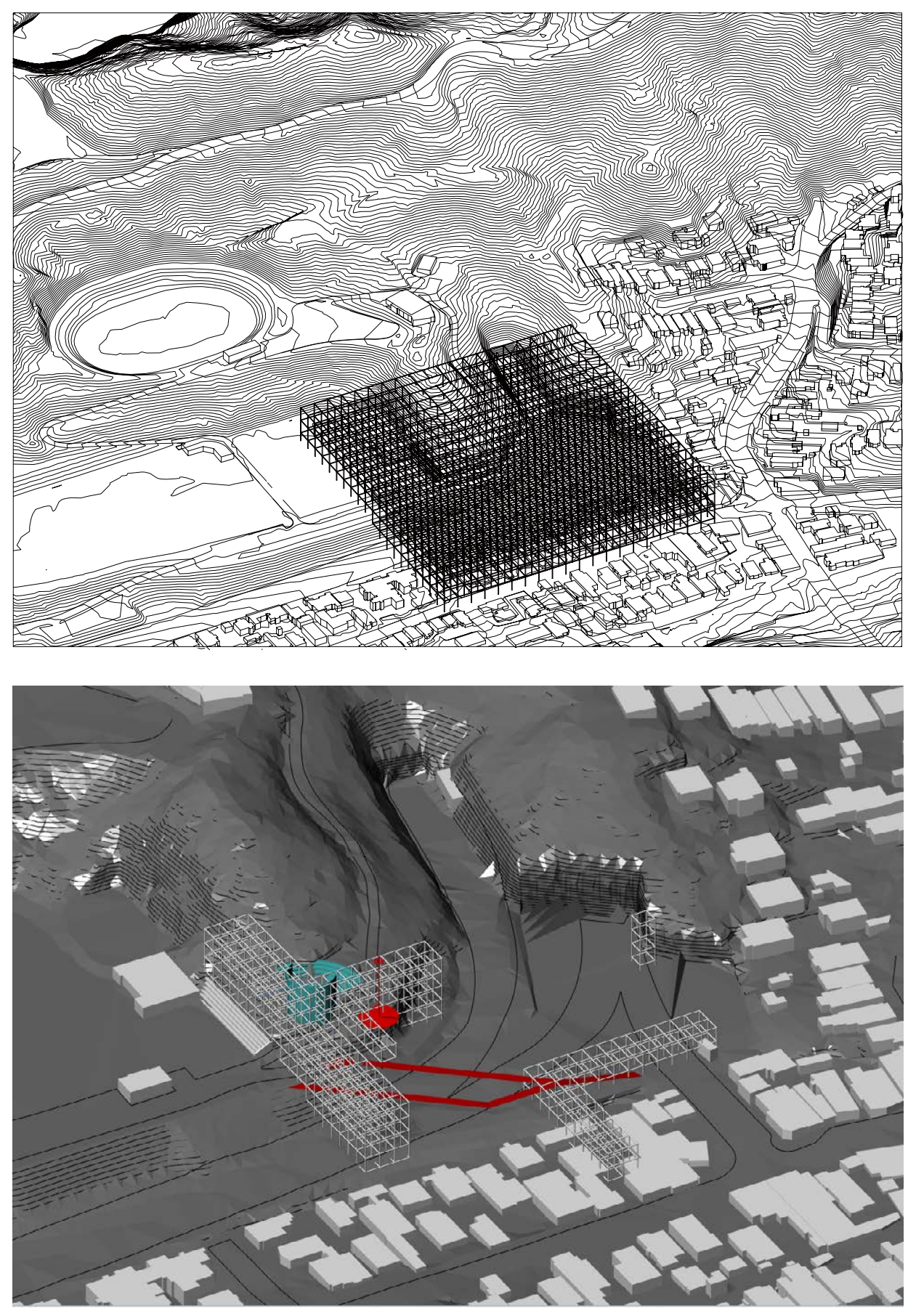

Fig 4.33 (Above) Placing a regular grid over the site.

Fig 4.34 (Left) Adjusting the regular grid and suspending elements within.

Fig 4.35 (Right) Plan sketch over the regular grid. 


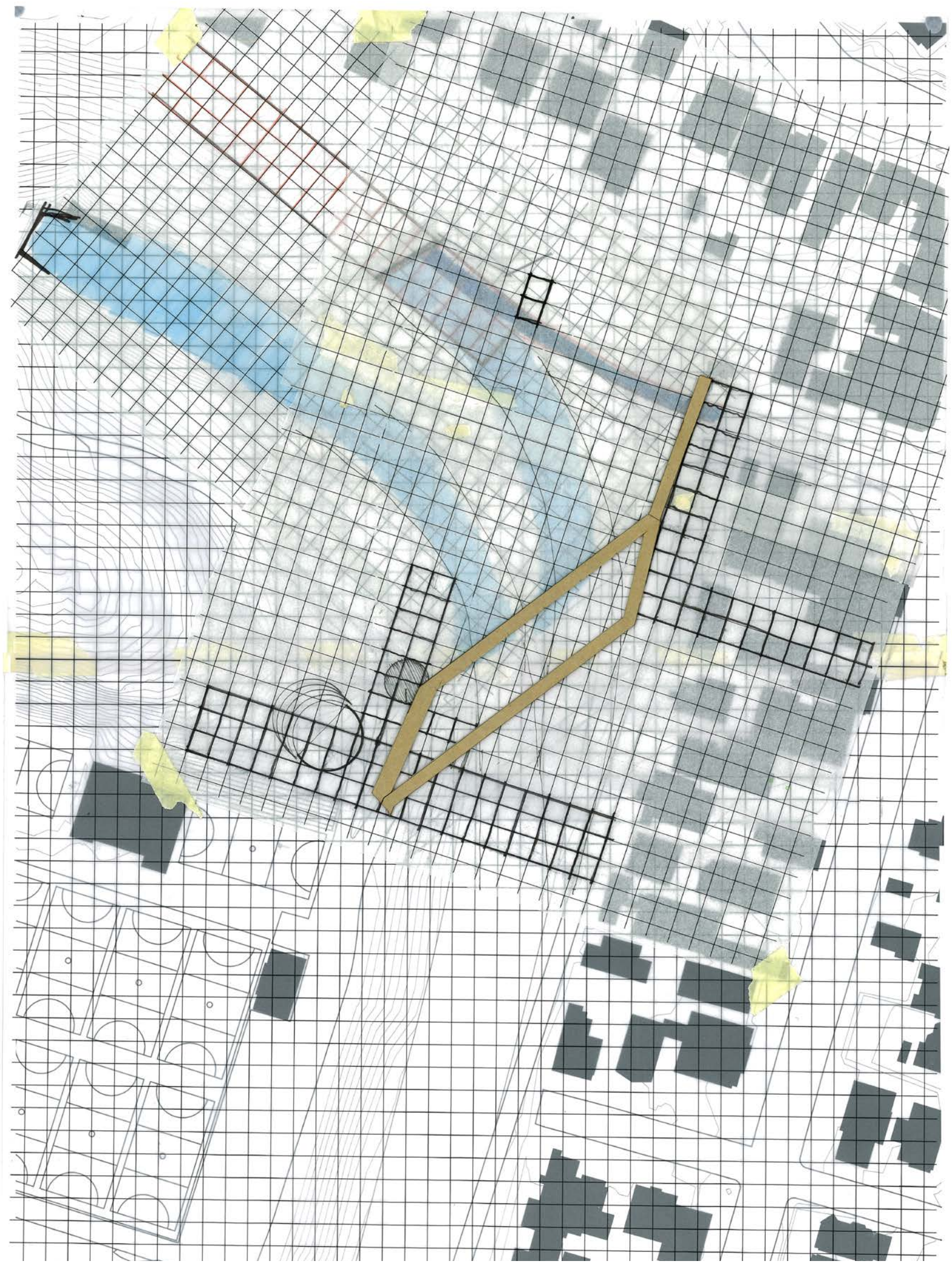




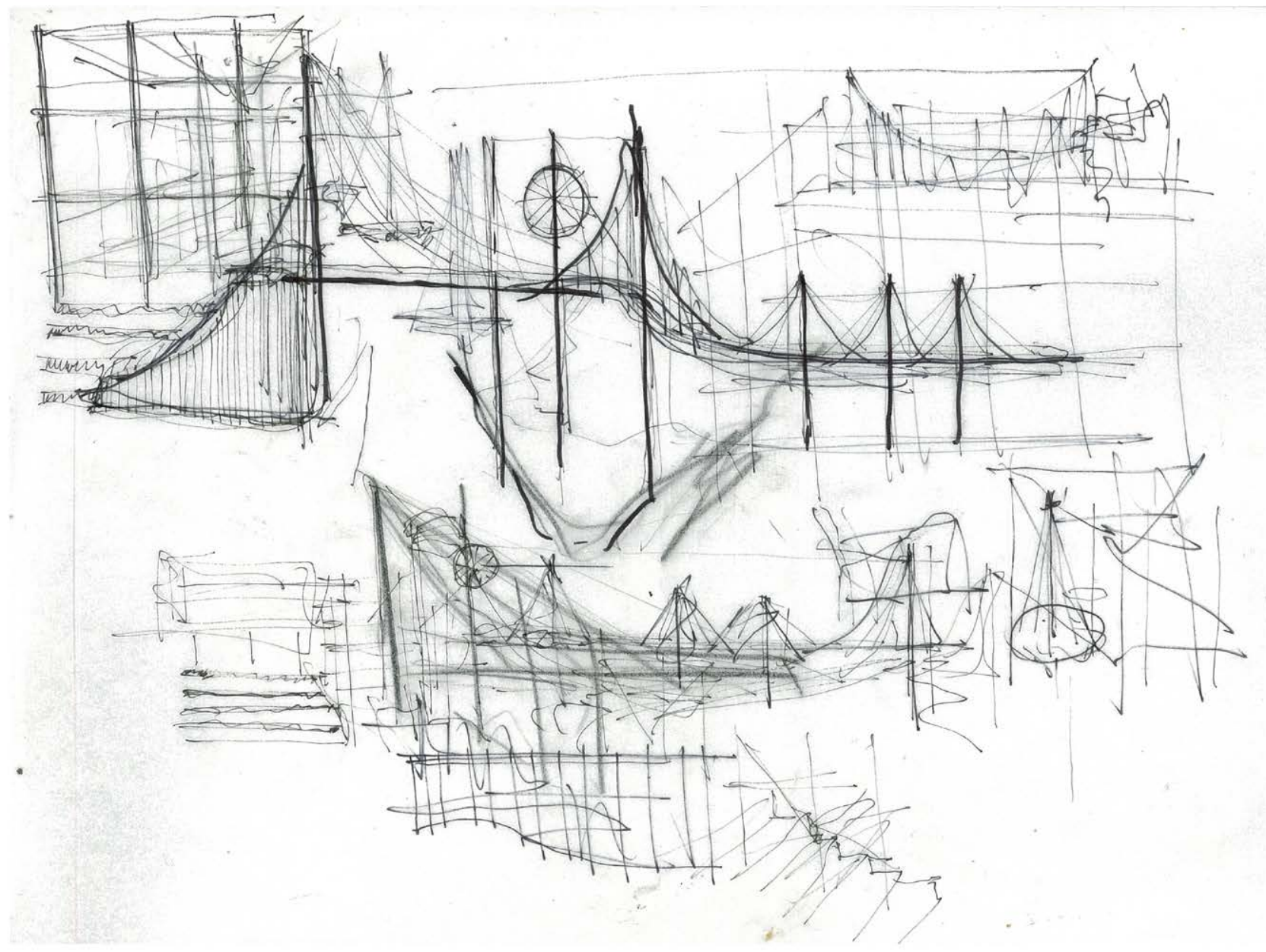

Fig 4.36 Loose sketching page developing paths and points of interest.

I developed a physical modelling process to expand on the scope of my sketches. I built loose models out of spaghetti, steel rods, 3D printed joints and nylon string to represent the mesh. I drew over the images in black pens, hatching patterns and swatches to add a sense of atmosphere and inhabitation. The mesh complimented the form of the trees. I drew them together. 


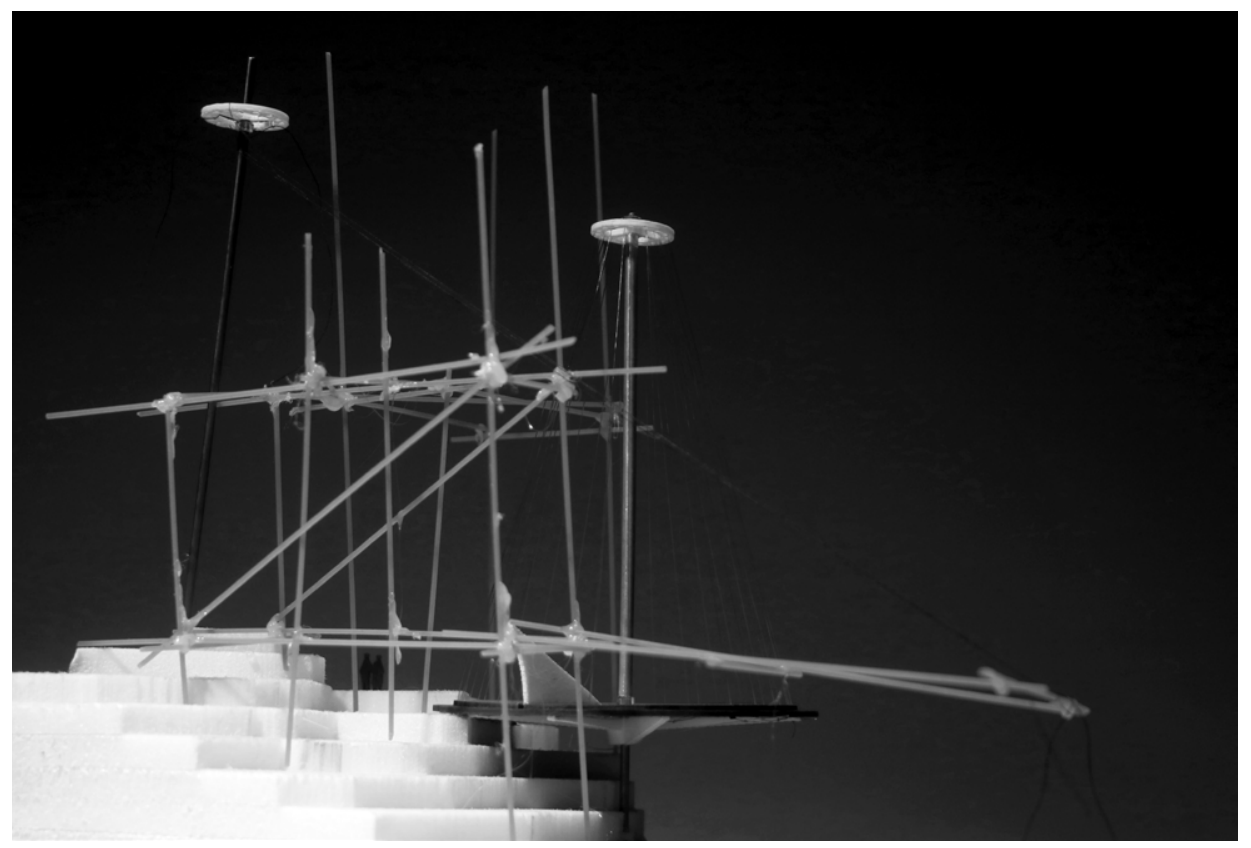

Fig 4.37 (Above) Spaghetti model mock up no. 1.

Fig 4.38 (Below) Graphic sketch of model.

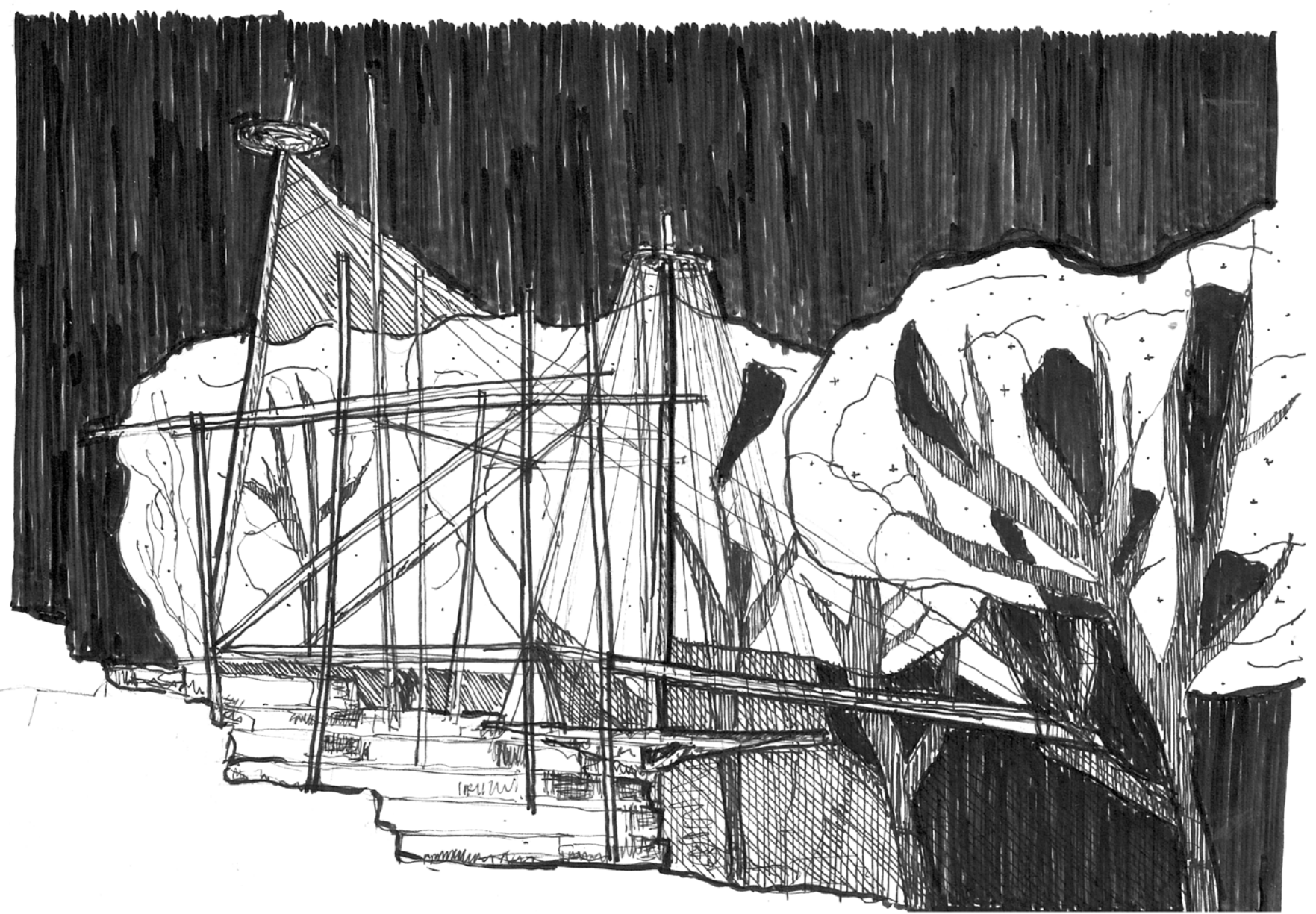




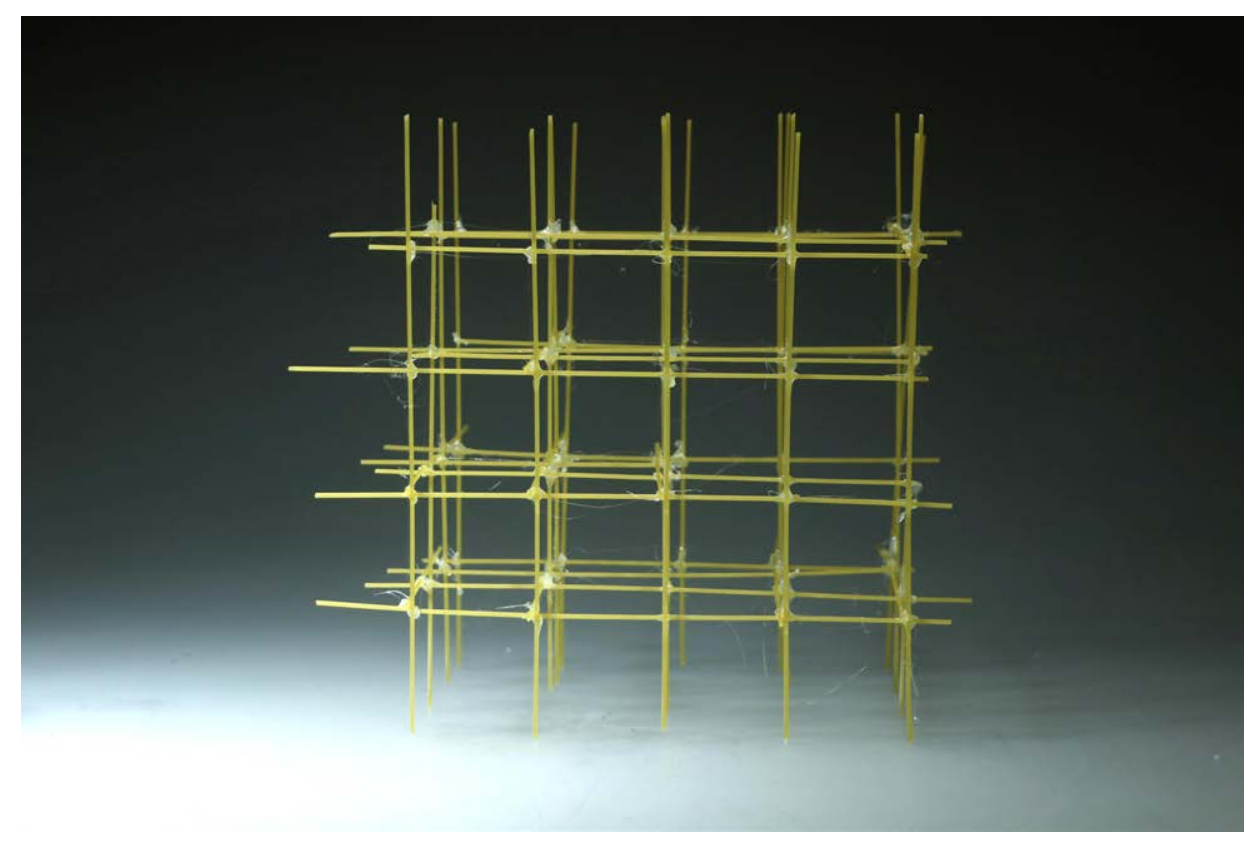

Fig 4.39 (Opposite) 3D mesh mock up with spaghetti \& hot glue.

Fig 4.40 (Below) Mock up sketch for a model.

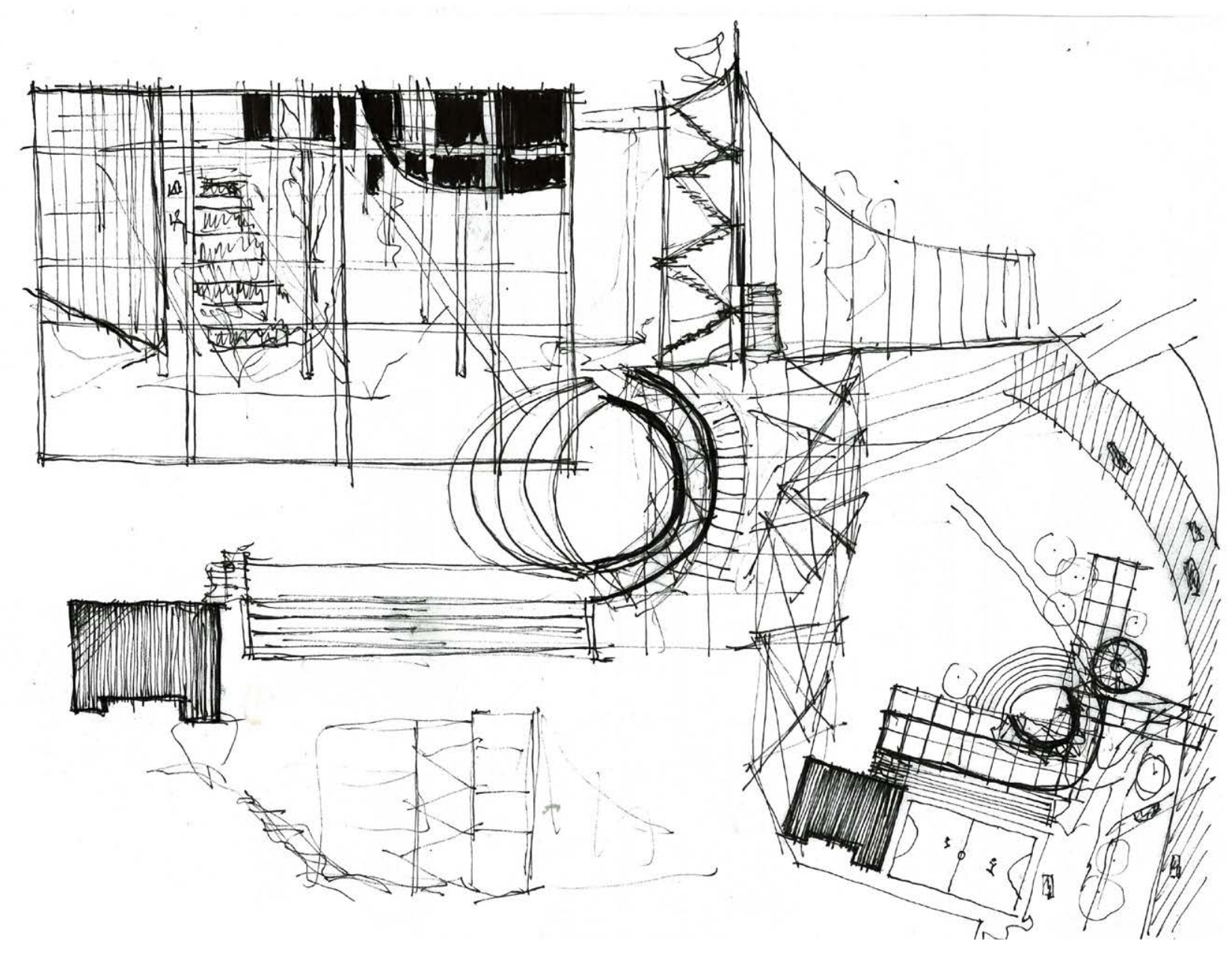




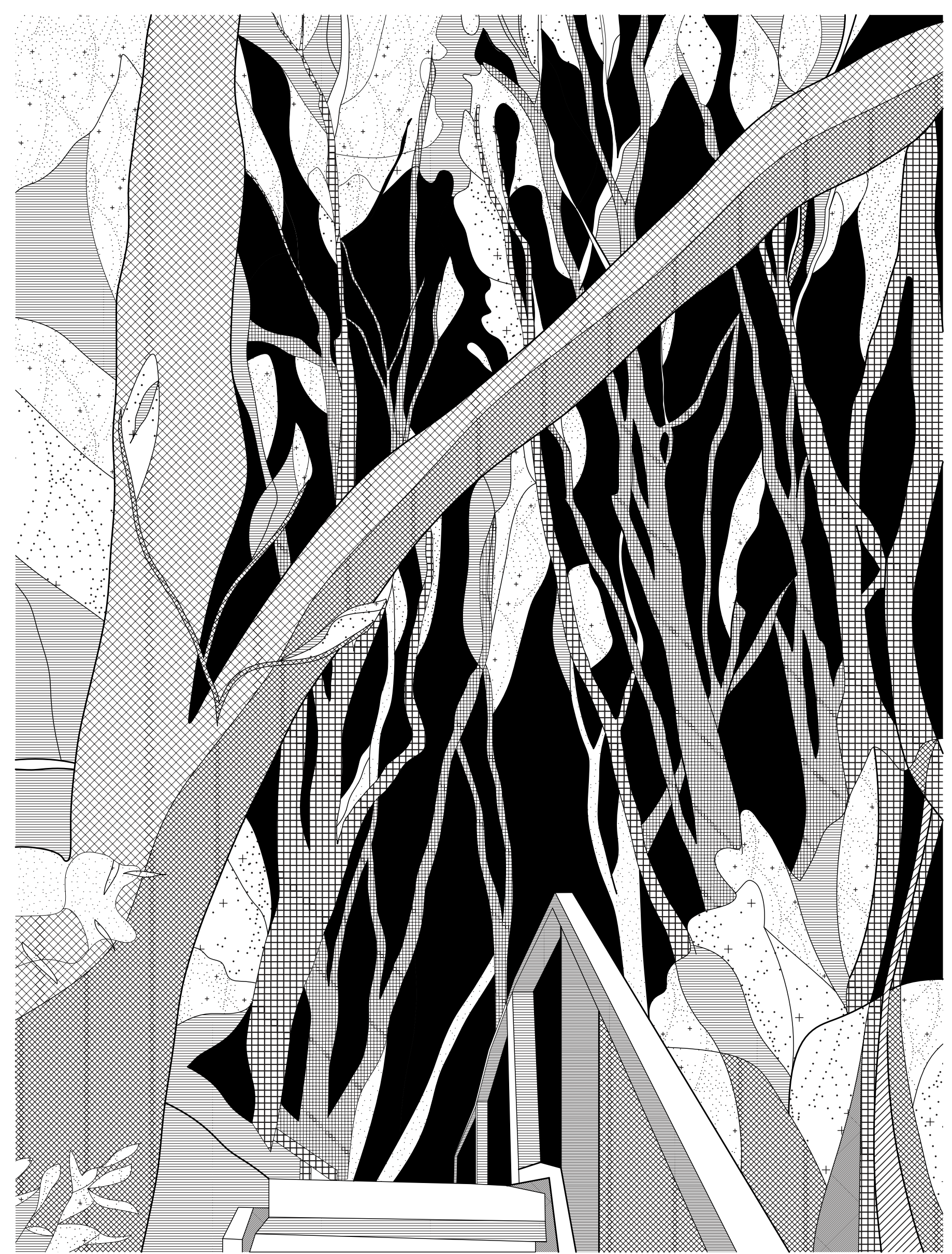

Fig 4.41 Pohutukawa pathway, digital graphic sketch. 


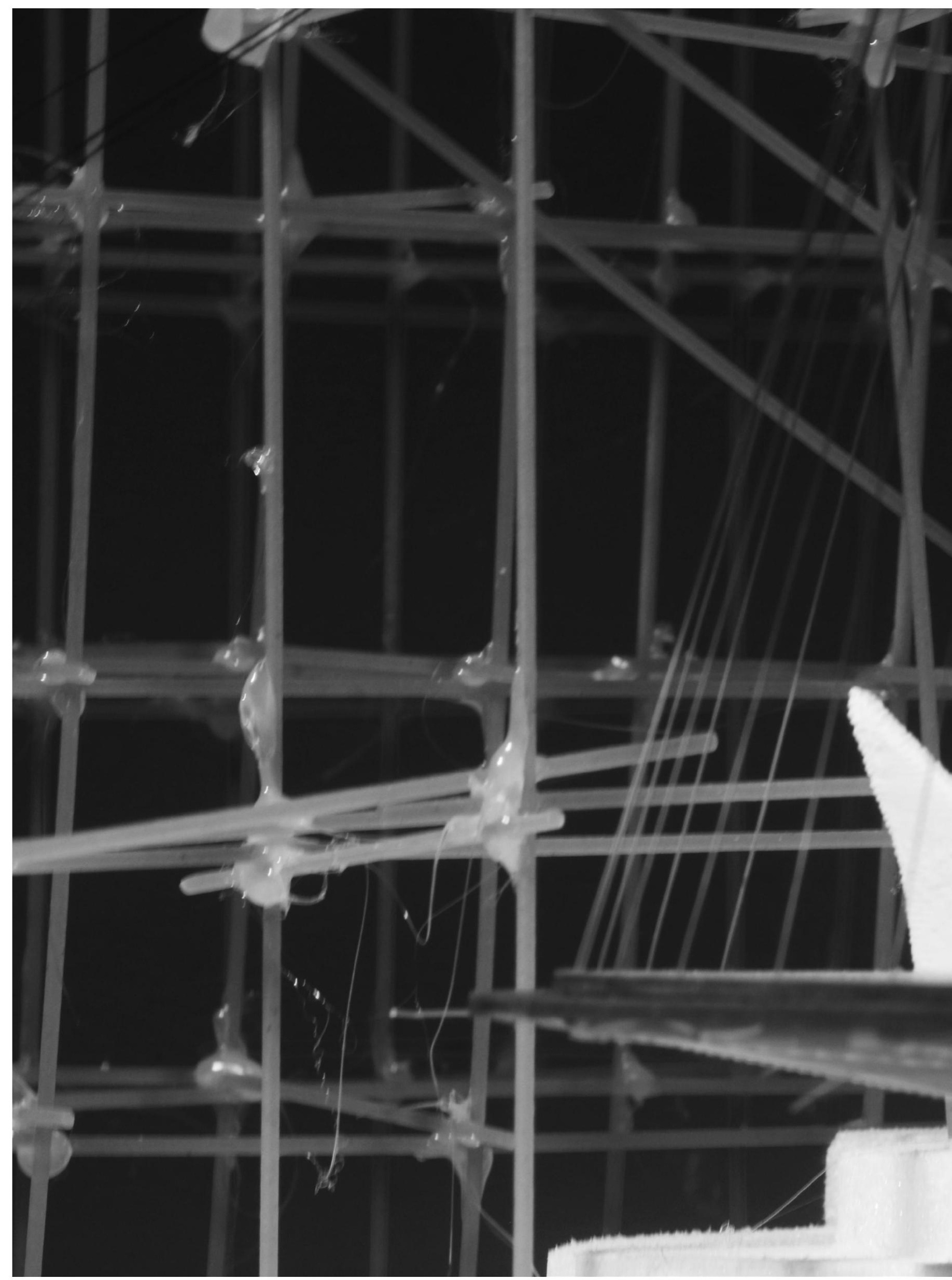

Fig 4.42 Sundial in a steel forest, model image. 


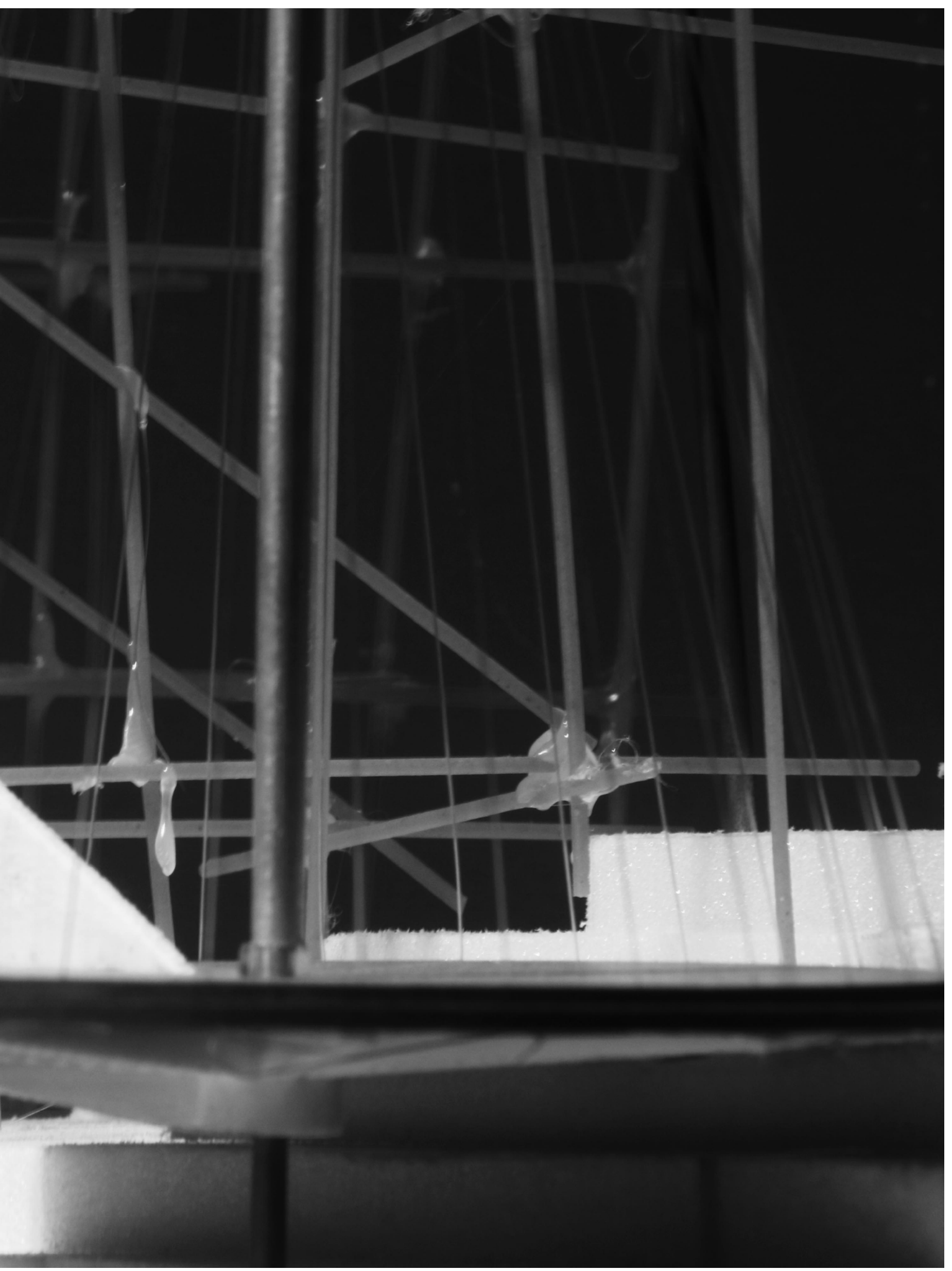




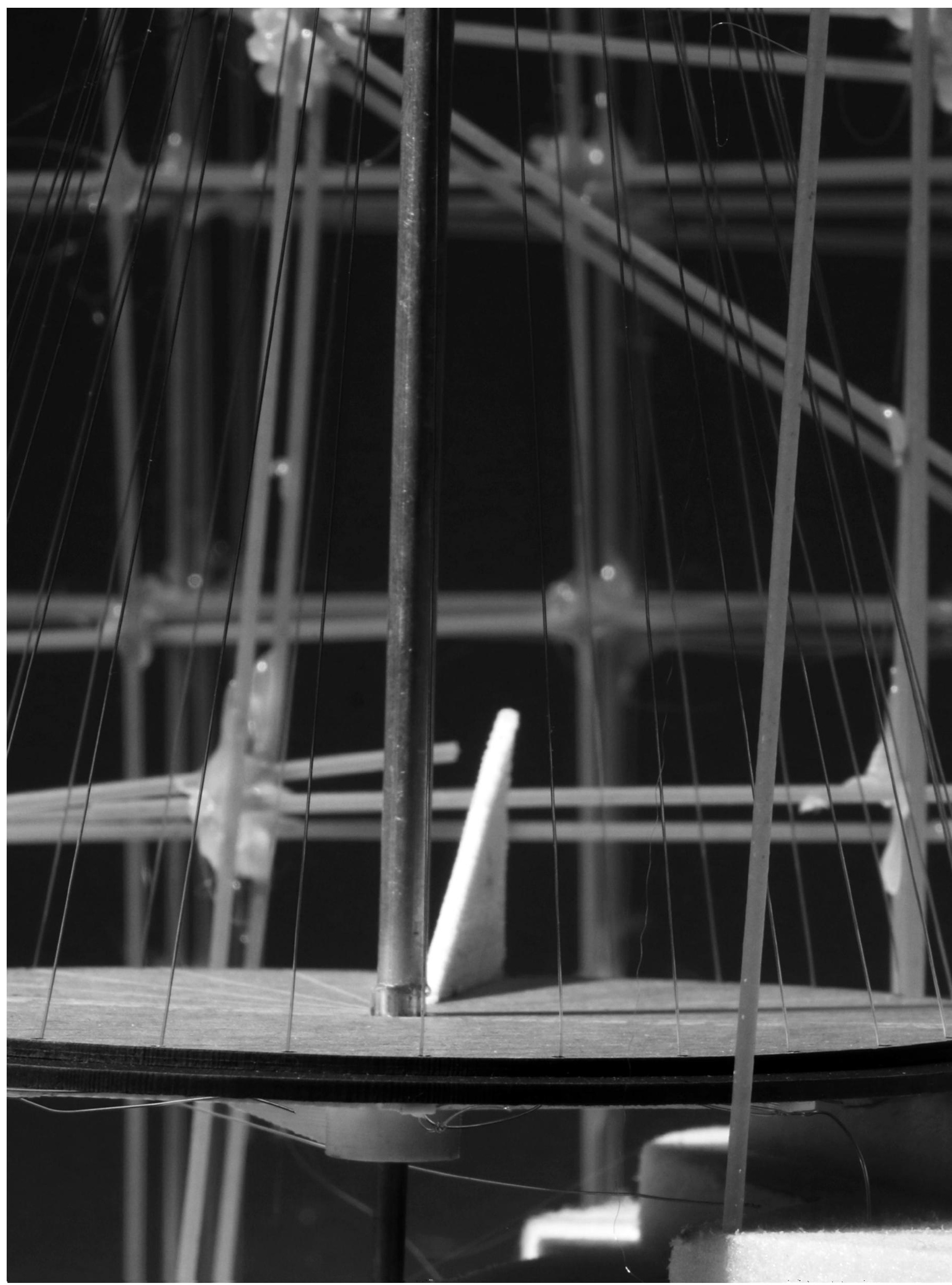

Fig 4.43 Sundial in a steel forest, model image. 


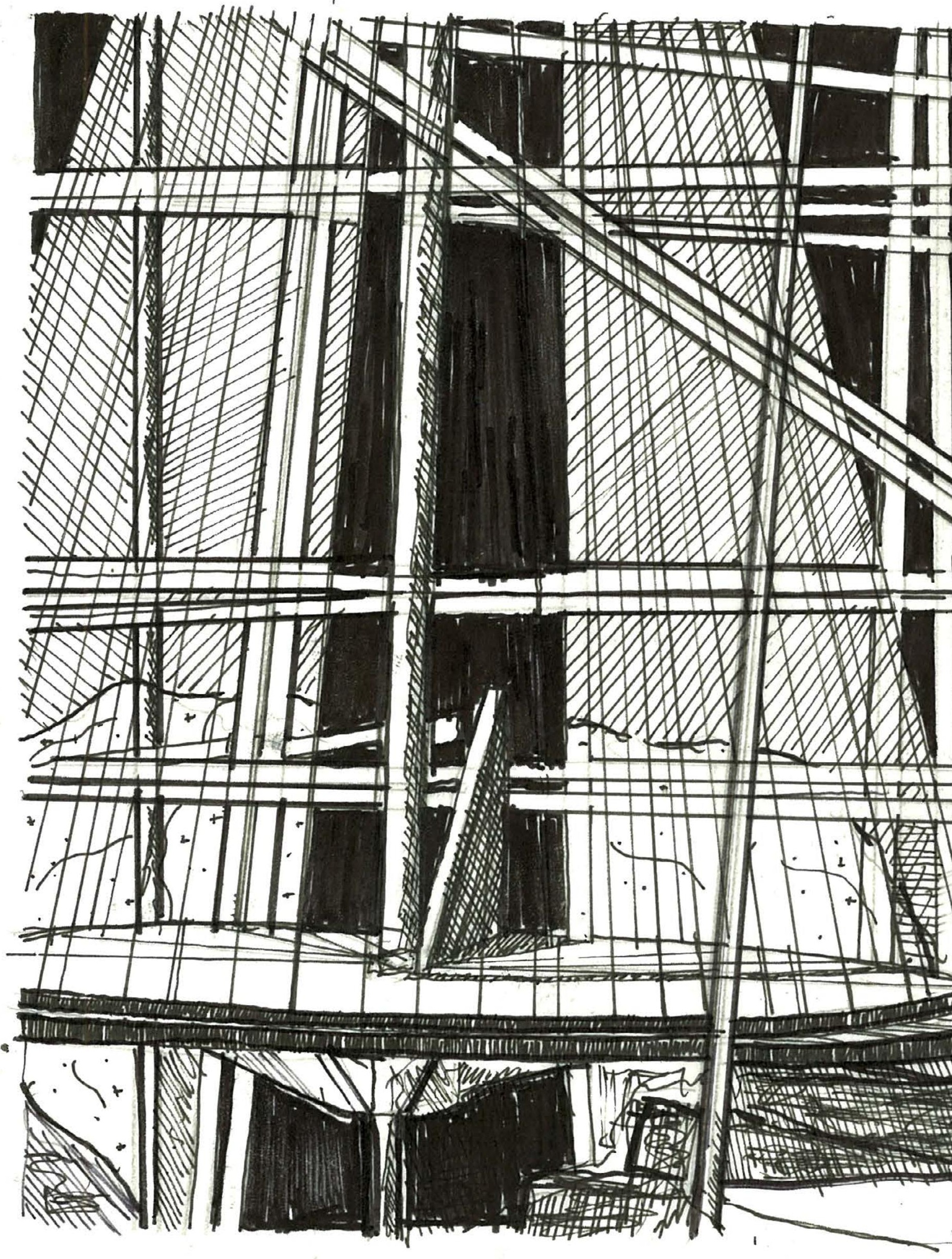

Fig 4.44 Sundial in a steel forest, graphic sketch, July 2018. 


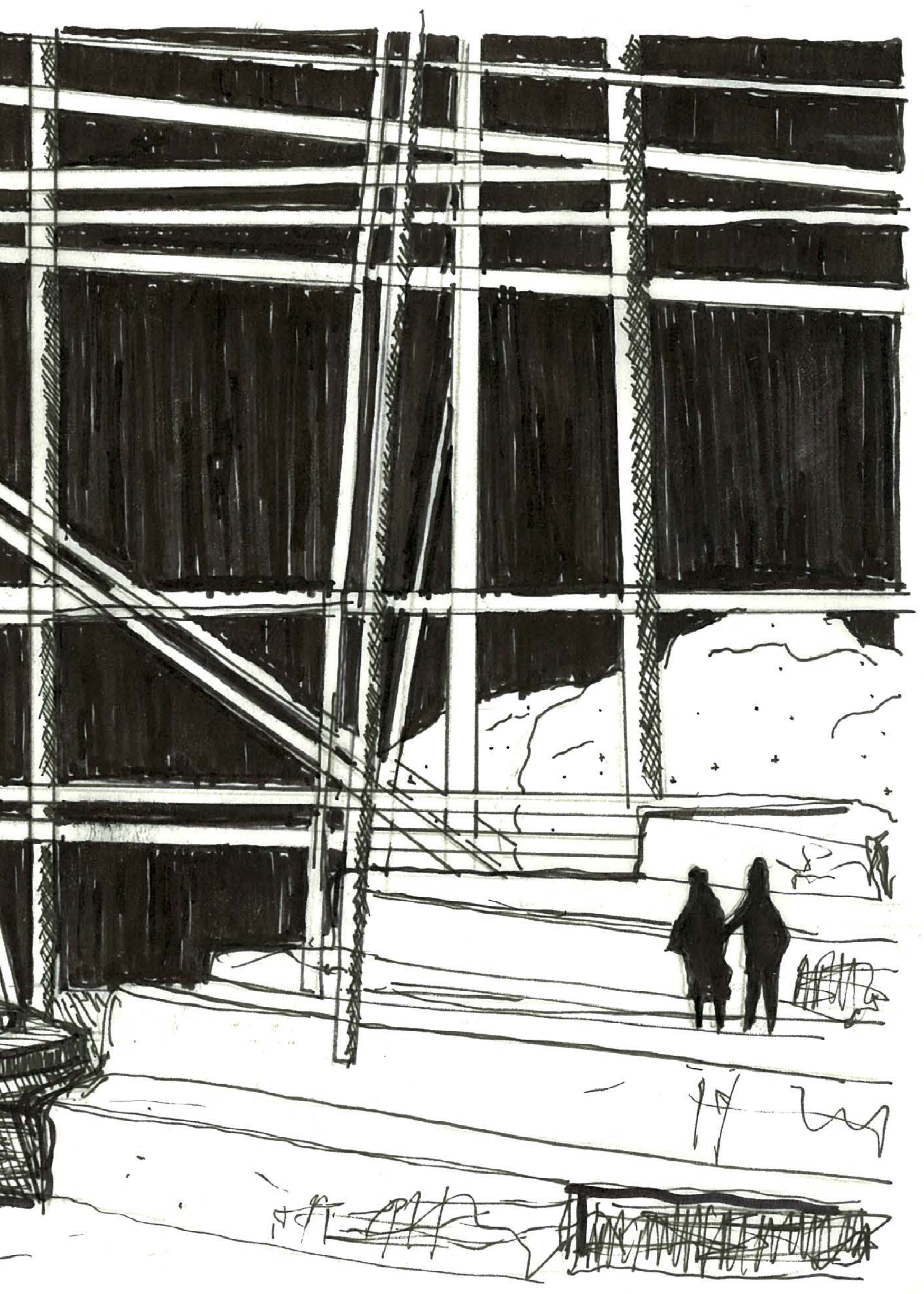




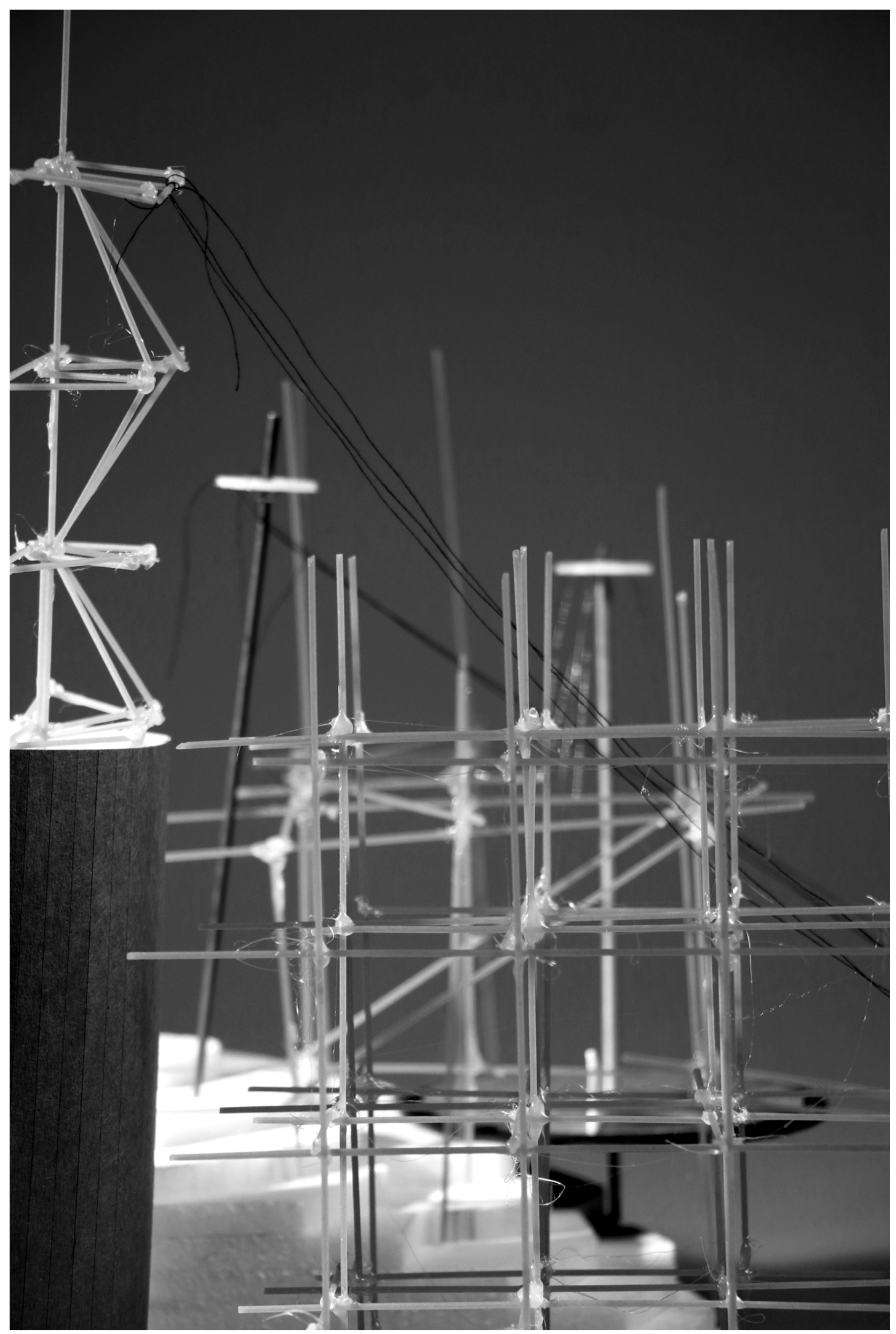

Fig 4.45 Tower, Pavilion \& Mesh model image. 


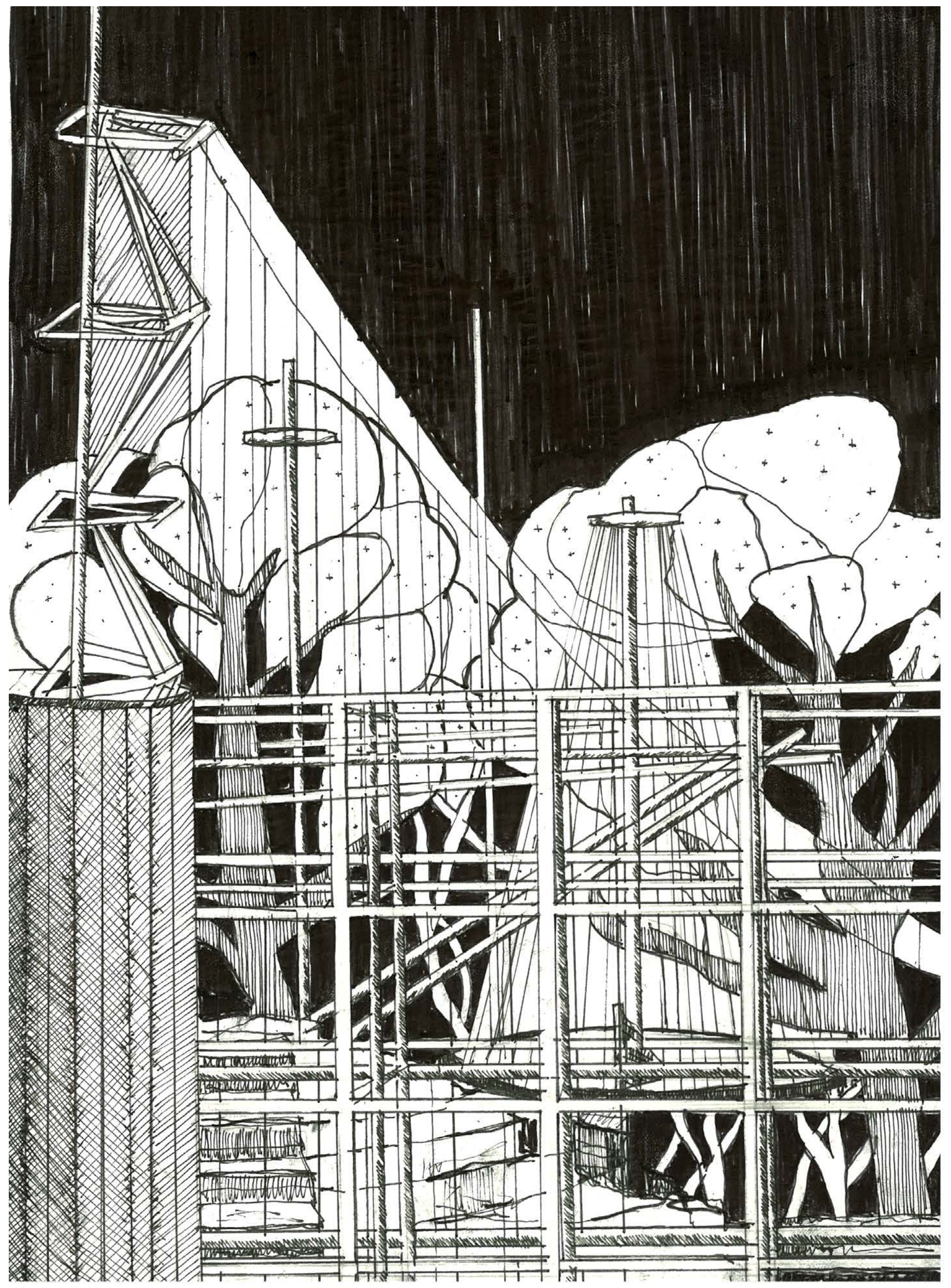

Fig 4.46 Tower, Pavilion \& Mesh, graphic sketch. 


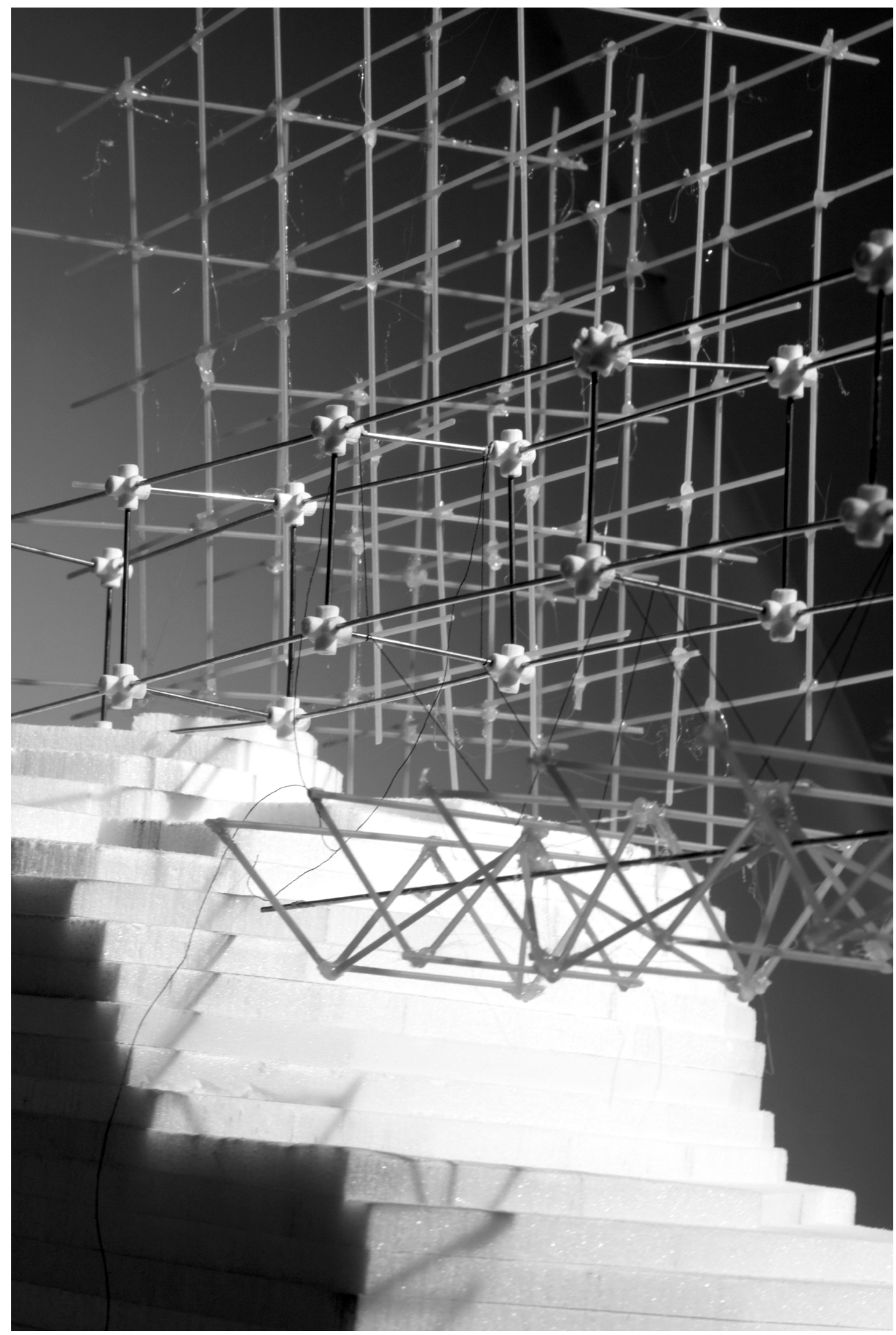

Fig 4.47 Bridge through trees, model image. 


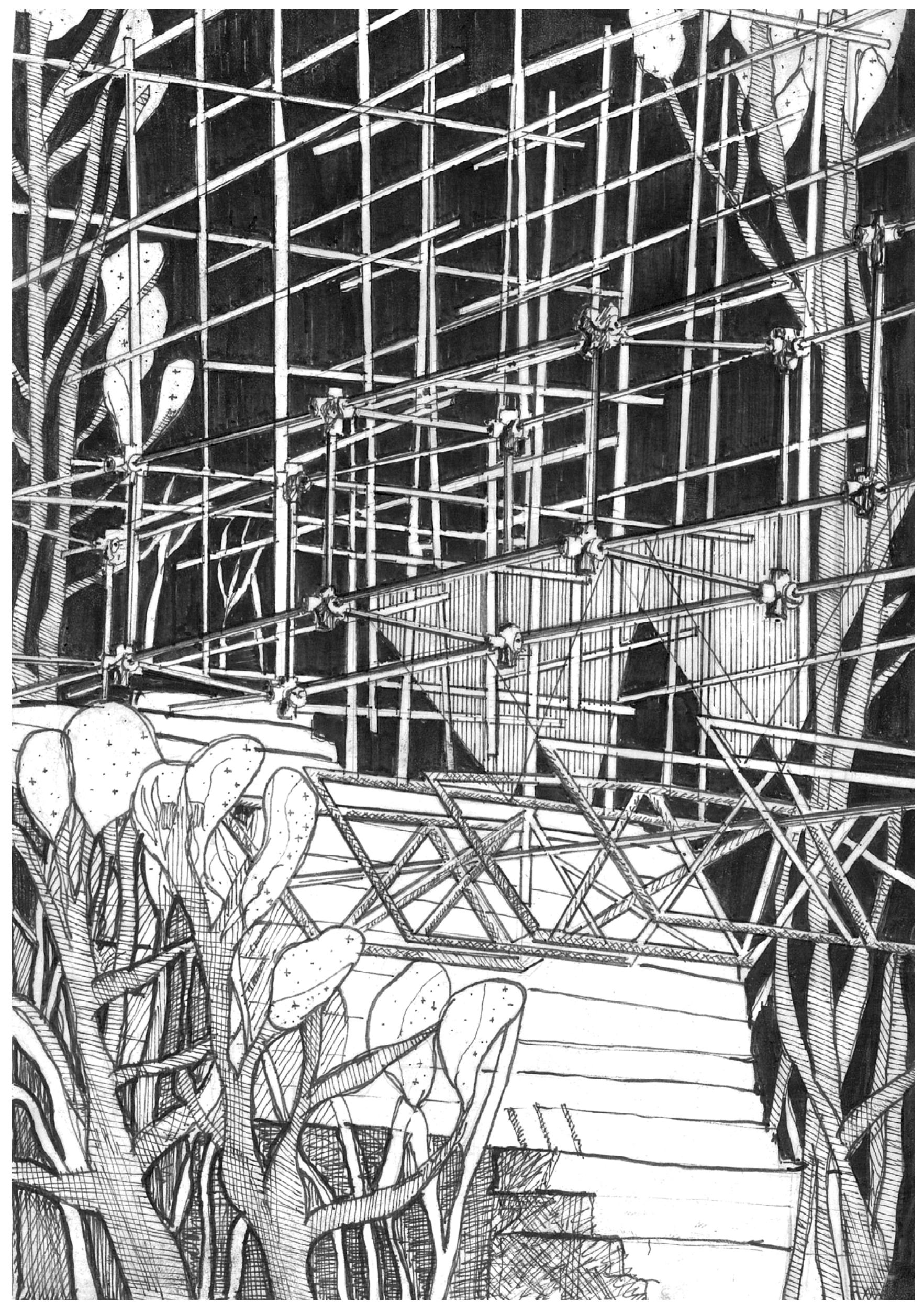

Fig 4.48 Bridge through trees, graphic sketch. 


\section{EDGE}

With these vignettes, I could speculate on the expanse of the mesh beyond. They were alluring studies, but they were confined to the borders of the perspective drawings. They had no plan or section aligned to them. For a while, I had put off the translation to the digital realm because it had inhibited the quality of the mesh, but I realised that I couldn't put it off any longer. I had to define 'the edge' of the environment to understand it, and to pursue it.

My previous attempts at digitising the mesh had resulted in rigid, regular grids. The allure of the mesh in the drawings was its inherent wonkiness, so I developed a method to 'shake up' the structure. The first attempts were arbitrary. I began by placing the grid across the necessary junctions and leaned some columns/ beams over whilst leaving others stationery.

The lack of regulation made this a time consuming process (Fig 4.50Fig 4.51).

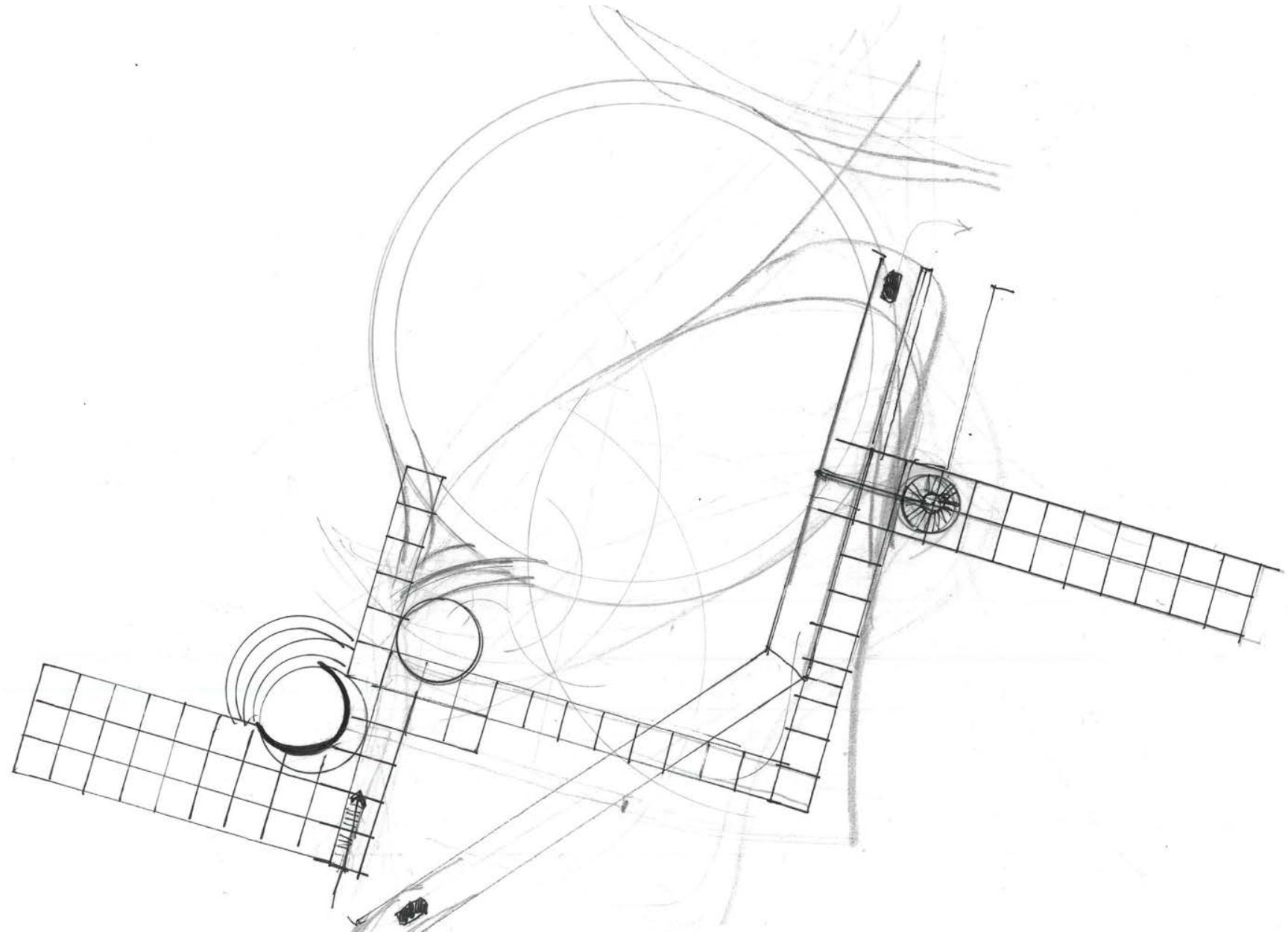

Fig 4.49 Sketch plan of the regular grid with paths and pavilions, August 2018. 


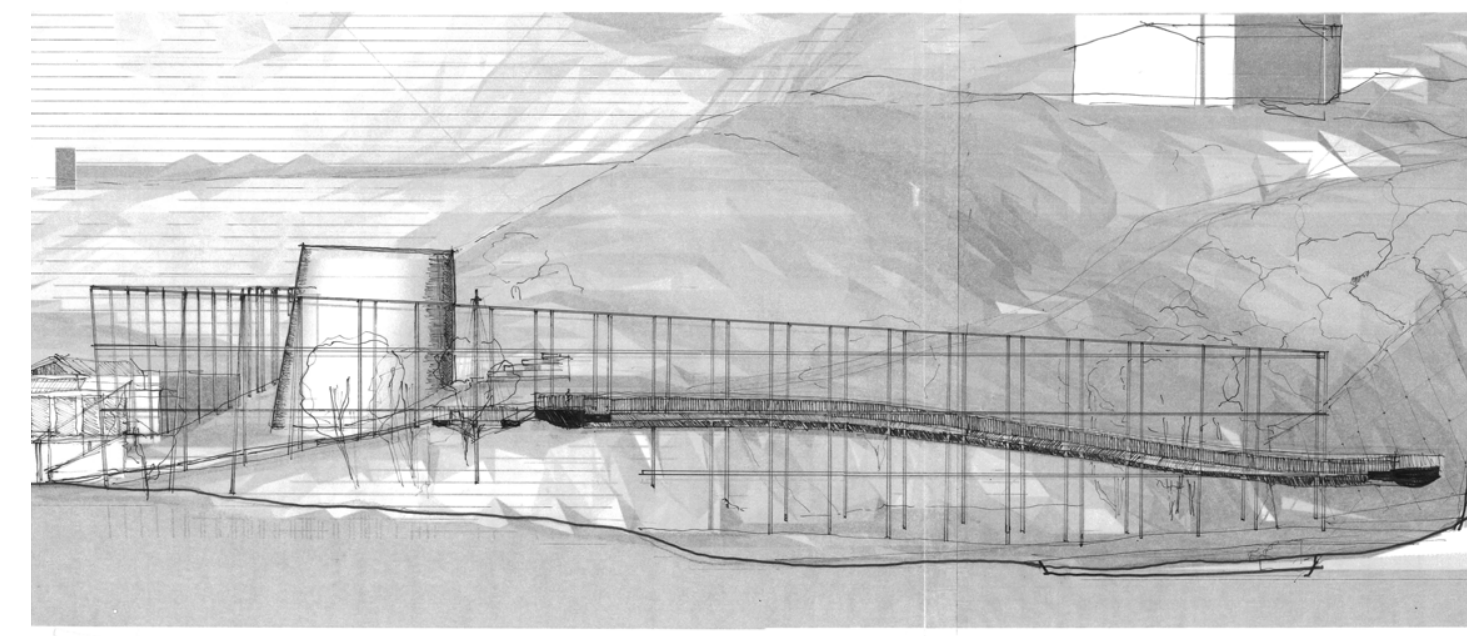

Fig 4.50 (Top \& Mid) Section sketches of the quasi-shaken-up structure $\&$ scheme.

Fig 4.51 (Below) Isometric diagram of said scheme.
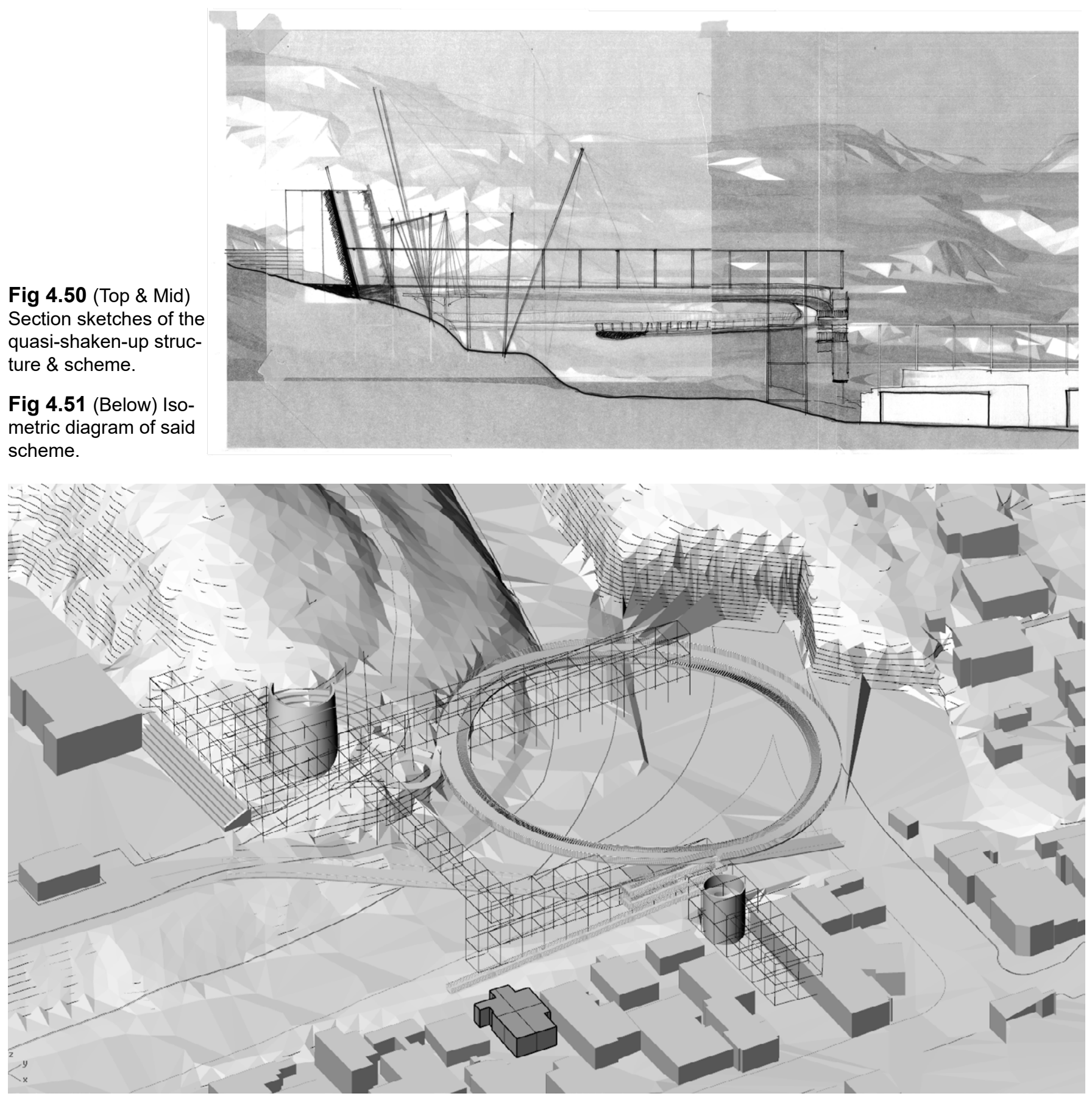
The formal marches to strict rhythms.

$W$ by the necessity to space out structure equally, like soldiers marching on a parade ground... Let the informal in. Have a syncopation - a rat-ta-ta-tatinstead of the dull metronomic one-two repeat of post and beam that rises and runs along our buildings in stark structural skeletons

(Balmond 2002).

I took two small pieces of music, arranged for fingerpicked guitar play. The repetition of two subtly different patterns can create a complex sound when played together. This conjured images of a chaotic-looking but inherently orderly structural system, where the angle and rotation of columns could relate in some way to the location and pitch of the note represented in Tablature (Tab).

Transposing the Tab into a structural framework allowed me to mass an irregular mesh quickly. I used the pattern shown in Fig 4.53 as a base and simply 'copied and pasted' it in plan, arbitrarily. I placed columns across the site where I wanted the artificial forest to expand and join the disparate territories. The legibility of the music was irrelevant.

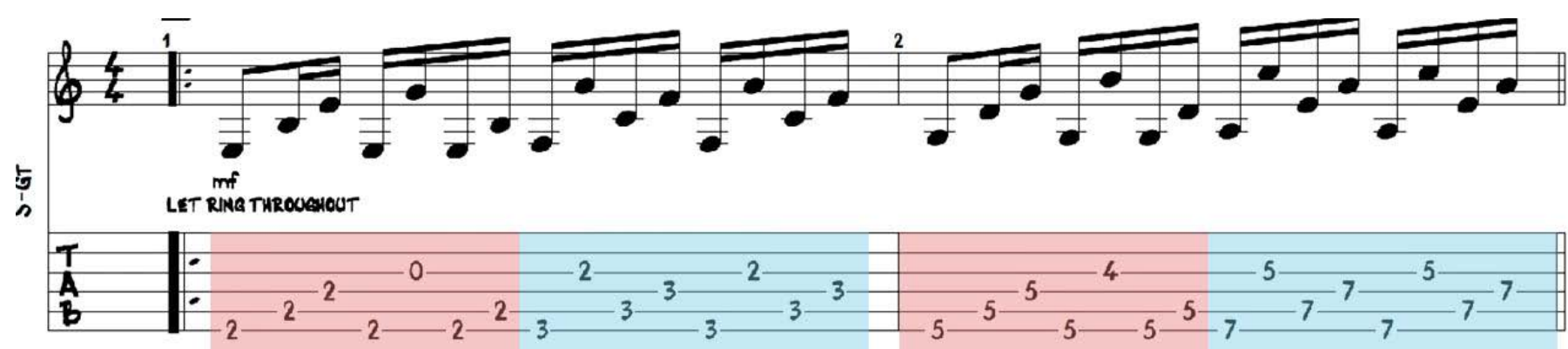

Pattern 1

Pattern 2

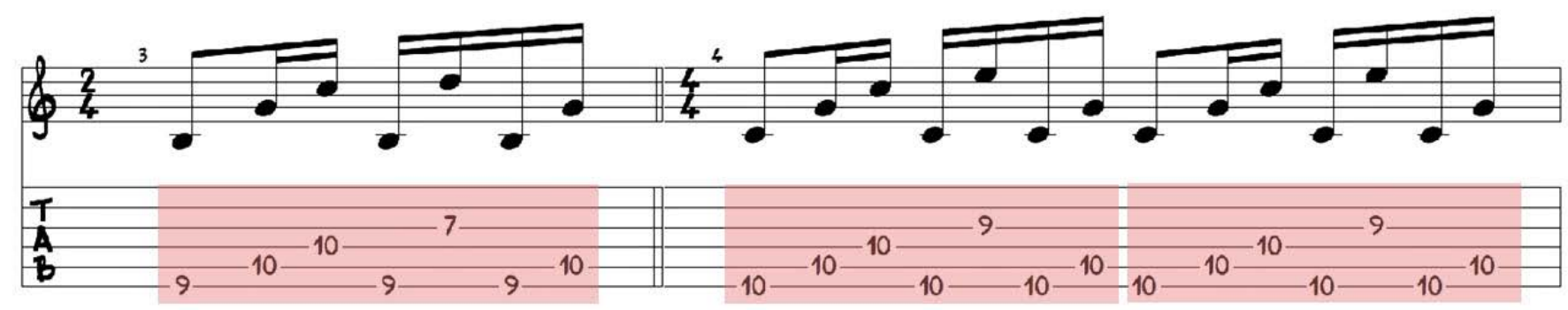

Fig 4.52 Tab from 'Untitled'. 


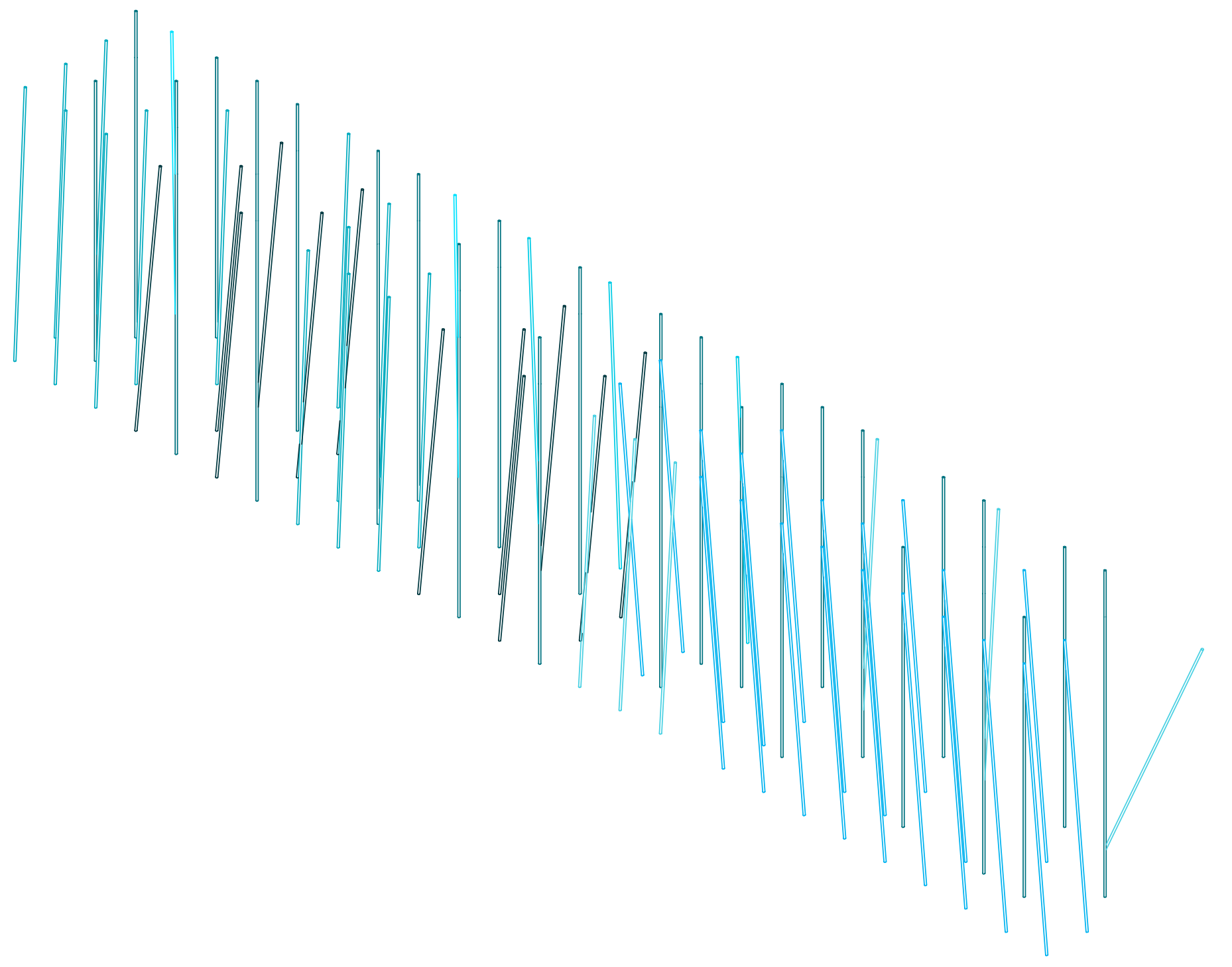

Fig 4.53 Results of transposing Tab from 'Untitled' into structural columns. 


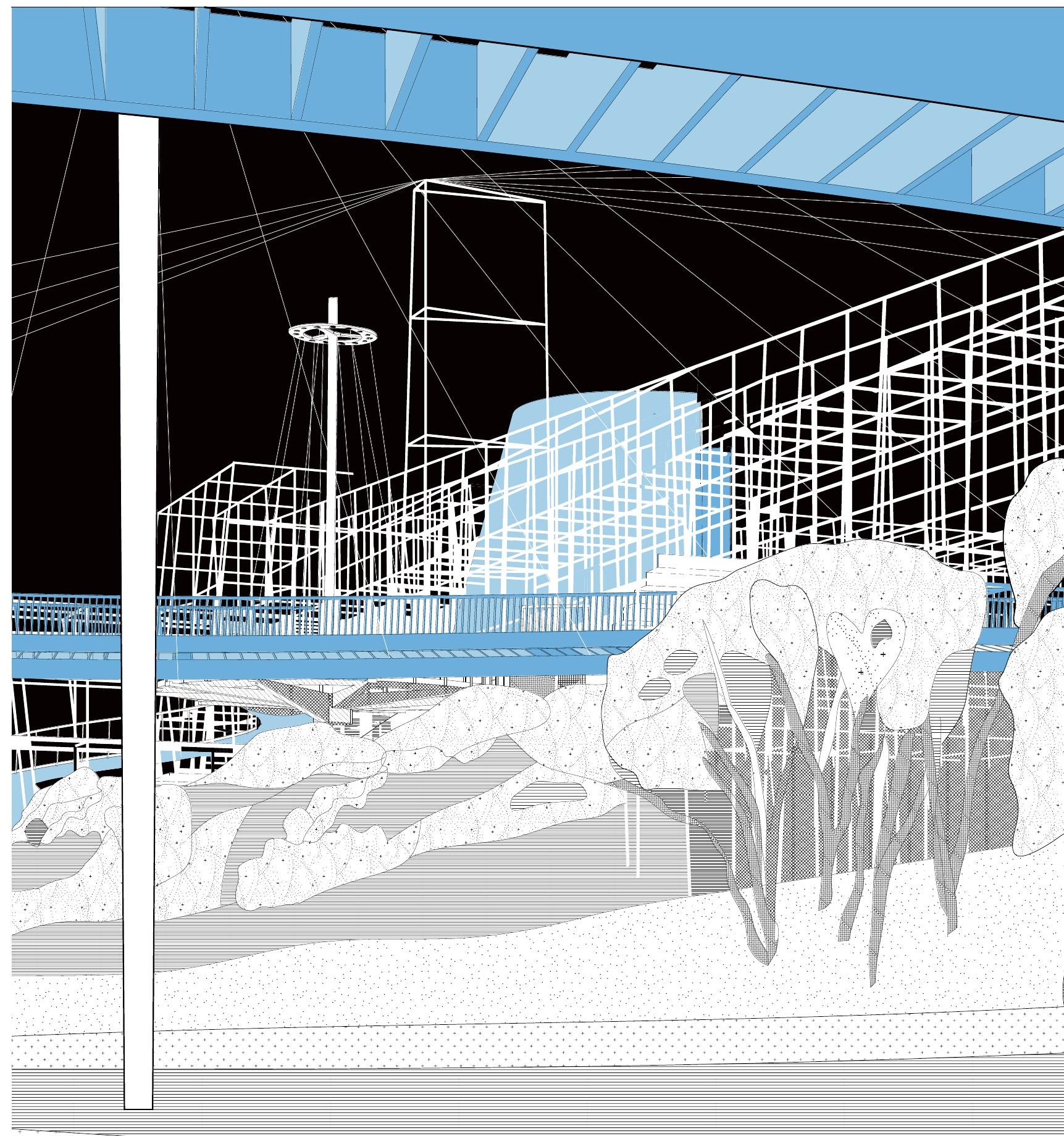

Fig 4.54 View of the scheme from Taurima Street. 


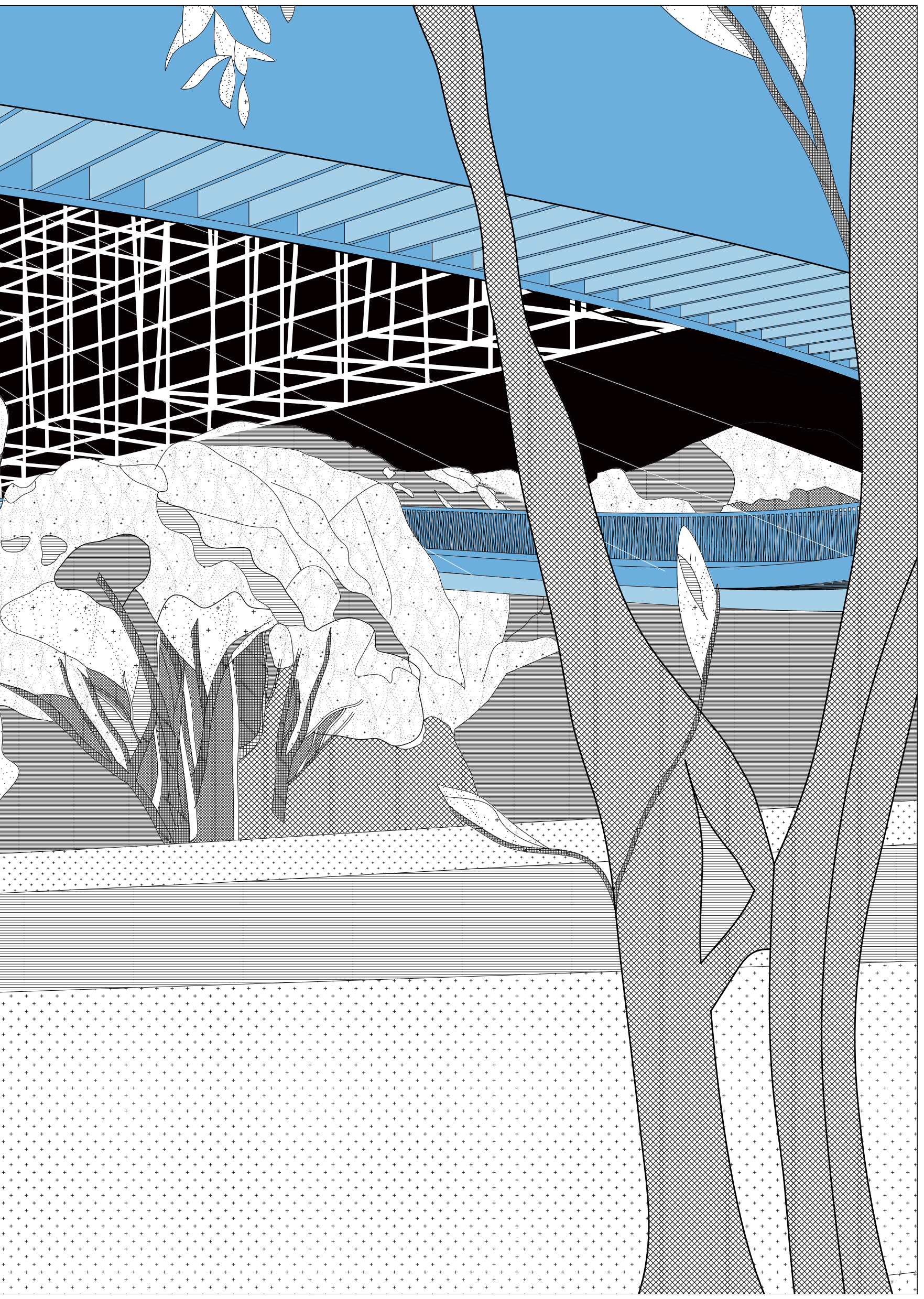




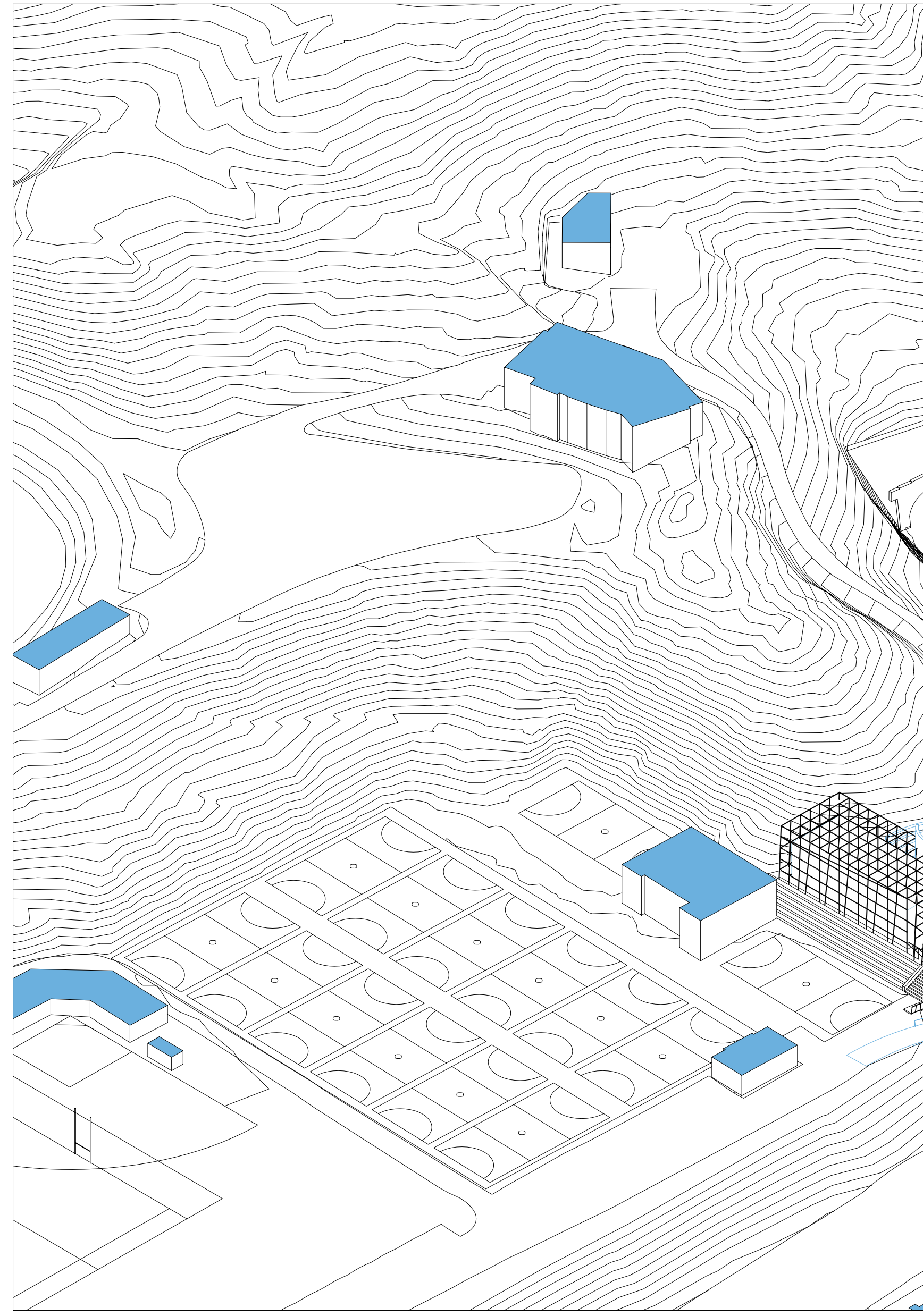

Fig 4.55 Isometric diagram of the scheme. 


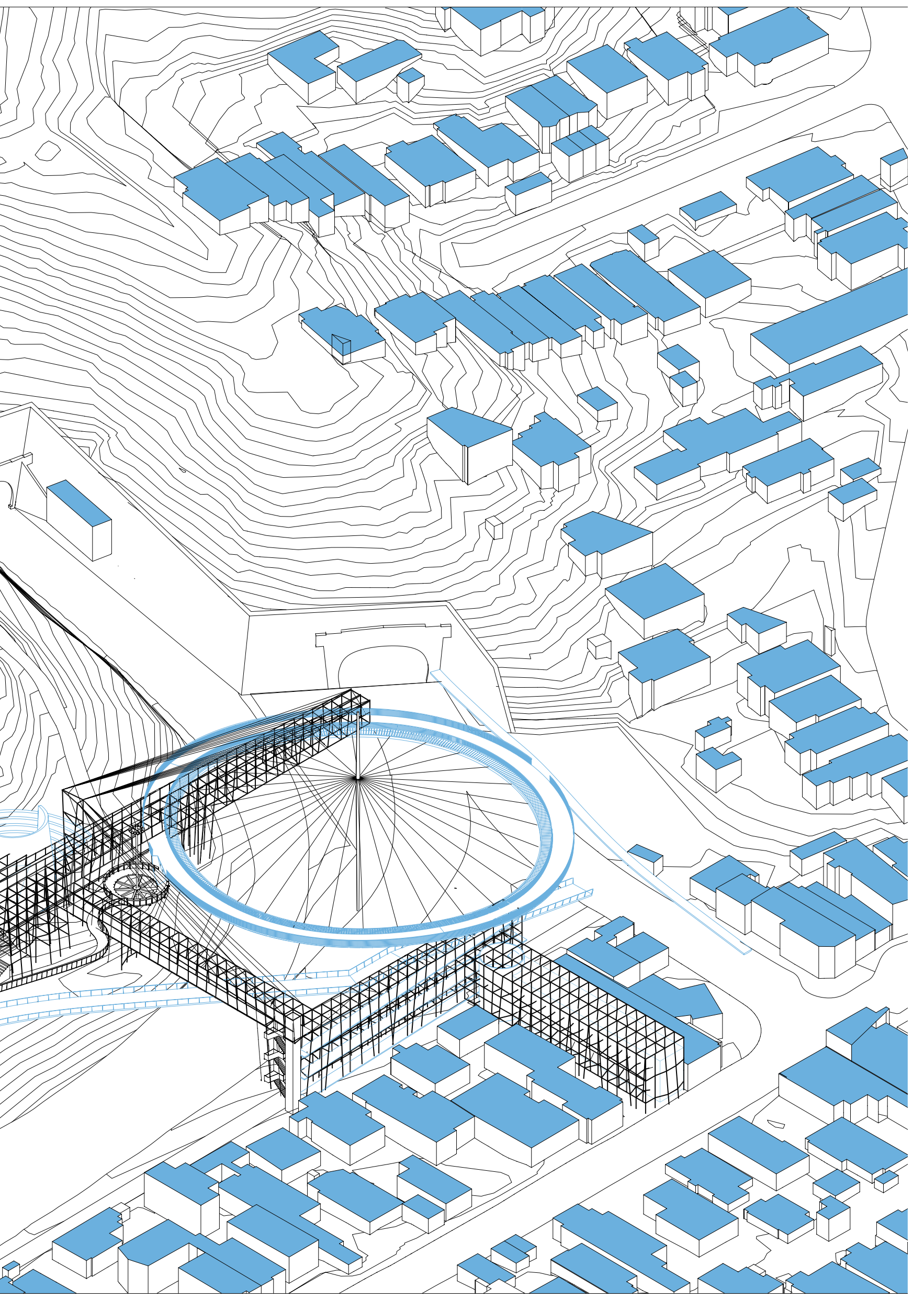



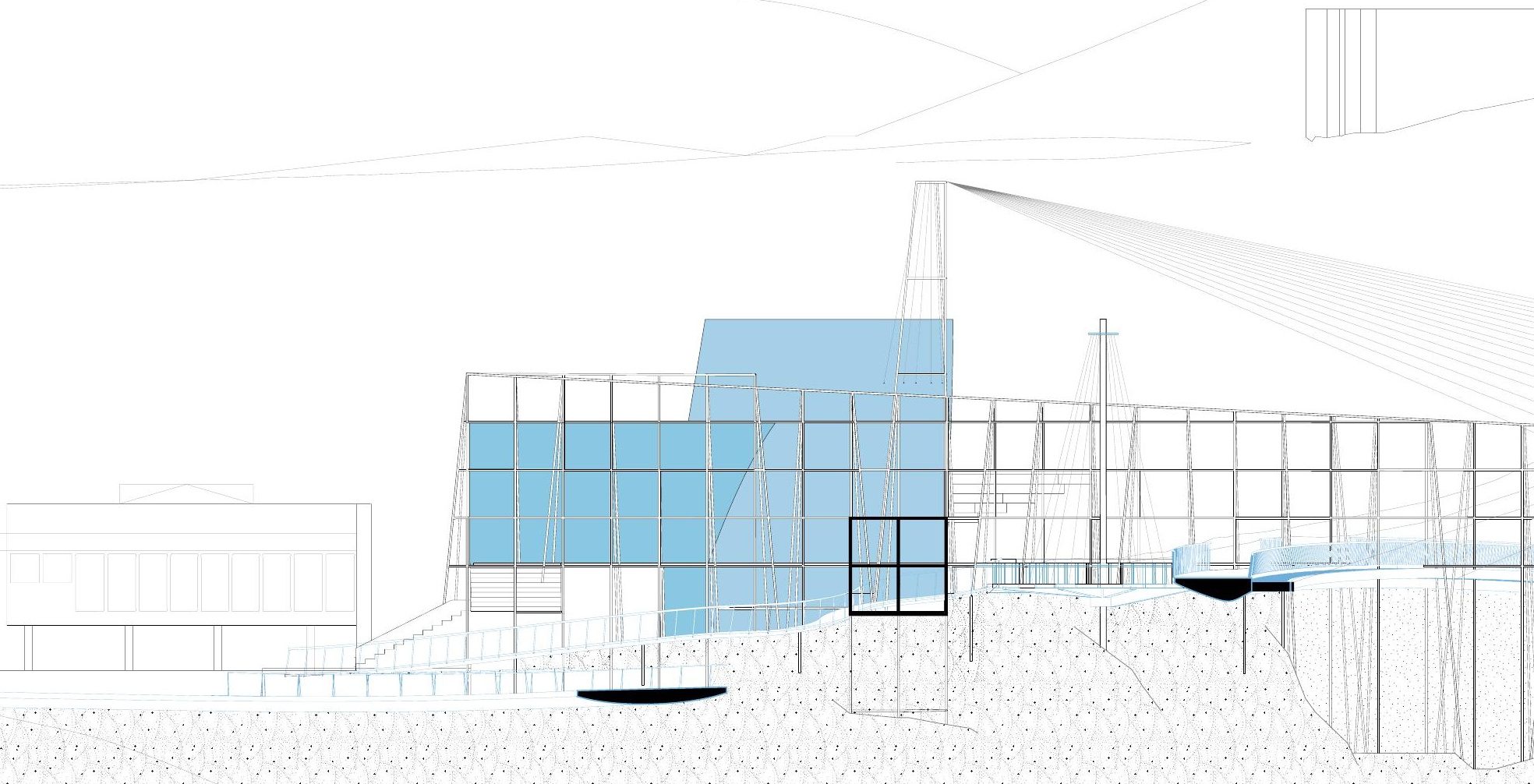

Fig 4.56 Section 1:200. 



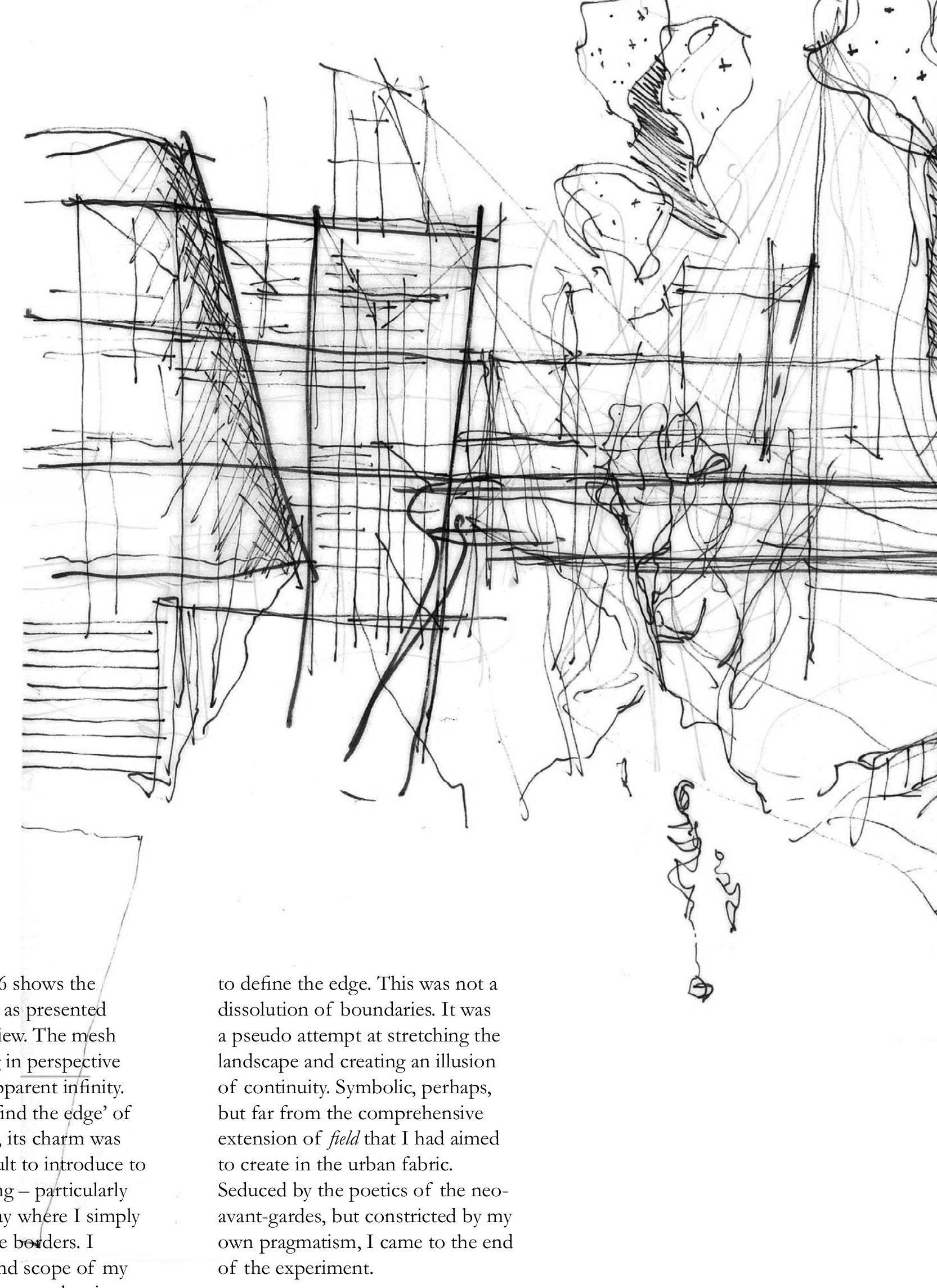
mesh awkward - not at the city (or global) scale of my precedents, but still inappropriate within its attainable limits. I realised that the romance of those projects came largely from their infinitely possible forms, whereas my project aimed

to define the edge. This was not a dissolution of boundaries. It was a pseudo attempt at stretching the landscape and creating an illusion of continuity. Symbolic, perhaps, but far from the comprehensive extension of field that I had aimed to create in the urban fabric.

Seduced by the poetics of the neoavant-gardes, but constricted by my of the experiment.

Fig 4.57 A fast \& loose sketch of the scheme, which occurred earlier than the digital drawings, displayed on previous pages. I found these physical drawings much more alluring than the scheme itself, leading me to re-think the scheme entirely. 


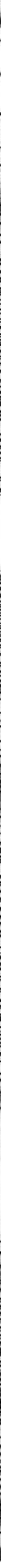


5.0

$$
5
$$




\section{Island}

The ubiquitous mesh structure offered some alluring moments, however it was difficult to rationalise in an urban scenario. A loop structure, which had appeared as a later element of the mesh had more pragmatic benefits, connecting the Town Belt, Village, and Tunnel in one sweeping movement. It also received a more positive reception than the mesh in dialogue with my peers, and later at my August review.

This experiment accepts the physical discontinuity of the urban fabric created by the road in Hataitai and aims instead, to create a distinct dialogue with it.

The discernible form of The Loop did not aim to integrate itself into the existing environment, but to create a distinctly new element within that environment. A series of connecting spaces on the periphery of The Loop provided subtle moments of integration with the surrounding urban spaces. I continued 'fast and loose' processes for these peripheral spaces. The development of The Loop required more 'precise and measured' digital tools.

Unlike the previous experiment, this approach is twofold. Where the first experiment sees the city as a continuous field and tries to integrate itself utterly within that field, the second recognises the allure of emphasizing distinct islands within the field as well as intervening with its continuation more subtly. I explored autonomy debates after developing this experiment.

This chapter demonstrates how the city fabric is both a field and a collection of discrete islands within a field. The two concepts can invigorate the effect of each other. 


\section{ARCHIPELAGO}

To classify city as an utterly continuous field would be contentious. Would that not indicate a homogenisation of the city fabric, devoid of the nuances that distinguish one moment from another? Aureli notes that 'the city is often depicted as a sort of self-organizing chaos,' but argues that the opposite is true: 'The city is always the result of political intention, often in the form of specific architectural projects' (Aureli, 2011). We might interpret these projects as islands, and these discrete islands collectively form an archipelago. Aureli proposes that autonomous architecture's capacity is to enact stoppages against urbanisms anonymity and formlessness in the city (Aureli, 2013).

Similarly, Oswald Mathias Ungers criticised traditional planning theory for defining the city as a 'single whole'. His 1977 manifesto with Rem Koolhaas - Berlin: a green archipelago (the city in the city) - supported the antithesis of a 'single whole' city. Like a field, perhaps. The authors saw post- war Berlin's population as a city in decline. Rather than allow the exodus of the city to impoverish the quality of the city fabric, they suggested a designed decay of Berlin.

Zones representing different structures, contents and forms were to be retained and strengthened, creating distinct urban islands. The ensuing decay of the remainder of the city would result in a 'green grid' for farmland and pastures, ecological reserves, 'infrastructure of the modern age', I.e. motorways and mobility space, and so on (Ungers and Koolhaas 1977). This would create an archipelago of discrete, legible enclaves, rich in human quality, and surrounded by a green lagoon of nature. Ungers and Koolhaas understand the value of unique and isolated islands within an ocean of anonymity.

The city fabric isn't utterly continuous, so why create the illusion that it is? I had aimed to create a deception of this sort in the Field experiment. However, in this pursuit I discovered the allure of the island instead. 
Fig 5.01 A diagram from Berlin: a green archipelago (The city in the city). 


\section{WANDERLUST}

The idea of the island carries connotations of isolation and solitude. I understand it not only as a physical separation form the city, but a cognitive separation from everyday life. One of the prevailing notions of the Field experiment was the idea of creating a framework for urban exploration. The superfluous nature of the mesh aimed to create many possible routes and places. This, perhaps was not achieved. However the idea remained. It was clear to me that I wasn't designing a simple bridge from A-B, a prosaic, onedimensional infrastructure that NZTA would build with the sole purpose of crossing the highway. In his Situationist Theses on Traffic, Guy Debord (a founding member of SI) noted 'we must replace travel as adjunct to work with travel as pleasure,' (Debord 1959).

I had been fascinated by the Situationist theory of dérive. It exposed to me that it is possible to explore everyday urban areas with a playful sense of wanderlust, and to construct moments distinct from the reality of the city. The notions of fantasy and escape from everyday life are echoed in Maurice Sendak's Where the Wild Things Are (Fig 5.02). Like Max's voyage to the 
jungle island, passage within the city is not restricted to instrumental activities. Jan Gehl theorises extensively on the importance of human-oriented spaces in the city where the pedestrian takes precedence over the vehicle, and where optional activities occur not because they are essential, but because they are enjoyable. These are 'Third spaces', where people might wander, sit, look, or 'linger and have a good time' (Gehl and Gemzøe 2004). With the diverse range of conditions ranging from the edge of the village, to the canopies of natural trees in the Town Belt, and proximity to sports facilities, my site provided a great many opportunities for these kinds of spaces. I had already alluded to this with models like the lilipad and sundial platforms that serve no essential value other than enjoyment.

I wanted to echo this notion throughout the project - the inherent enjoyment of wandering around Hataitai, but all the while unique from everyday life in the park, in the village or on the road.

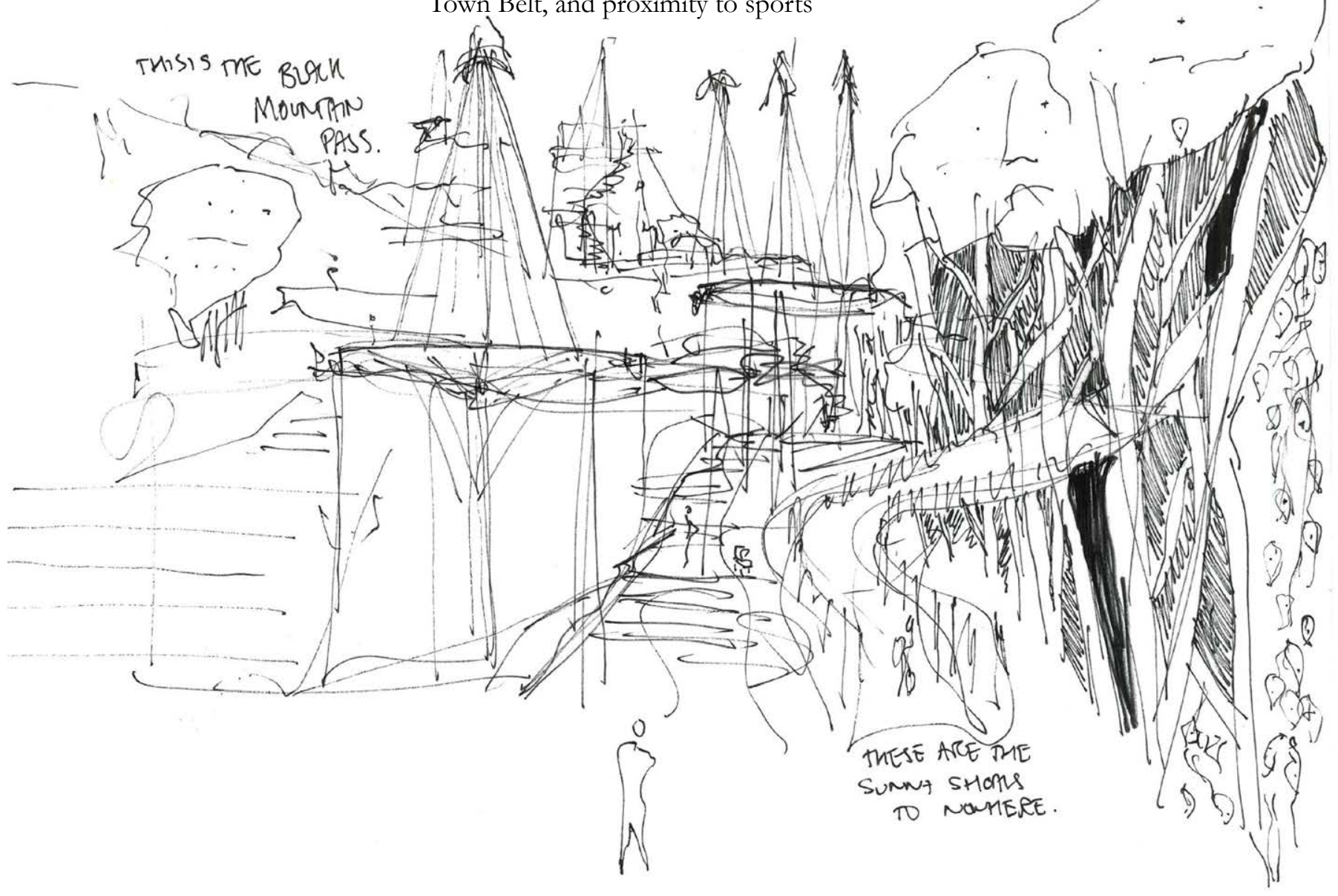

Fig 5.03 This is the black mountain pass. These are the sunny shoals to nowhere. The lyrics of $A$ Boat to an Island on the Wall (Ben Howard) evoke notions of reverie and isolation in a similar vein to Maurice Sendak's illustrations. 


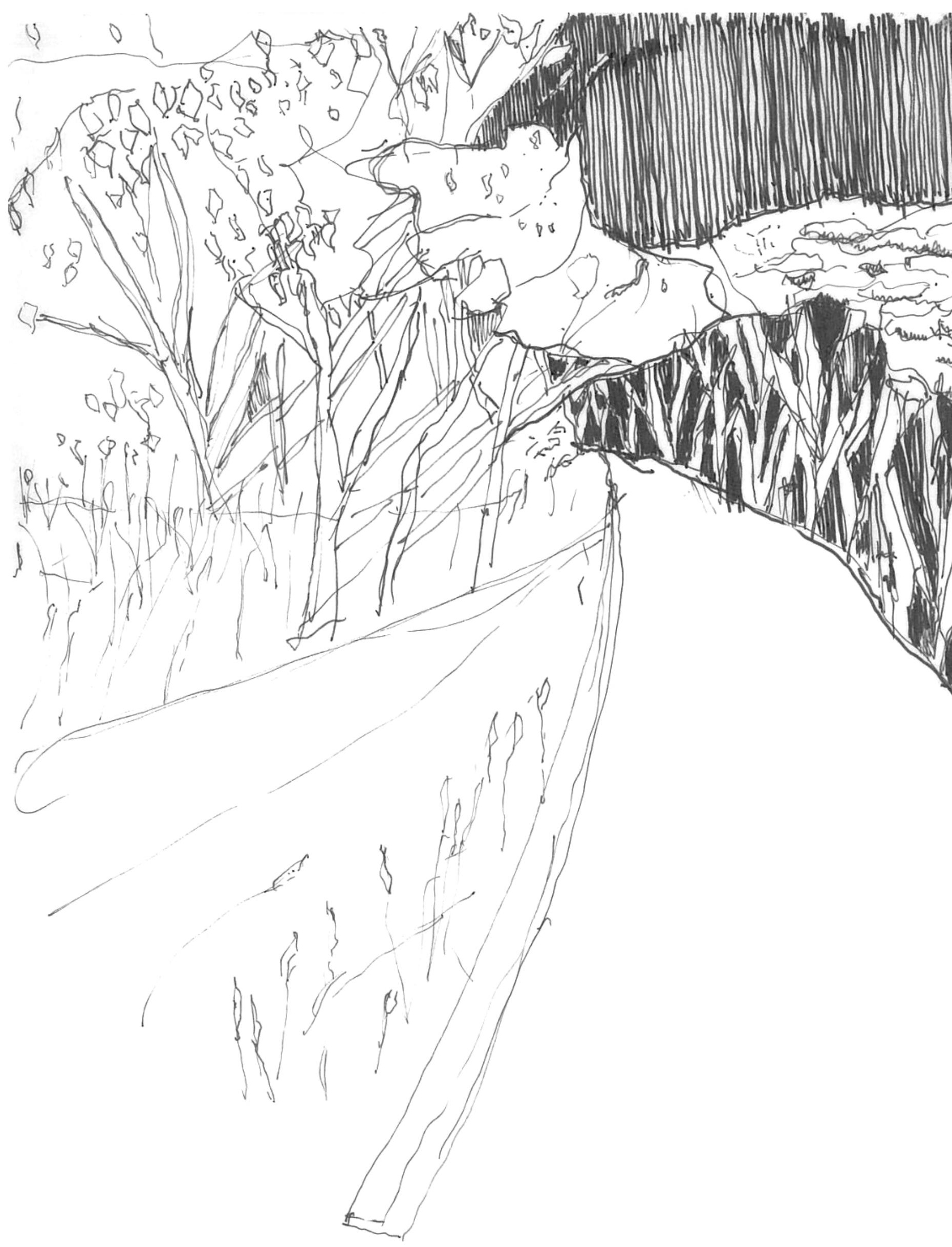

Fig 5.04 Under a canopy of trees. 


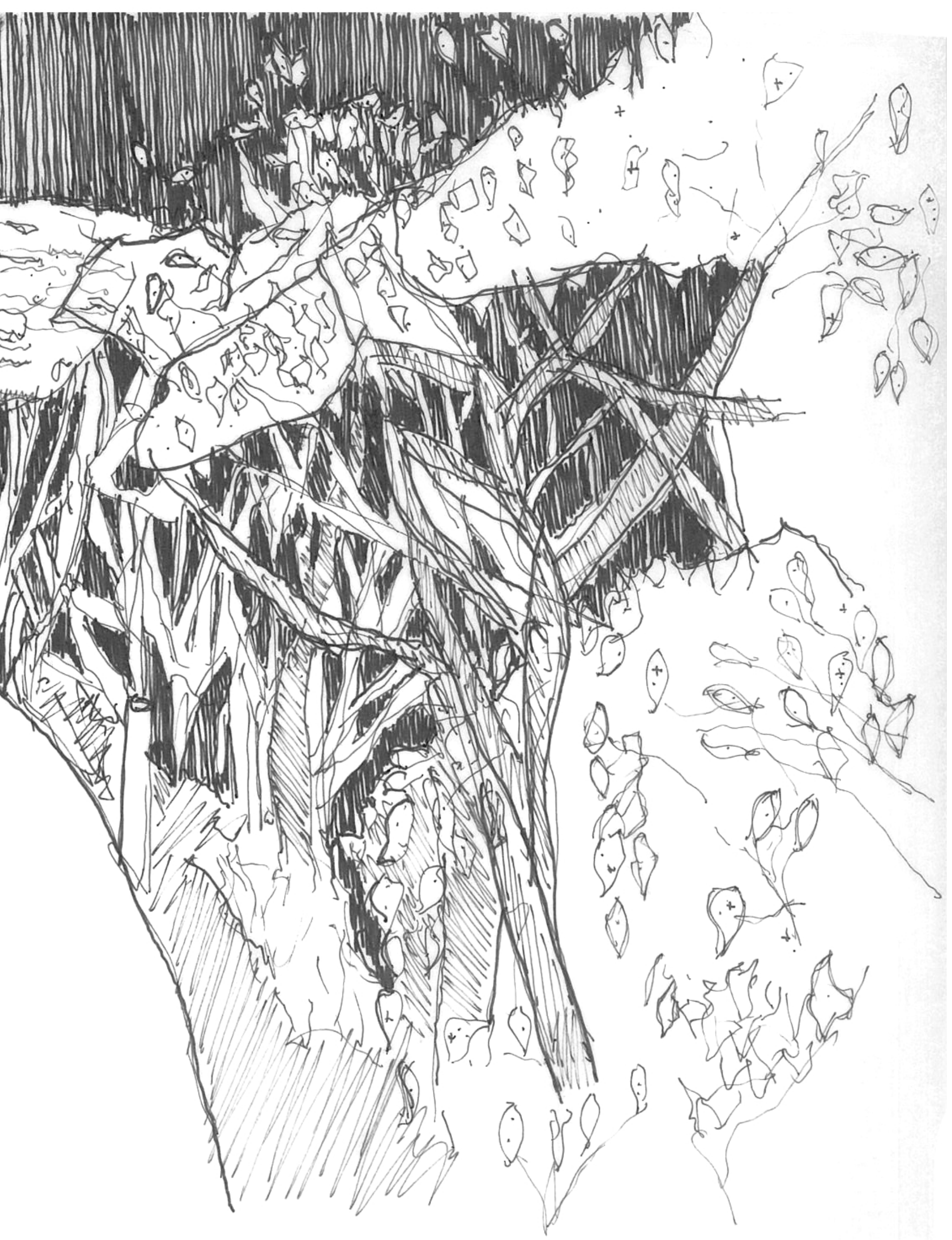




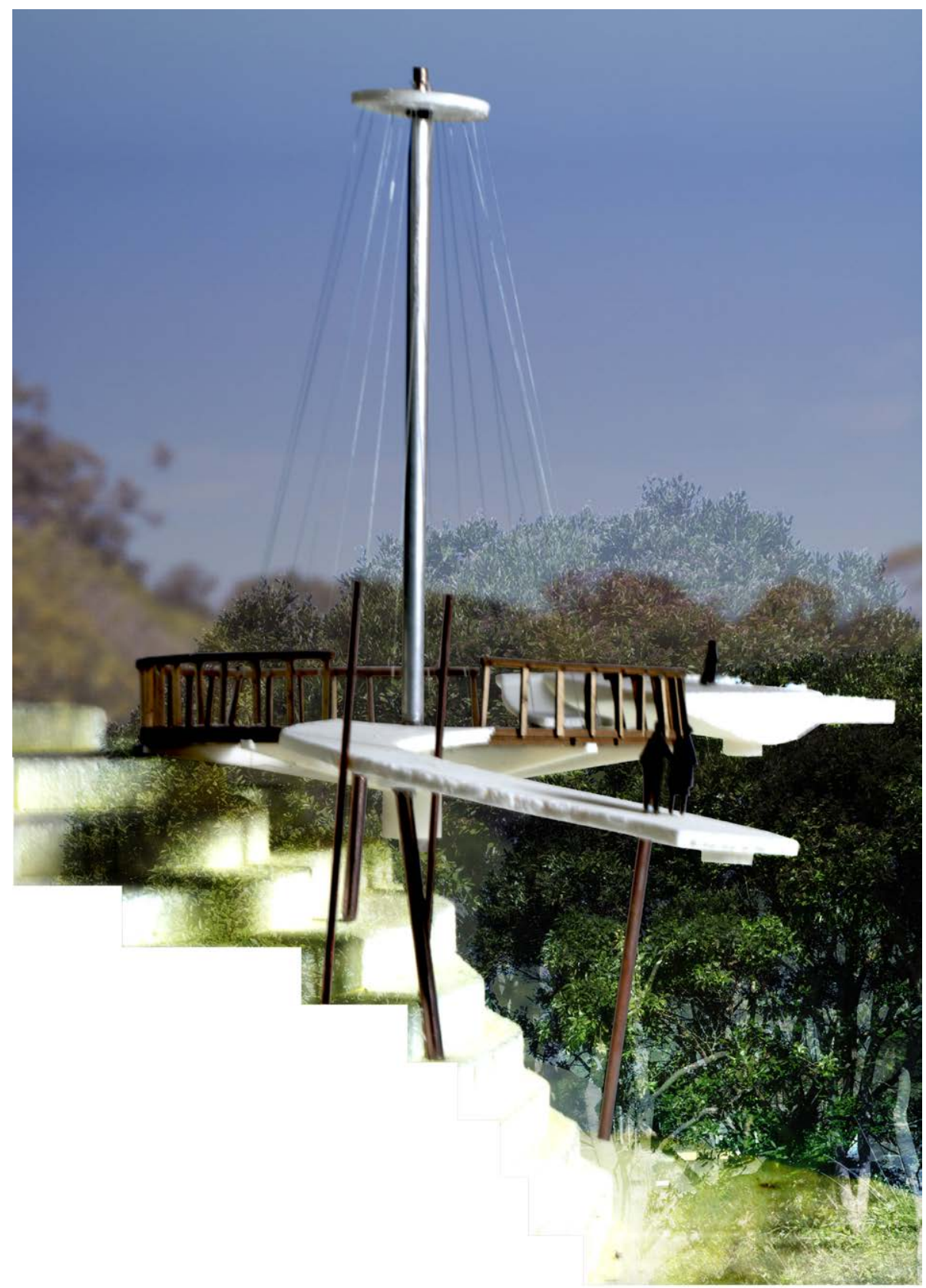

\section{LOOP}

The Loop, a discernible, isolated figure, was a fitting beginning for this new pursuit. It had emerged as an experiment near the end of the Field experiment (Fig 5.06). However, at that stage, it was a secondary instrument to the mesh. I discovered its true potential serendipitously, upon removing the mesh entirely. The Loop assumed the role of a circular bridge, $80 \mathrm{~m}$ in diameter, linking the village, park, and tunnel in one move. Pragmatic, but playful. Its dogmatic figure was absolute in the surrounding field. An island. The removal of the mesh unveiled to me the allure of discrete and finite moments. A model diorama of the lilipad platform above the Pohutukawa Trees provided one of the first supporting images (Fig 5.05).
Fig 5.05 (Above) Lilipad in the trees, connected to The Loop and park with pathways. This was stronger without the mesh.

Fig 5.06 (Opposite) Master plan from the end of the Field experiment where The Loop emerged and superseded the mesh. 


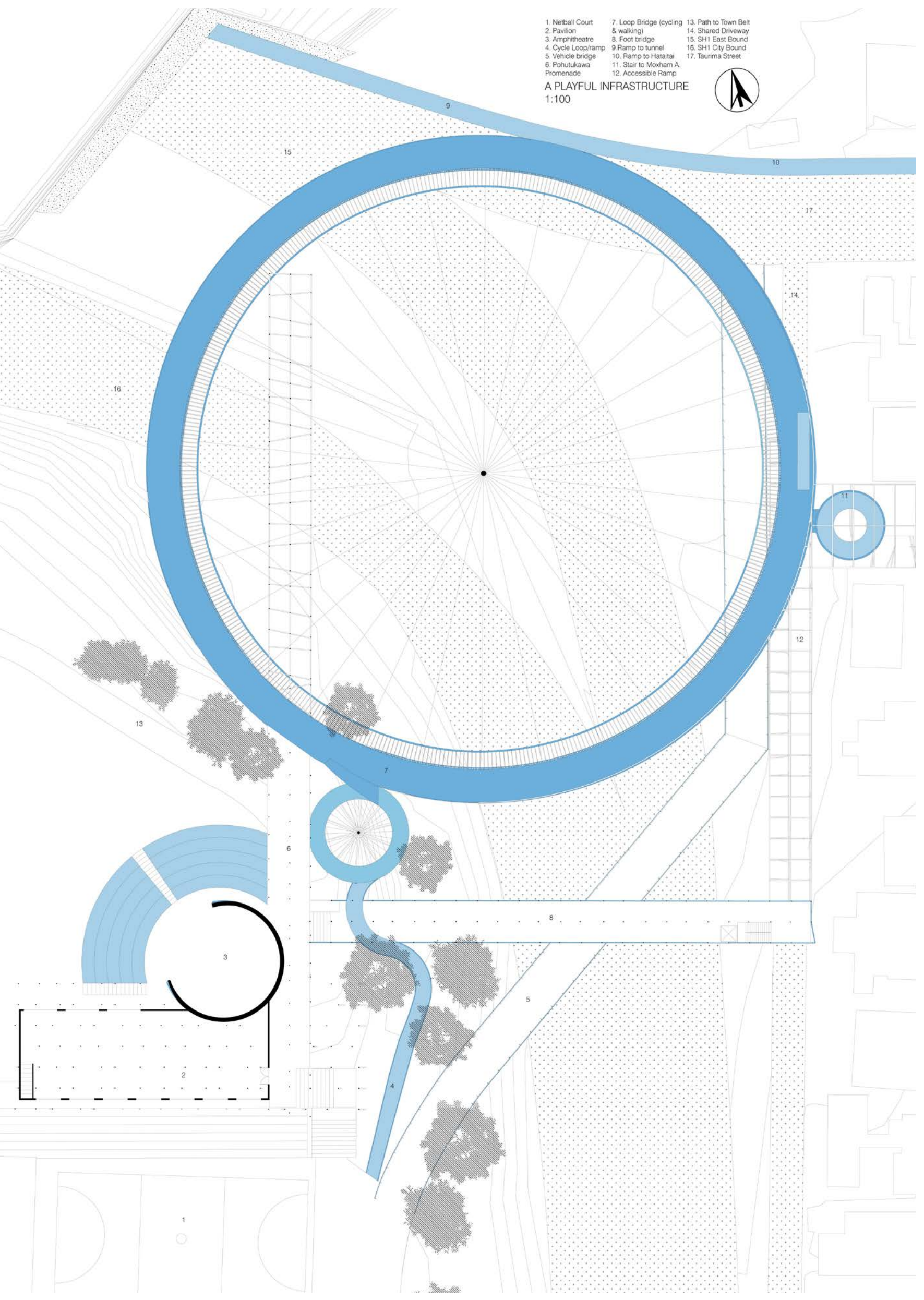




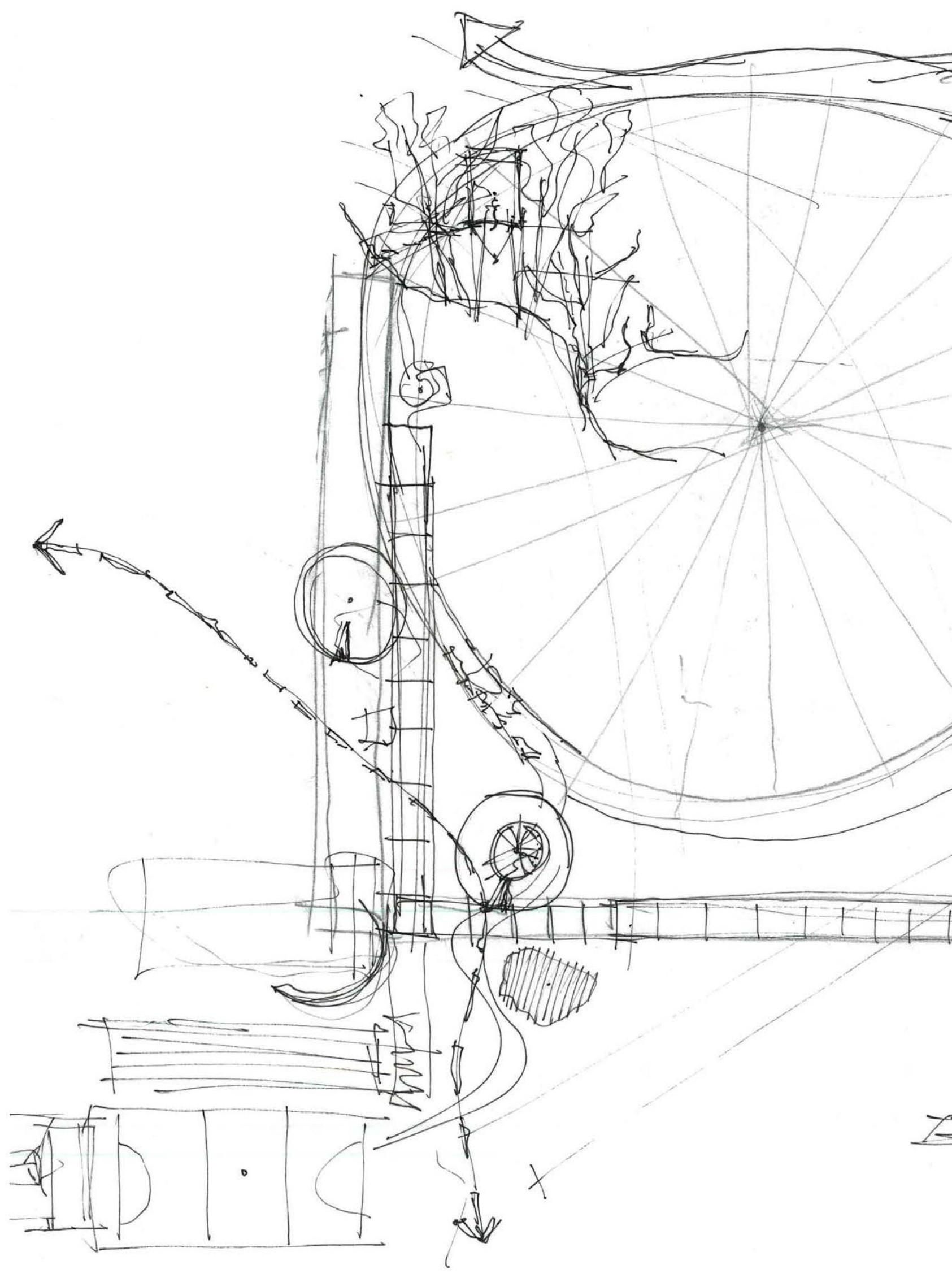

Fig 5.07 Sketchbook page from the removal of the mesh at the early stages of the experiment. 


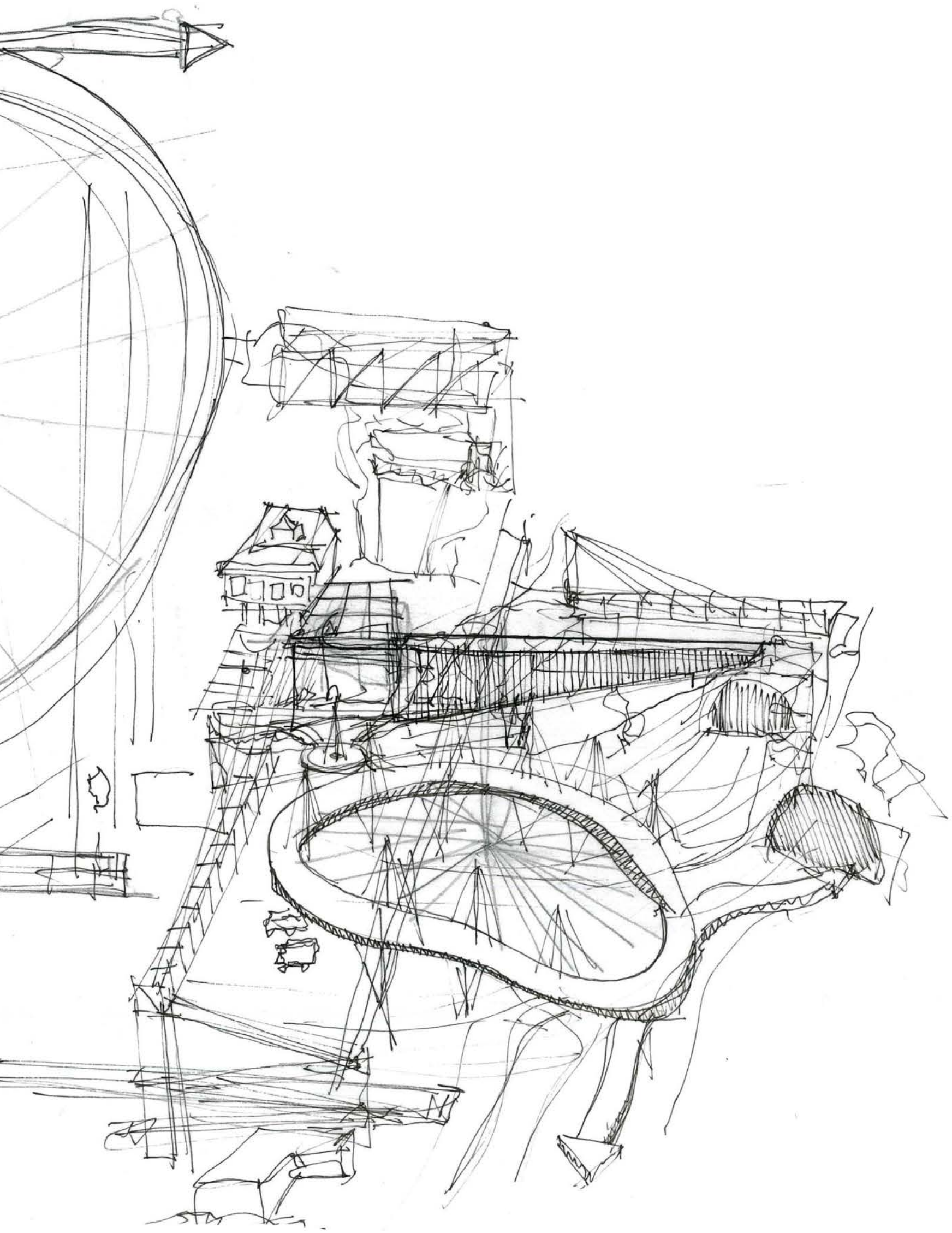




$$
\begin{aligned}
& a \\
& a \\
& a
\end{aligned}
$$


Fig 5.08 (Opposite) Diagramming the first moves of The Loop, adding new joining pathways.

Fig 5.09 (Below) An early progress model with a large pylon and continuous railing.
Upon removing the mesh, I embarked upon a series of experiments to enrich the potentials of The Loop. There was already a meandering arm joining The Loop to the park, and a similar entity emerging from the pedestrian path of the tunnel, kissing the north tangent of The Loop and threading into the village. I added two more of these playful connections- one at the eastern side to create a connection with the shared lane and Moxham Ave, and another reaching into the steep slope of the Town Belt.

The Loop's relationship to the undulating geography, road and village required 'precise and measured' modelling methods. Unlike the majority of the
Field experiments, this required categorically digital tools. This was first done in Rhino, then with Grasshopper, a parametric plug-in for Rhino.

After creating many variations of loop and curve placements, the program allowed me to apply various cross sections and objects at regular intervals to the curves. I could then manipulate the resulting geometry to test height above ground, undulation, diameters, and so on. The first tests were diagrammatic and undetailed to gauge scale. These developed into detailed models of continuous deck sections and balustrades, with rib structures, balusters, pylons at the appropriate interludes.

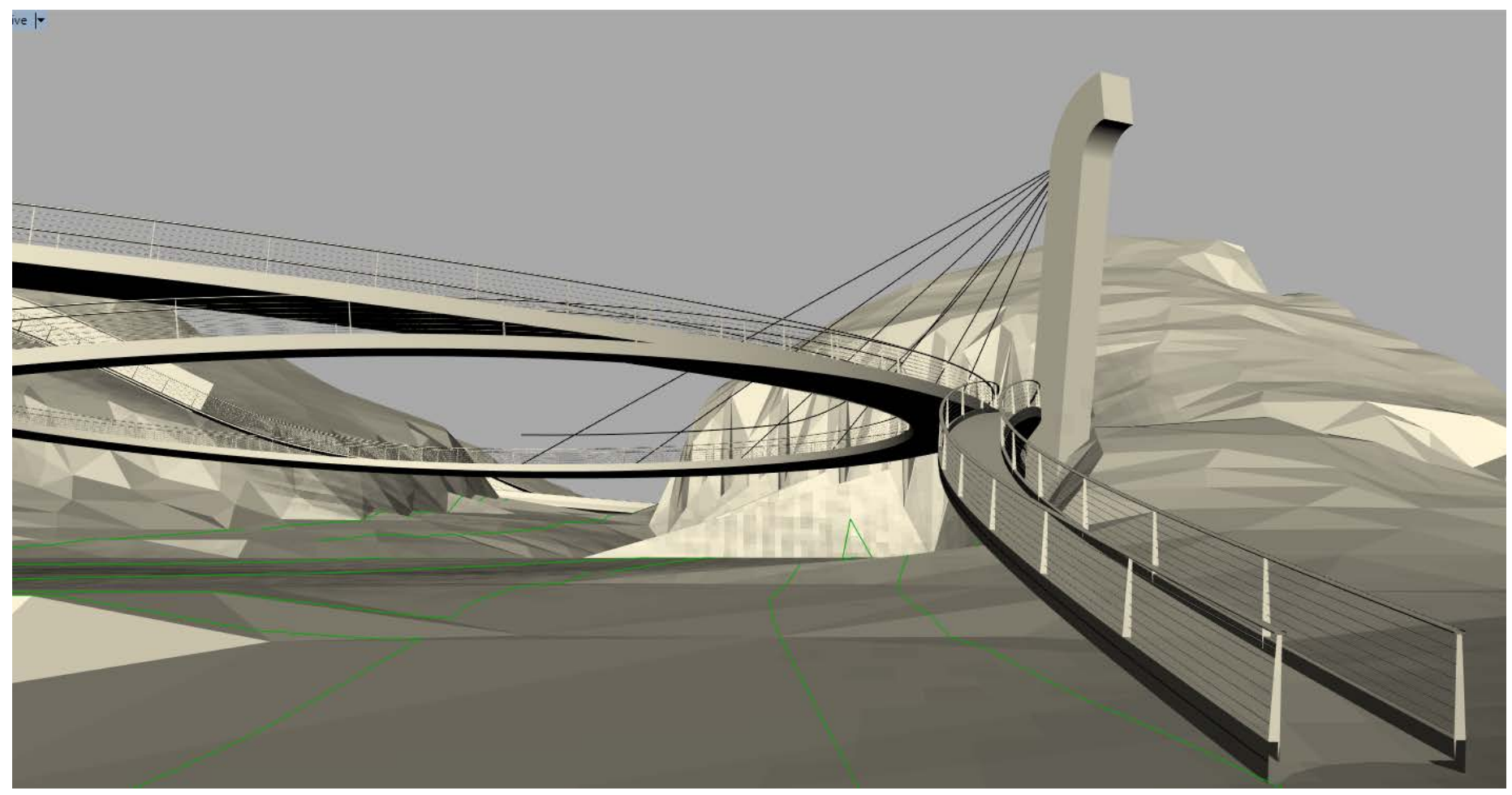



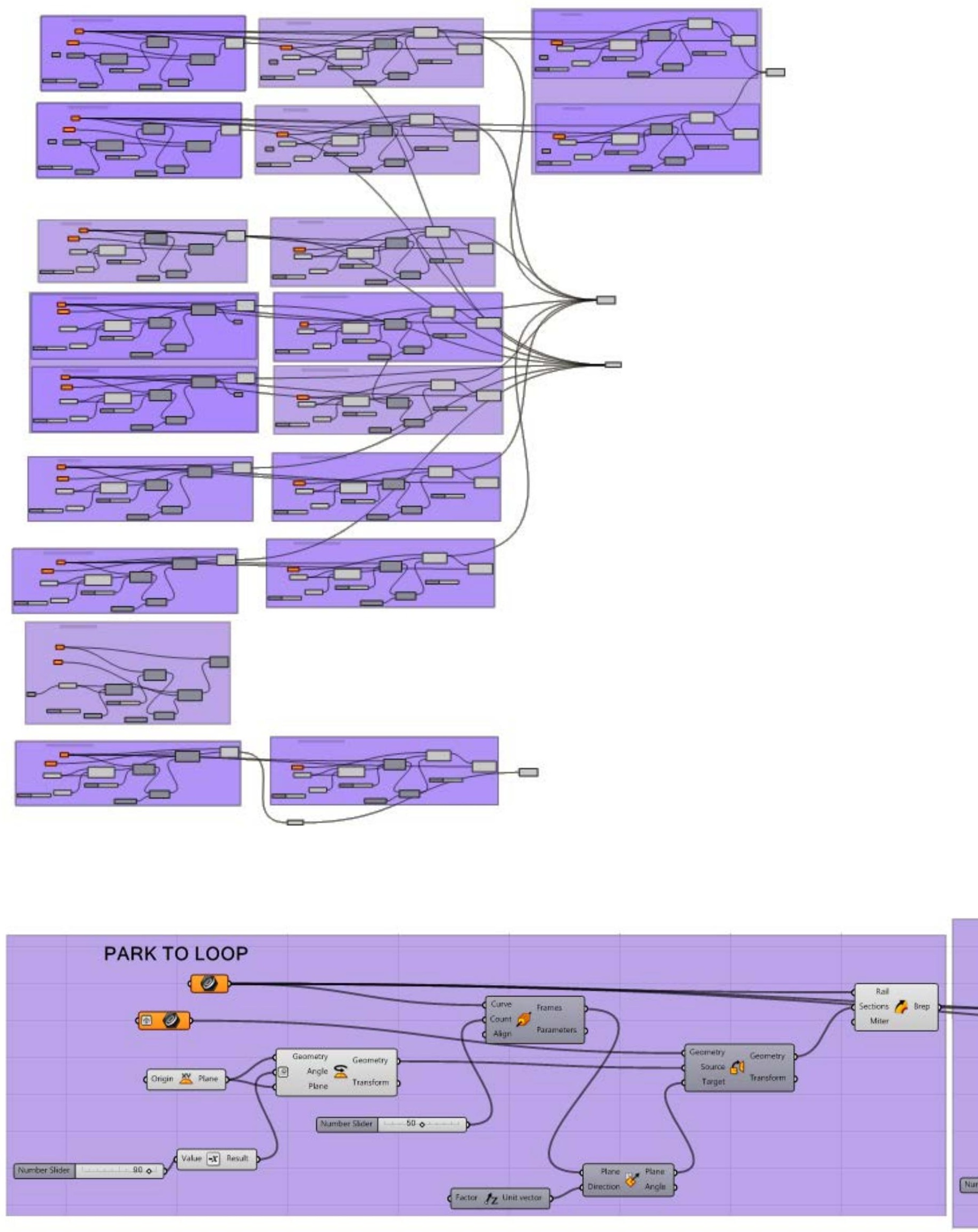


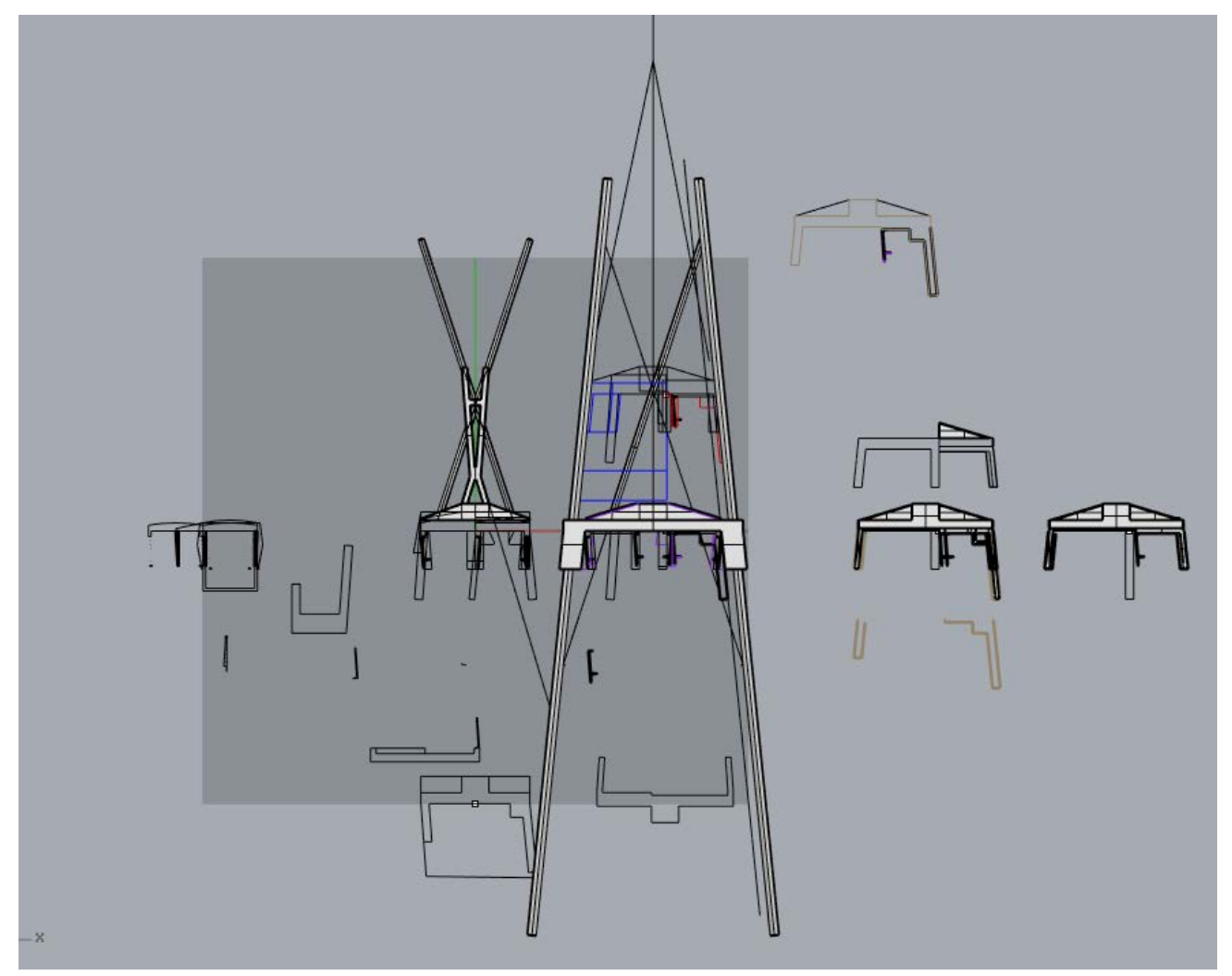

Fig 5.10 (Above) Multiple deck sections and structures to be tested in Grasshopper.

Fig 5.11 (Opposite) A Grasshopper script with many curve and object based components.

Fig 5.12 (Below) Close up of a script with a curve based component (left) and an object based component (right).

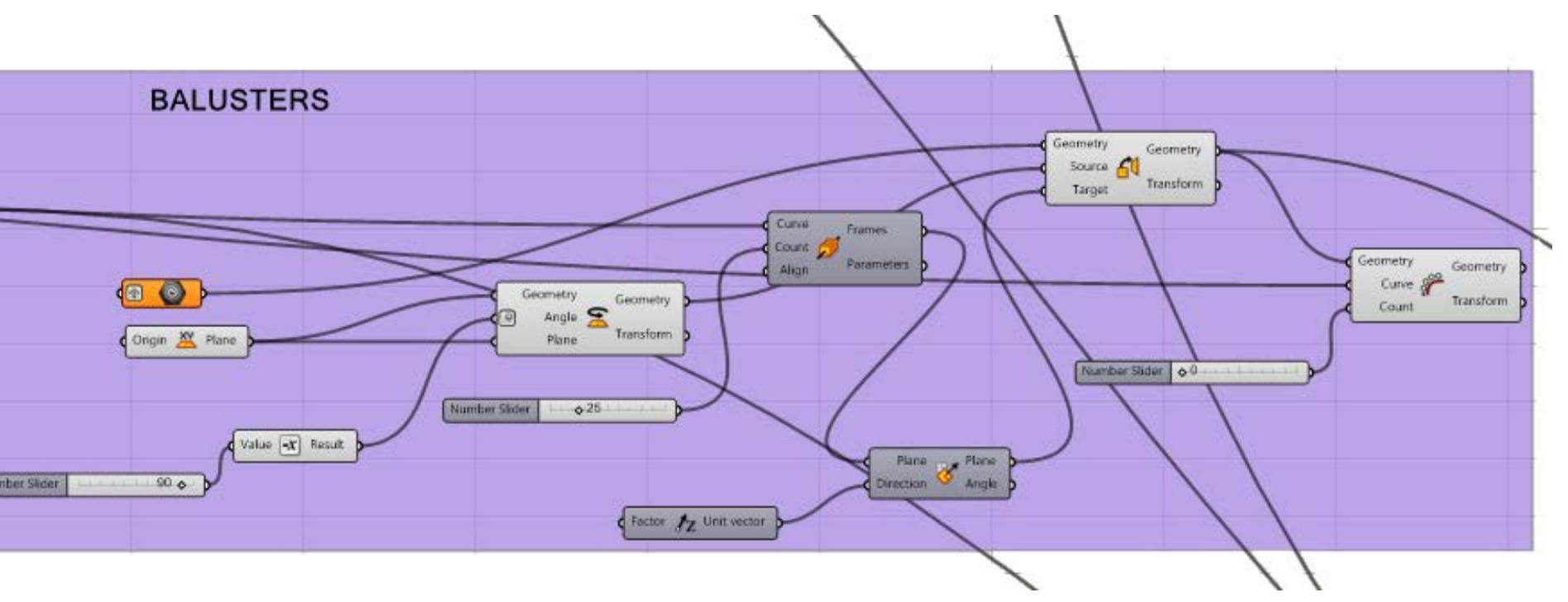




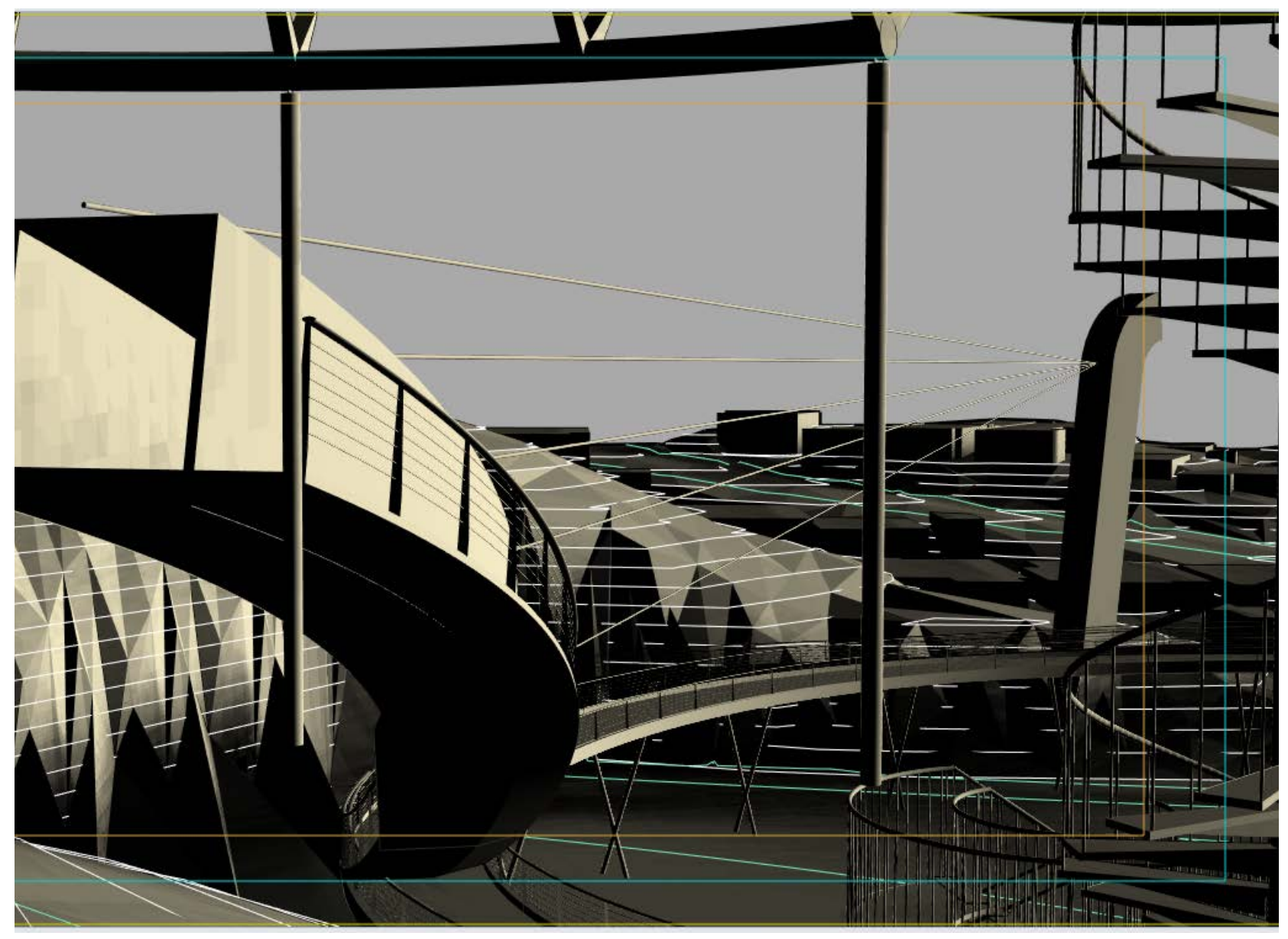

Fig 5.13 Digital progress model testing a steep bike ramp. 


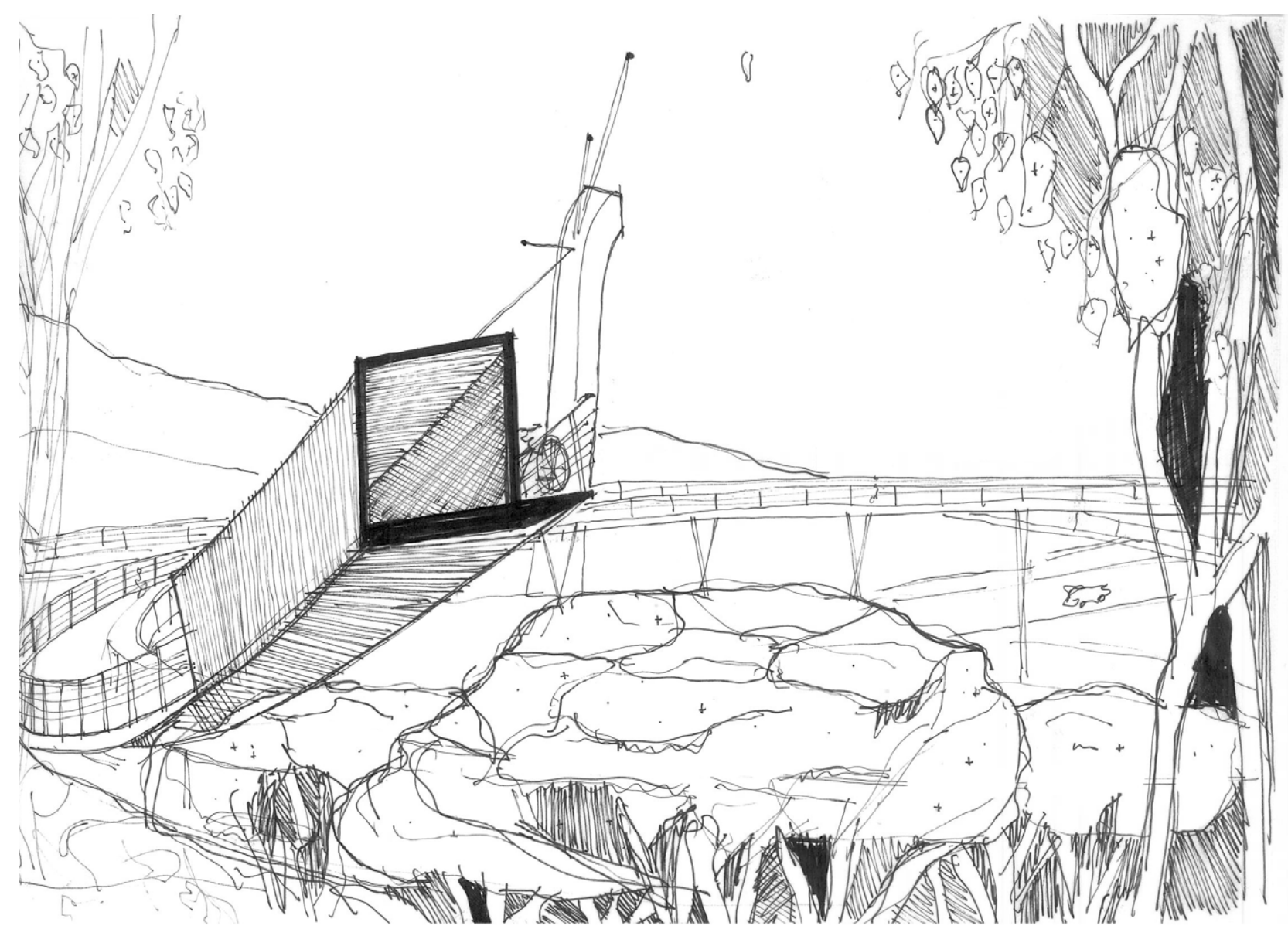

Fig 5.14 Sketch of the same model. 
Fig 5.15 Wellington's City to Sea Bridge provides a rare 'strange' moment in the city. The sculptures adorning the bridge combine art, mythology and narrative but are intrinsically alluring in themselves. 


\section{FRIVOLOUS INFRASTRUCTURE}

I used this precise, digital method

to answer a question requiring a rational response - how can we bridge the highway and connect three isolated territories? The second element to this experiment derives from a more informal pursuit - how can we inject strange, unique, and enjoyable moments into the urban fabric?

In Chapter 2, I alluded to the importance of play in society, with theories like Homo Ludens. Playful moments are rare in the city fabric, and almost non-existing in infrastructure design. This is mostly justifiable for the latter category roads and highways are dedicated to efficiency and instrumentality.
But where is the infrastructure dedicated to strange moments and non-essential activities? I resumed 'fast and loose' processes to develop informal, whimsical structures like the lilipad from the Field experiment. Like in said experiment, these structures aimed to integrate themselves into the landscape. Small moments like trees on the hillside.

An early experiment focused on the area behind the netball court in the Town Belt. I experimented with a programmed pavilion, sunken into the landscape, with changing rooms and kiosks. A pathway adorned with sculptural platforms provided strange and unique moments.

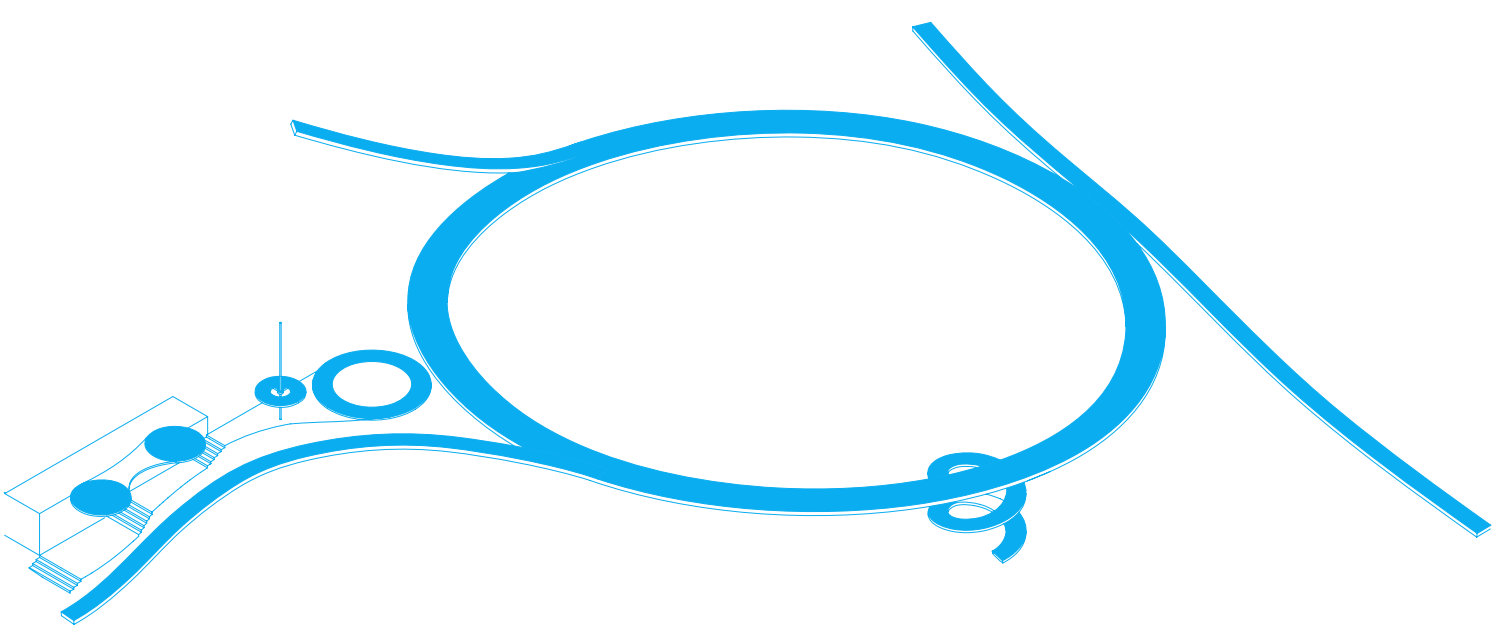

Fig 5.16 Diagram of the dense pavilion and promenade based scheme. 

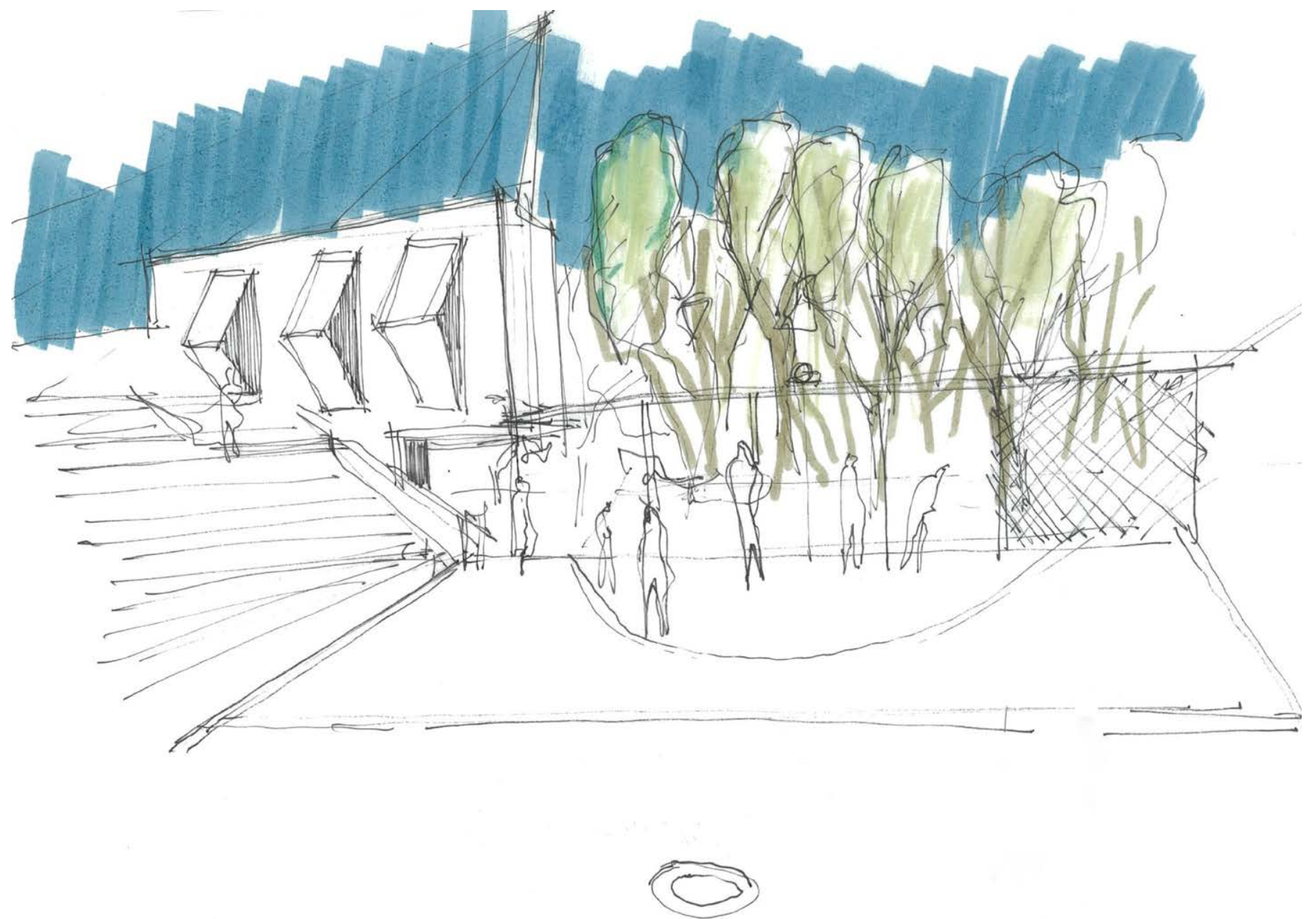

Fig 5.17 A sports-oriented pavilion for netball court users and visitors. 


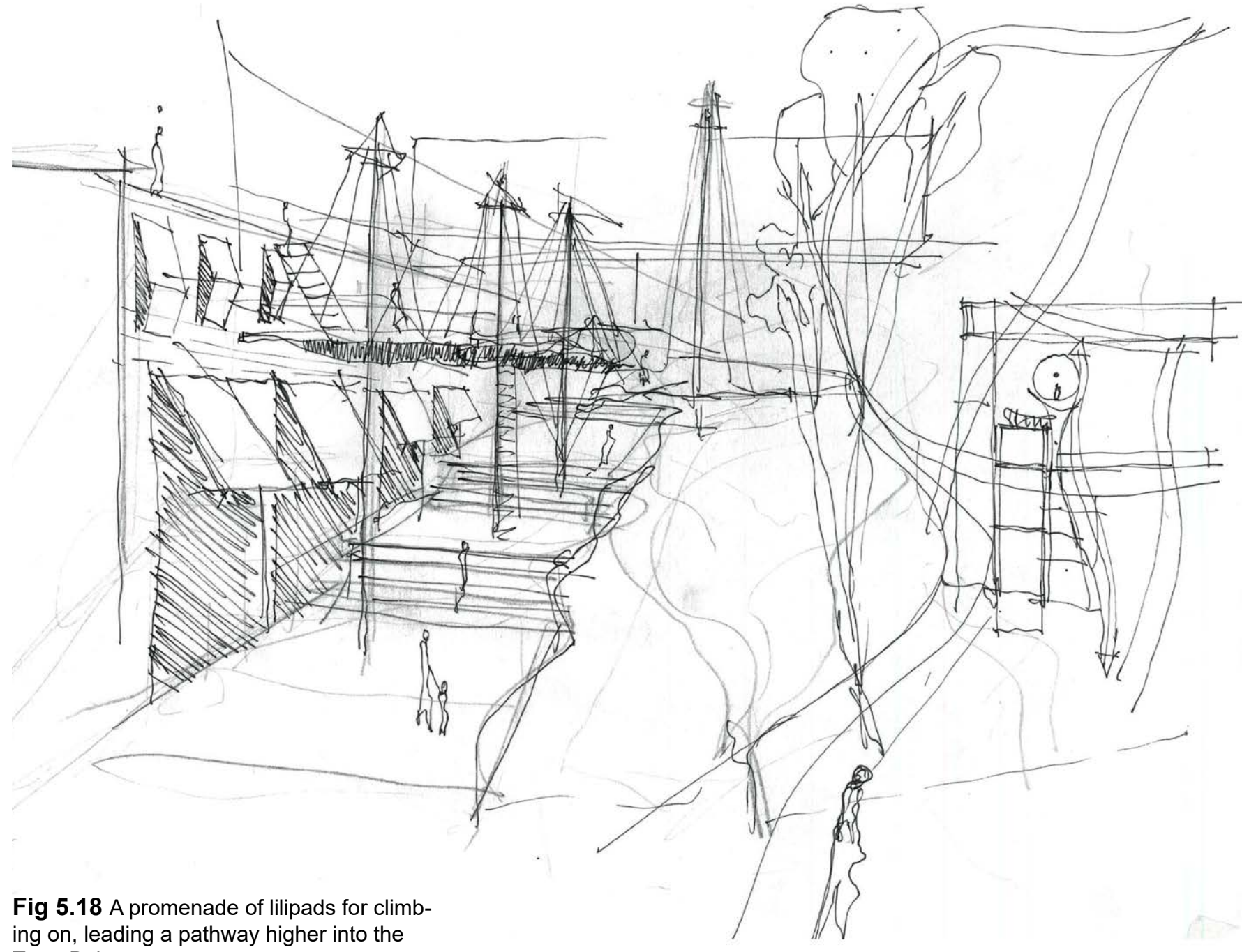
ing on, leading a pathway higher into the Town Belt. 


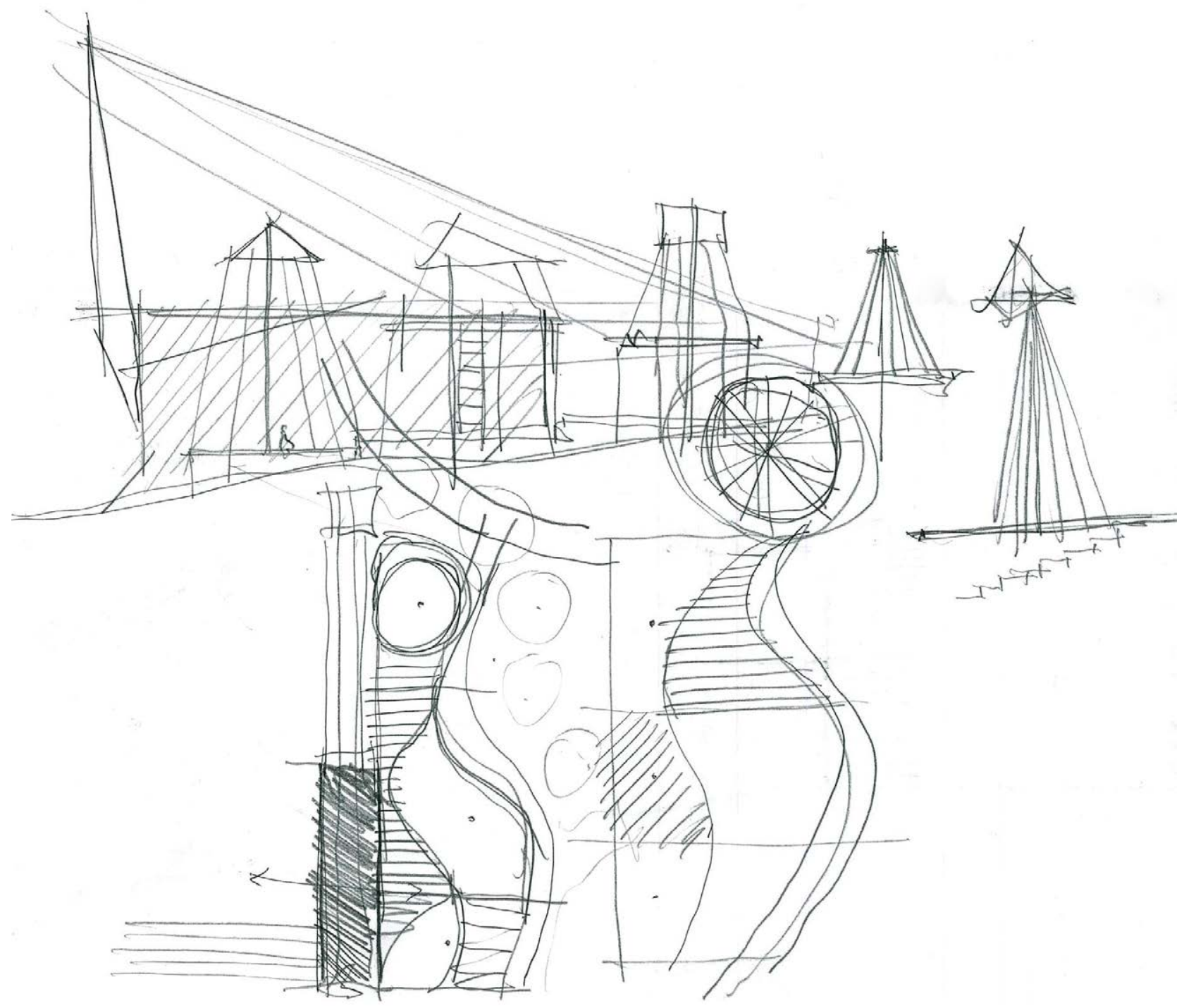

Fig 5.19 Developing the dense prome-

nade and pavilion on the shoulder of the Town Belt. 


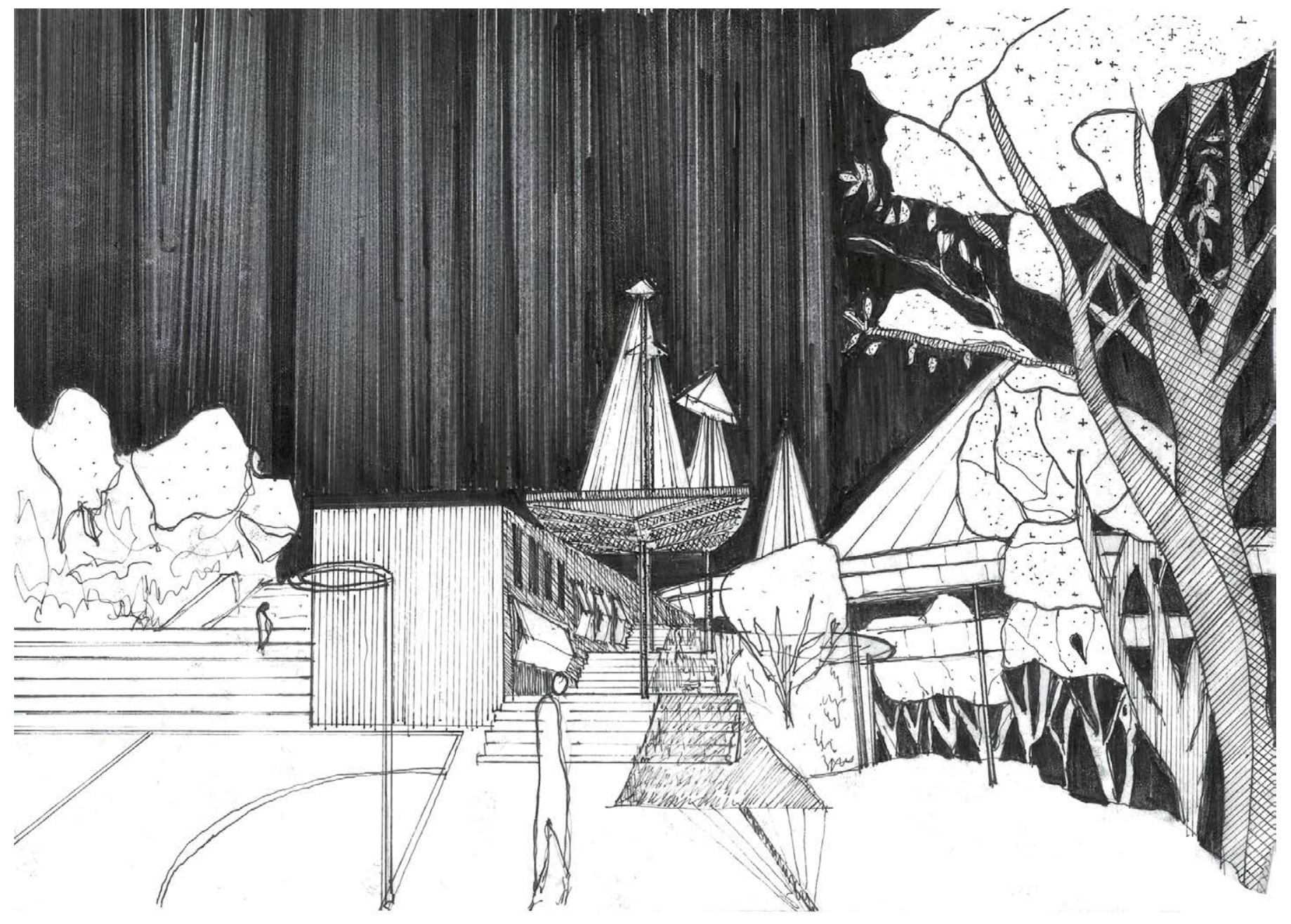

Fig 5.20 Perspective sketch of pavilion and promenade. 

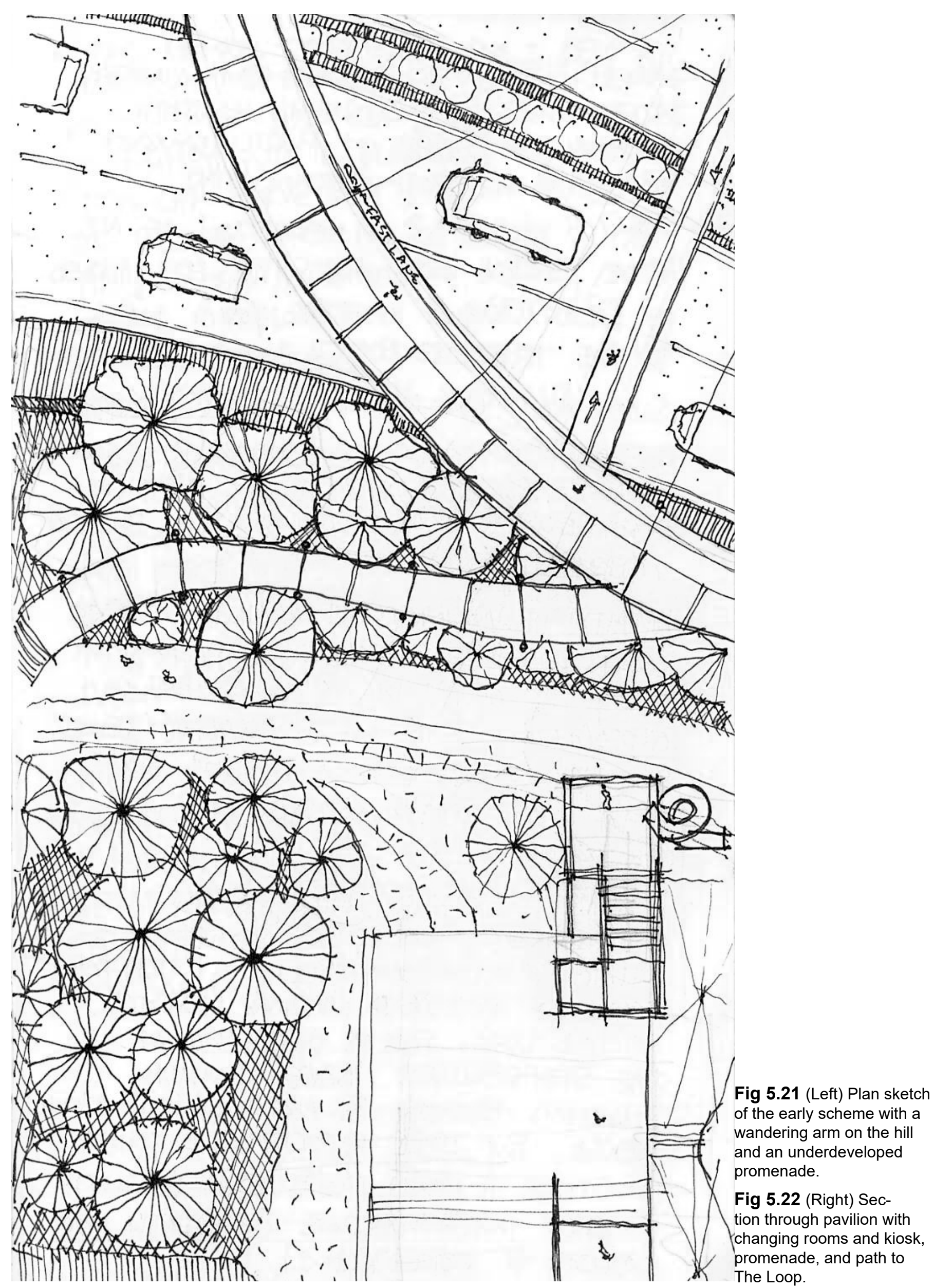


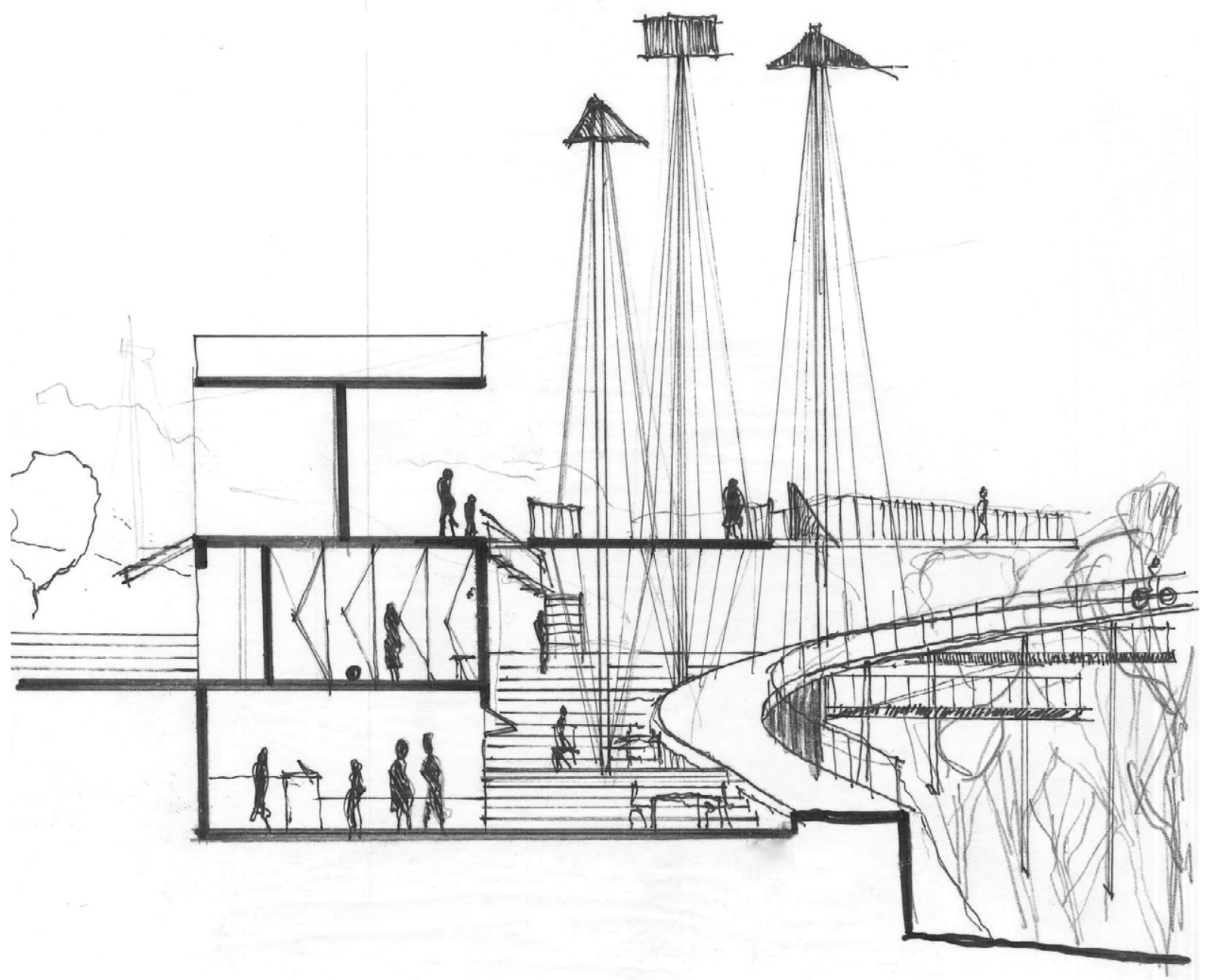




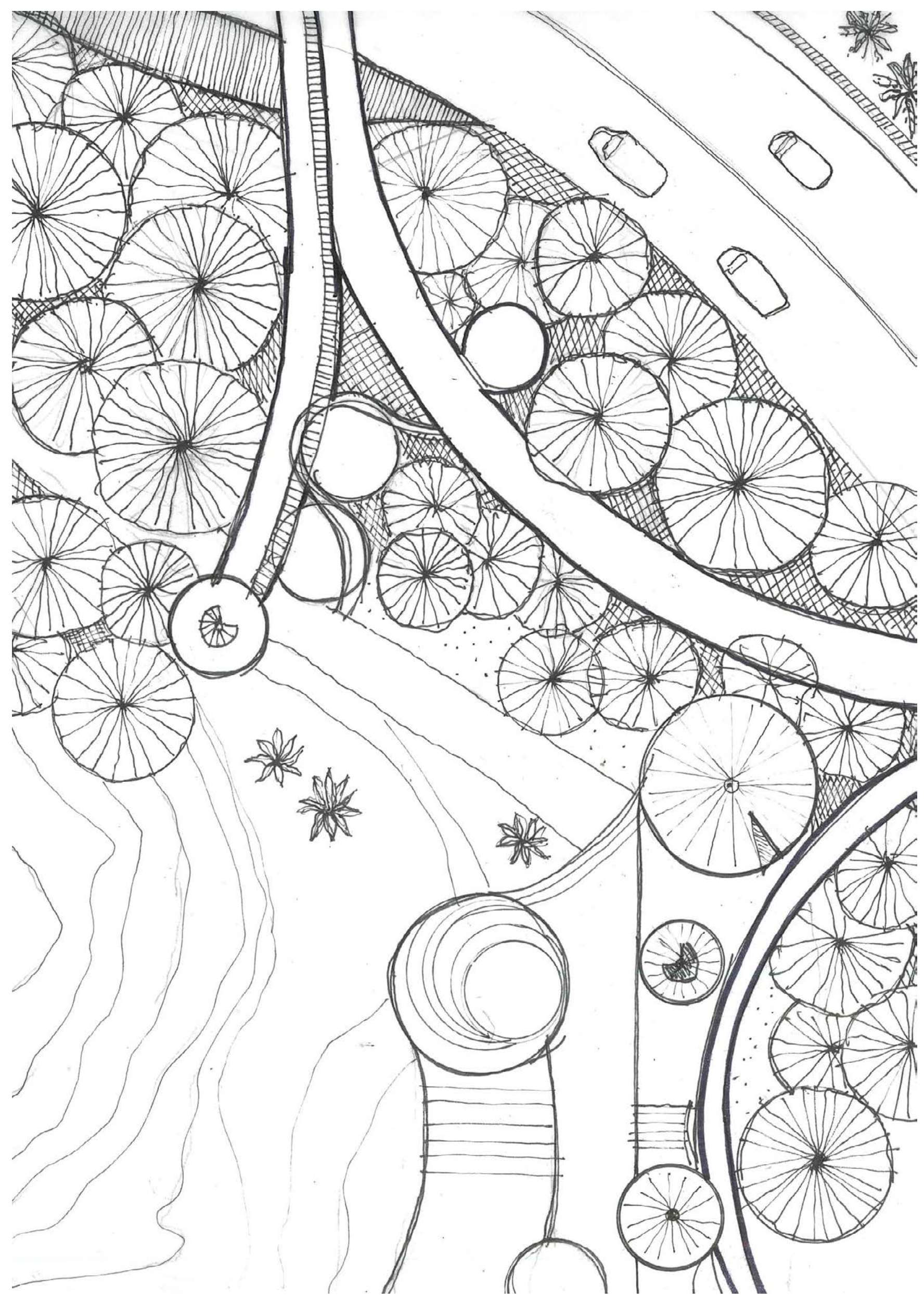




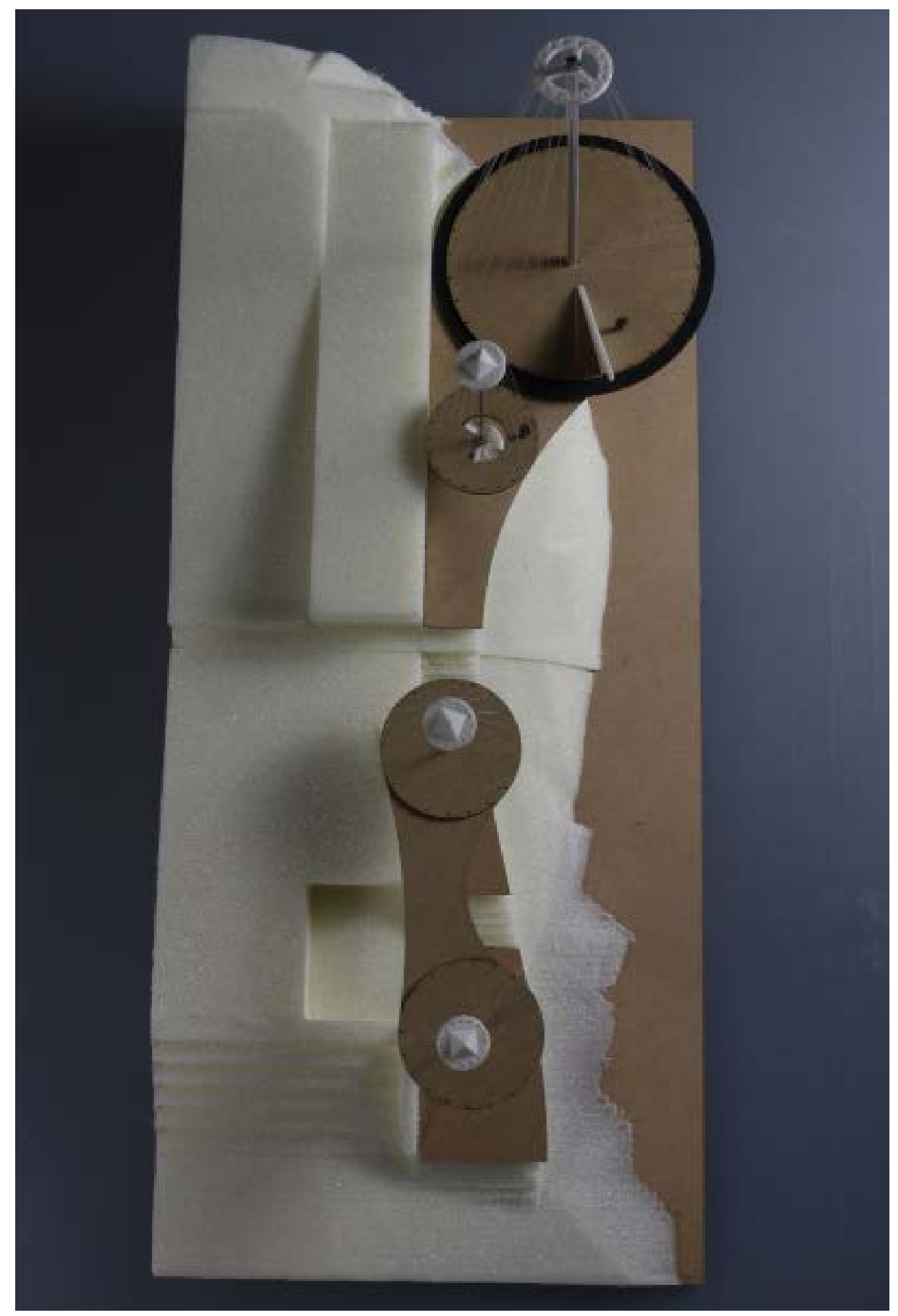

Fig 5.23 (Opposite) Plan sketch developing promenade and arms.

Fig 5.24 (Above) Promenade model. The CNC machining made space for a pavilion to be inserted into but this was later removed. 


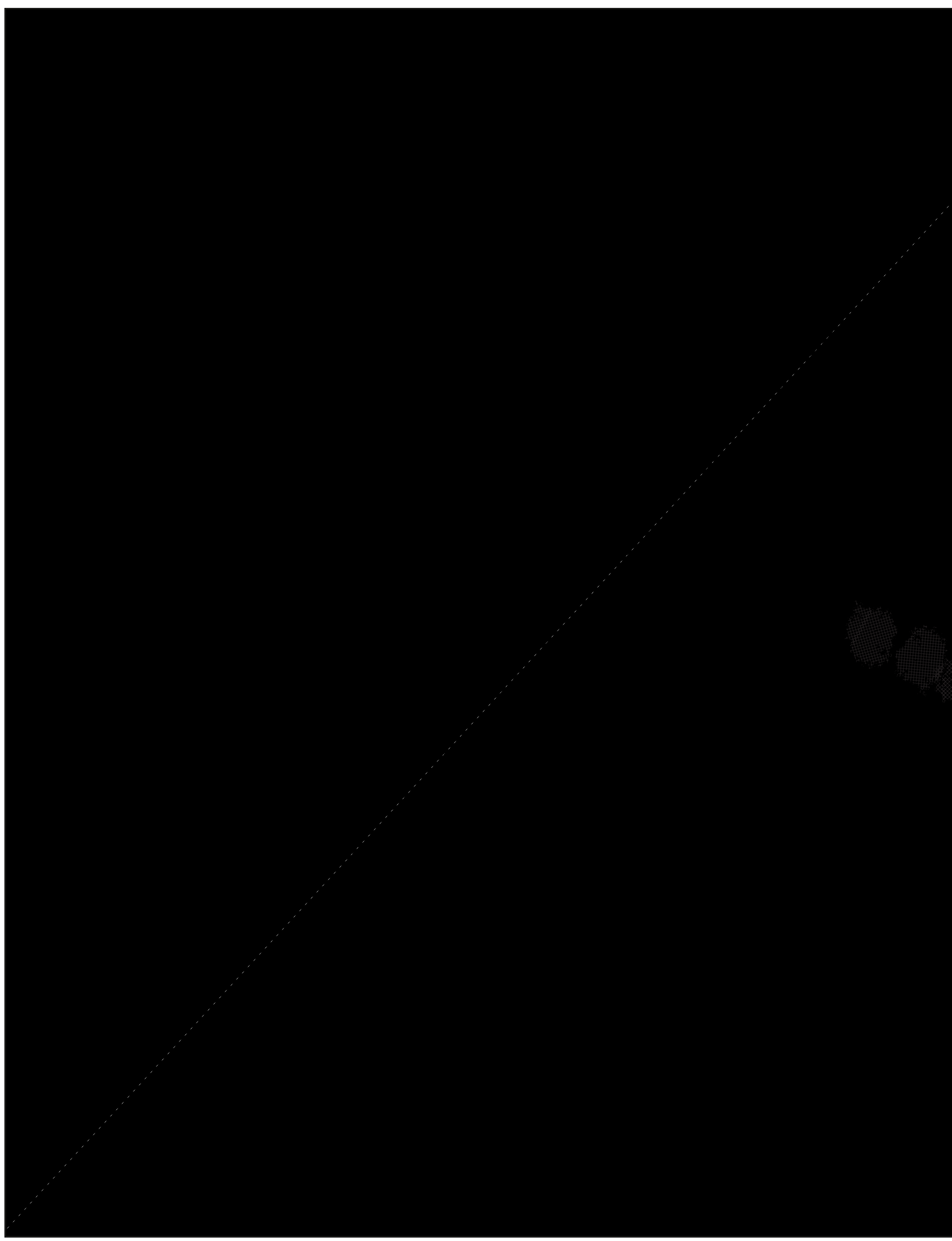

Fig 5.25 Promenade and pavilion based design.

136 


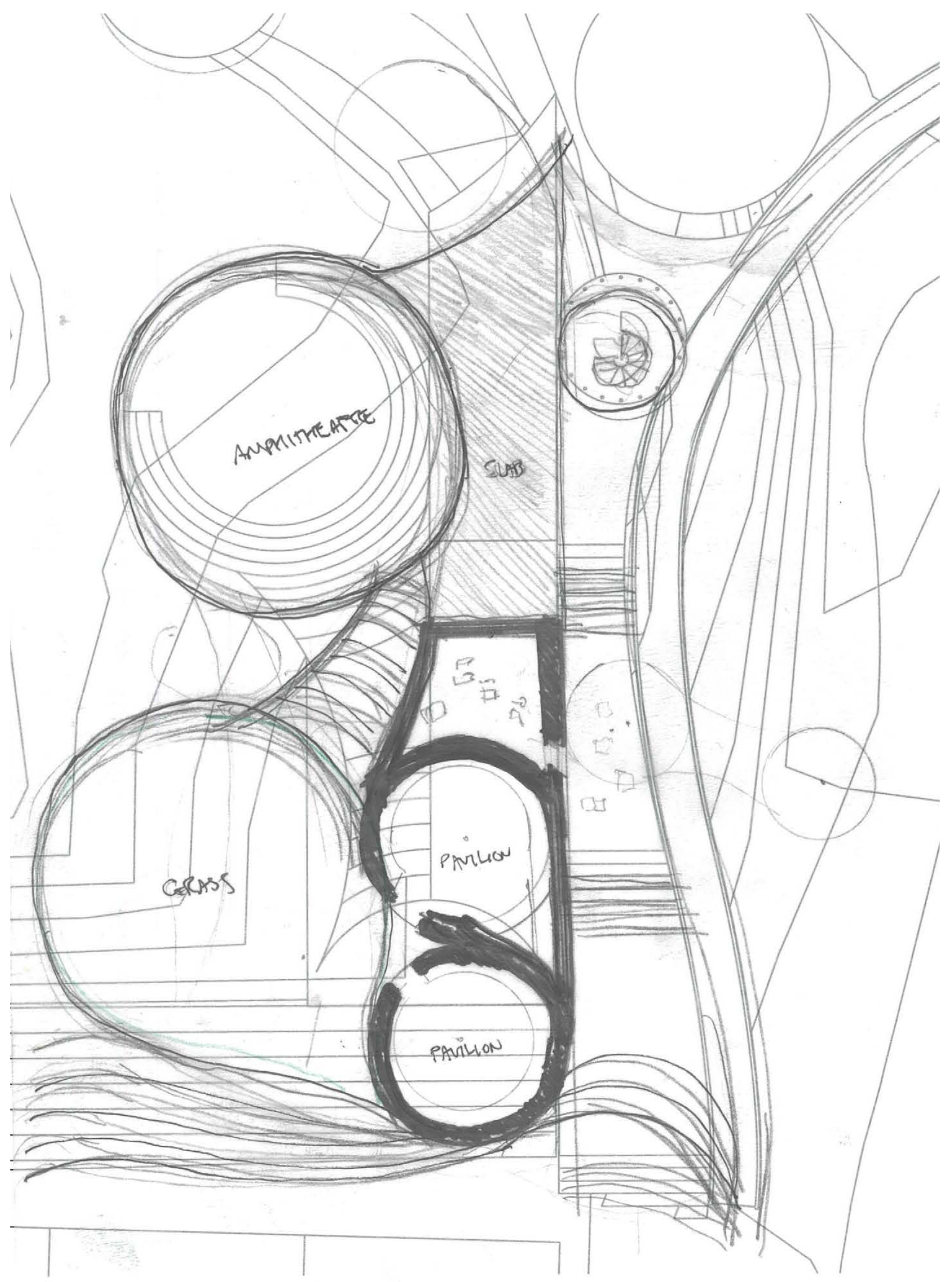


Fig 5.26 (Opposite) Planning the circular pavilions. This was the final attempt at densifying the area.

Fig 5.27 (Below) Diagrams of shift from orthogonal to circular pavilions.
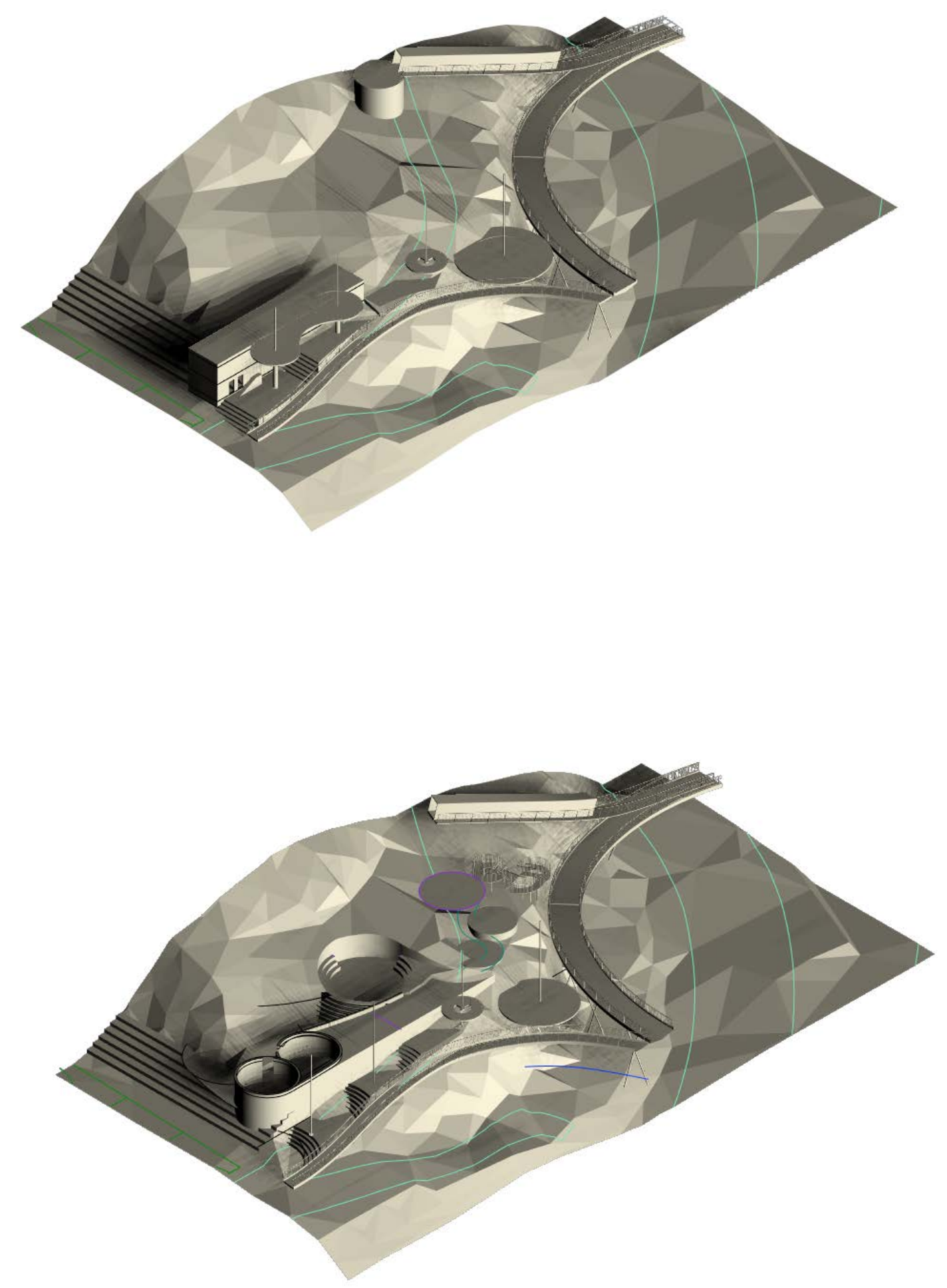
Fig 5.28 Buskenblaserstraat, one of van Eyck's 734 interstitial Amsterdam playgrounds,

c. 1956. 


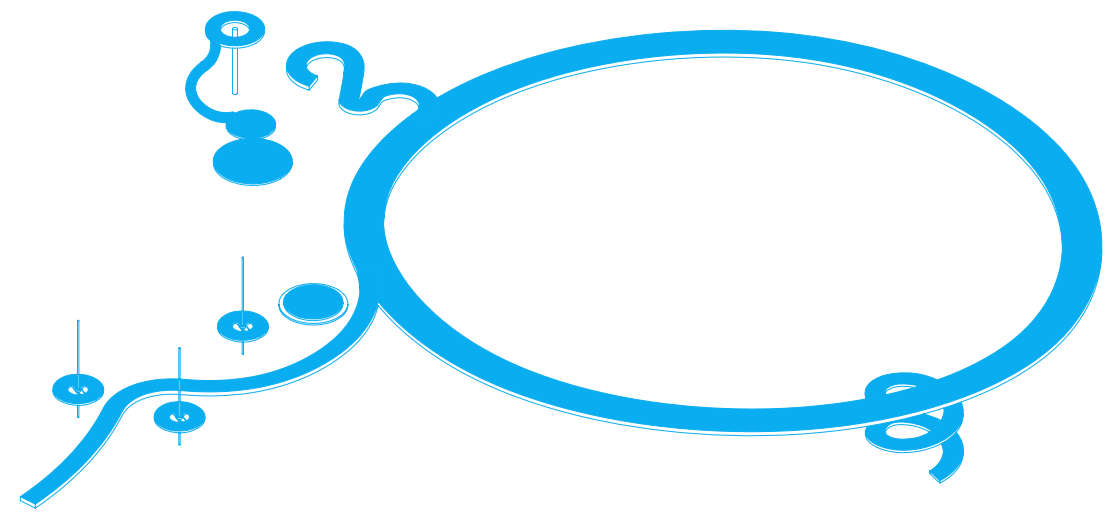

The pavilion came and went. I removed the orthogonal block and distributed more of the circular forms among the site. I removed density from the space around the superseded pavilion, allowing the existing natural settings to take over. This was inspired by Aldo van Eyck's approach to urban design, which favoured small, site-specific interventions over large scale planning. His humble Amsterdam playgrounds are 'not placed on a piece of land cleared for that purpose but inserted in interstices within the living urban fabric' (Lefaivre 2007). This approach exemplifies the possibility of revealing moments or islands within the existing fabric of the quotidian city. It opposes largescale intervention, like fabricating a pseudo field. It also echoes Ungers' ethos that the concept of the city as an archipelago (of unique moments) needs only to be revealed as its latent existence (Ungers and Koolhaas 1977). 


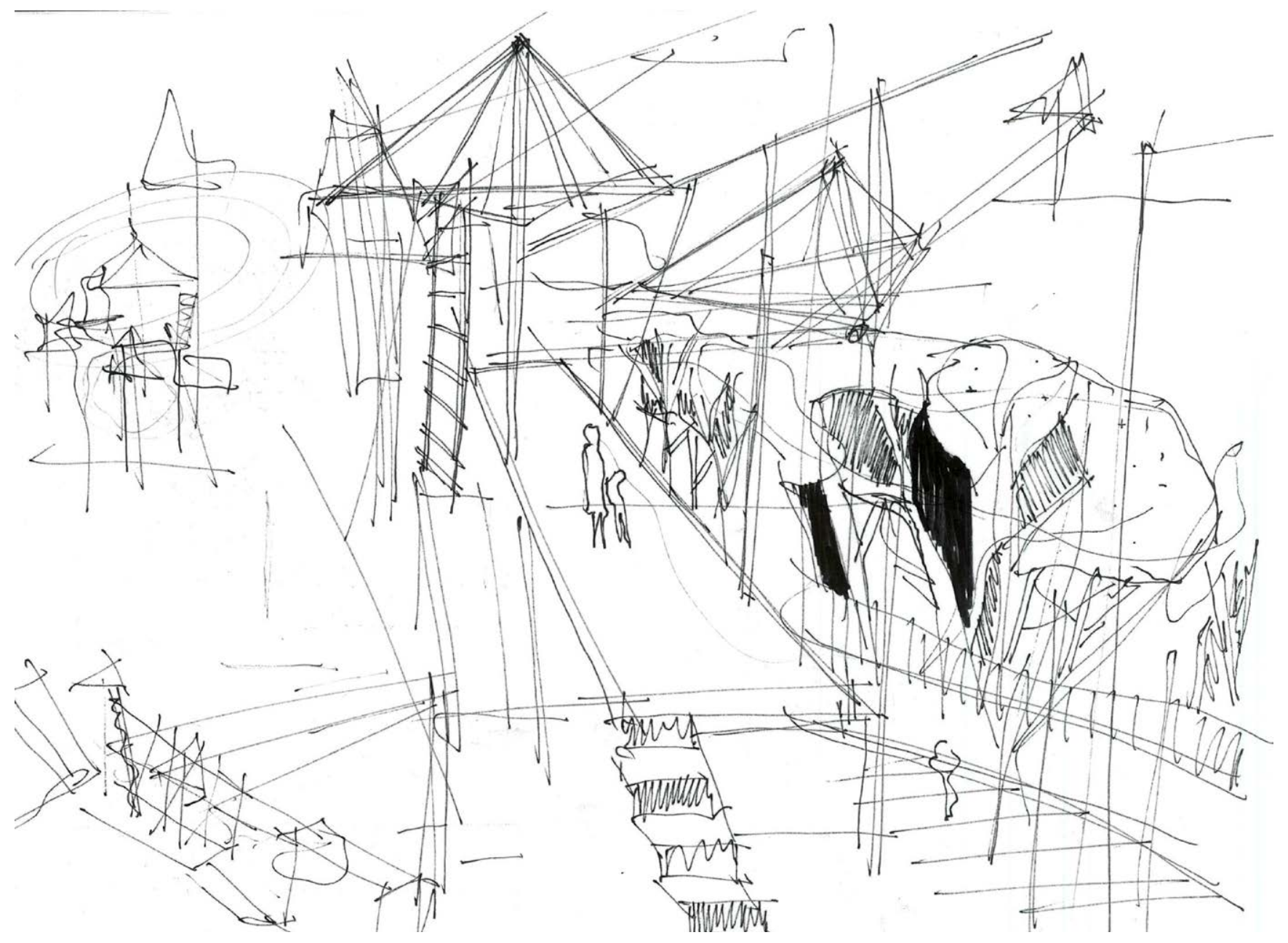

Fig 5.30 Loose sketch removing density from the promenade area. 


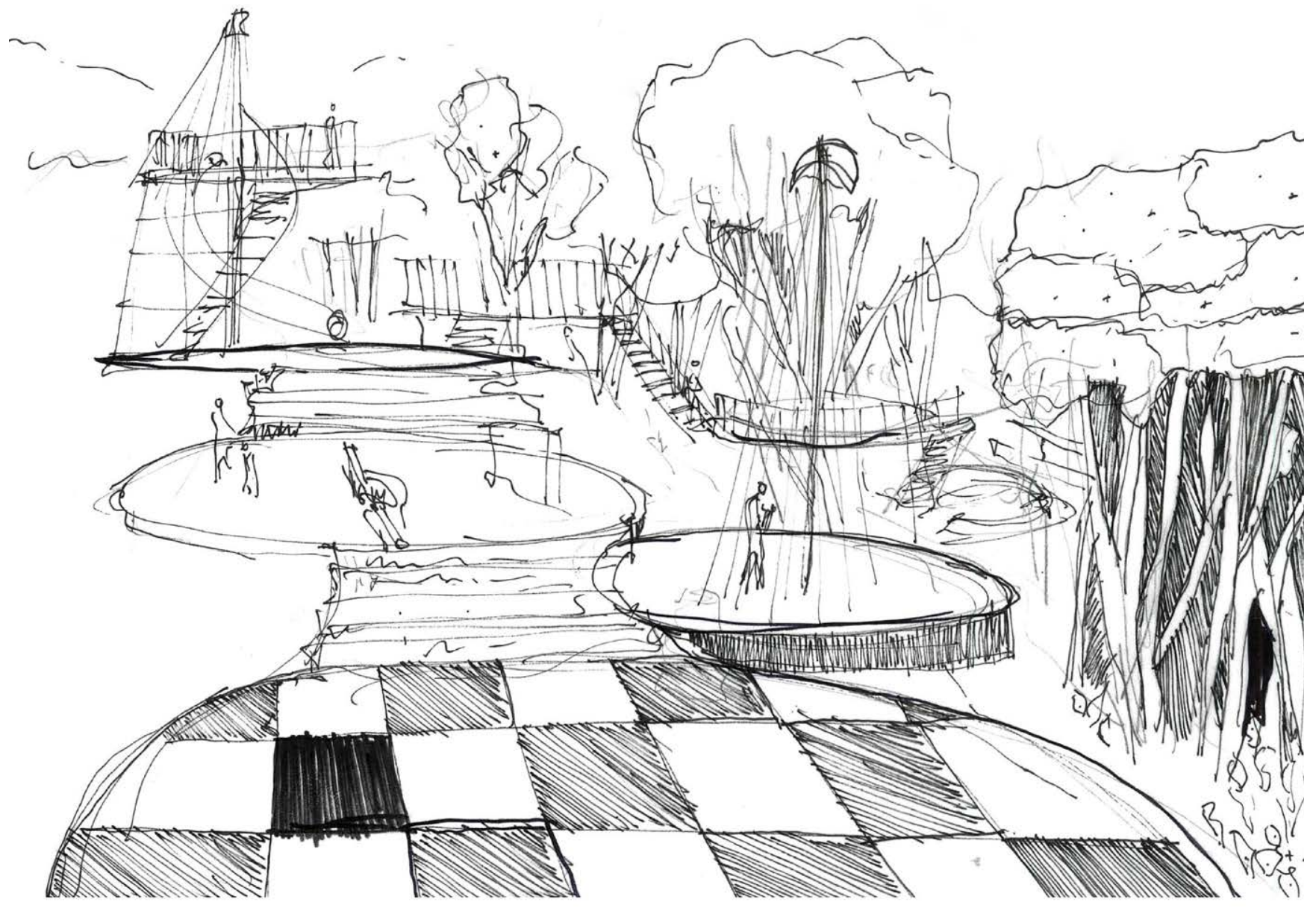

Fig 5.31 A playground in the Town Belt facilitating a pathway into the hill as well as informal spaces. 


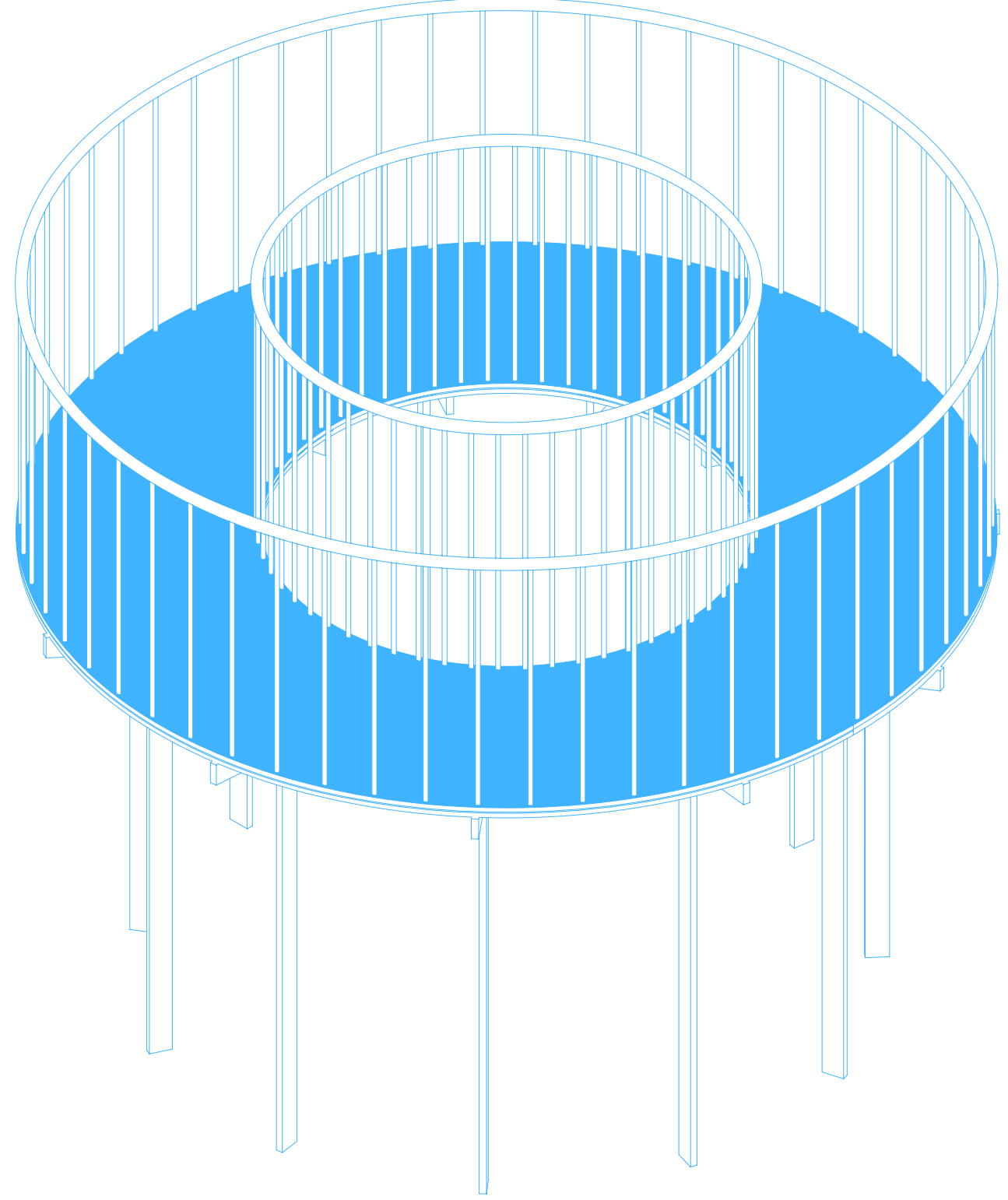

Fig 5.32 Circular platform.

Fig 5.33 (Opposite) Section of a circular platform. Central voids could allow these kinds of structures to sit on the hillside around tree trunks and create pathways and playful platforms. 


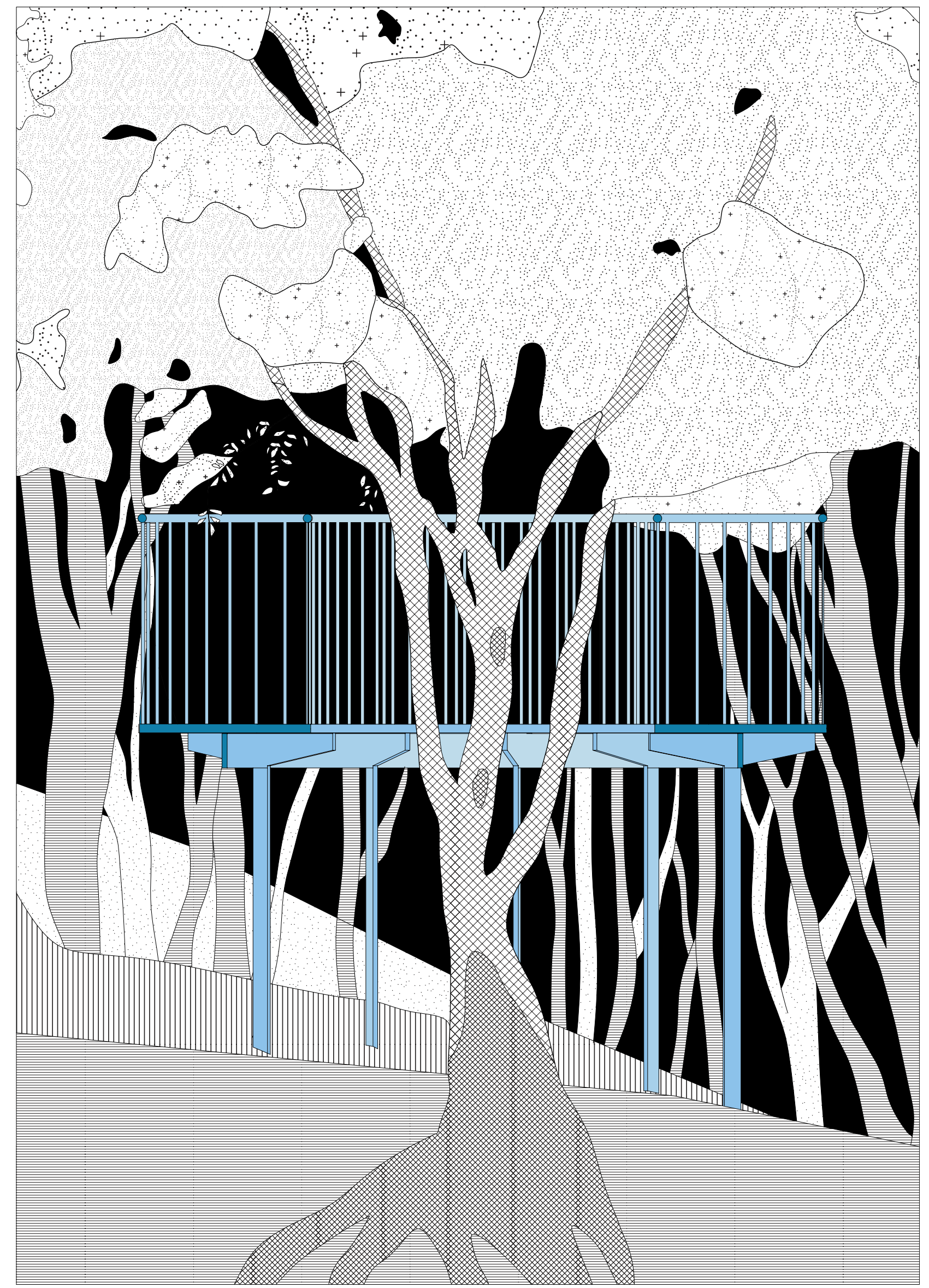




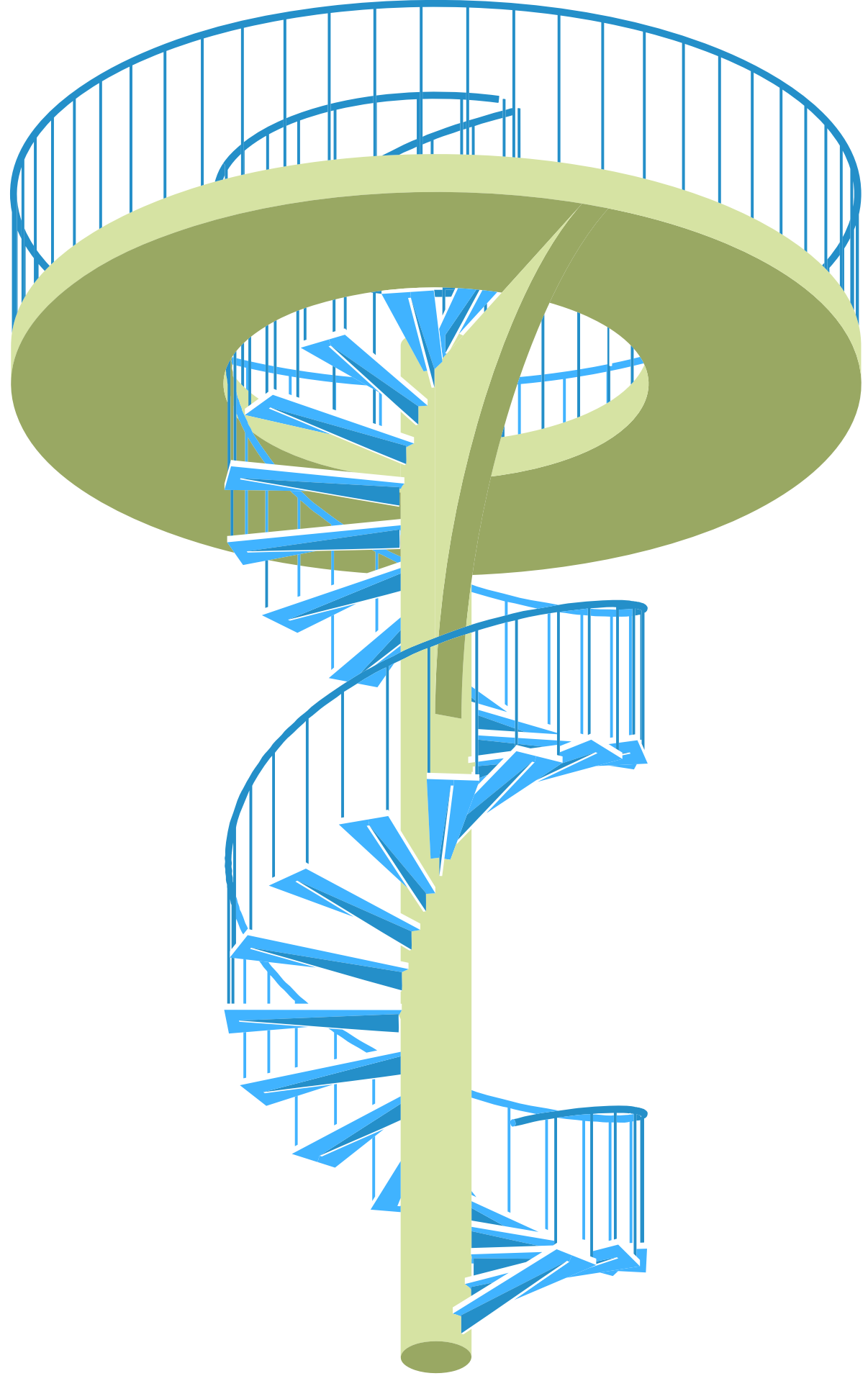

Fig 5.34 Worms-eye digital diagram of a spiral stair platform. 


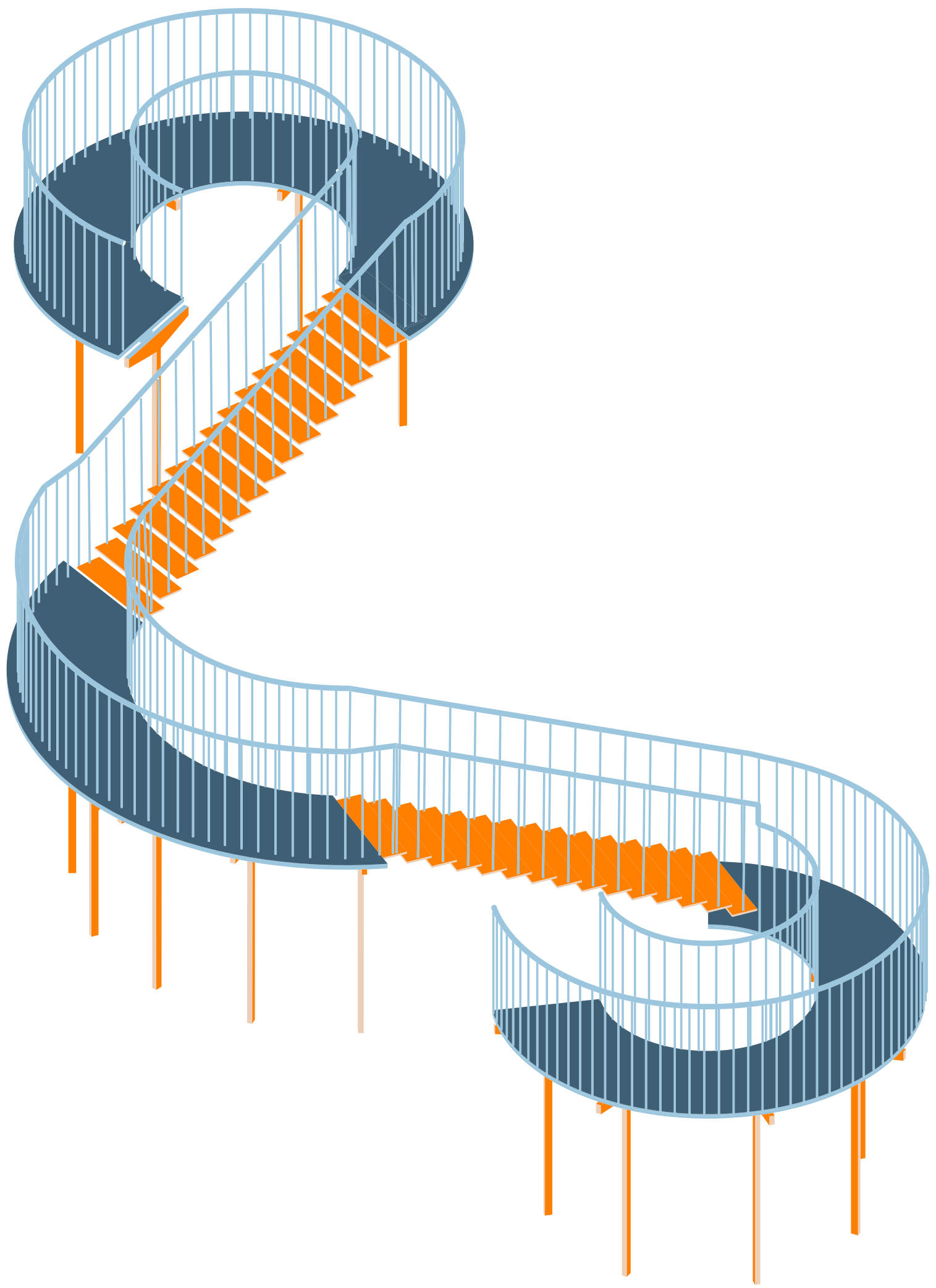

Fig 5.35 Developing one of the meandering arms linking The Loop to the upper shoulder of the Town Belt. 


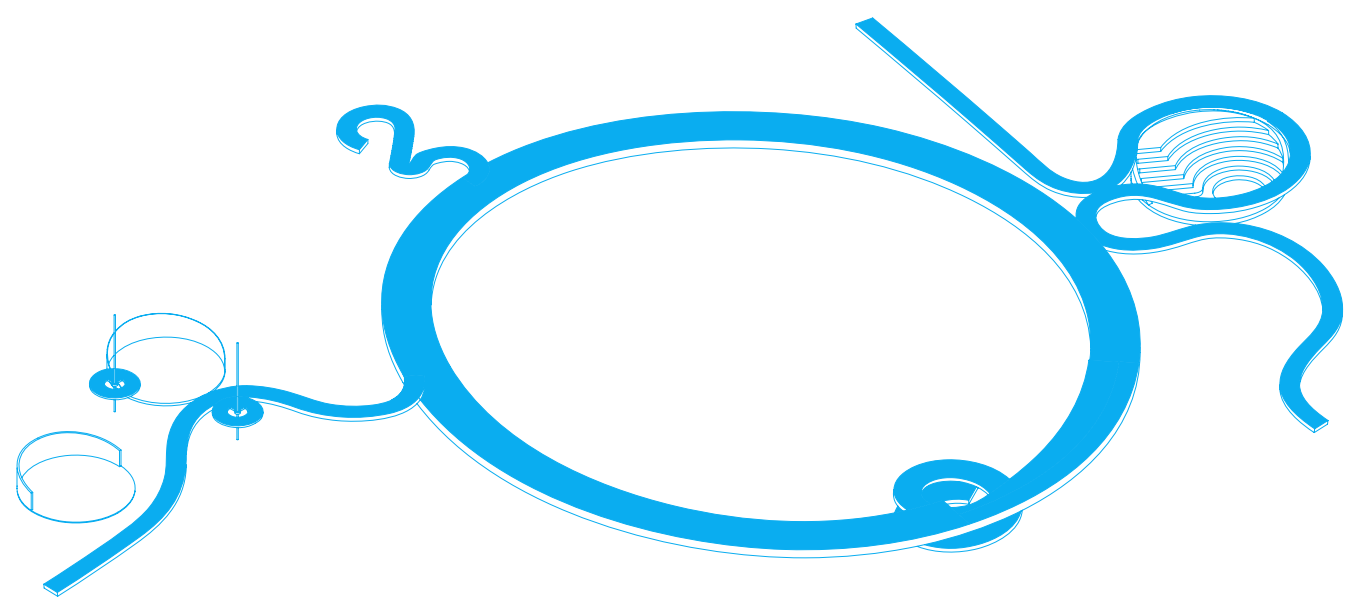

Fig 5.36 (Above) Diagram of major shifts.

Fig 5.37 (Below) Wonderland, a fantasy landscape composed of tangible everyday features.

Four meandering arms developed in parallel with the informal peripheral spaces. Their placements shifted iteratively to integrate with the landscape and to compliment the play spaces around them.

Two large retaining walls became prominent features in the Town Belt node, alongside the lilipads.
These strange and whimsical objects, the 'garden pavilions,' aim to create an atmosphere reminiscent of a fantasy landscape (Fig 5.37). A little moment in Hataitai that is at once utterly connected to, yet completely isolated from the reality of the surrounding city. 

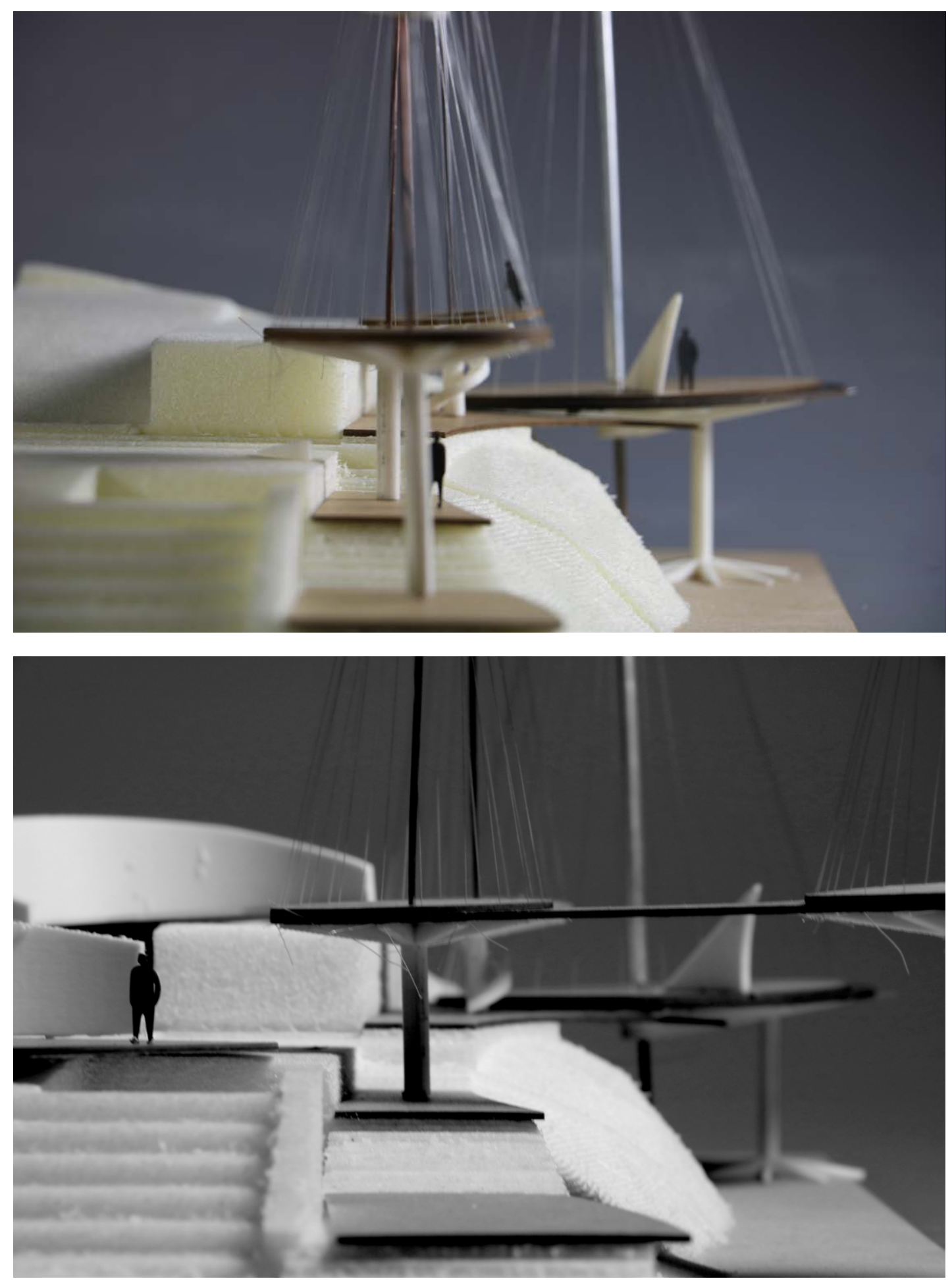

Fig 5.38 -

Fig 5.39 I removed the square pavilion and placed more circular objects there instead. Two large 3D printed retaining walls become prominent features in this model.

Fig 5.40 (Following spread) Graphic sketch of model scene. 


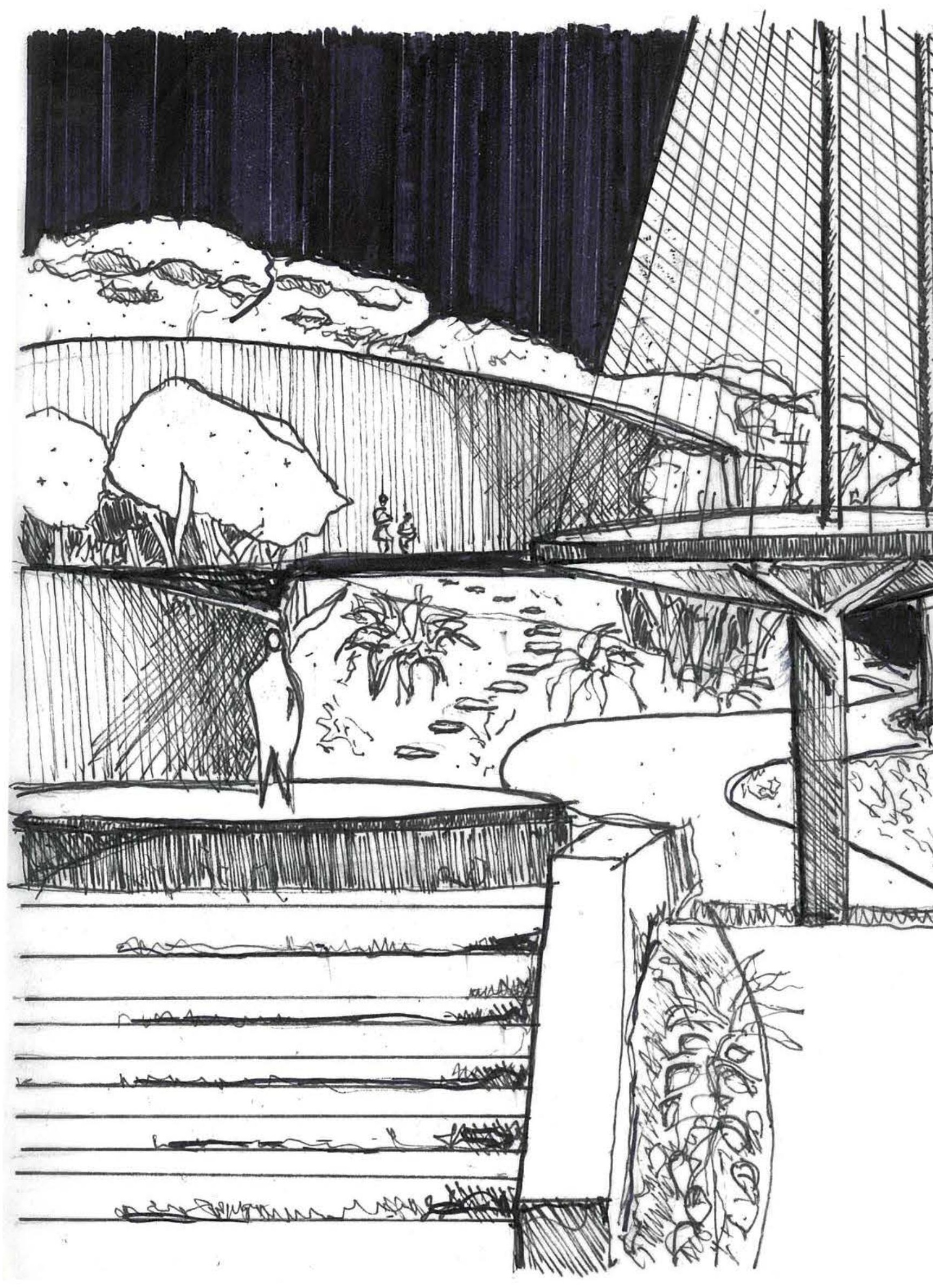




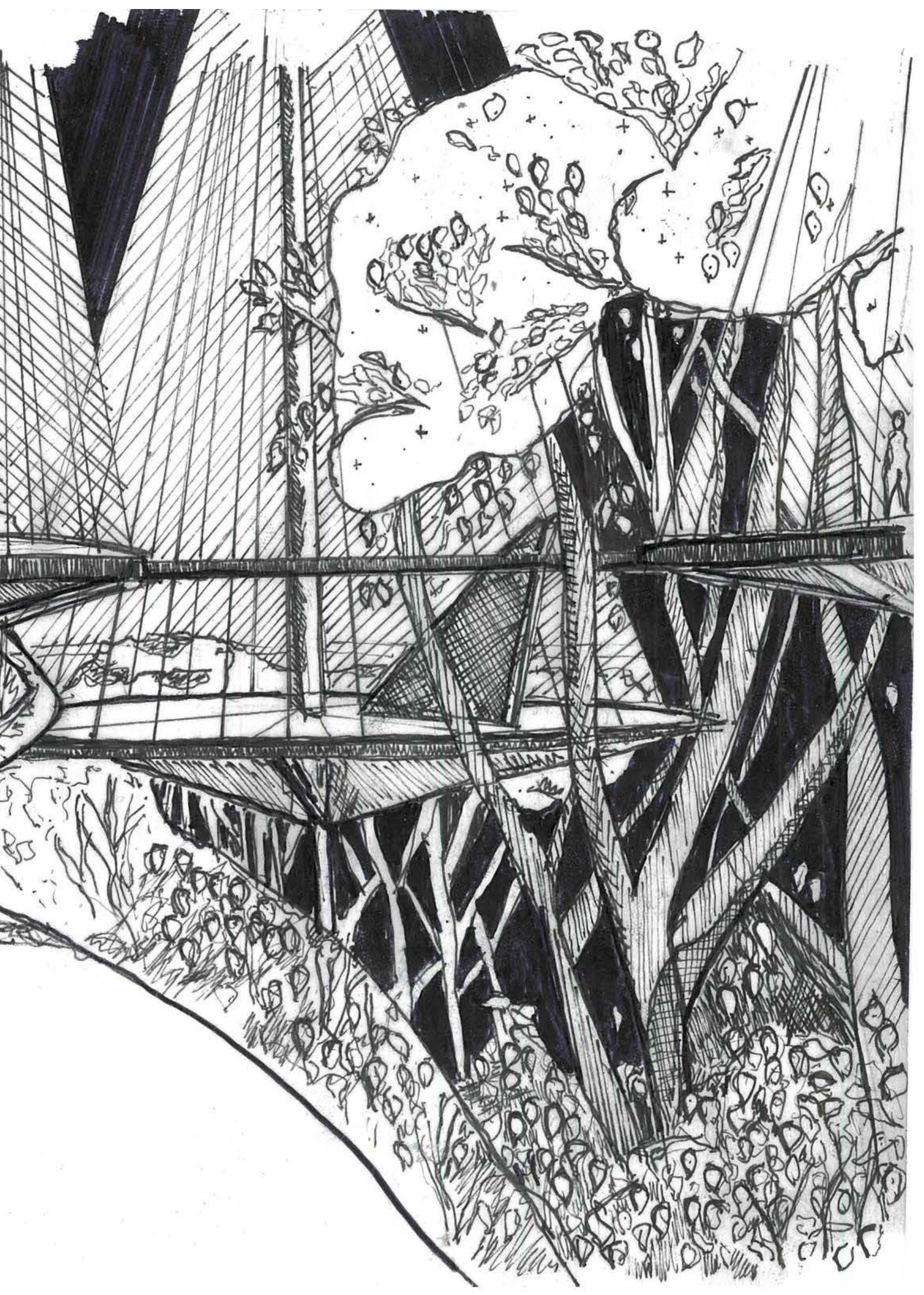


My 'fast and loose' processes aim to integrate their subjects into the existing landscape, or field. This is why I always sketch the trees and context. My 'precise and measured' processes are deliberately detached from the surrounding context.

The resulting Loop does not aim to integrate into the surrounding city. It is an isolated island, hovering above, and creating a dialogue with the fragmented ground below. It provides a new layer in the city fabric - for the pedestrian isolated, absolute, and autonomous from the forces of the city below.

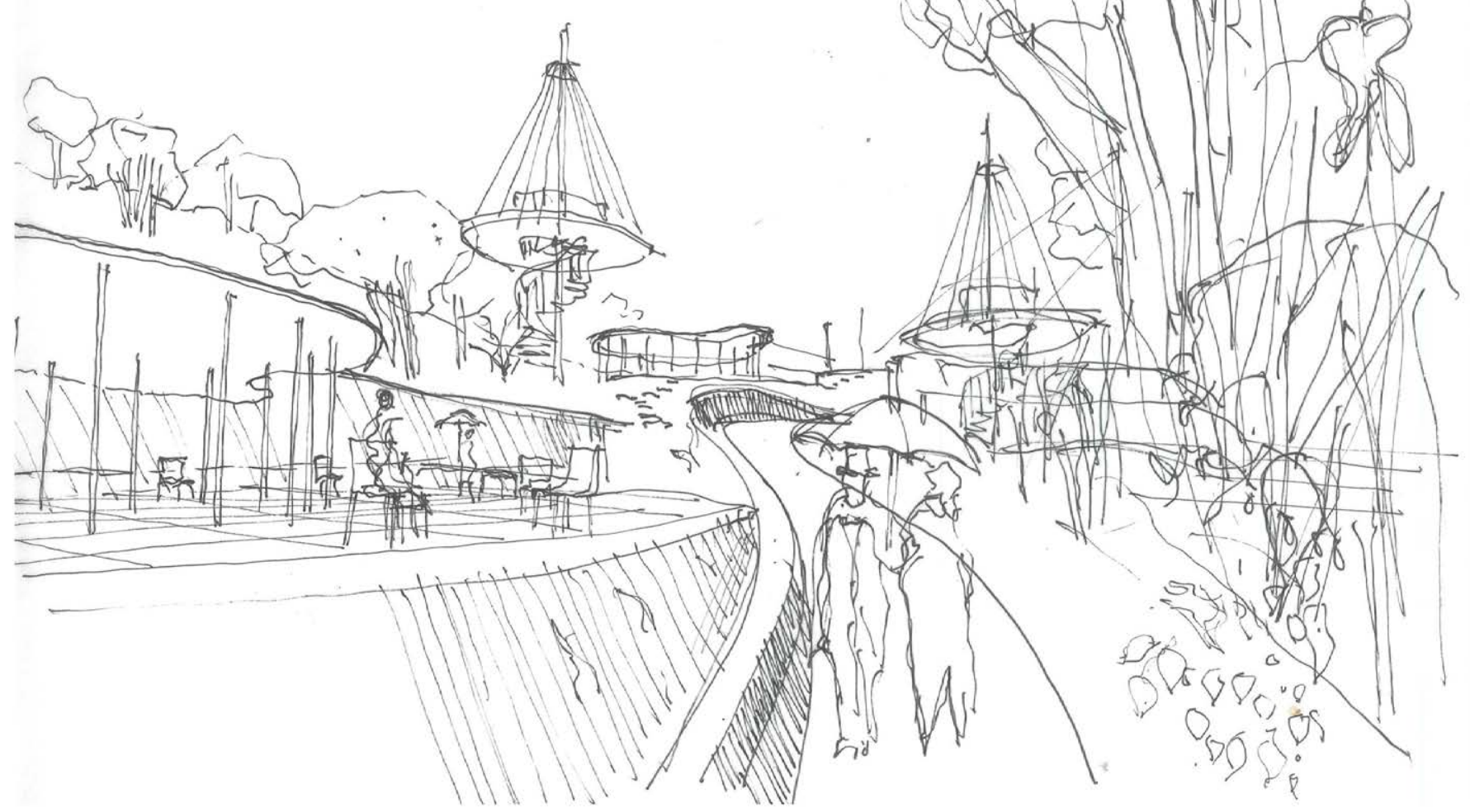

Fig 5.41 Free hand sketch of the garden pavilion pathway. I wanted to create a whimsical space detached from the reality of the city. 


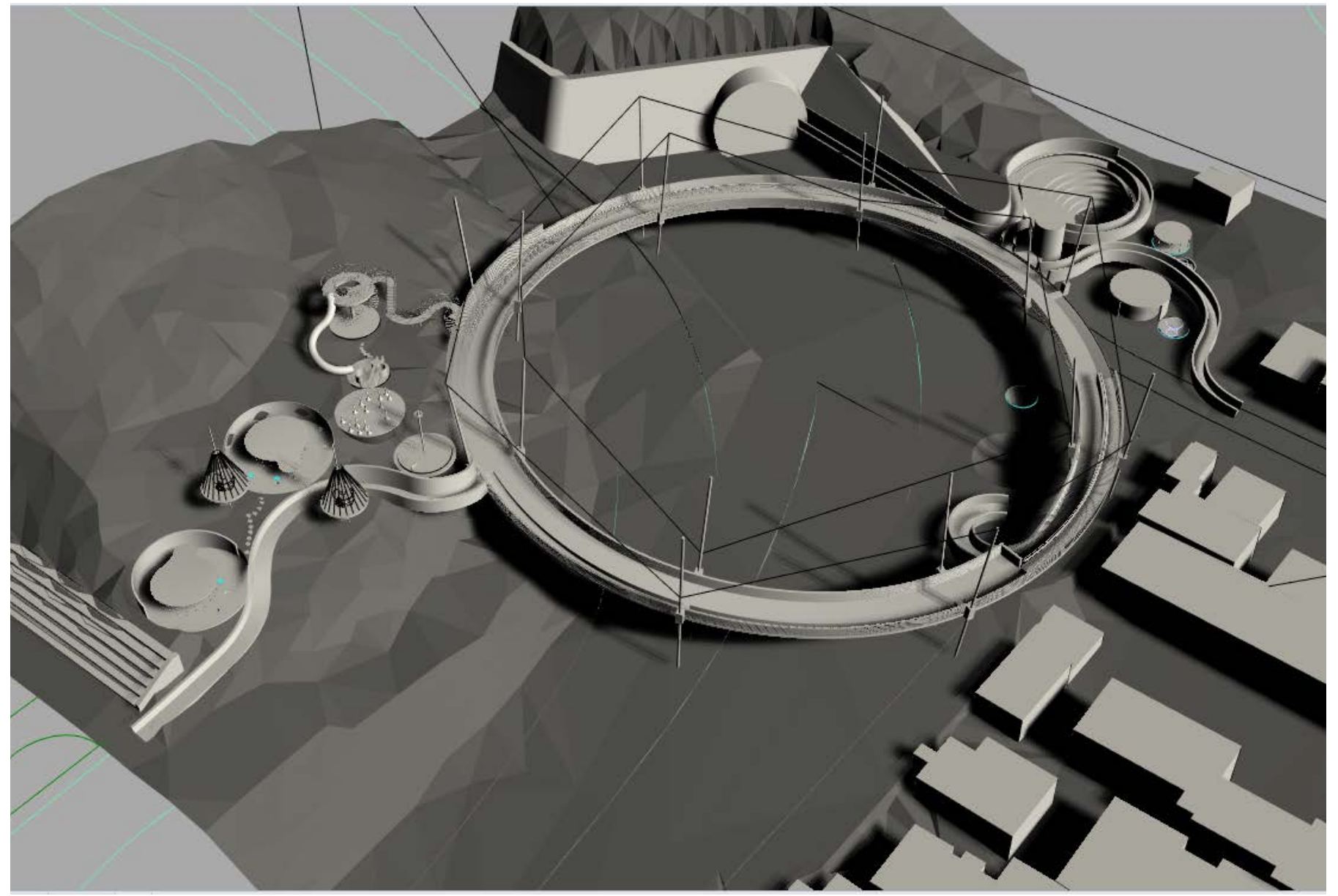

Fig 5.42 Snap shot of the developed digital Rhino model. 

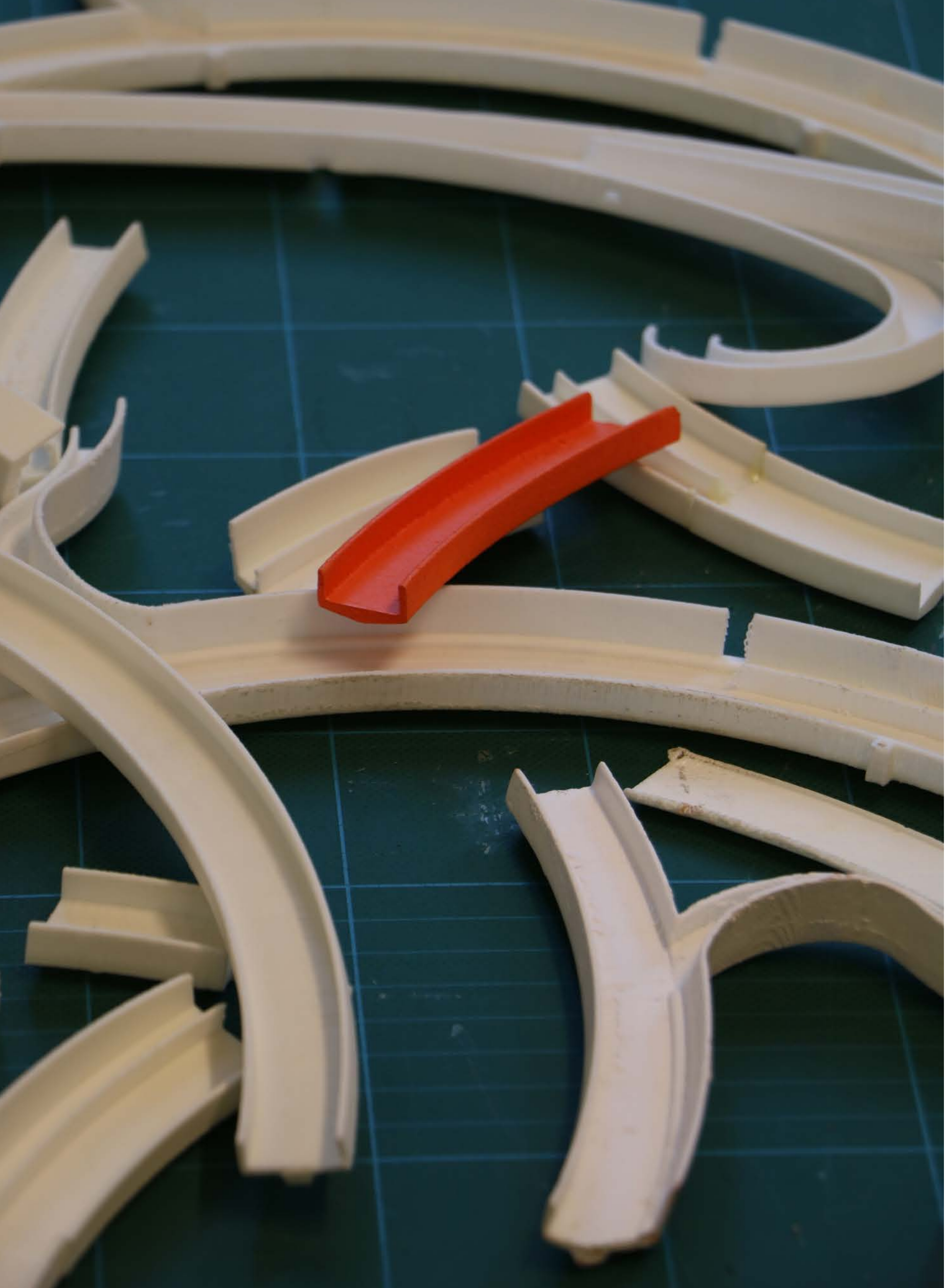


\section{FABRICATION}

I developed the scheme at two scales; 1:1 digital modelling and a 1:200, diagrammatic scale, for which I tested numerous loop and arm configurations with $3 \mathrm{D}$ printed models. My 'fast and loose' field and 'precise and measured' island methods were in consistent dialogue. This back-and-forth process provided the framework from which I developed the final scheme.

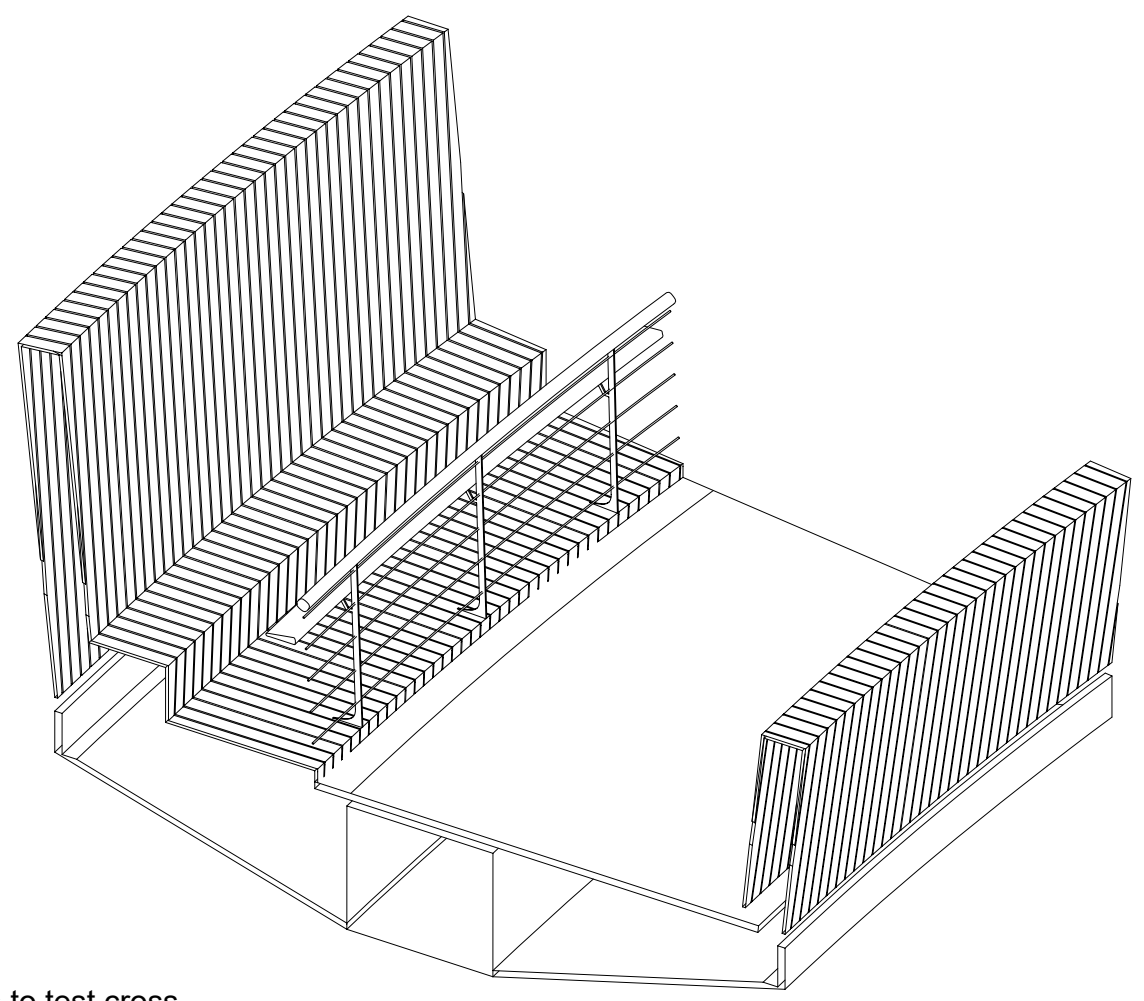

Fig 5.43 (Left) Multiple 3D printed bridge decks to test cross section, structure, width at 1:200.

Fig 5.44 (Right) Section diagram of deck with seating and separate flows for pedestrians and cyclists.

Fig 5.45 (Below) Bridge deck testing with Grasshopper.

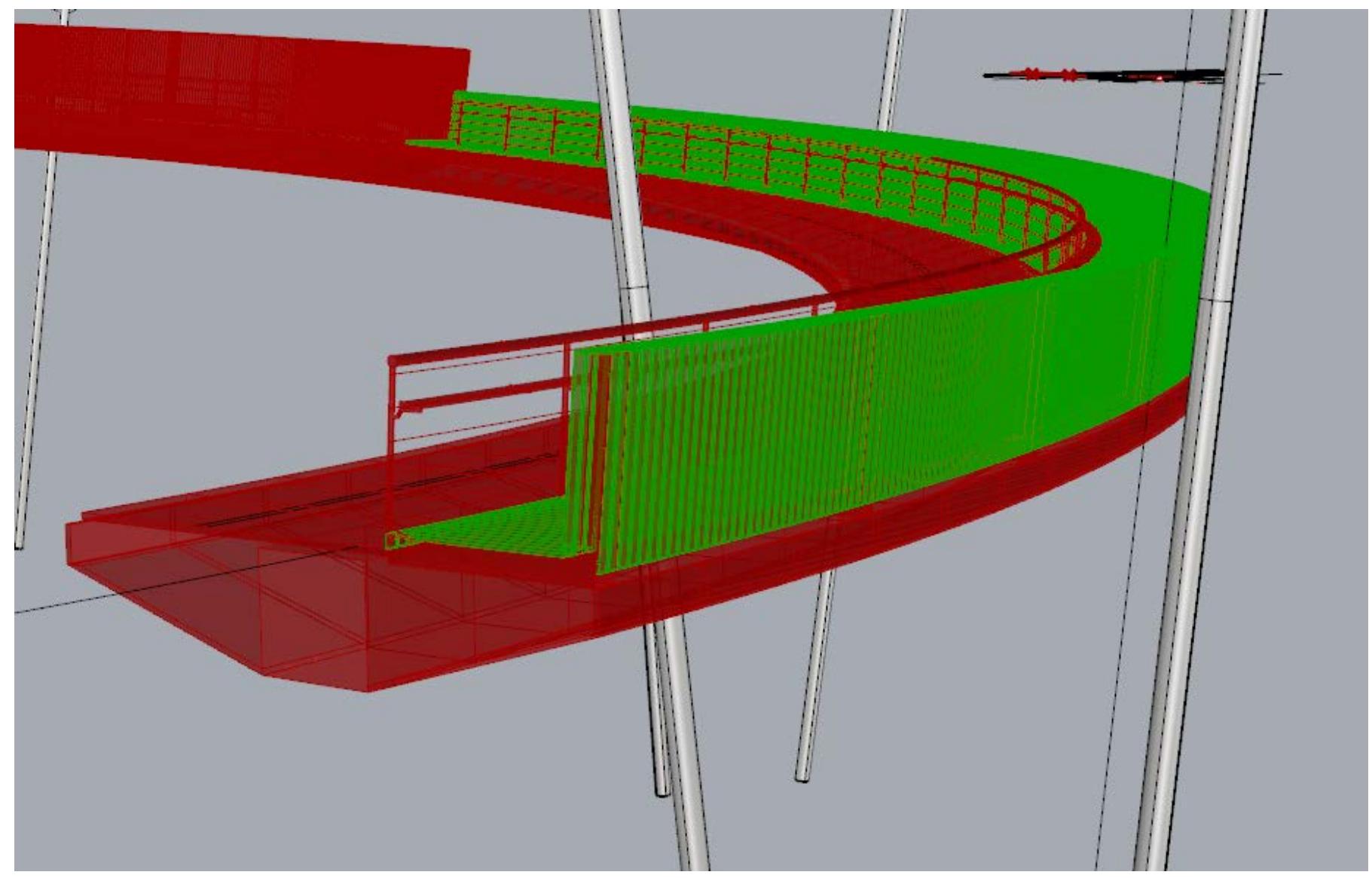



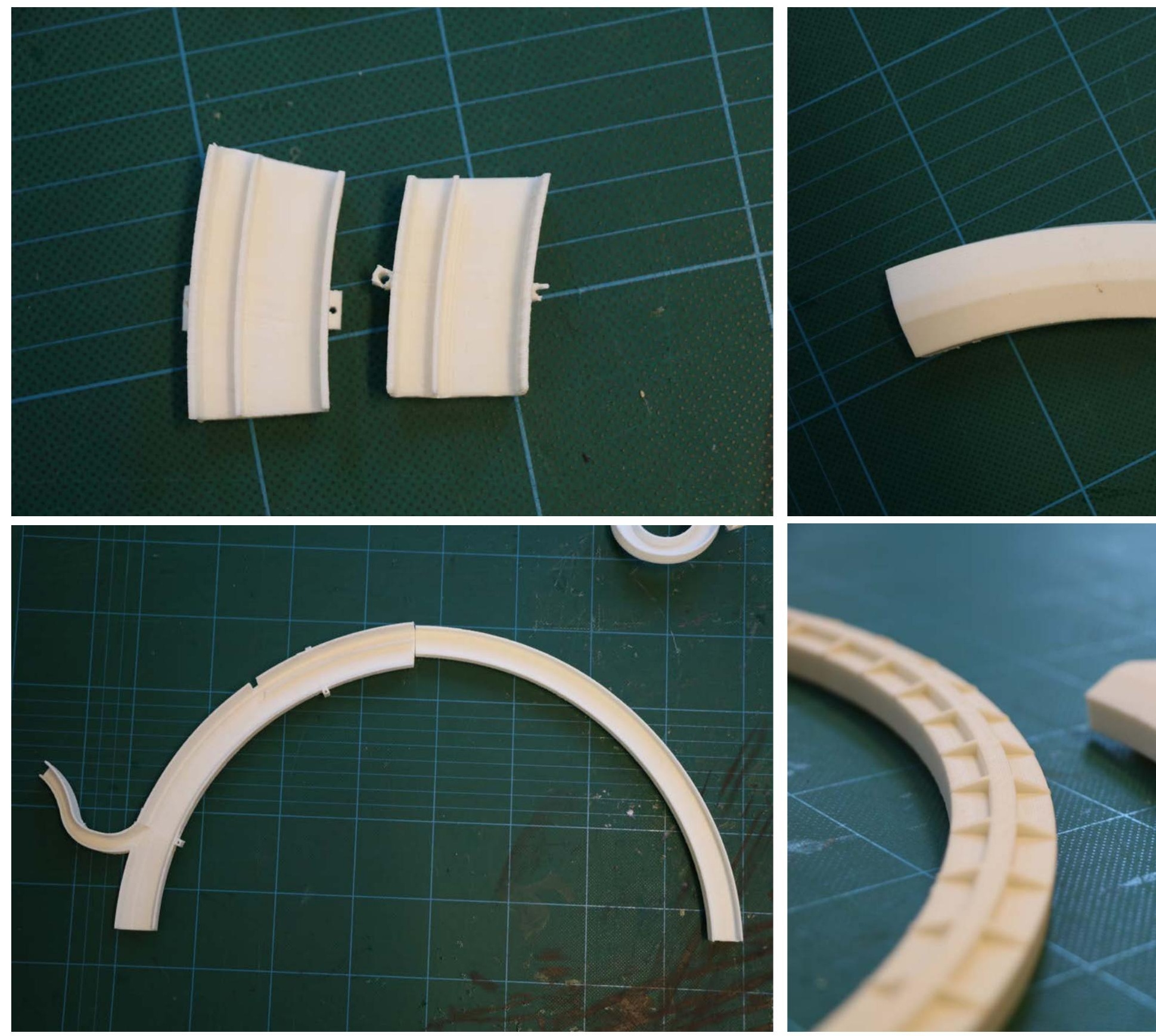

Fig 5.46 (Clockwise from top left) Testing structural holds for the pylons.

Fig 5.47 Printing joints, the final model did not use joints.

Fig 5.48 The printed joints did not line up well.

Fig 5.49 Multiple deck sections.

Fig 5.50 I widened the deck from $4 \mathrm{~m}$ to $5 \mathrm{~m}$ (at 1:1), and hid the rib structure.

Fig 5.51 The extra metre of deck width was noticeably wider. 

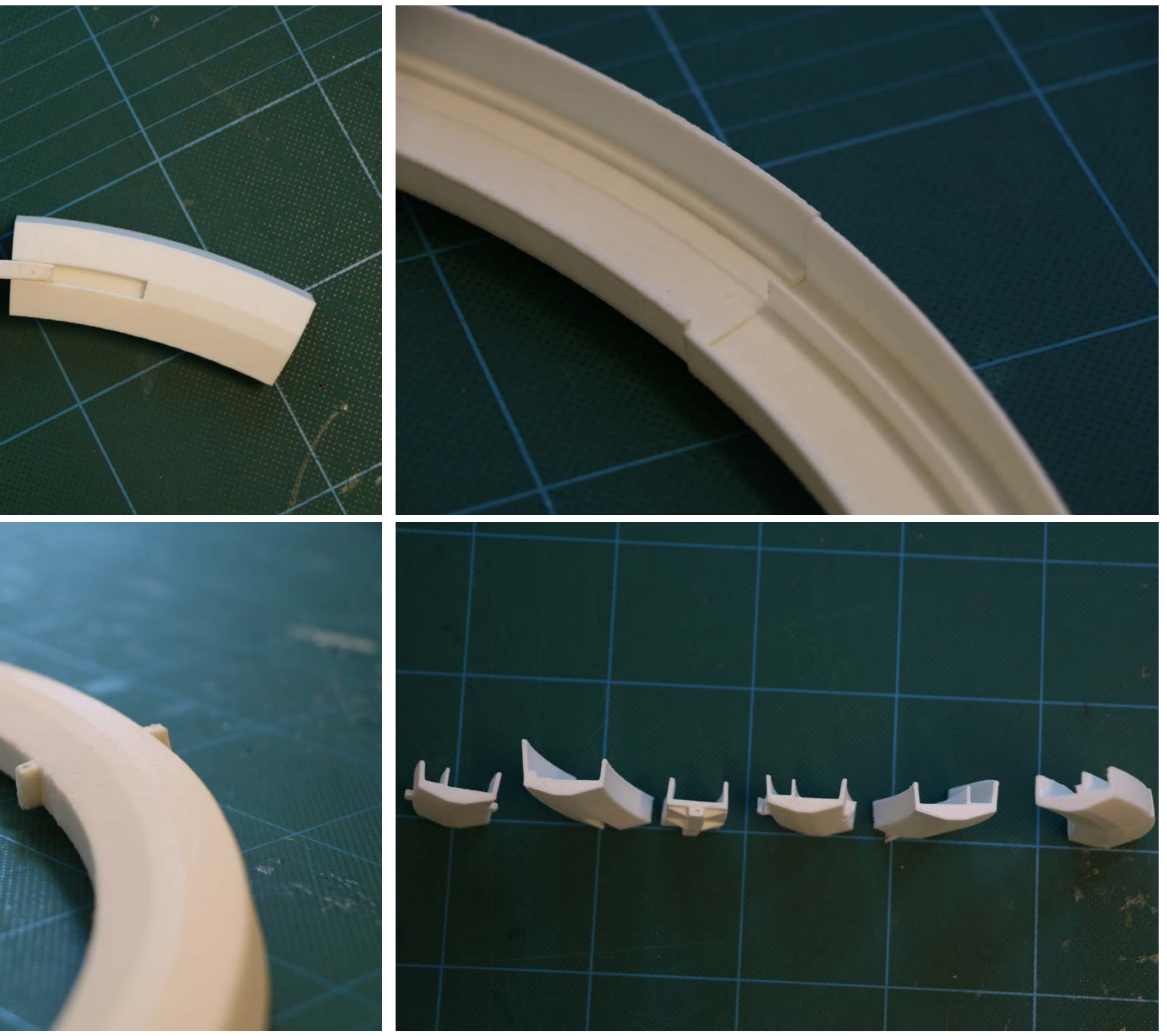

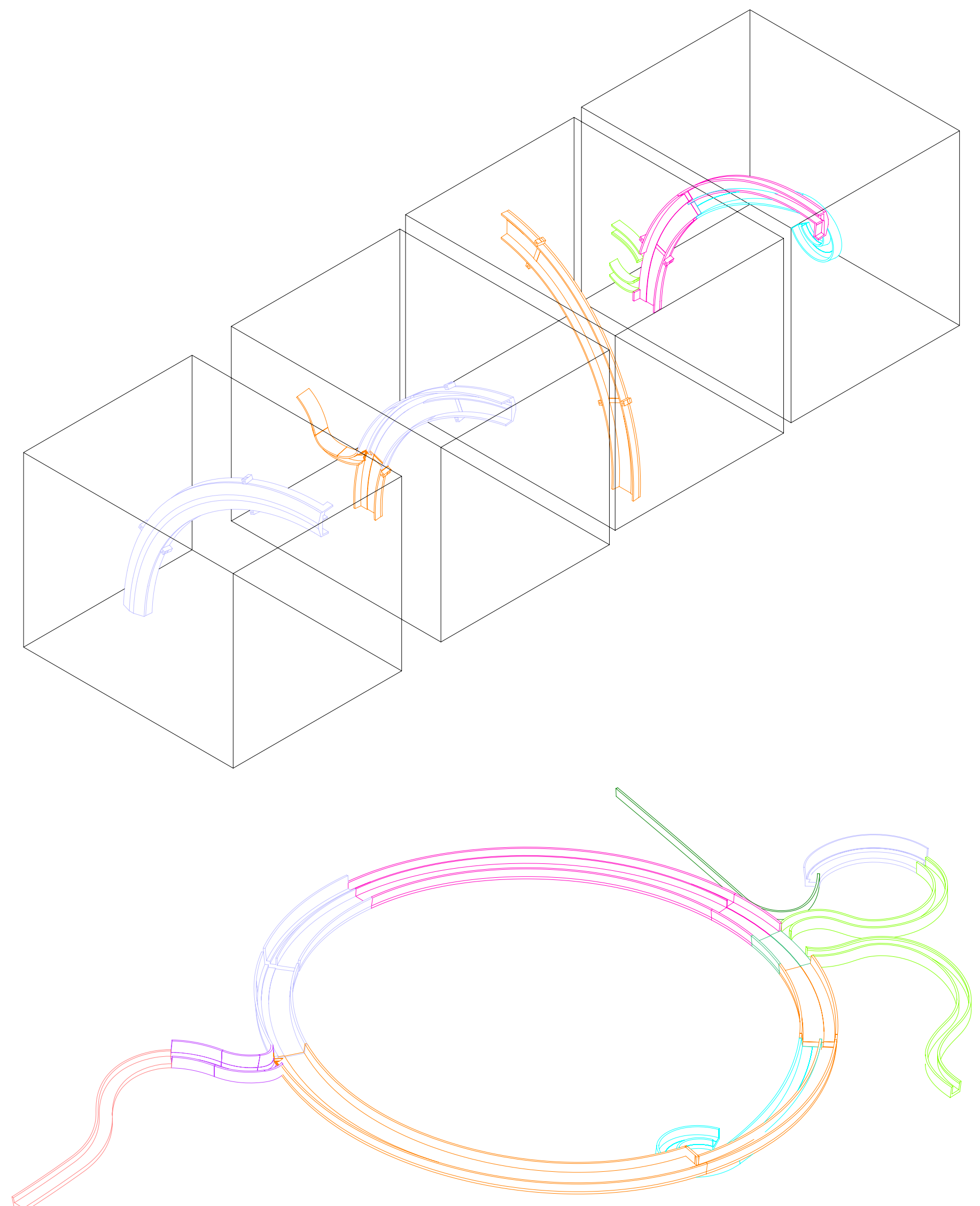
I built a 1:200 model of the final scheme over the final weeks of design (throughout November). This comprises of:

A CNC milled Fijian Kauri landscape, approximately 800x800mm.

3D printed Loop, arm and pavilions. The Loop itself was printed in four components and glued together.

Laser cut buildings and platforms.

Mild steel pylons with drilled holes for the cotton thread cables.

A structural base of ply, and steel legs from an old workshop bench.

(Special thanks to Garry, Graeme, Phil, and Ken for their workshop assistance).

Fig 5.52 (Opposite Top) The main Loop was printed in four separate pieces, using the full height of the 3D printers. The print boxes are $205 \times 205 \times 215 \mathrm{~mm}$.

Fig 5.53 (Opposite Bottom) Diagram of the printed loop components at 1:200.

Fig 5.54 (Below) The four components of The Loop glued together. The diameter of the model Loop is $400 \mathrm{~mm}$.

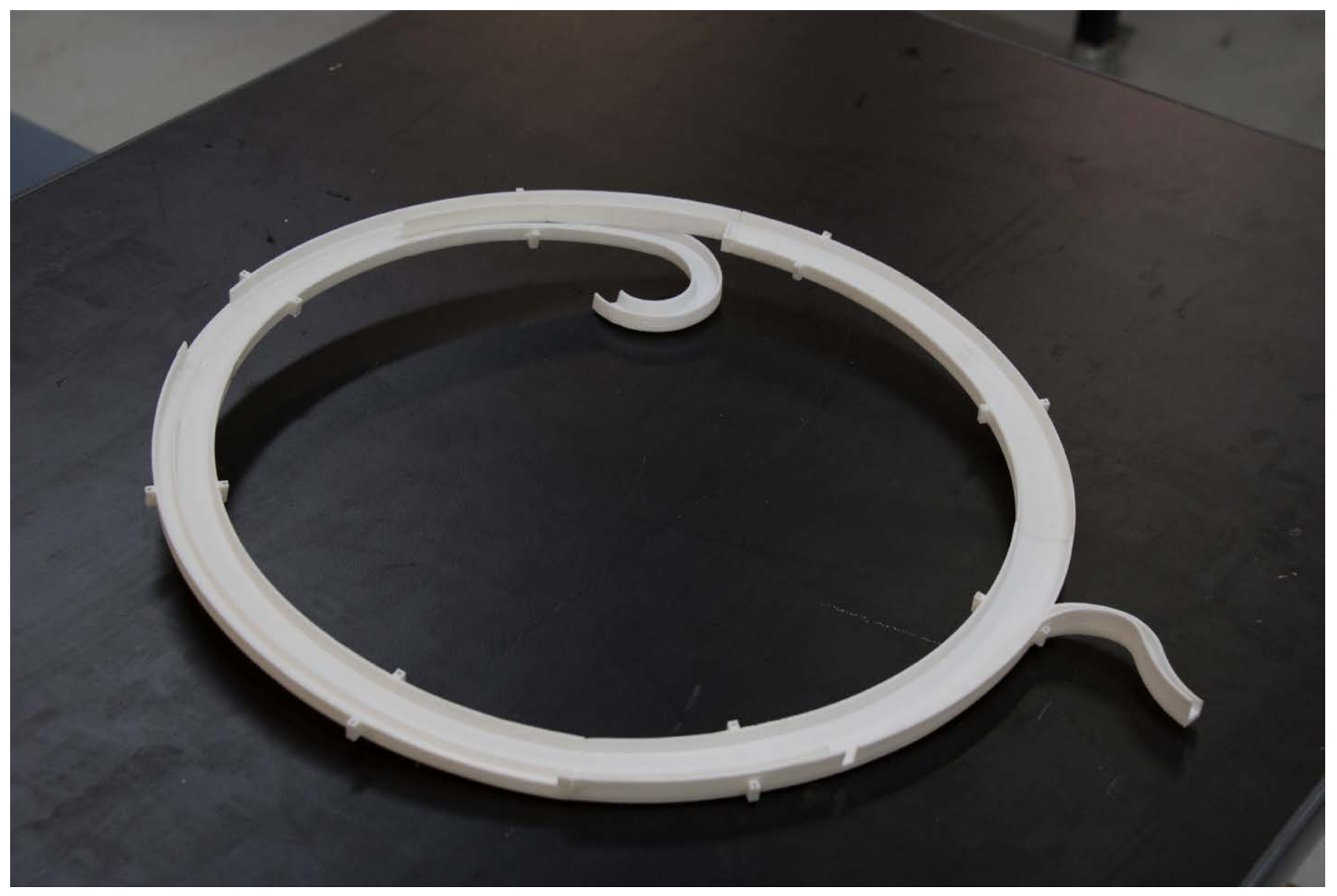



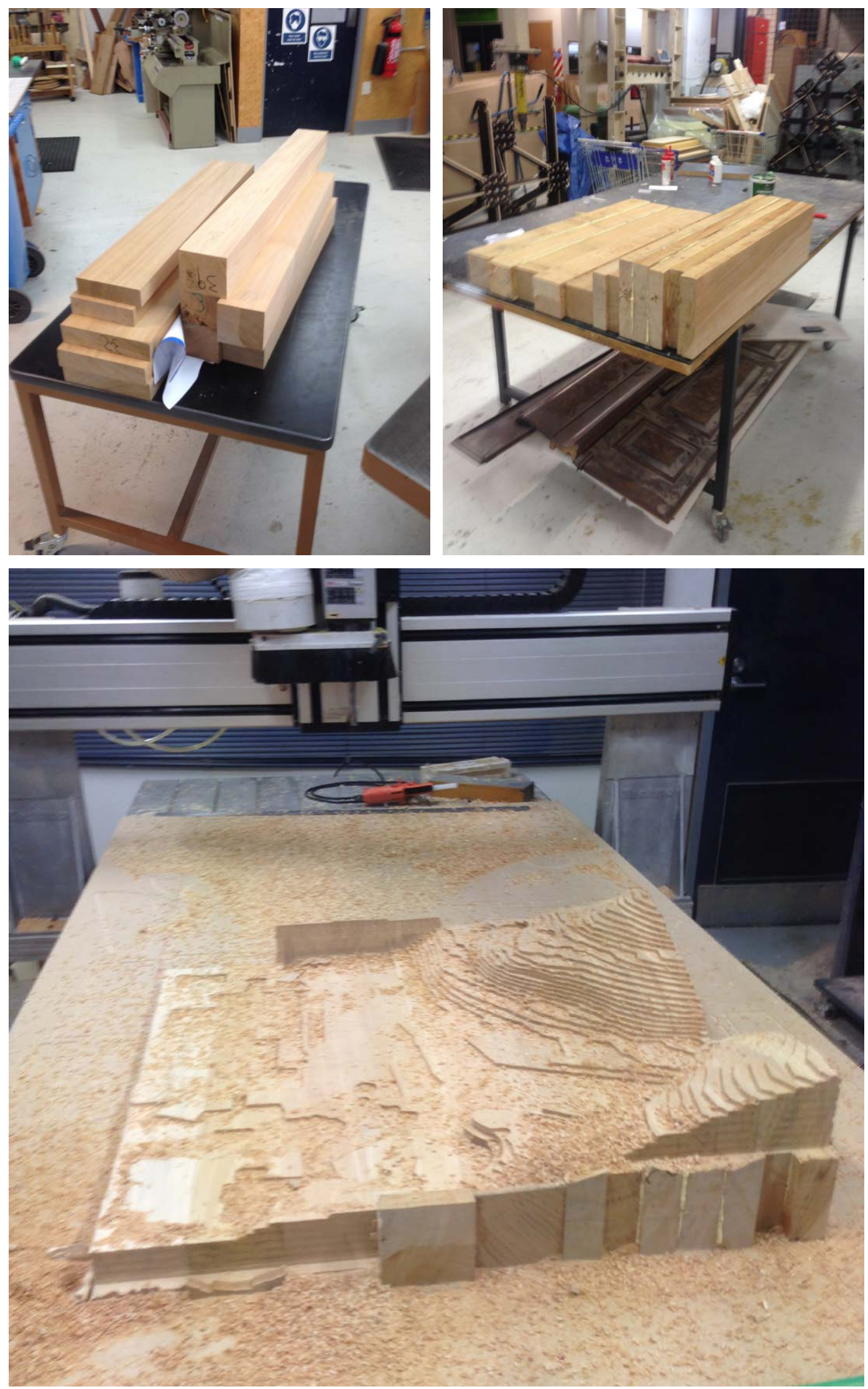

Fig 5.55 (Top Left) Approx. 9.6m of Fijian Kauri, in three profiles for the terrain model.

Fig 5.56 (Top Right) The timber was laminated over a couple of days.

Fig 5.57 (Below) First (rough) cut of the timber. Machining took two full days. 


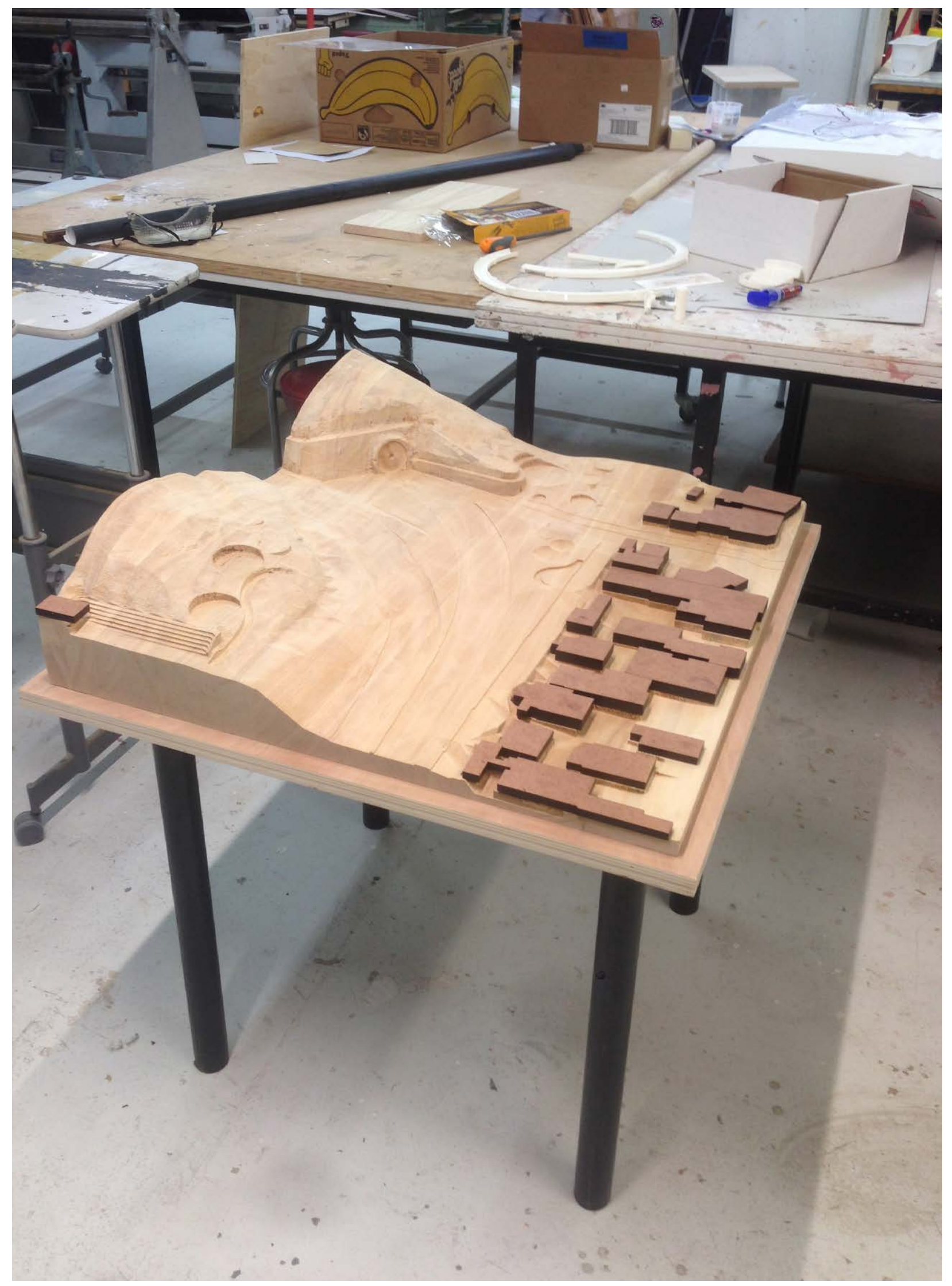

Fig 5.58 Sanded and smoothed timber with laser cut buildings and a plywood base. 


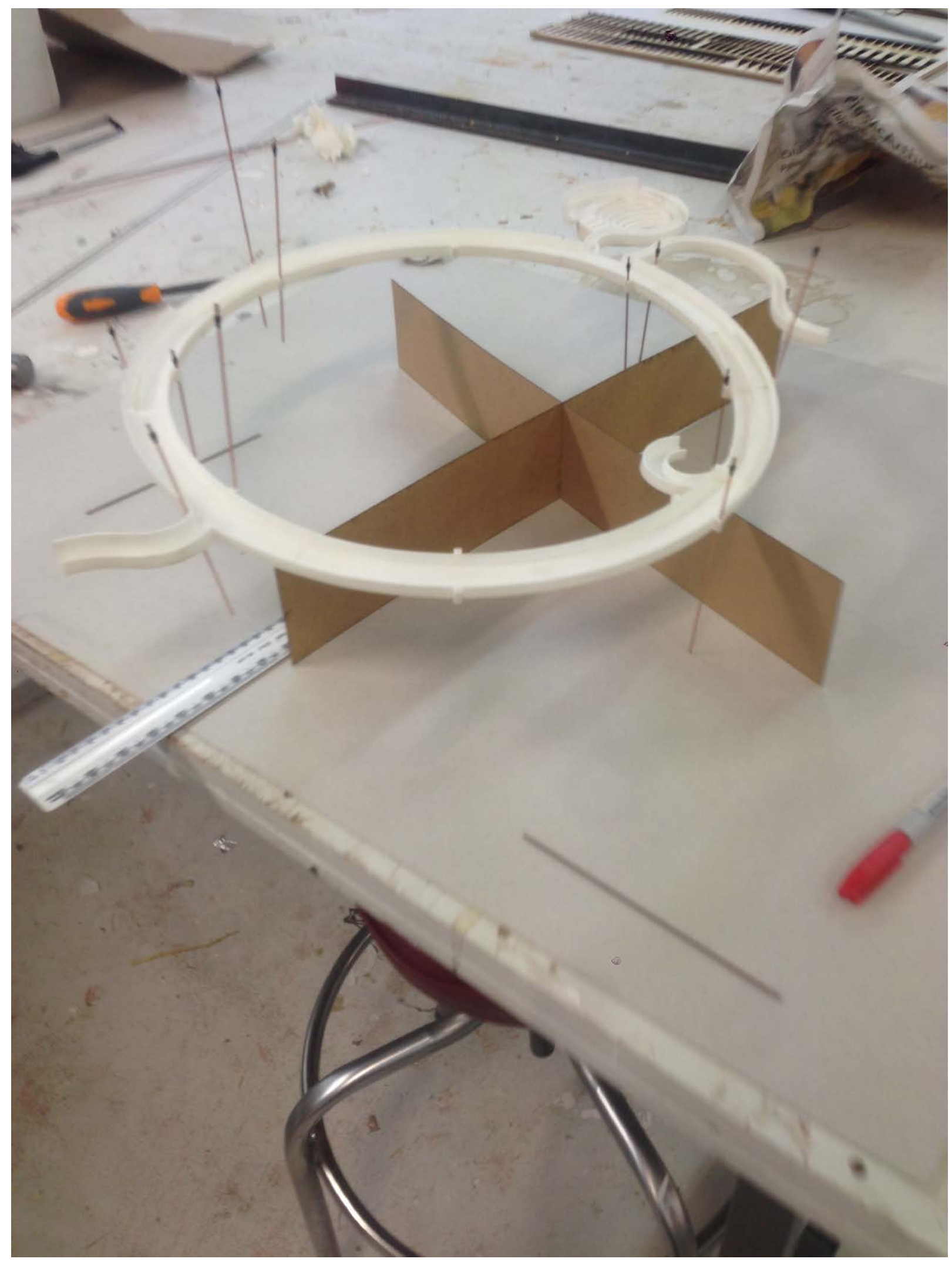

Fig 5.59 Sizing the pylons to maintain a consistent height. 


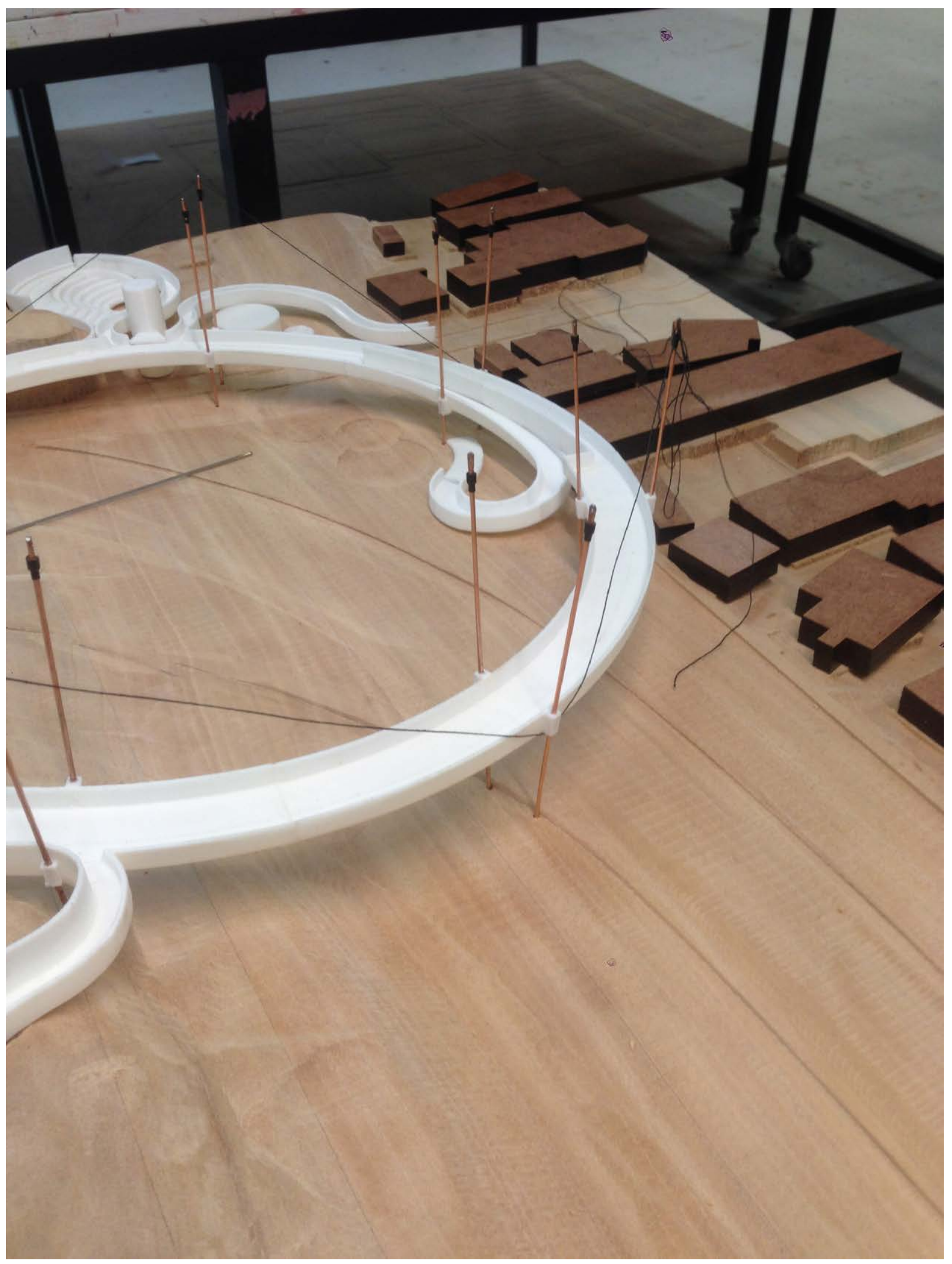

Fig 5.60 Placing The Loop in situ with drilled holes. Cables were tied on as final touches. 
($$
\text { ( }
$$

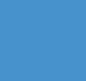

$$
6.0
$$

(20

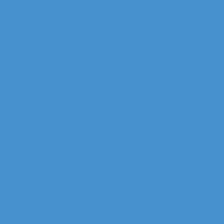




\section{Island and Field}

The first experiment aimed to manipulate the human perception of the field by extending the pedestrian realm over that of the vehicle. The second experiment more modestly placed an island above the field to distinguish between the two realms, and then aimed to connect them more subtly. This latter, dual approach developed a framework for iterative experiments from which I developed the final scheme.

This chapter begins with a detailed description of the final scheme, Trivial Pursuit. It then summarizes the two distinct experiments, which presented the theoretical framework for this scheme, and critically reflects on the holistic process.

The autonomous Loop facilitates a pedestrian and cycling bridge, linking the new Mt Victoria Tunnel to Hataitai Village and the Town Belt (over a new four-lane highway). A series of programmed spaces on the periphery of The Loop connect it to the surrounding urban areas and facilitate social play spaces, which aim to create enjoyment in the quotidian urban fabric in Hataitai.

The scheme does not take an extreme view of either of the two approaches identified in the process, but attempts to balance them against each other. Through this project, I have come to understand more about the value of visual and physical continuity, but also the allure of the autonomous object and its ability to create a unique moment in the city fabric.

The two distinct approaches to urban design synthesised in the scheme demonstrate how we might augment the urban fabric by creating rich places, whilst addressing the fundamental need to connect pedestrian spaces 

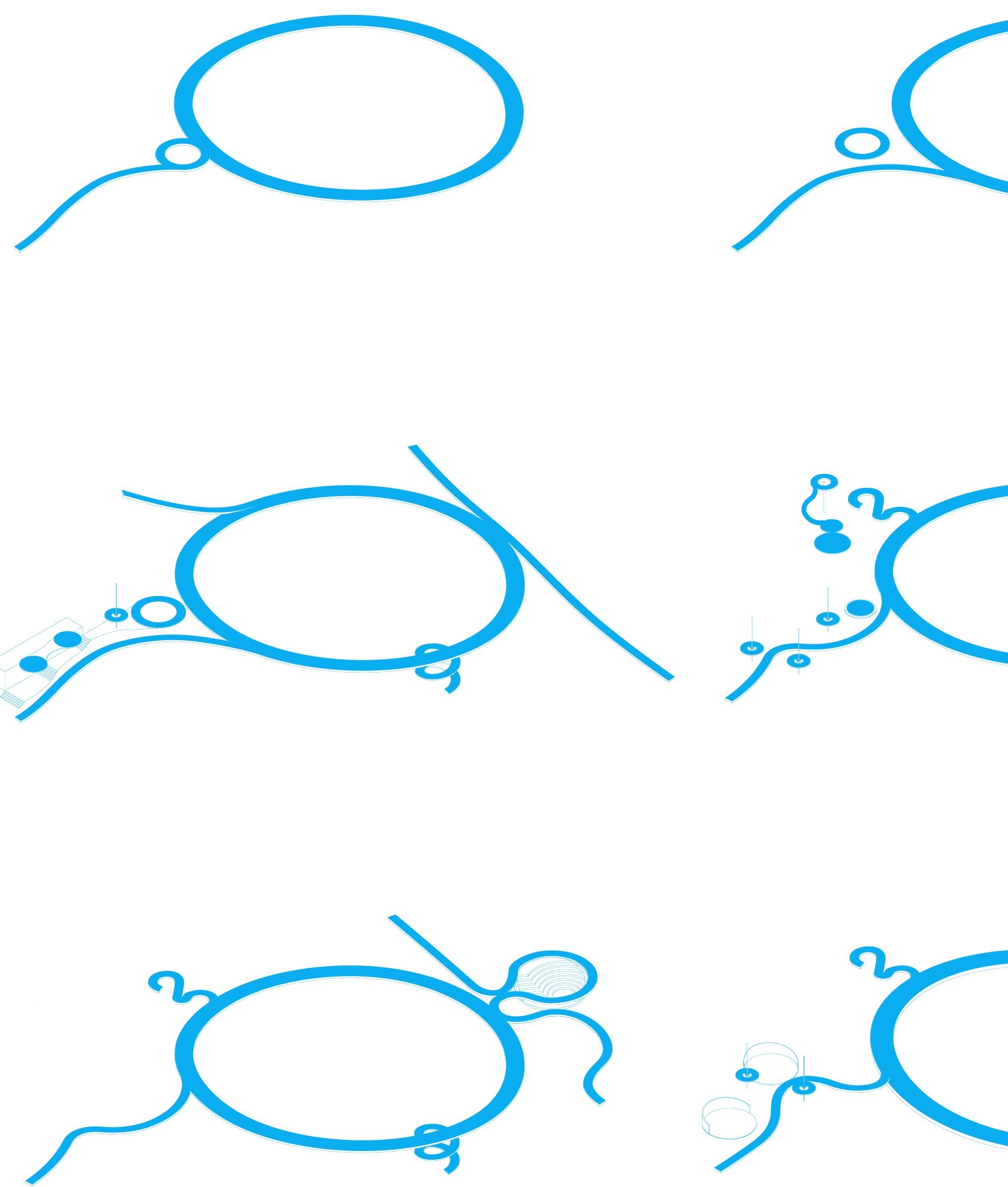

Fig 6.01 Progression diagrams of The Loop's wandering arms and play spaces. 

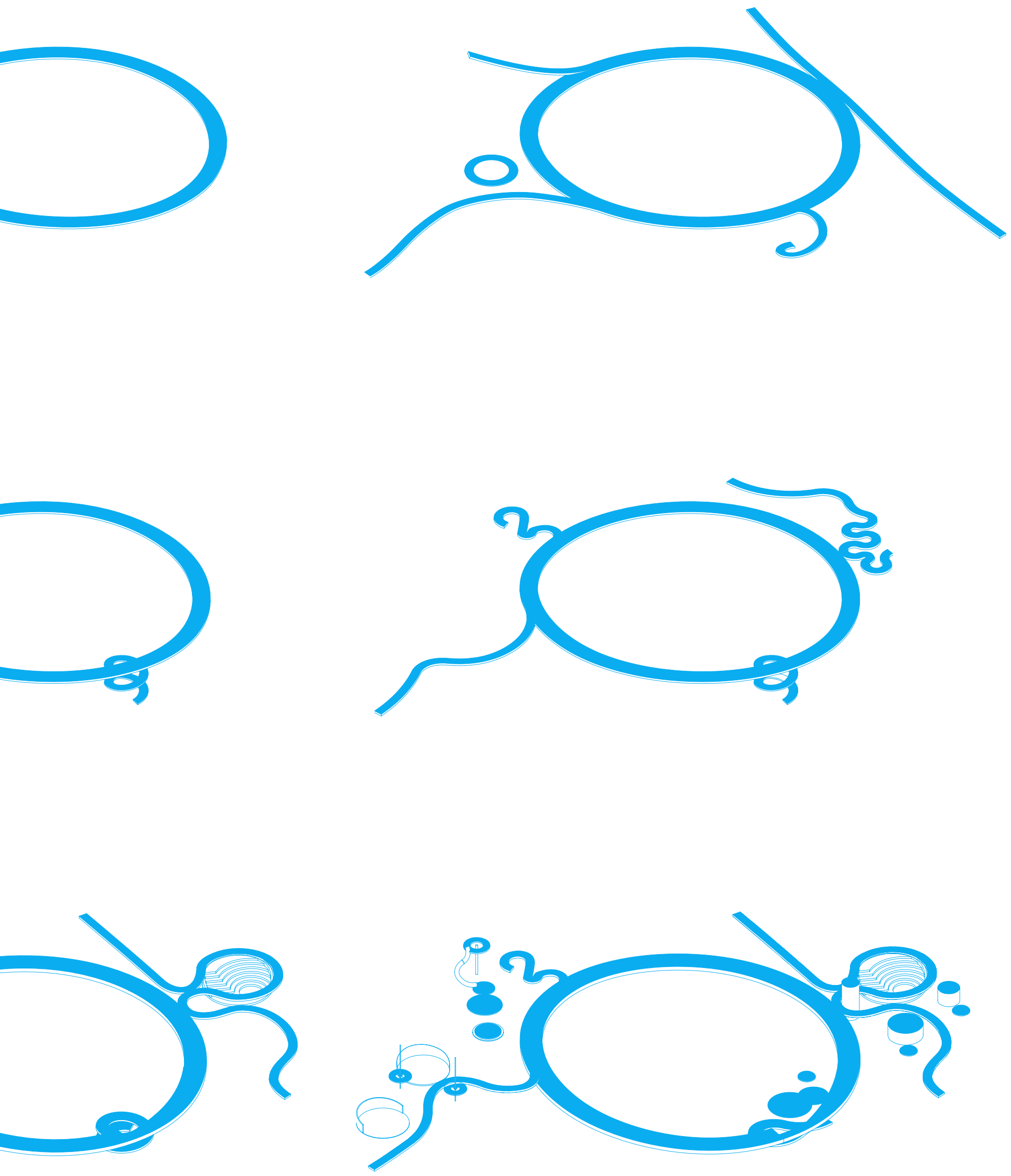


\section{TRIVIAL PURSUIT}

The focal point of the final scheme is a circuitous bridge, $80 \mathrm{~m}$ in diameter - The Loop. It hovers above the highway and creates a distinct new layer in Hataitai, for pedestrians and cyclists. The bridge deck consists of two channels; a $3 \mathrm{~m}$ channel for fast moving bicycles and runners, and a $1.5 \mathrm{~m}$ channel for leisurely activity. The former is consistent with the Dutch Design Manual for Bicycle and Pedestrian Bridges, which suggests $2.9 \mathrm{~m}$ for two-way cycle traffic on slope (ipv Delft, 2015). I envisage traffic moving in one direction like a roundabout, but acknowledge that two-way traffic could also be acceptable. The two channels are separated by a step, and railing in some sections, as recommended by the manual.

A quarter section of The Loop, backing into the Town Belt, and partially shaded by Pohutukawa trees, is benched to encourage lingering and social interaction. Facing northeast, this space would also receive sun throughout the day. The bridge itself is a meeting place, rather than simply a transition space. A third space like those described by Jan Gehl.

At a maximum grade of $9.6 \%$, The Loop is near the upper limit for cycling, but still acceptable. Four meandering arms provide access to The Loop. A series of playful pavilions and structures occupy the spaces around these arms on the periphery of The Loop. These provide opportunities for sociability and recreation to function effectively like an urban playground.

Fig 6.02 Aerial view facing southwest. 


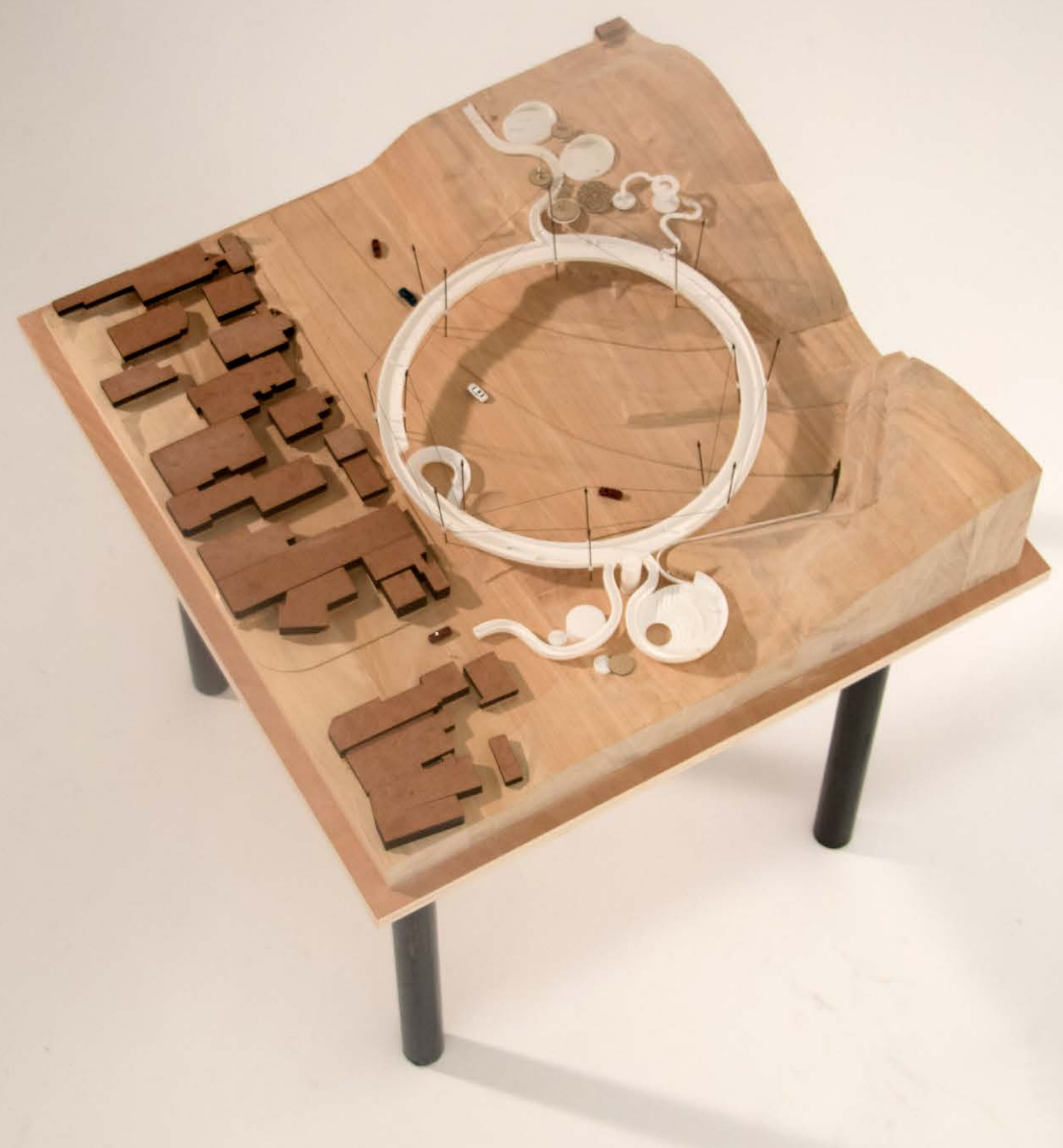




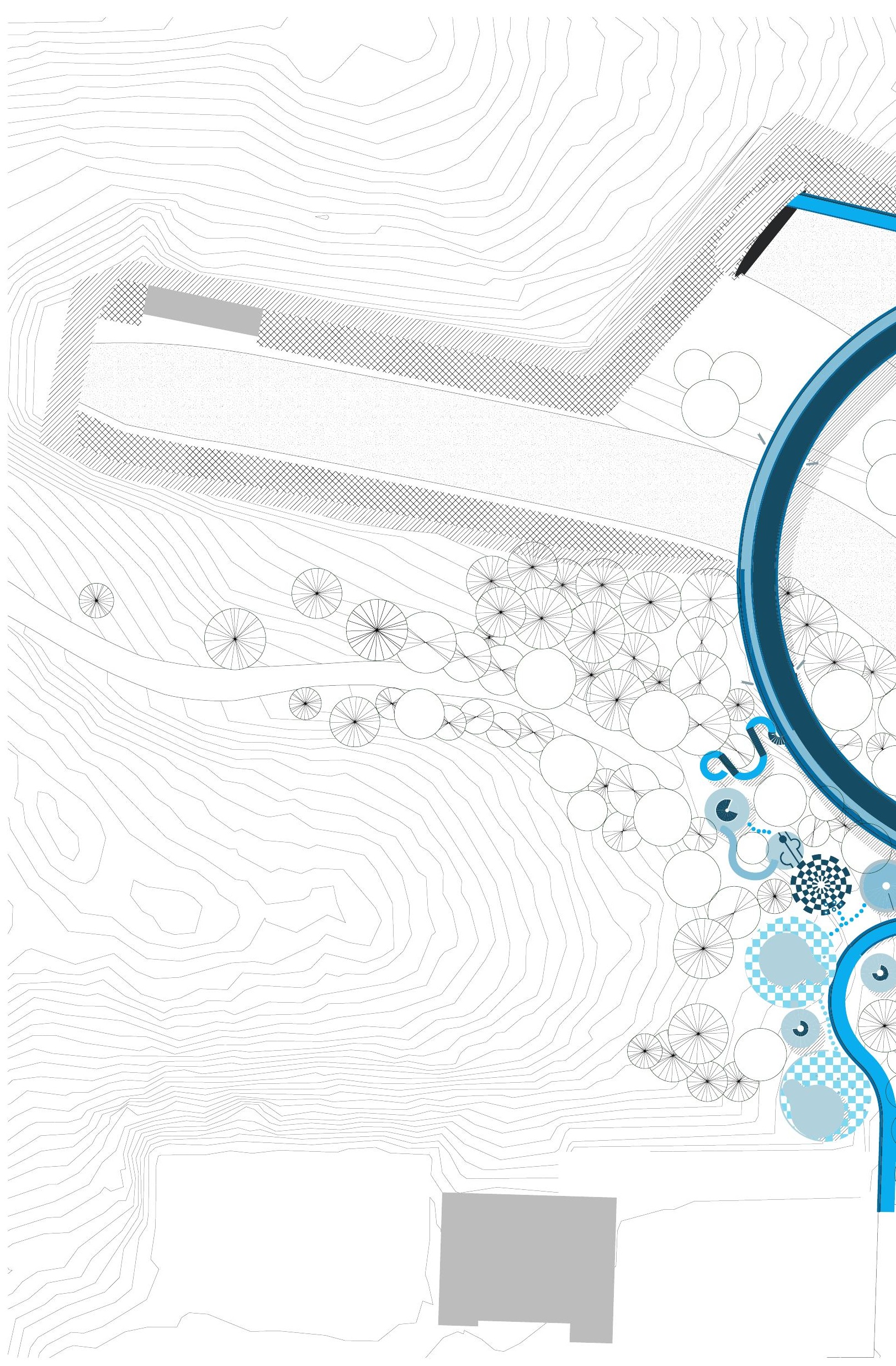




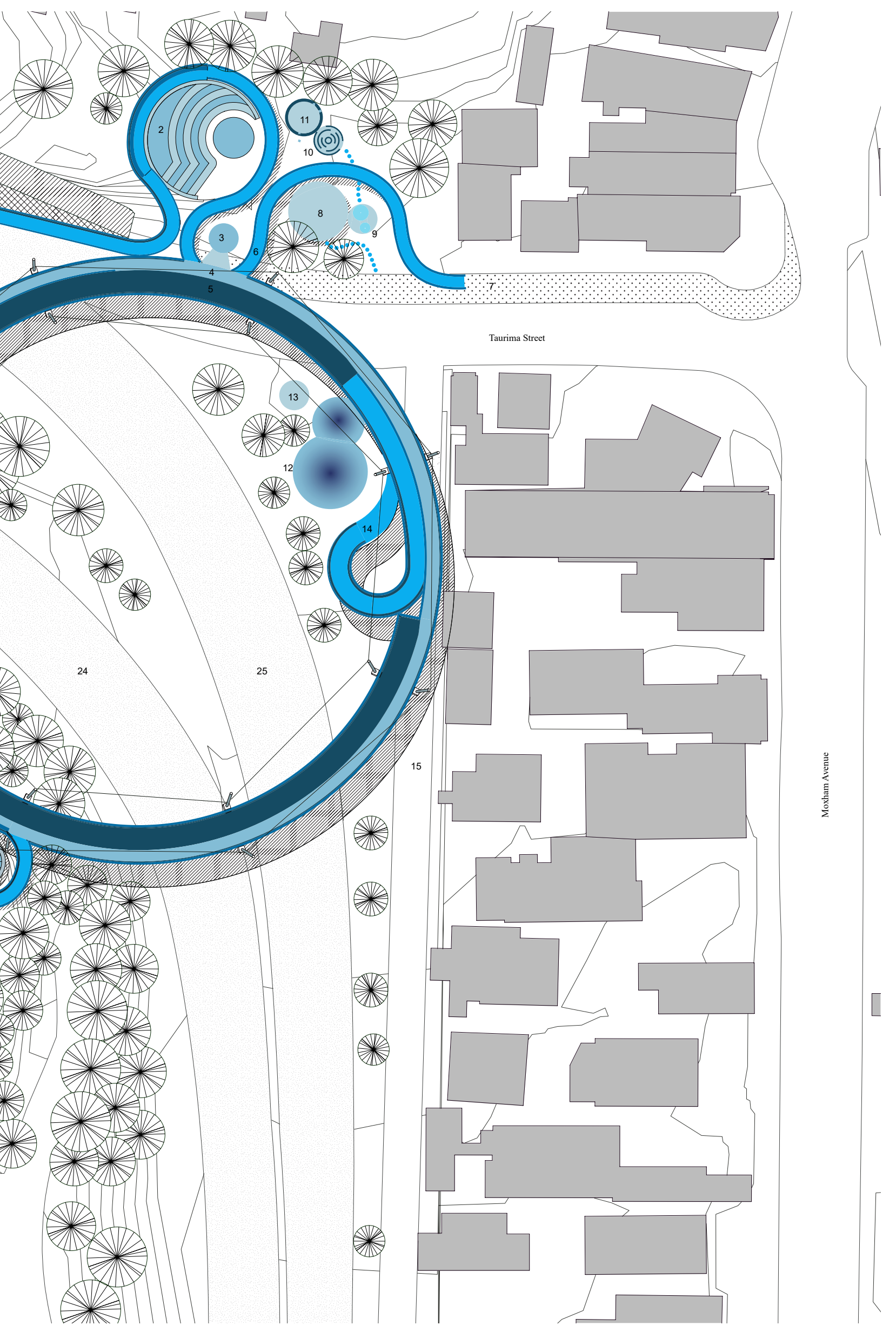




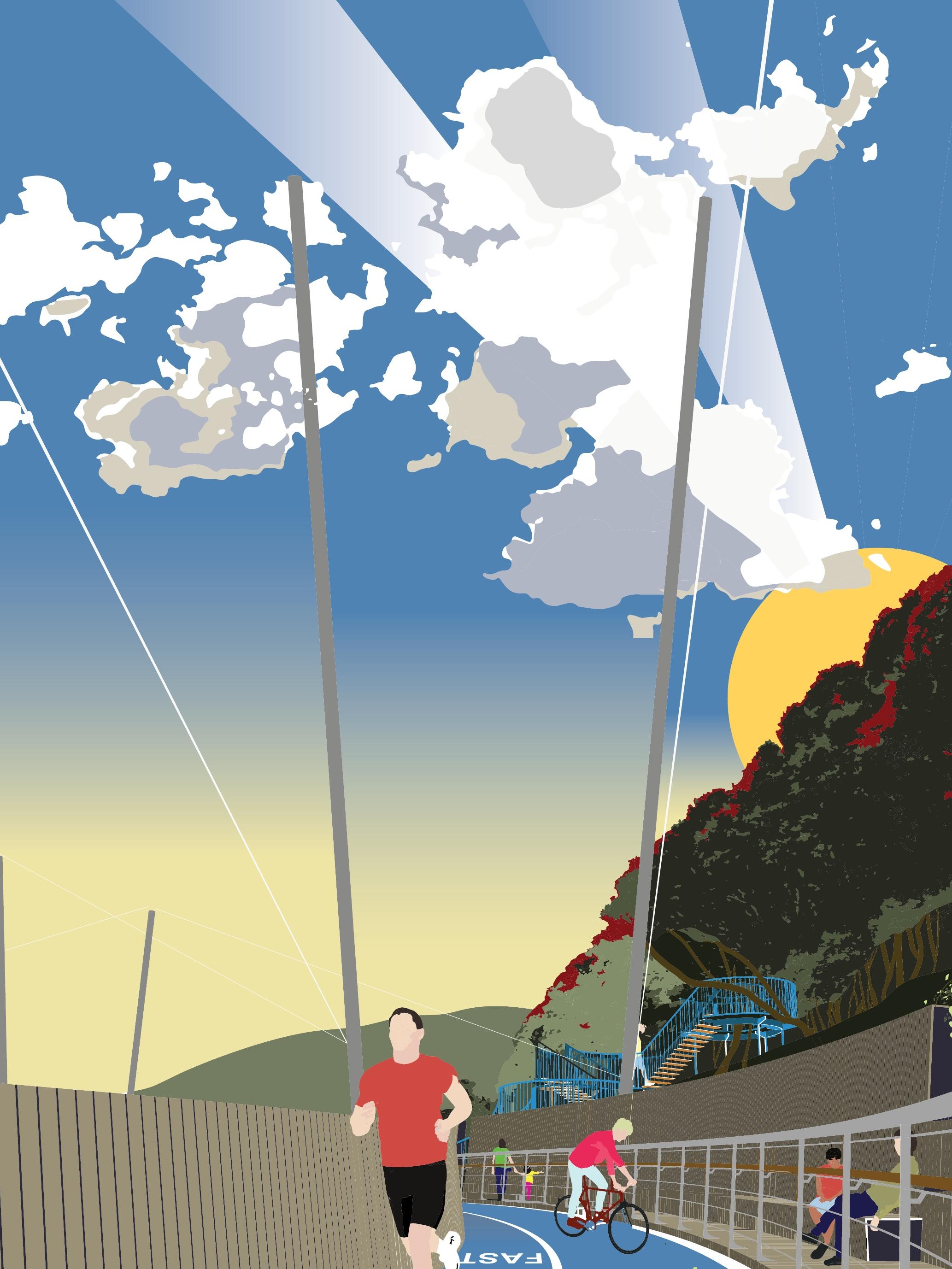




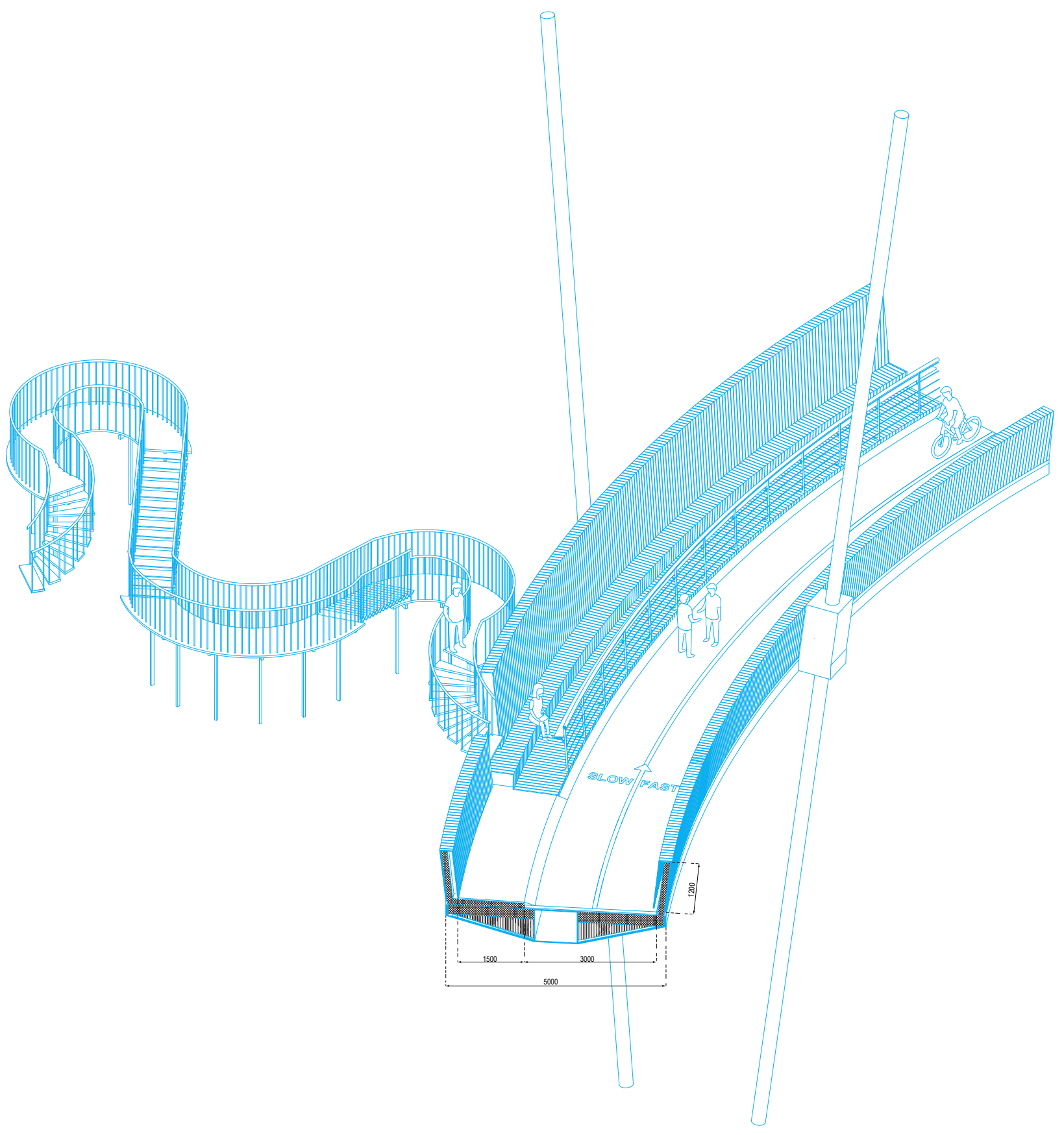

\section{UPPER TOWN BELT NODE}

A winding staircase links The Loop to the steep reaches of the Town Belt above the tunnel entry. The sinuous landings dodge the tree trunks allowing their canopies to rise above and envelop the pathway. Circular platforms create a playground of spaces down to the park. A viewing tower, slide, Byzantine chessboard and sundial make up these spaces.

Fig 6.04 (Opposite) Bridge deck with dual channels, seating space and a stairway into the Town Belt.

Fig 6.05 (Above) Section diagram of The Loop and meandering stair to Town Belt. 


\section{PARK NODE}

A long, meandering arm connects the sports facilities of Hataitai Park to The Loop. The pathway snakes gently up the hill and is surrounded by whimsical climbing platforms and garden pavilions. These structures occupy the spaces in, amongst and above the trees and aim to evoke a feeling of wilderness that seem far from the reality of the city. 


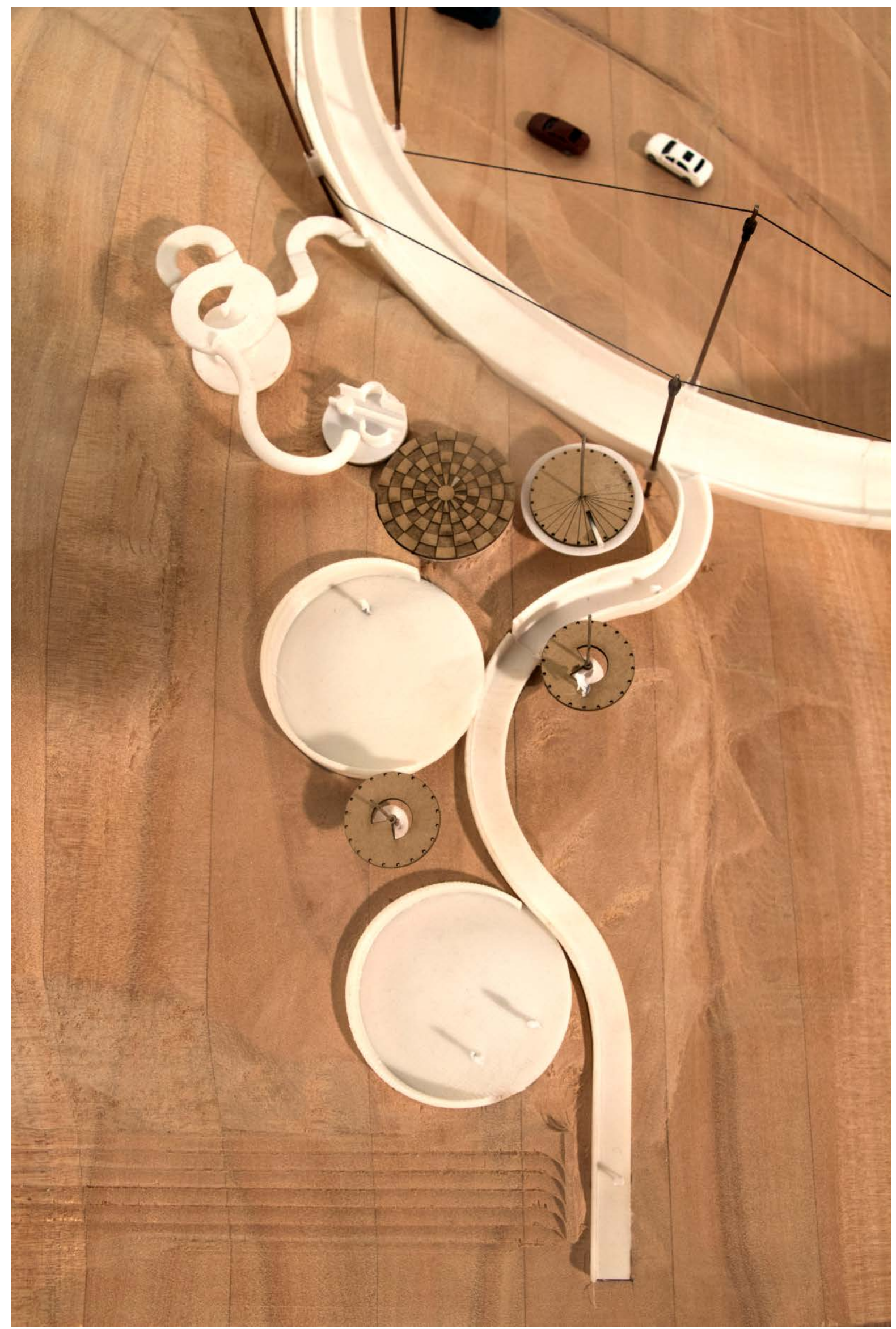

Fig 6.06 Park node and Town Belt node from above. The pathways meander through playful pavilions and trees.

Fig 6.07 (Following spread) The whimsical and wild pathway from Hataitai Park to The Loop. 


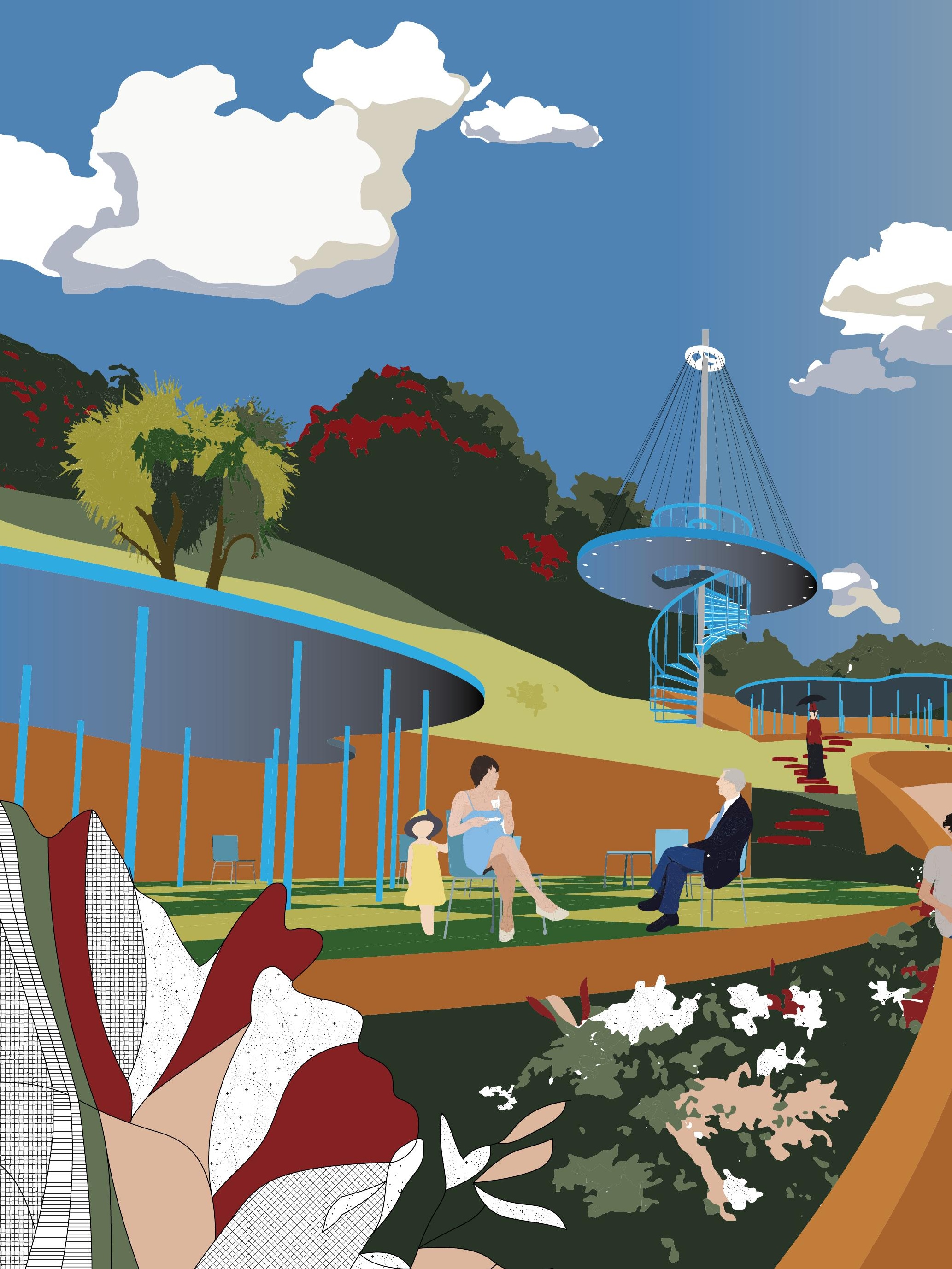




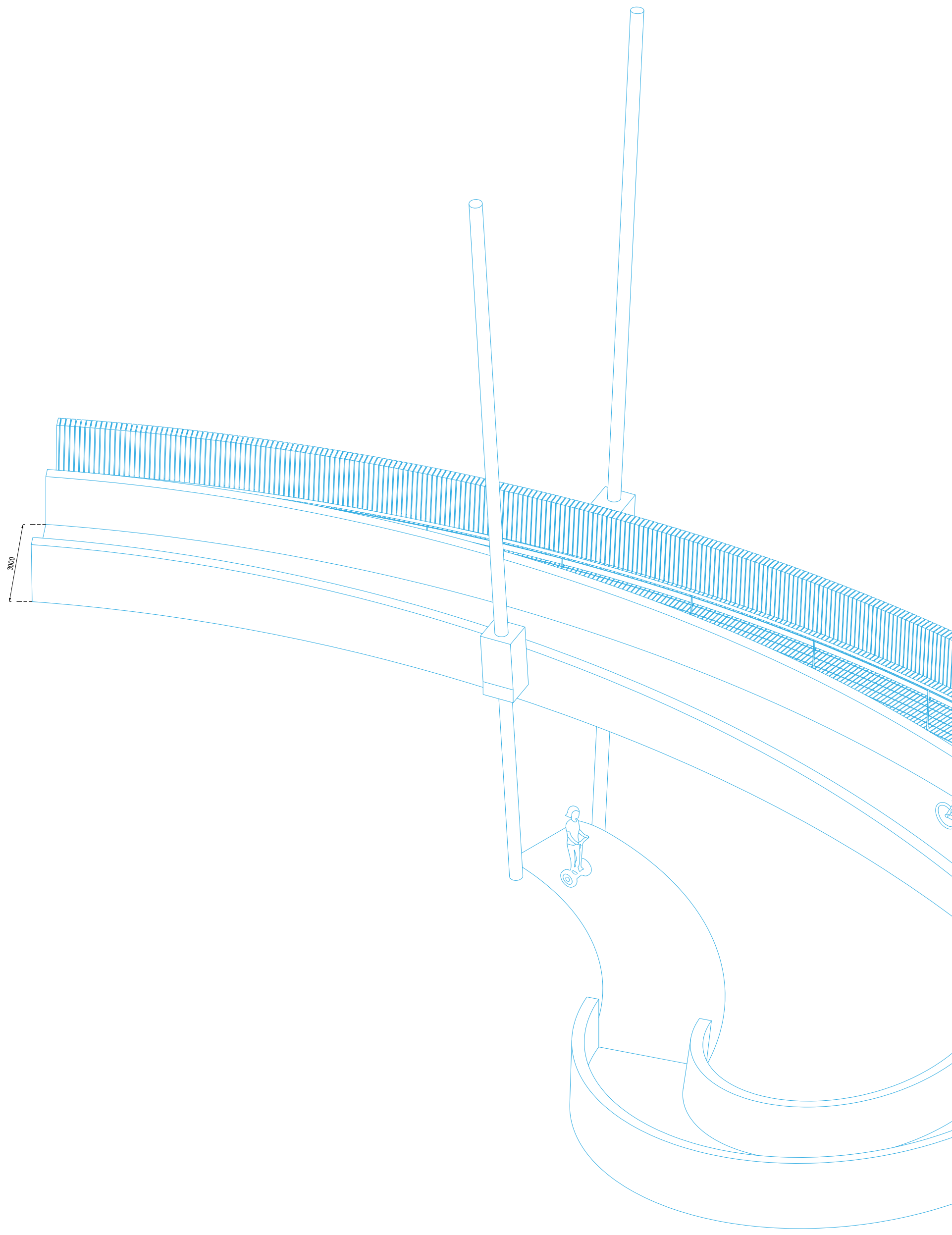




\section{VILLAGE NODE}

A gently-arcing arm joins The Loop to ground level, joining up with the shared traffic lane between the highway and Moxham Avenue. This Fietsstraat is a cycle/ pedestrian priority lane, where the vehicle is a guest. A skate park occupies the grassed space between the village and the highway.

Fig 6.08 Section diagram of spiraling ramp from The Loop to shared path. 


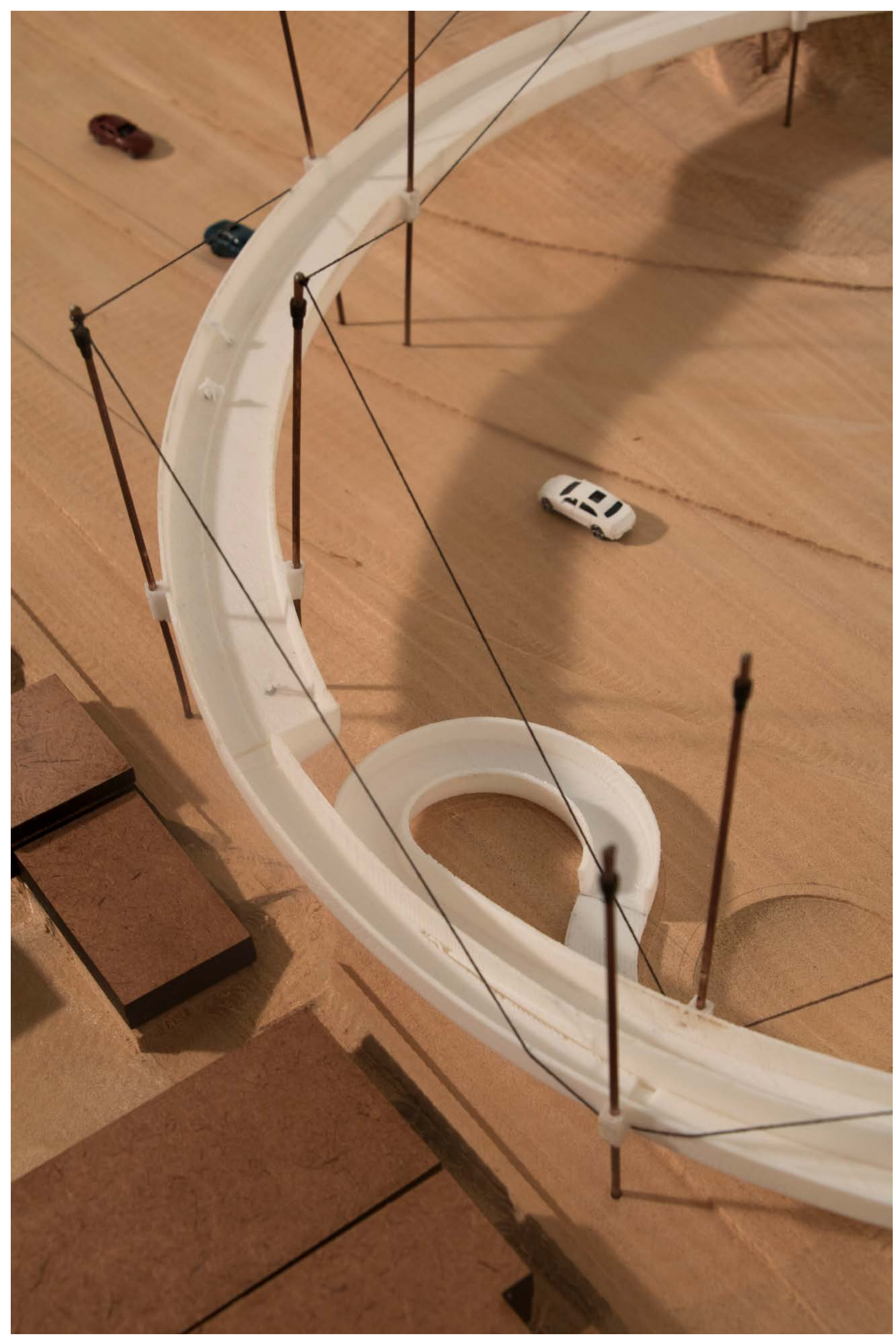




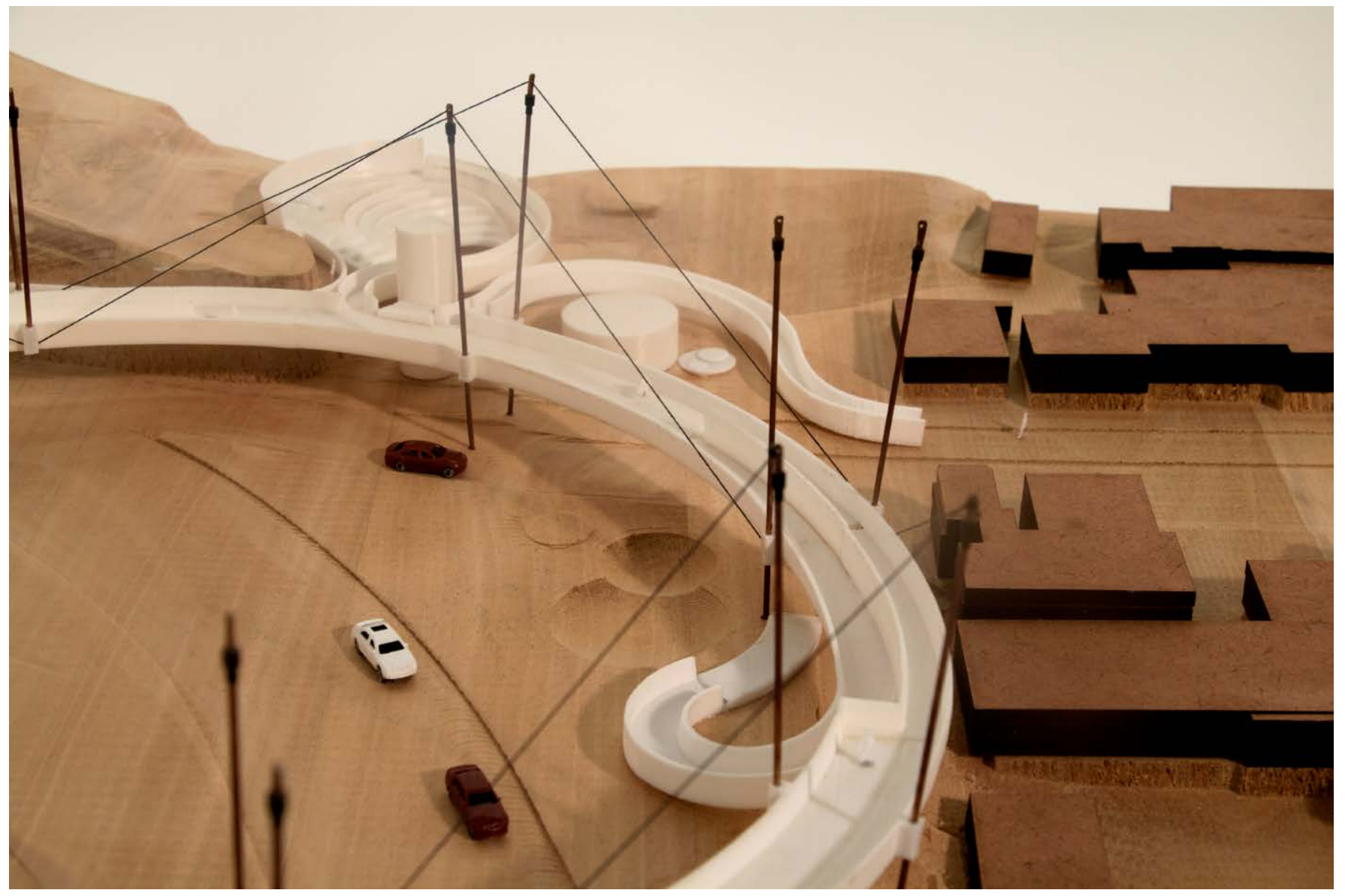

Fig 6.09 (Opposite) Aerial view southwest.

Fig 6.10 (Above) Aerial view north. 


\section{TUNNEL NODE}

The cycling/pedestrian path emerges from Mt Vitoria Tunnel no.2. The path circles playfully around the amphitheatre before joining The Loop. Traffic can join The Loop, or continue meandering down the arm into Hataitai Village on Taurima Street. An elevator provides access directly down to street level. A BBQ pavilion, seating space, public toilets, and a dog-wash station are dotted around this arm.

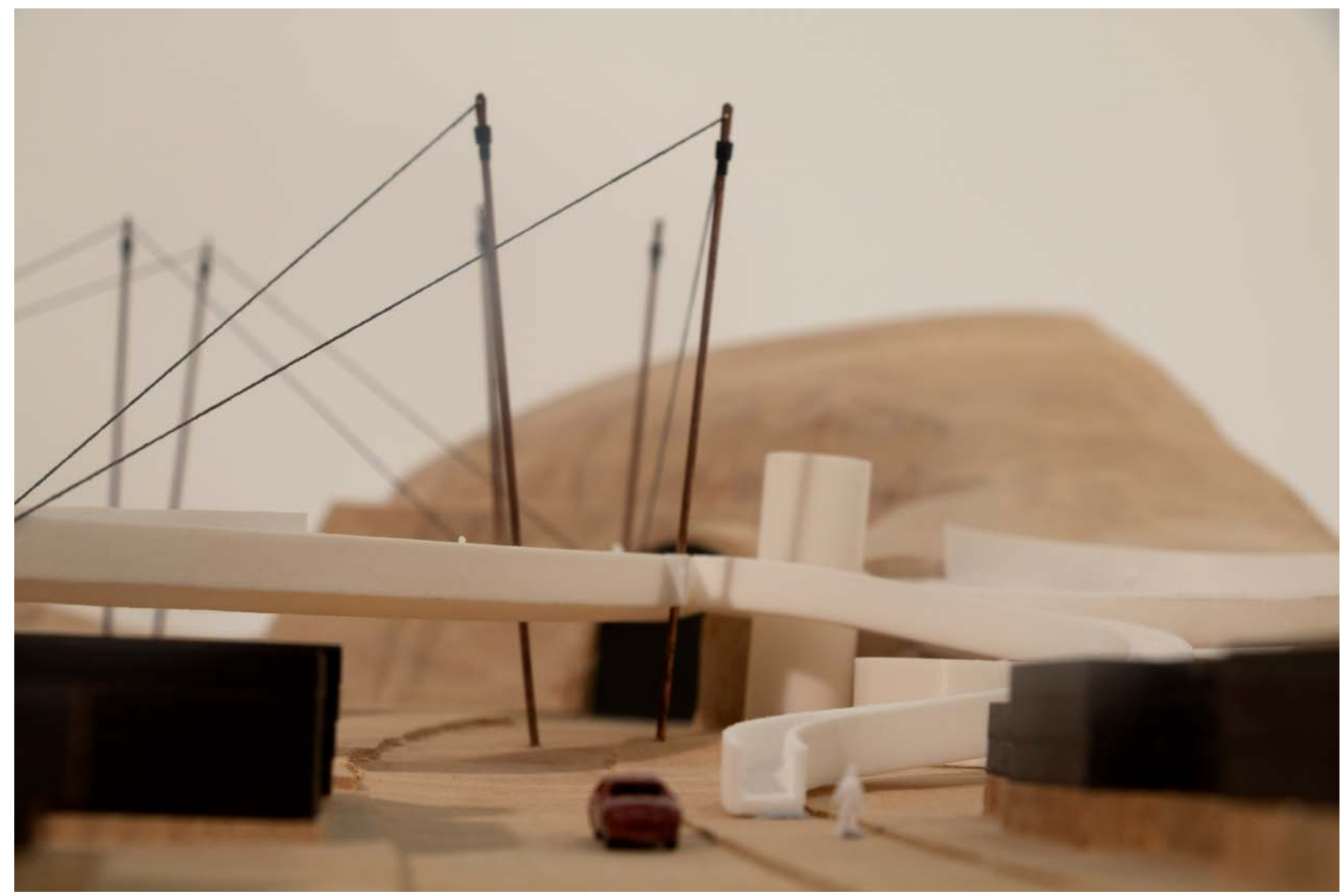

Fig 6.11 View towards the tunnel portal from Taurima Street. 


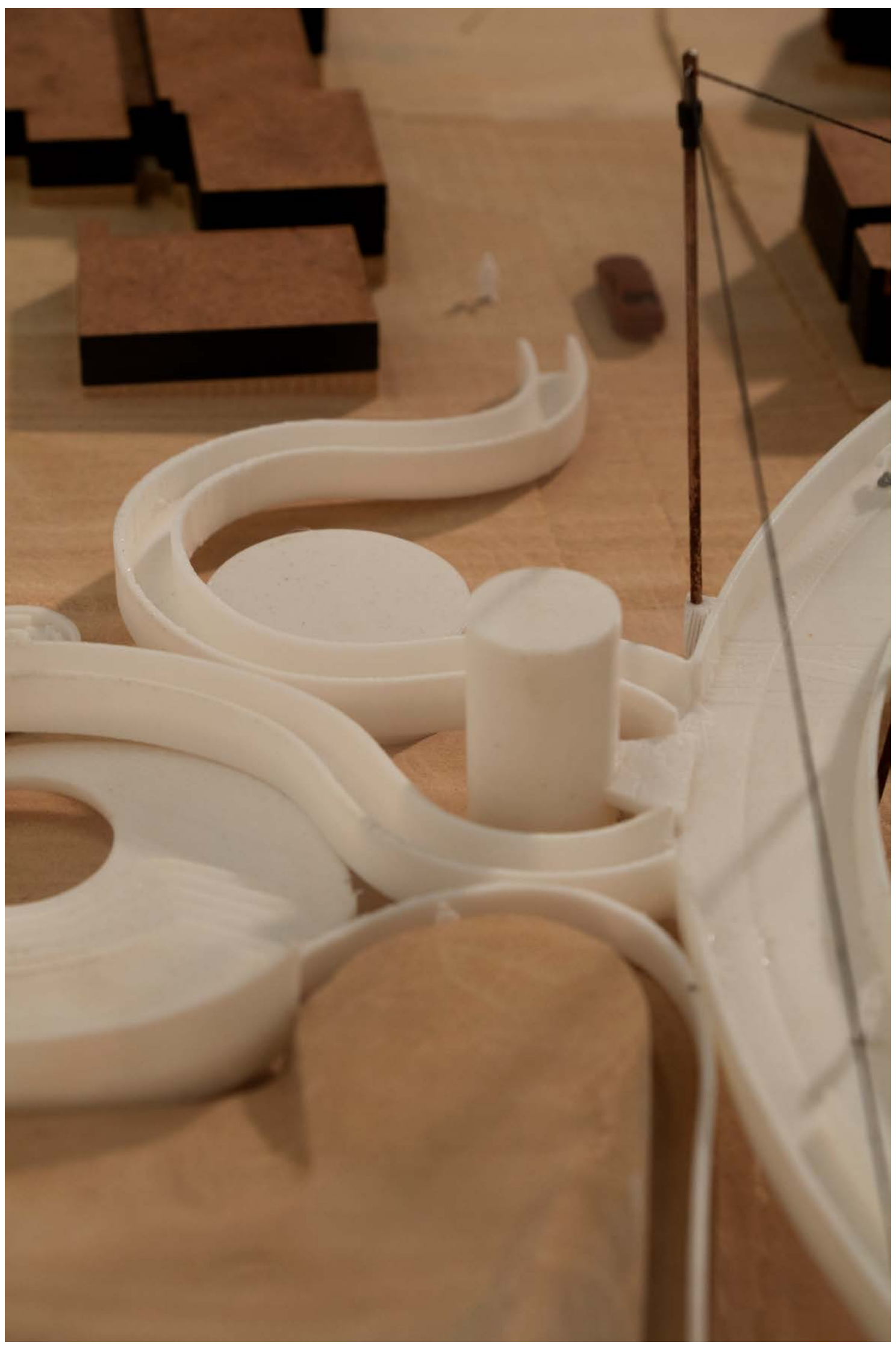

Fig 6.12 Aerial view of the snaking path emerging from the tunnel. 


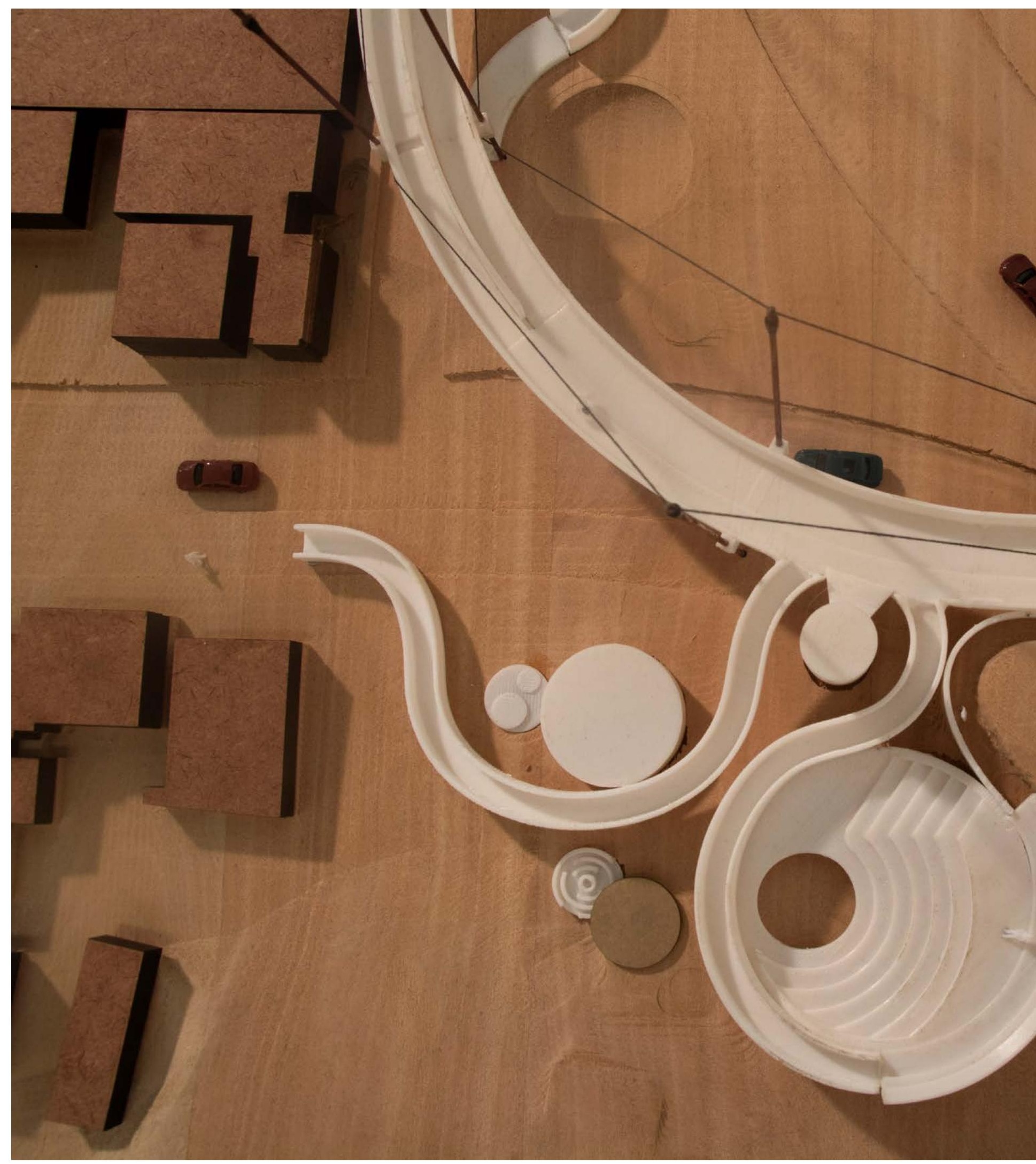

Fig 6.13 Plan view of north half of the scheme. South is at the top of the image. 
Each of these nodes/periphery spaces aim to operate as sitespecific sculptures as much as urban design interventions. They occupy the leftover spaces in Hataitai, and provide infrastructure that is not fundamental to the operation of the city, but make urban exploration more surprising and serendipitous. The meandering paths and The Loop celebrate the long way around. Enjoyability takes precedence over efficiency.
The scheme is washed with a Situationist desire for pleasure and urban wanderlust. The Loop presents an isolated moment in the city fabric. Detached and autonomous, it is an island in an archipelago that makes up the city fabric of Wellington. Its prominence upon emergence from the Mt Victoria Tunnel and gateway-like presence upon arrival from the airport add to this notion.

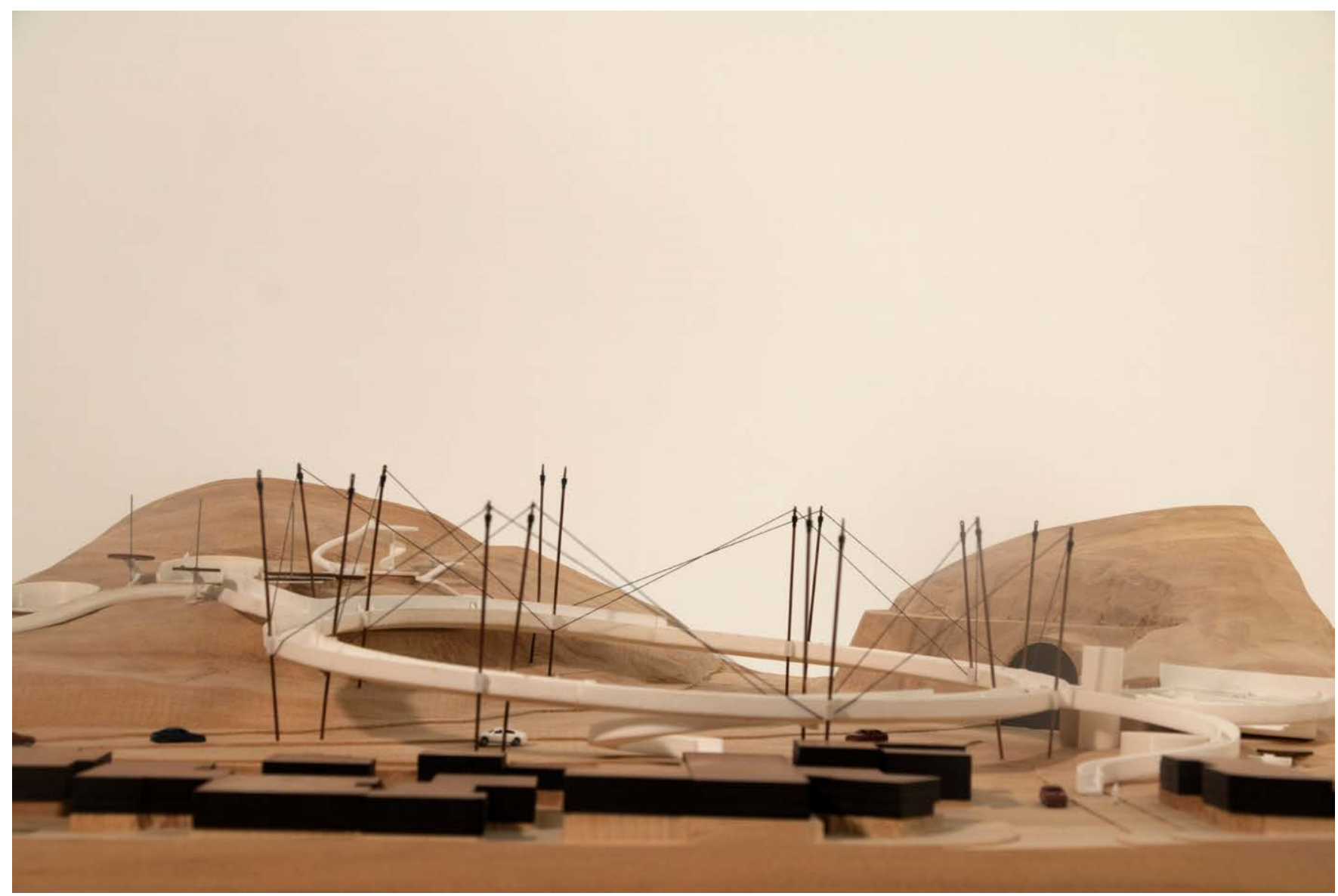

Fig 6.14 East elevation from Hamilton Road, above Hataitai Village 


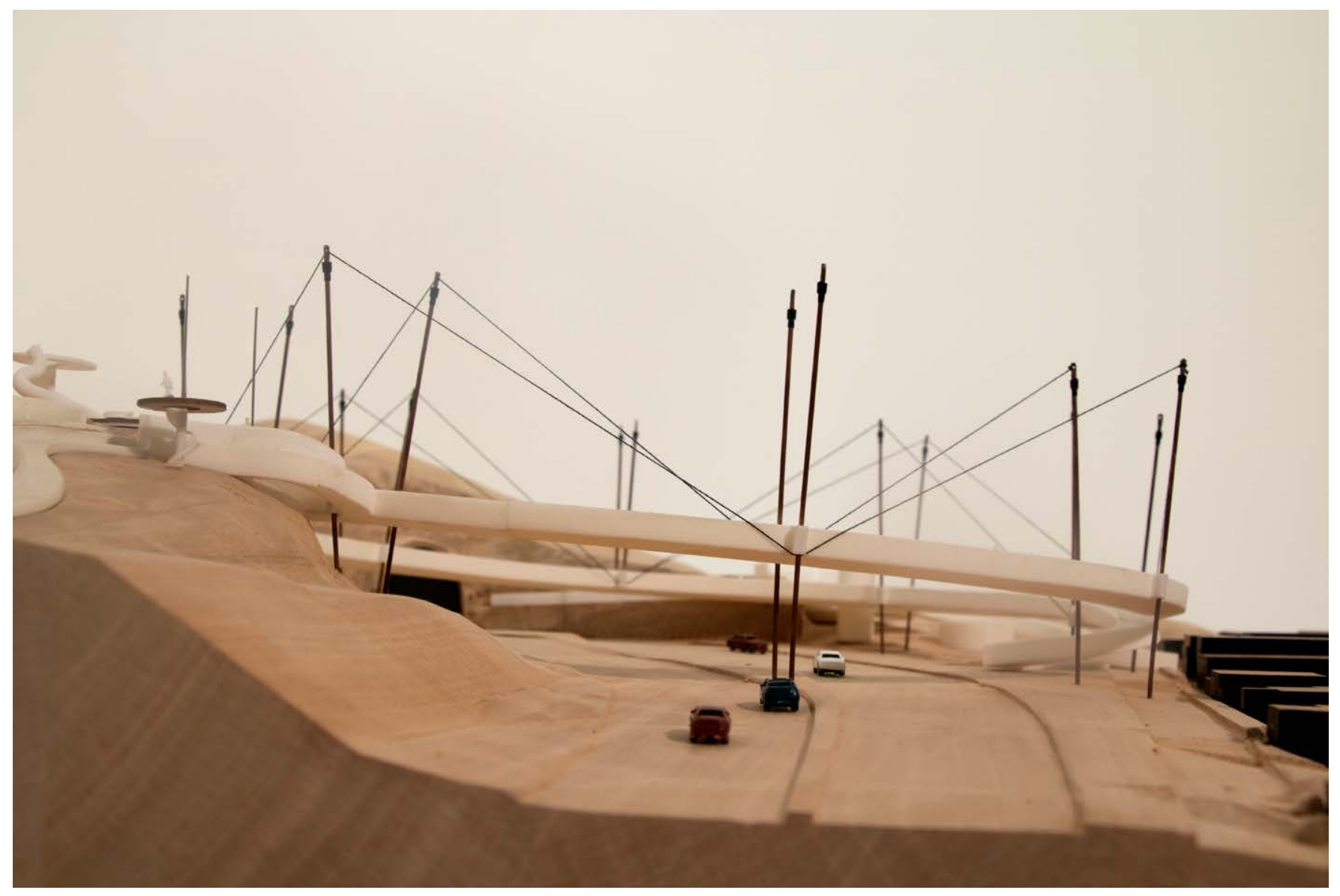

Fig 6.15 North elevation and view from State Highway 1, city bound. 


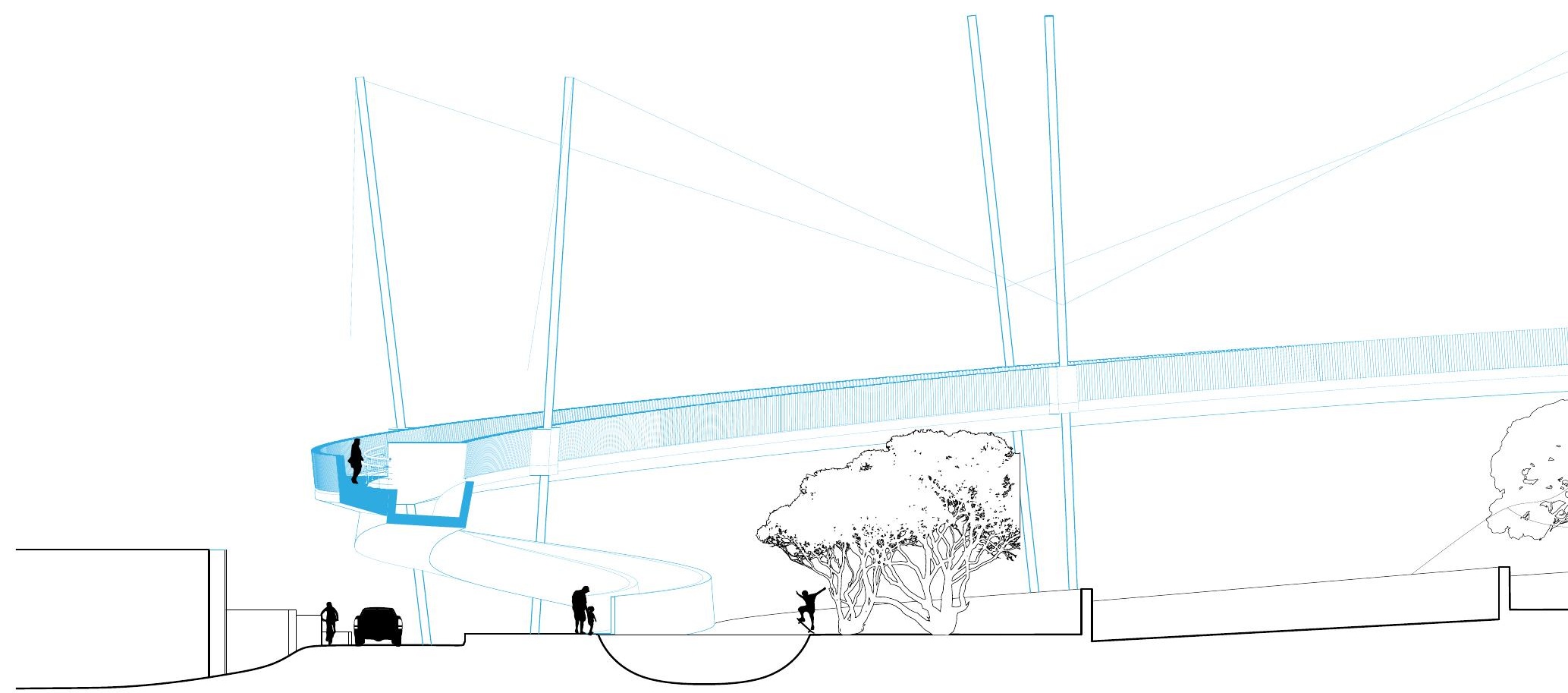

Fig 6.16 Loop Section through State Highway 1, looking south. Not to scale on spread. 


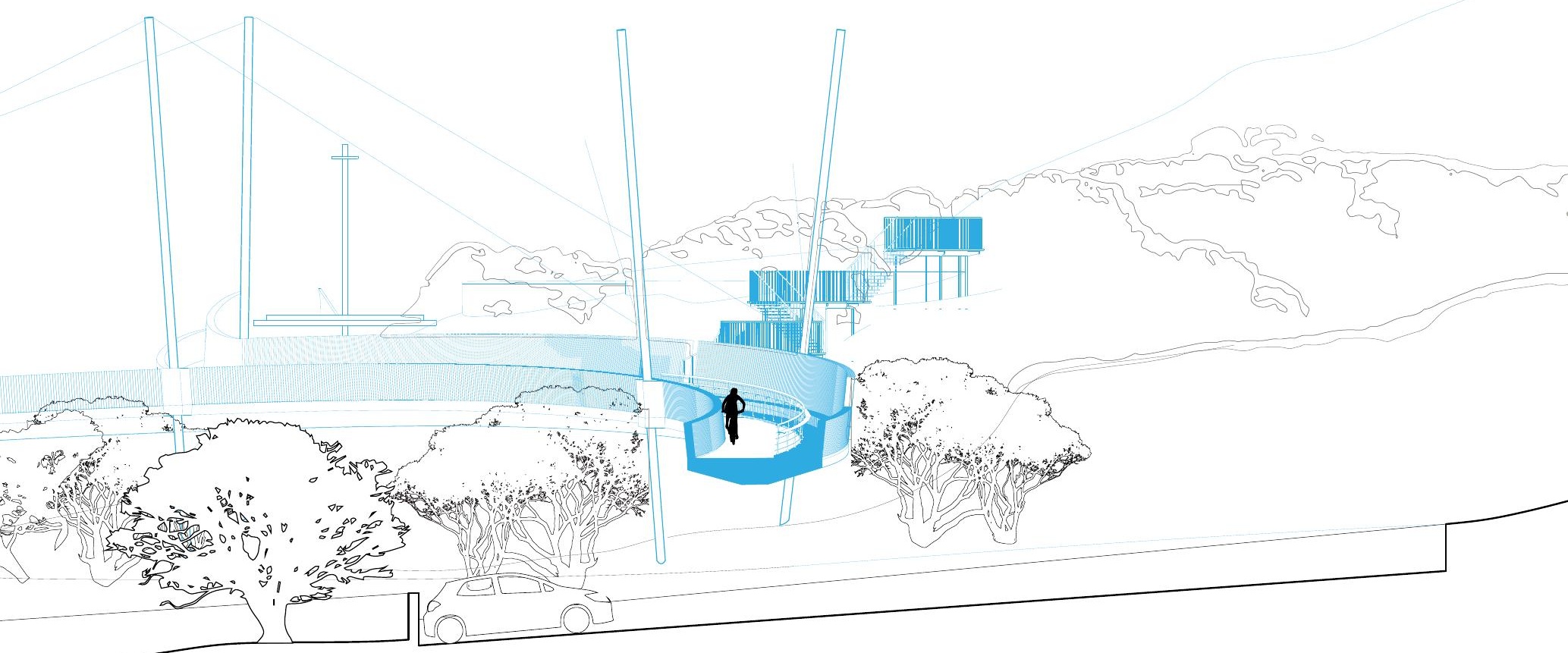




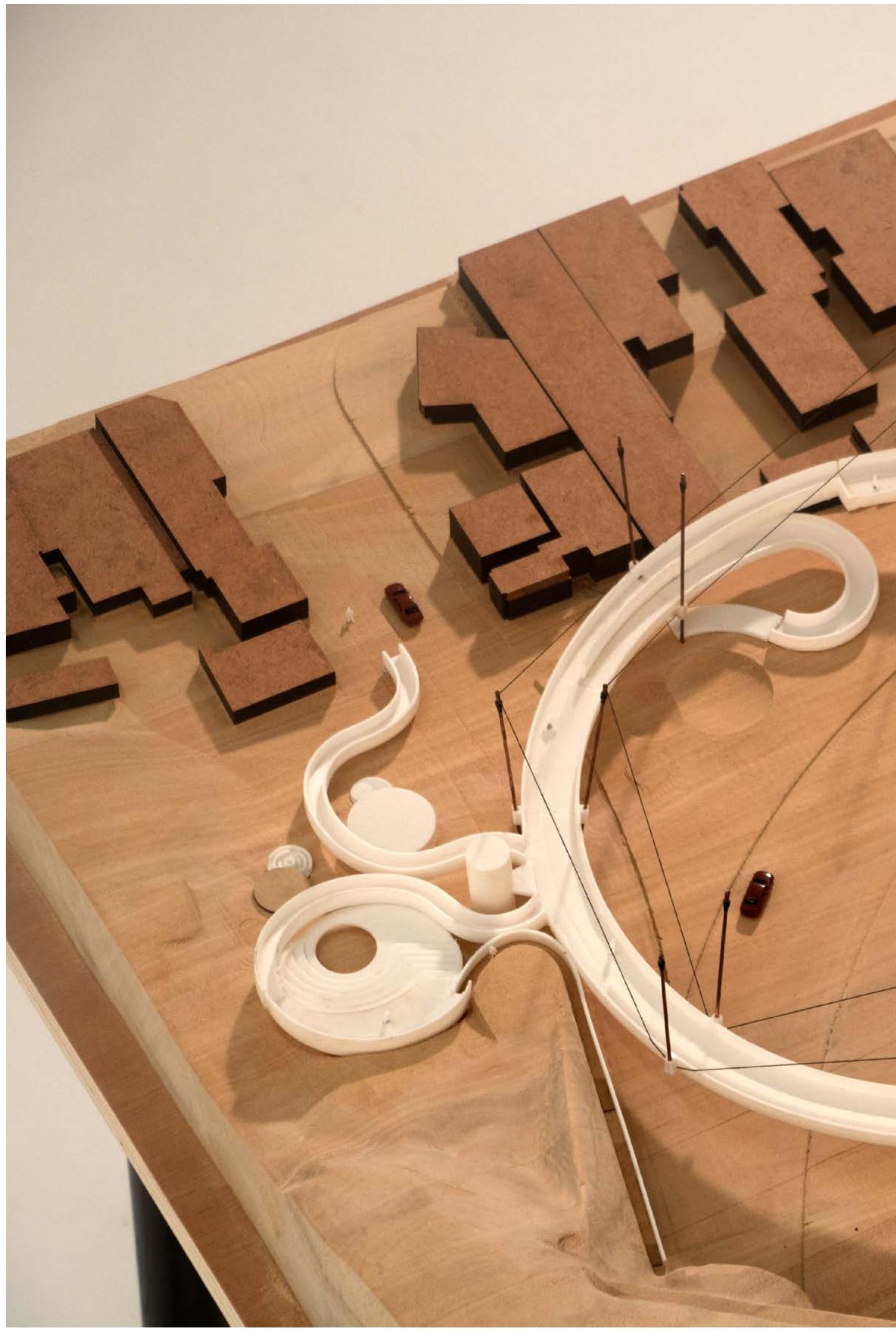

Fig 6.17 Aerial perspective from above the tunnel portals, looking southeast. 


\section{SUMMARY}

Island and Field investigates two distinct interpretations of the urban fabric, and subsequently presents two unique projects - Field and Island. I used these two urban readings to investigate how we might occupy a leftover urban area affected by traffic infrastructure, and also enrich the pedestrian and cycling culture in that area.

Field was an experiment that manipulated the physical and visual continuity of the urban fabric. Utilising avant-garde projects like Constant's New Babylon, and a physical manifestation of play, this project aimed to obscure the physical boundaries between Hataitai Village and the Town Belt with a ubiquitous pedestrian milieu.

Island presented a discrete and isolated moment in the existing fabric. This experiment fits more neatly into discussions around autonomy. An object - The Loop - links the isolated urban territories, which are severed from each other by State Highway 1:

The Mt Victoria Tunnel pedestrian lane, Hataitai Village and the Town
Belt. The Loop does not aim to assimilate into the surrounding fabric like the Field experiment. It accepts the disconnections imposed by the roads and responds with a new layer above.

The final scheme, Trivial Pursuit, combines moments from Island and Field, proposing a site-specific architecture, which aims to create rich urban spaces while overcoming disconnections in the pedestrian fabric. The Loop is a circuitous bridge, which provides a vital piece of urban infrastructure for pedestrians and cyclists. A collection of wandering arms and play spaces integrate more subtly into the respective urban territories at the periphery of The Loop. The Loop, its meandering pathways, and urban play spaces encourage the Trivial Pursuit of movement and activities, which occur for their inherent enjoyment rather than fundamental need. It is a playful infrastructure, which transcends motivations of pure efficiency and instrumentality, to inject a rare moment of frivolous enjoyability into the quotidian fabric of the city. 


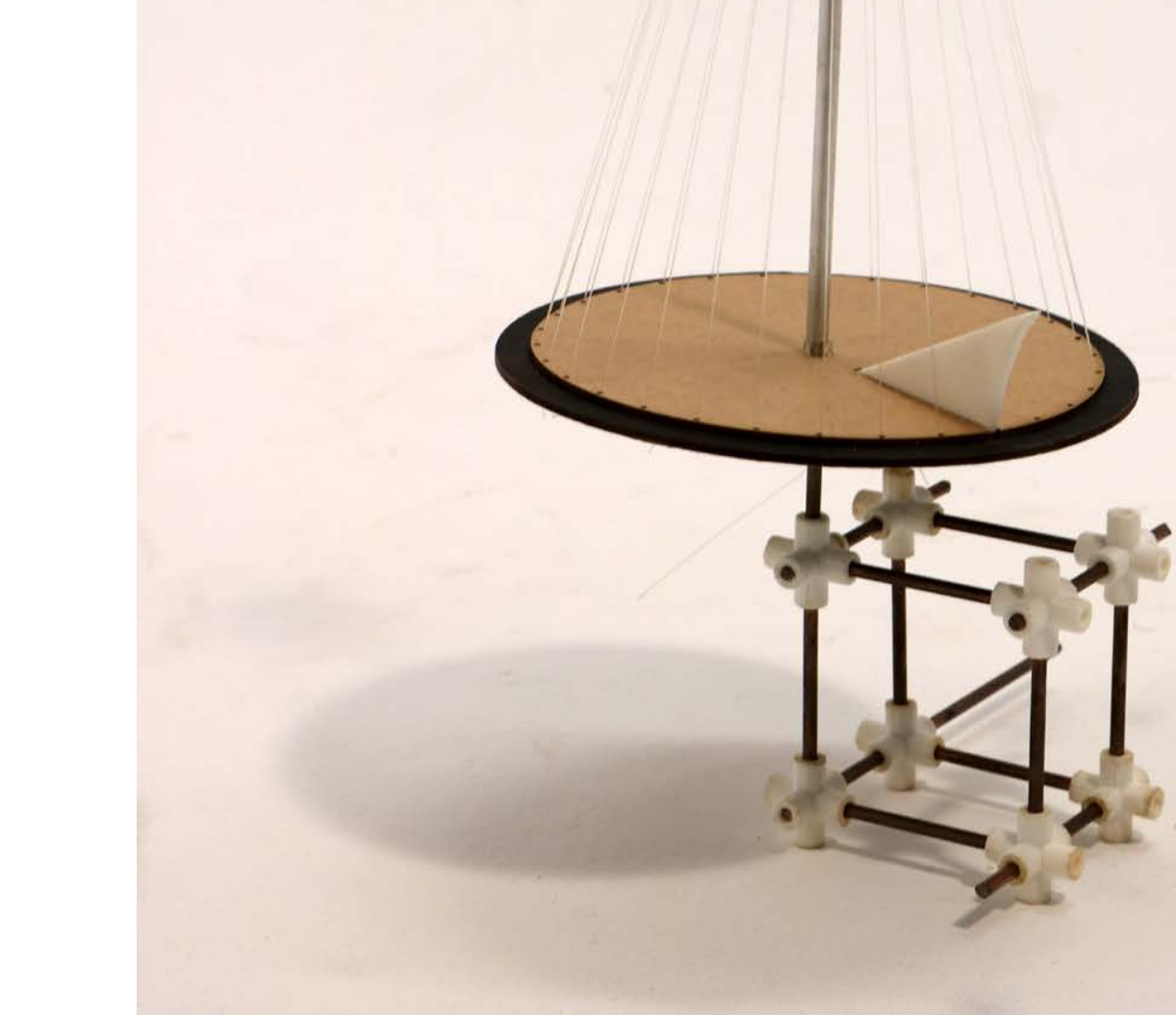




\section{CRITICAL REFLECTION}

Traffic infrastructure is a utilitarian pursuit that usually contributes to better-connected cities on a macro-scale. However, it can also create fragmented urban landscapes and non-places for the human experience. A preference for private vehicles in New Zealand, and continued investment into its associated infrastructure, has resulted in generally minimal pedestrian and cycling provisions, and disconnected urban places.

Around the world, more cities are beginning to embrace greener, active transport solutions as an alternative to private vehicles. Some countries, like the Netherlands, have traditionally constructed adequate infrastructure for cyclists. But these are slow-burning cultural investments that cannot simply be planned for cities like Wellington or Auckland overnight. New Zealand cities are now commonly getting 'instant' mobility alternatives such as bike and e-scooter sharing platforms. They are novel, innovative solutions, which may contribute to taking a few cars off the road, but they do not solve wider infrastructural issues.

However, in a time where there is undoubtedly an increased push for active mobility and greener solutions, Island and Field provokes a disciplinary question - How might we respond to traffic infrastructure in a car-centric city? The architect's role in seeking alternatives to the autocratic 'default' solutions typically bestowed upon us by government agencies is critical.

The two experiments I have collated as Island and Field demonstrate two vastly different approaches to urban intervention. The Field experiment highlighted the value of visual and physical continuity in the pedestrian realm, and the tensions that this can create with the associated traffic infrastructure, and surrounding urban territories. It also uncovered the allure of the autonomous object, which I subsequently developed in the Island experiment. This approach provided more pragmatic benefits and viable solutions as infrastructure design. However, the first experiment was not in vain. The final scheme demonstrates how these two approaches can be synthesised as a site-specific architecture in a real urban situation. It attempts to provoke an alternative way to approach the design of infrastructure in the city. This multi-modal approach aims to not only connect spaces, but also provide places to inhabit and enjoy as a vital part of the city fabric. Like Liane Lefaivre said, 'the city is a playground' (2007).

There are a great many social, political and cultural tensions at play beyond the limits of this project. Perhaps most pivotal are the attitudes and behaviours of those who provide and use the infrastructure of a city. My project addresses only one of many possible nodes in Wellington where this might occur. However, the shifting of attitudes takes time. Perhaps, what we can offer as designers, are little moments of idealism in the present city, so that the future city is an altogether more humanised and well-connected fabric. 


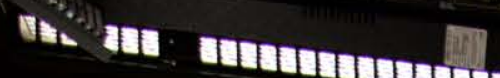

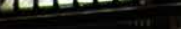




\section{REFERENCES}

Allen, S. (1999). Points and lines: diagrams and projects for the city, Princeton Architectural Press.

Allen, S., et al. (2010). "Landscape infrastructures." Infrastructure as Architecture. Designing Composite Networks. Berlin: jovis Verlag: 36-45.

ArchDaily. (2015, July 22). The Luchtsingel/ZUS. Retrieved from ArchDaily: https://www.archdaily. com/770488/the-luchtsingel-zus

ArchDaily. (2016, July 5). LightPathAKL / Monk Mackenzie Architects + Landlab. Retrieved from ArchDaily: https://www.archdaily.com/790707/ lightpathakl-monk-mackenzie-architects

Aureli, P. V. (2011, March 11). Intellectual Work and Capitalist Development: Origins and Context of Manfredo Tafuri's Critique of Architectural Ideology. Retrieved from The City as a Project: http:// thecityasaproject.org/2011/03/pier-vittorio-aureli-manfredo-tafuri/

Aureli, P. V. (2013). The City as a Project. Ruby Press.

Aureli, P. V. (2011). The Possibility of an Absolute Architecture. MIT Press.

Balmond, C. (2002). Informal. Prestel Publishing.

Bicyle Dutch. (2018, Janurary 2). Dutch cycling figures. Retrieved from Bicyle Dutch: https://bicycledutch.wordpress.com/2018/01/02/dutch-cycling-figures/

Conder, T. (2009). Development and application of a New Zealand car ownership and traffic forecasting model.

Debord, G. (1959). Situationist Theses on Traffic.

Forbes, M. (2015, August 21). Basin Reserve flyover project killed off by the High Court. Retrieved from Stuff: https://www.stuff.co.nz/motoring/ news/71325907/null

Friedman, Y. (2016, January 27). Interview with Yona Friedman: "Imagine, Having Improvised Volumes 'Floating' In Space, Like Balloons. (V. Belogolovsky, Interviewer)

Gehl, J. and L. Gemzøe (2004). "Public spaces-public life."

Huizinga, J. (1956). "Homo Ludens Vom Ursprung der Kultur im Spiel."

Humphris, A. (2010, March 11). 'Public transport Buses'. Retrieved from Te Ara - the Encyclopedia of New Zealand: http://www.TeAra.govt.nz/en/ photograph/22518/wellington-tram-tunnel
Id Profile. (2018). Wellington City Community Profile. Retrieved from Id Profile: https://profile. idnz.co.nz/wellington/population?WebID $=180$

ipv Delft. (2015). Brief Dutch Design Manual for Bicycle and Pedestrian Bridges. Delft.

Kebbell, S., \& Ombler, J. (2018). Nudging towards urban walkability in a car-dependent New Zealand neighbourhood. Wellington.

Lefaivre, L. (2007). Ground-up city: Play as a design tool, 010 Publishers.

Lefebvre, H. (1947). Critique of Everyday Life.

Lefebvre, H. (1996). "The right to the city." Writings on cities.

Lemonier, A. (2014). La ville en suspens - The suspended city. In M. Frédéric, Architecture : concept \& notation (pp. 45-57). Paris.

Let's Get Wellington Moving. (2017). Public Engagement.

Luchtsingel. (2016). 4 Parts of the Singel. Retrieved from Luchtsingel: http://www.luchtsingel. org/over-de-luchtsingel/5-onderdelen/

McCrone, D. (2016). Mt Victoria Tunnel. Retrieved from Mt Victoria Historical Society: http:// mtvictoria.history.org.nz/mt-victoria-tunnel/

New Zealand Transport Agency. (2013). Basin Bridge Assessments. Wellington: NZTA

New Zealand Transport Agency. (2013). The new Mt Victoria tunnel. New Zealand Government.

New Zealand Transport Agency. (2018). Memorial Park. Retrieved from New Zealand Transport Agency: https://www.nzta.govt.nz/projects/wellington-northern-corridor/the-tunnel-to-tunnel-inner-city-transport-improvements/memorial-park

New Zealand Transport Agency. (2018). Waterview Tunnel. Retrieved from NZTA: https://www. nzta.govt.nz/projects/the-western-ring-route/ waterview-tunnel

New Zealand Transport Agency. (2018). Waterview Tunnel. Retrieved from NZTA: https://www. nzta.govt.nz/projects/the-western-ring-route/ waterview-tunnel

Nieuwenhuys, C. (1959). Another city for another life. In M. Wigley, Constant's New Babylon: The Hyper-architecture of Desire (pp. 115-116).

Nieuwenhuys, C. (1966, August 6). Haagse Post. (R. Koolhaas, Interviewer) 
O'Neil, A. (2015, April 5). 150 years of news: Protests against inner-city bypass exposed deep rift in Te Aro district heritage. Retrieved from Stuff: https://www.stuff.co.nz/dominion-post/capital-life/67617028/null

Richard, C. (n.d.). Dérive and Psychogeography: Situationist practices of urban space. Retrieved from Immeidacy: http://immediacy.newschool. edu/?p=397

Sadler, S. (1999). The situationist city, MIT press.

Schiller, F. (1920). Letter 15. In F. Schiller, The Aesthetic Letters. Boston: Little Brown.

Shaw, C. and M. L. Russell (2016). Benchmarking cycling and walking in six New Zealand cities: Pilot study 2015, New Zealand Centre for Sustainable Cities, University of Otago.

Taylor, M. C. (2003). Refusing Architecture. In J. Culler, Deconstruction: Critical Concepts in Literary and Cultural Studies.

Tschumi, B. (1974). Fireworks.

Ungers, O. M., Koolhaas, R., Kollhoff, H., Riemann, P., \& Ovaska, A. (1977). Berlin: a green archipelago (The city in the city). Lars Müller Publishers

Wellington City Council. (2019). History of the Town and Green Belts. Retrieved from Wellington City Council: https://wellington.govt.nz/recreation/ enjoy-the-outdoors/parks-and-reserves/management/history-of-town-and-green-belts

Wigley, M. (1998). Constant's New Babylon: the hyper-architecture of desire, 010 Publishers.

Zwolle, C. (2014, Septermber 29). New Zealand road infrastructure. Retrieved from Skyscraper City: https://www.skyscrapercity.com/showthread. php? $\mathrm{t}=494066$ \&page $=23$ 


\section{LIST OF FIGURES}

\section{All figures not attributed are my own}

Figure 0.01

Donne, J. (1624). No Man is

an Island.

Figure 1.01 Ellis, R. (1969). Motorway/ City. Retrieved from Auckland Art Gallery: https:// www.aucklandartgallery.com/explore-art-andideas/artwork/3578/motorwaycity

Figure $1.03 \quad$ Stent, K. (2017, September 15). Island Bay Cycleway 're-engagement' costs push \$240k while peak usage backpedals. Retrieved from Stuff: https://www.stuff.co.nz/ dominion-post/capital-life/96784143/island-baycycleway-reengagement-costs-push-240k-whilepeak-usage-backpedals

Figure 2.01 Dominion Post (1968, April 2). Early start possible on road tunnel. Dominion Post. Retrieved from Wellington City Archives.

Figure 2.03 Alexander Turnbull Library. (1884). Landmarks 1884. In I. Howman, \& E. Lindsay, Hataitai - A Collection of Memories. Wellington.

Figure 2.07 New Zealand Transport Agency. (2013). Basin Bridge Assessments. Wellington: NZTA.

Figure 2.08 Scott, L. (2006, December 14). Walk the Wellington Inner City Bypass. Retrieved from Liberty Scott: http://libertyscott.blogspot.com/2006/12/walk-wellington-inner-city-bypass.html

Figure 2.09 New Zealand Transport Agency. (2013). Basin Bridge Assessments. Wellington: NZTA

Figure 2.10 Young, N. (2015, September 1). Pukeahu National War Memorial Park. Retrieved from Architecture Now: https://architecturenow.co.nz/articles/pukeahu-national-war-memorial-park/

Figure 2.11 Eye of the Fish. (2013, December 2). O No Sunbathing. Retrieved from Eye of the Fish: http://eyeofthefish.org/wp-content/ uploads/2013/12/dullroad2.jpg

Figure 2.12 Cook, P. (1964). AD Classics: The Plug-In City / Peter Cook, Archigram Retrieved from ArchDaily: https://www.archdaily. com/399329/ad-classics-the-plug-in-city-petercook-archigram

Figure $2.14 \quad 2016$, September 1). Marcel Duchamp's 'Bicycle Wheel' - 1913. Retrieved from An Art Lover's Blogspot: http://anartlovers. blogspot.com/2016/09/marcel-duchamps-bicycle-wheel-1913.html
Figure 2.15 Debord, G. (1957). Psychogeography. Retrieved from Mapping Weird Stuff: https://mappingweirdstuff.wordpress. com/2009/06/14/mapping-weird-stuff-psychogeography/

Figure 2.16 Dogma. (2007). Stop-City, Dogma. Retrieved from Socks Studio: http:// socks-studio.com/2011/07/10/stop-city-by-dogma-2007-08/

Figure 2.17 Sendak, M. (1963). Where the Wild Things Are. New York: Harper \& Row.

Figure 3.01 Hartnett, S. (2018, November 22). New Zealand's Waterview Connection: putting people at the heart of a motorway project. Retrieved from Floor Nature: https://www.floornature.com/blog/waterview-connection-nuova-zelanda-le-persone-al-centro-di-u-14237/

Figure 3.02 New Zealand Transport Agency. (2018). Waterview Tunnel. Retrieved from NZTA: https://www.nzta.govt.nz/projects/thewestern-ring-route/waterview-tunnel

Figure 3.03 landlab. (2015). Te Ara I Whiti - Light Path_. Retrieved from landlab: http:// landlab.co.nz/light-path/

Figure $3.04 \quad J a m i e s o n, A . ~(2016$, September 24). Lightpath features in photography competition. Retrieved from Auckland Council: http://ourauckland.aucklandcouncil.govt.nz/ articles/news/2016/09/lightpath-features-in-photography-competition/

Figure 3.05 + Figure 3.06 van Duivenbode , O. (2015, July 22). The Luchtsingel / ZUS. Retrieved from ArchDaily: https://www.archdaily. com/770488/the-luchtsingel-zus

Figure 4.07 Tschumi, B. (2011). $A D$ Classics: Parc de la Villette / Bernard Tschumi Architects. Retrieved from Archdaily: https://www. archdaily.com/92321/ad-classics-parc-de-la-villette-bernard-tschumi

Figure 4.15 Friedman, Y. (2016, January 27). Interview with Yona Friedman: "Imagine, Having Improvised Volumes 'Floating' In Space, Like Balloons. (V. Belogolovsky, Interviewer)

Figure 4.16 Price, C. (1961). Fun Palace for Joan Littlewood Project, Stratford East, London, England (Perspective). Retrieved from MoMa: https://www.moma.org/collection/ works/842

Figure 4.25 Nieuwenhuys, C. (1963). New Babylon. Retrieved from Macba: https:// www.macba.cat/en/new-babylon-3207 
Figure 4.26 Nieuwenhuys, C. (circa 1960). Constant (1920-2005). (New Babylon).

Lithograph. Retrieved from Invaluable: https:// www.invaluable.com/auction-lot/constant-19202005-new-babylon-lithograph-3739-c-f0a083df00

Figure 5.01 Ungers, O. M., Koolhaas, R., Kollhoff, H., Riemann, P., \& Ovaska, A. (1977). Berlin: a green archipelago (The city in the city).

Figure 5.02 Sendak, M. (1963). Where the Wild Things Are. New York: Harper \& Row.

Figure 5.03 Howard, B. (2018). A Boat to an Island on the Wall [Recorded by Ben Howard]

Figure 5.15 Collins, R. (2007, June 25). City to Sea Bridge at Daybreak. Retrieved from Ross Collins: https://rosscollins.smugmug.com/ Landscapes/Wellington/City-to-Sea-Bridge-atDaybreak/

Figure 5.28 Amsterdam City Archive (2017, July 4). Aldo van Eyck's Playgrounds: Aesthetics, Affordances, and Creativity. Retrieved from Frontiers: https://www.frontiersin.org/articles/10.3389/fpsyg.2017.01130/full

Figure 5.37 Kinkade, T. (n.d.). Alice in Wonderland Giclee on Canvas. Retrieved from Forgotten Treasures: https://forgottentreasurez. $\mathrm{com} /$ product/thomas-kinkade-alice-in-wonderland-giclee-on-canvas/ 

